\title{
Evaluation of a Re-established Walleye Population within a Hydropower Reservoir Recovering from Acidification
}

\author{
Dustin M Smith
}

Follow this and additional works at: https://researchrepository.wvu.edu/etd

\section{Recommended Citation}

Smith, Dustin M, "Evaluation of a Re-established Walleye Population within a Hydropower Reservoir Recovering from Acidification" (2018). Graduate Theses, Dissertations, and Problem Reports. 7294. https://researchrepository.wvu.edu/etd/7294

This Dissertation is protected by copyright and/or related rights. It has been brought to you by the The Research Repository @ WVU with permission from the rights-holder(s). You are free to use this Dissertation in any way that is permitted by the copyright and related rights legislation that applies to your use. For other uses you must obtain permission from the rights-holder(s) directly, unless additional rights are indicated by a Creative Commons license in the record and/ or on the work itself. This Dissertation has been accepted for inclusion in WVU Graduate Theses, Dissertations, and Problem Reports collection by an authorized administrator of The Research Repository @ WVU. For more information, please contact researchrepository@mail.wvu.edu. 
Evaluation of a Re-established Walleye Population within a Hydropower Reservoir Recovering from Acidification

\author{
Dustin M. Smith \\ Dissertation submitted \\ to the Davis College of Agriculture, Natural Resources, and Design \\ at West Virginia University
}

in partial fulfillment of the requirements for the degree of

Doctor of Philosophy in

Forest Resource Science

Stuart Welsh, Ph.D., Chair

Kyle Hartman, Ph.D.

Patricia Mazik, Ph.D.

David Smith, Ph.D.

David Wellman, M.S.

Division of Forestry and Natural Resources

Morgantown, West Virginia

2018

Keywords: reservoir, biomonitoring, acidification, hydropower, Walleye, acoustic telemetry, fish community, water quality

Copyright 2018 Dustin M. Smith 


\title{
ABSTRACT \\ Evaluation of a Re-established Walleye Population within a Hydropower Reservoir Recovering from Acidification
}

\author{
Dustin. M. Smith
}

Cheat Lake, a hydropower reservoir in northern West Virginia, was impacted for decades by acid mine drainage and acid precipitation. Acidification of Cheat Lake likely reduced fish species richness and fish abundance. From 1952-1977, only 15 fish species were collected, cumulatively. Additionally, the fish community was dominated by acid tolerant species such as Brown Bullhead (Ameiurus nebulosus) and White Sucker (Catostomus commersonii) ( $82 \%$ of mean annual relative abundance), while acid intolerant species such as Walleye were extirpated. Due to legislative action and subsequent funding of water quality treatment within the watershed (e.g., Surface Mining Control and Reclamation Act of 1977), acidification issues have been mitigated over time. My study aimed to quantify temporal changes in the fish community of Cheat Lake, as they might be related to improvements in water quality. Additionally, from a fishery management perspective, I focused on evaluating population characteristics and spatial ecology of a reestablished Walleye (Sander vitreus) population in Cheat Lake.

I examined changes in water quality data (1952-2015) and fish community data (19522015) from Cheat Lake. Main lake $\mathrm{pH}$ averaged less than 5.0 prior to 1990 and averaged 5.8 in 1990. Since 1997, pH has averaged greater than 6.0 every year indicating reduction in acidification of Cheat Lake. Based on boat electrofishing and gill net surveys, I found that the fish community of Cheat Lake has significantly changed over time, likely owing to improvements in water quality. From 1990-2015, 18,387 fishes were collected using these methods.

Additionally, 44 species were collected representing a substantial increase in species richness. The mean annual relative abundance of fishes captured from 2011-2015 was over 4 times greater than that from 1990-2001. Also, fish community composition significantly changed over time from 1990-2015. Changes in fish community composition were largely driven by increases in abundance of acid intolerant fish species such as Smallmouth Bass (Micropterus dolomieu).

I also evaluated population characteristics of the Walleye population. As expected, initiation of stocking significantly increased abundance of Walleyes within Cheat Lake as indicated by increases in gill net catch per unit effort (CPUE). Age and growth analysis indicated that the Cheat Lake Walleye population was characterized by fast growing individuals that reach large maximum sizes. Both male and female Cheat Lake Walleyes reach quality size $(\geq 380$ $\mathrm{mm}$ ) after two years of growth. Specifically, female Walleyes reached larger maximum sizes (female $L^{\infty}=754 \mathrm{~mm}$; male $\mathrm{L} \infty=502 \mathrm{~mm}$ ) and grew faster after age-3 than male Walleyes. Increasing natural reproduction was also evident as indicated by collection of young of year in the fall of non-stocking years and through evaluation of year classes from age and growth data.

Telemetry data provided information on distribution and movement patterns of Cheat Lake Walleyes. Walleyes exhibited seasonal and sex-based differences in distribution and 
movement, and large scale movements were correlated with water temperature and river discharge. Male Walleyes were found to use riverine habitats more often than female Walleyes, while females primarily used main lake habitats. All Walleyes showed a tendency for increases in core range shifts and changes in linear range in the spring and fall months. Shifts in core range and increases in linear range during spring were due to spawning movements. Both male and female Walleyes migrated to the headwaters of Cheat Lake prior to spawning, with male Walleyes migrating earlier than female Walleyes. For all Walleyes, upstream spawning migrations were correlated with elevated water temperatures $(75 \%$ of migrations at water temperatures $>4.1^{\circ} \mathrm{C}$ ). After spawning, female Walleyes typically migrated back to main lake habitats, while the majority of male Walleyes continued to use riverine habitats. During fall, individuals occupying riverine habitats made downstream movements to the main lake where they remained throughout the winter.

Changes in the fish community and the establishment of a quality Walleye fishery were made possible due to water quality treatment within the watershed. Cheat Lake now supports a relatively diverse fish community, including abundant sportfish species. A reestablished Walleye population provides a unique fishery for anglers, where Walleye grow fast and have the potential to reach trophy sizes. Data on the improvements and status of the fish community, as well as movement data on the Walleye population, provide valuable information to managers and anglers alike. This information will be valuable for future management of the Cheat Lake fish community and will help conserve this valuable resource. 


\section{Dedication}

I dedicate this dissertation to my wife Ashley, for her never-ending support of my career and academic endeavors, and for sacrificing without question so that I may pursue my dreams. I also dedicate this to my daughter Samara, who is the light of my world and means more to me than any degree ever could. 


\section{Acknowledgements}

I have had the support of many while pursuing my degree, and I know undoubtedly that their support was what made my continued pursuit and ultimate completion of this dissertation possible. I must thank my family for supporting me throughout my academic and career endeavors. My Mom and Dad both instilled in me a love of the outdoors, and have supported me every step of the way. My wife Ashley has selflessly followed me wherever my career has taken us, and allowed me to pursue my dreams despite her sometimes putting her dreams on hold...for her I am eternally grateful and I absolutely could not have done this without her. My daughter Samara is the light of my world and always managed to put a smile on my face even in the most difficult times. Everything I do is for her and I hope to one day be able to support her dreams just as others in my life have supported mine.

In addition to family, I have countless friends and colleagues to thank for their support. Nate Taylor and Corbin Hilling were both instrumental in completing the field work and both provided valuable advice in the development of this research. They both gave tirelessly to this project working extremely late hours, weekends, and even holidays to help complete the work. Throughout the project, they were both incredibly hard workers, valuable colleagues, and most importantly, irreplaceable friends. I am grateful to Scott Morrison and Frank Jernejcic for providing me with valuable advice throughout the project both related to this research and to my career. Scott introduced me to the telemetry methods I would end up using throughout the study and provided first hand field work advice that could be obtained nowhere else. Frank provided me with endless information and knowledge about my study area Cheat Lake and the work done in the watershed that he has been a part of for so many years. I thank all those who assisted with field work throughout the project including Missy Braham, Brian Crabill, Wendell Hofer, Amanda Renick, Bri Tierney and Zack Vucurevich. I thank my other fellow Welsh lab grad students Joni Aldinger, Austin Rizzo, and Patricia Thompson who were always willing to 
lend a hand regardless of conditions and made the work that much more enjoyable. I thank my committee members Kyle Hartman, Pat Mazik, David Smith and Dave Wellman for helping me with the development of this research, for offering sound advice, and for the invaluable knowledge that each of them provided. I thank Becky Nestor, without which all WVU Coop grad students would be lost, for doing so much for me whether it be related to my pursuit of my degree or simply for the pleasant conversations we would have each day. Finally, I thank my advisor Stuart Welsh for giving me the opportunity to pursue this project, for putting in long hours helping with field work, for his unwavering positive attitude, his assistance and advice with all things related to the project, for his endless support and patience, for introducing me to the sport of ice fishing and letting me tag along, and most importantly his understanding of the importance of family.

The funding for this research was provided in part by Cube Hydro Partners, LLC and the West Virginia Division of Natural Resources. I am thankful for their financial support for this project, which has allowed me to further my education and experience. I would also like to thank the West Virginia Division of Forestry and Natural Resources and the USGS Cooperative Fish and Wildlife Research Unit for providing equipment, facilities, and other resources that have made this work possible. 


\section{Table of Contents}

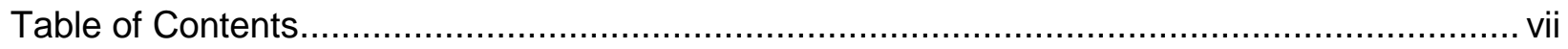

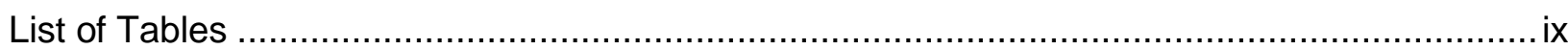

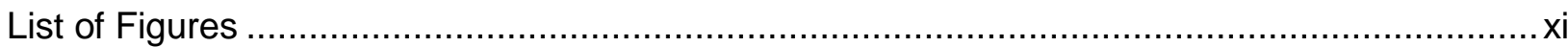

Chapter 1 - Ecology of Fish Communities in Altered Reservoir Ecosystems with Special

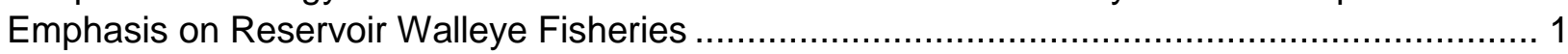

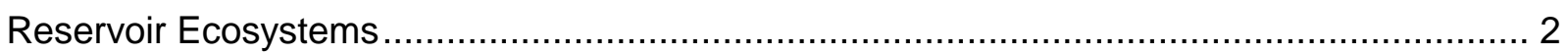

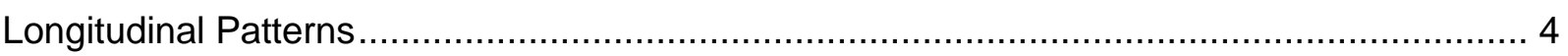

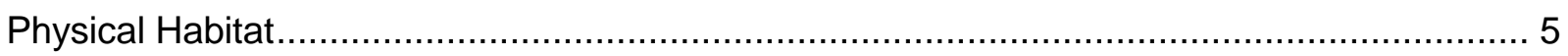

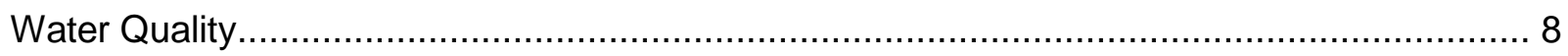

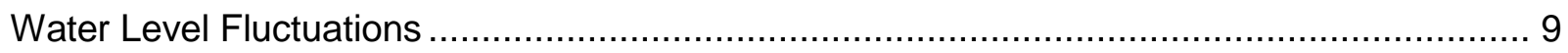

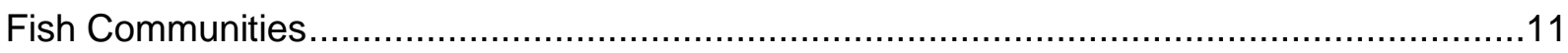

Acidification and Recovering Aquatic Ecosystems................................................... 13

Ecology of Walleye in the context of Reservoir Systems.............................................. 15

Spawning and Early Life Stages .........................................................................

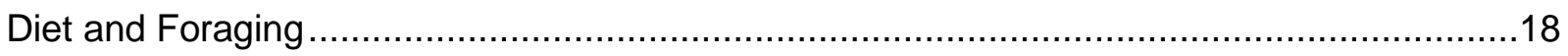

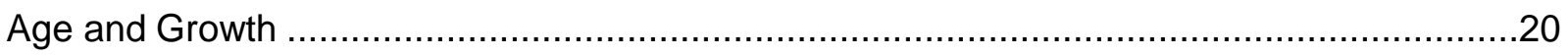

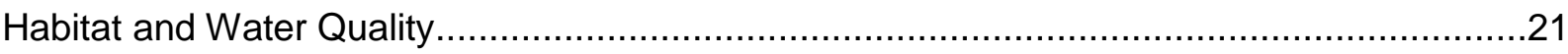

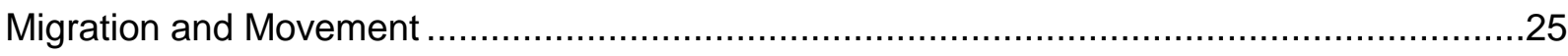

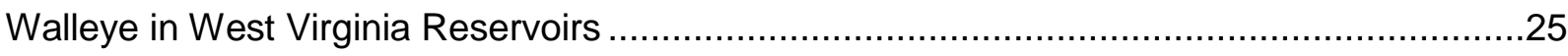

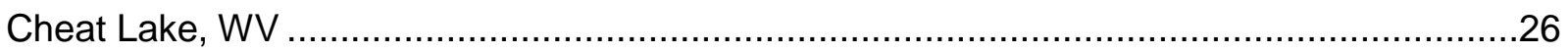

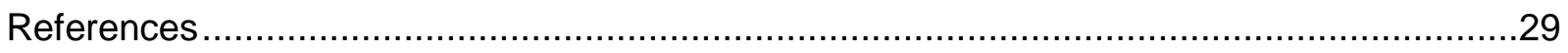

Chapter 2 - Long-term recovery of a fish community in an acid impacted hydropower reservoir

Abstract




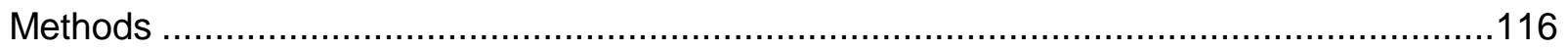

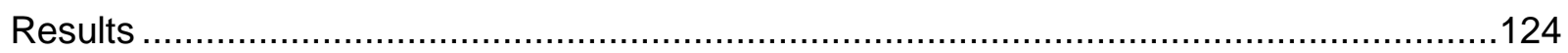

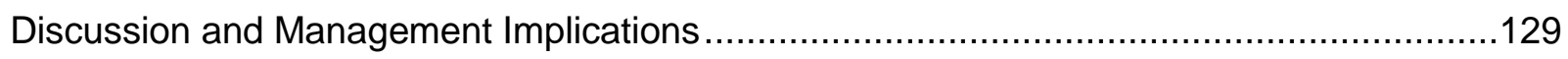

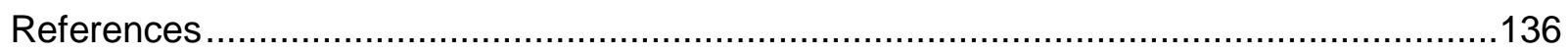

Chapter 4 - Seasonal distribution and space use patterns of Walleyes in a hydropower reservoir .

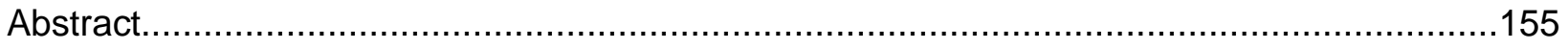

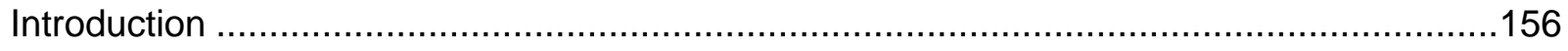

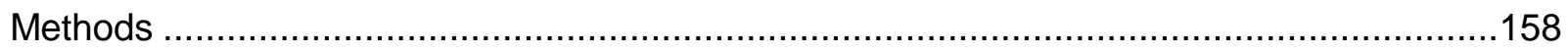

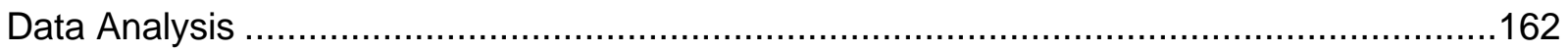

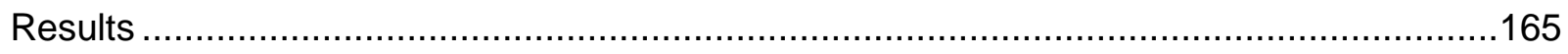

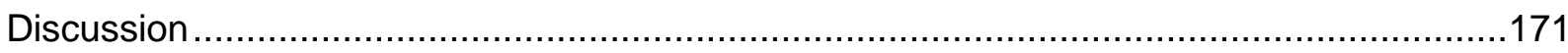

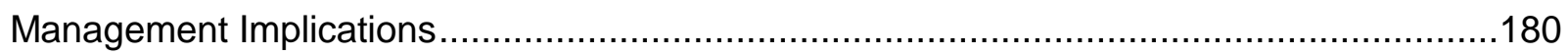

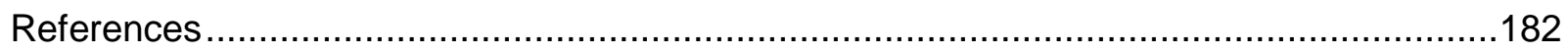

Chapter 5 - Environmental correlates of large scale seasonal movements of Walleyes in a

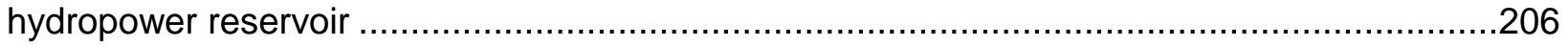

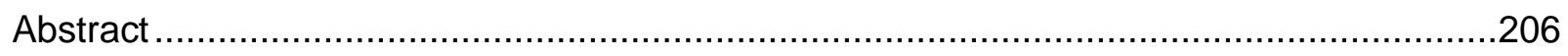

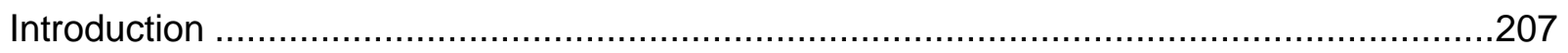

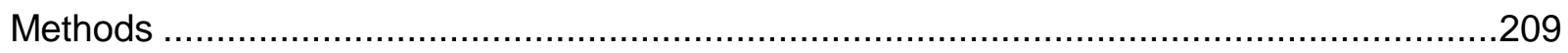

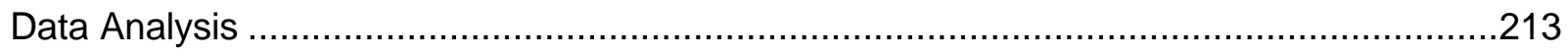

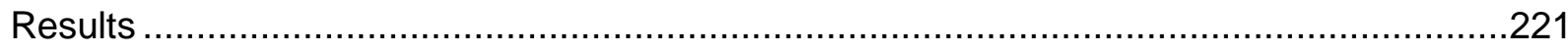

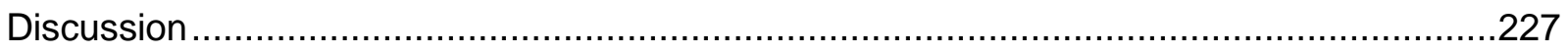

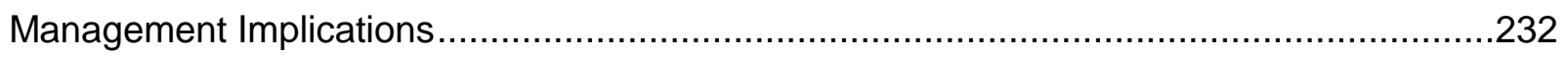

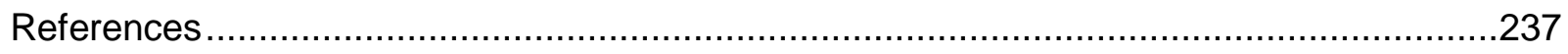

Chapter 6 - Future Management Strategies for the Fish Communities of Cheat Lake, WV ....257

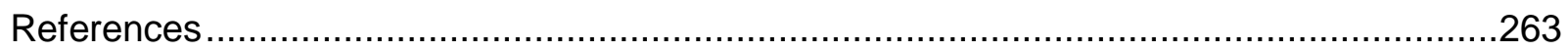




\section{List of Tables}

Table 2.1. Temporal trends in total catch for electrofishing and gill net surveys in Cheat Lake by region

Table 2.2. Temporal trends in CPUE for electrofishing (fish/hr.) and gill net (fish/net-night) surveys in Cheat Lake by region....

Table 2.3. Temporal trends in CPUE for electrofishing (fish/hr.) by decade and lake region. Bolded species and values with an asterisk indicate significance in mvabund results. $E=$ Embayment Zone $\mathrm{M}=$ Main Lake Zone $\mathrm{R}$ = Riverine Zone. 1990s = surveys from 1990, 1997, and 1998; 2000s = surveys from 2001, 2005, and 2008; 2010s = surveys from 2011, 2012, 2013, 2014, and 2015. Standard errors in parentheses.

Table 2.4. Mean relative abundance of species captured from 1952-1977 .96

Table 2.5. Analysis of deviance and variance table from generalized linear mixed model analyses for overall fish abundance and species richness. Asterisk * indicates statistical significance at $\alpha=0.05$

Table 2.6. Results of mvabund analysis of fish community composition changes. Species with significant contribution to the parameter deviance are listed with percent contribution provided in parentheses. Asterisk * indicates statistical significance at $\alpha=0.05$.

Table 3.1. Number of Walleyes stocked in Cheat Lake since reintroduction began in $1999 \ldots 142$

Table 3.2. AICc model selection results for candidate growth models for Cheat Lake 142

Table 3.3. Parameter estimates for von Bertalanffy (VBGM), Gompertz, and logistic growth models for Cheat Lake, WV Walleye growth

Table 3.4. Summary of length at age data for Cheat Lake Walleyes (Females).

Table. 3.5. Summary of length at age data for Cheat Lake Walleyes (Males).

Table 3.6. von Bertalanffy growth parameters for Walleyes in Cheat Lake, North American average (Quist et al. 2003) and for five other West Virginia reservoirs

Table 3.7. Summary of diet contents from Cheat Lake Walleyes $(n=33)$.

Table 4.1. Overall proportional use (\%) of lake zones by male and female Walleyes in Cheat Lake.

Table 4.2. Summary of individual Cheat Lake Walleye telemetry histories. $\mathrm{RI}=$ residency index. Zone abbreviations: $L=$ lower main lake $M=$ middle main lake $R=$ riverine zone $C=$ Cheat River

Table 4.3. Average overall proportional use (with standard errors in parentheses) of lake zones by tagged Walleyes from 2012-2015.

Table 4.4. Mean proportional occurrence of lake zones in monthly core use areas occupied by Walleyes in Cheat Lake

Table 4.5. Monthly core use area lake zones occupied by Walleyes in Cheat Lake $(\mathrm{L}=$ lower main lake zone, $\mathrm{M}=$ middle main lake zone, $\mathrm{R}=$ riverine zone, and $\mathrm{C}=$ Cheat River).

Table 4.6. Results of generalized linear mixed model analysis of monthly core range shifts in Walleyes in Cheat Lake, WV. Sex (female) and Month (January) are used as the baseline for 
the estimation of the categorical variables sex and month, and therefore, do not appear in the model summary

Table 5.1. Annual count of tagged Walleyes migrating to riverine zone of Cheat Lake prior to spawning, including pre-spawn period duration, earliest movement dates, and number of days with migration.

Table 5.2. Summary statistics of three environmental variables (mean daily lake elevation, mean daily river discharge, and mean daily water temperature) during days of upstream prespawn migration and days without upstream pre-spawn migration.

Table 5.3. Parameter estimates for best-fitting logistic regression model using environmental variables to describe upstream pre-spawn migration of Walleyes in Cheat Lake, WV from 20122015. The intercept includes Year 2015.

Table 5.4. Parameter estimates for best-fitting logistic regression model using environmental variables to describe downstream post-spawn migration of Walleyes in Cheat Lake, WV from 2012-2014.

Table 5.5. Parameter estimates for best-fitting logistic regression model using environmental variables to describe large non-spawning movements of Walleyes in Cheat Lake, WV from 2012-2014.

Table 5.6. BIC model selection statistics for 30 candidate models fit to a 2012-2015 time series of daily upstream pre-spawn migration of Walleyes in Cheat Lake, WV. Single variable and additive-effects models included year (YR), sex (SX), percent lunar illumination (LI), water temperature (WT), log transformed river discharge (RD), and lake elevation (LE). $\triangle \mathrm{BIC}$ is the difference between a model and a model with the lowest BIC value

Table 5.7. BIC model selection statistics for 45 candidate models fit to a 2012-2014 time series of daily downstream post-spawn migration of Walleyes in Cheat Lake, WV. Single variable and additive-effects models included year (YR), season (SEAS), sex (SX), percent lunar illumination (LI), water temperature (WT), log transformed river discharge (RD), and lake elevation (LE). $\triangle \mathrm{BIC}$ is the difference between a model and a model with the lowest $\mathrm{BIC}$ value 248

Table 5.8. BIC model selection statistics for 45 candidate models fit to a 2012-2014 time series of daily long distance non-spawning movements of Walleyes in Cheat Lake, WV. Single variable and additive-effects models included year (YR), season (SEAS), sex (SX), percent lunar illumination (LI), water temperature (WT), log transformed river discharge (RD), and lake elevation (LE). $\triangle \mathrm{BIC}$ is the difference between a model and a model with the lowest BIC value 


\section{List of Figures}

Figure 2.1. Biomonitoring sampling locations for Cheat Lake 100

Figure 2.2. Temporal trends in water quality for main Cheat Lake and embayments (19562016). Gray bars represent mean annual pH. Black bars overlayed on gray bars represent minimum annual $\mathrm{pH}$. The black line transecting all bars highlights $\mathrm{pH}$ of 6.0 .....

Figure 2.3. Temporal trends in species richness by lake zone. Black dots represent mean annual species richness. Standard error bars are given.

Figure 2.4. GLMM model predicted values of species richness by lake zone over time (19902015). $E$ = Embayment Zone, $L=$ Lower Lake Zone, $M=$ Middle Lake Zone, $R=$ Riverine Zone. Colored lines represent model predicted values of species richness. Colored bands represent $95 \%$ confidence intervals for species richness value predictions. 103

Figure 2.5. Temporal trends in electrofishing CPUE (fish/hr.) by lake zone for large bodied fishes in Cheat Lake (1990 - 2015). Main lake zone = lower lake and middle lake combined. Standard error bars are given

Figure 2.6. GLMM model predicted values of fish abundance (CPUE (fish/hr.)) by lake zone over time (1990-2015). E = Embayment Zone, $L$ = Lower Lake Zone, $M=$ Middle Lake Zone, $R$ $=$ Riverine Zone. Colored lines represent model predicted values of CPUE. Colored bands represent $95 \%$ confidence intervals for CPUE value predictions. 105

Figure 2.7. Temporal trends in electrofishing CPUE (fish/hr.) for Smallmouth Bass in Cheat Lake $(1990$ - 2015). Standard error bars are given. 106

Figure 2.8. Temporal trends in gill net CPUE (fish/net-night) for Channel Catfish and Brown Bullhead (1990-2015). Standard error bars are given.

Figure 2.9. NMDS results plotted by year using Cheat Lake fish survey presence/absence data from 1952-1977 and 1990-2015. 108

Figure 2.10. NMDS results plotted by lake zone (Riverine, Middle Lake, Lower Lake, and Embayments) for electrofishing survey CPUE data (fish/hr.) on Cheat Lake. 108

Figure 2.11. NMDS results plotted by year (1990-2015) for electrofishing survey CPUE data (fish/hr.) on Cheat Lake. 109

Figure 3.1. Walleye gill net sampling locations in Cheat Lake, WV. 147

Figure 3.2. Temporal changes in CPUE (Walleyes/net-night) of Fall Walleye gill net surveys for Cheat Lake. Error bars represent one standard error. Black dashed line represents the first year of Walleye stocking in 1999. 148

Figure 3.3. Sex-specific length frequency distribution (25-mm bins) of Cheat Lake, WV Walleyes $(\mathrm{n}$ (females) $=57, \mathrm{n}$ (males) $=38, \mathrm{n}$ (immature $)=28$ ) collected for age and growth analysis.

Figure 3.4. Age frequency distribution (adjusted +1 year for comparison with Quist et al. 2003 growth standards) of Cheat Lake, WV Walleyes $(n=123)$ collected for age and growth analysis during fall of 2013 and 2014 .

Figure 3.5. The von Bertalanffy growth model fit to length at age data for 123 Cheat Lake Walleyes (ages 1-14). Female growth model is represented by black line and female mean 
length at age represented by circles. Male growth model is represented by blue line and male mean length at age represented by triangles. The von Bertalannfy model parameters for males and females are provided.

Figure 3.6. Comparison between growth rates of female Cheat Lake, WV Walleyes to the average North American growth rate (Quist et al. 2003) using von Bertalanffy growth models.

Figure 3.7. Comparison between growth rates of male Cheat Lake, WV Walleyes to the average North American growth rate (Quist et al. 2003) using von Bertalanffy growth models.

Figure 3.8. Comparison between growth rates of female Cheat Lake, WV Walleyes to the Walleye growth rates in five other West Virginia reservoirs (East Lynn, Burnsville, Stonecoal, Tygart, and Summersville Lakes) using von Bertalanffy growth models

Figure 3.9. Comparison between growth rates of male Cheat Lake, WV Walleyes to the Walleye growth rates in five other West Virginia reservoirs (East Lynn, Burnsville, Stonecoal, Tygart, and Summersville Lakes) using von Bertalanffy growth models

Figure 3.10. Year class frequency of Walleyes collected for age and growth analysis $(n=123)$ during fall of 2013 and 2014. Years when fingerlings were stocked are represented by black bars. Years without Walleye stockings are represented by cross-hatched bars.

Figure 4.1. Acoustic telemetry receiver locations and associated lake zones in Cheat Lake, WV

Figure 4.2. Typical core range for Walleyes occupying the middle main lake zone of Cheat Lake, WV .

Figure 4.3. Typical core range for Walleyes occupying the riverine zone of Cheat Lake, WV.

Figure 4.4. Typical core range for Walleyes occupying the Cheat River, upstream of Cheat Lake, WV .

Figure 4.5. Mean proportional monthly lake zone use by male Walleyes in Cheat Lake, WV. Error bars are \pm standard error.

Figure 4.6. Mean proportional monthly lake zone use by female Walleyes in Cheat Lake, WV. Error bars are \pm standard error. 202

Figure 4.7. Mean proportion of monthly core range shifts by male and female Walleyes in Cheat Lake, WV 203

Figure 4.8. Mean monthly deviation in receiver use (linear range) by Walleyes in Cheat Lake, WV. Error bars are \pm standard error . 204

Figure 4.9. Mean monthly deviation in residency index by male and female Walleyes in Cheat Lake, WV. Error bars are \pm standard error 205

Figure 5.1. Study site location and map showing location of acoustic receivers, separation of main lake zone and riverine zone (represented by black bar in between two entry points), and location of spawning area in Cheat Lake, WV. Lower Main Lake is located from the dashed line to the dam 
Figure 5.2. Daily proportion of tagged Walleyes migrating into the riverine zone (gray bars) and associated water temperature (black line) data for 2012-2015

Figure 5.3. Proportion of temporary downstream pre-spawn movement events from riverine zone into main lake zone 254

Figure 5.4. Monthly post-spawn migration of tagged Walleyes into the main lake represented by proportion of tagged fish migrating per month and separated by sex.... 255

Figure 5.5. Lake elevation and water temperature during Walleye spawning 2012-2015. April $1^{\text {st }}$ lake level restriction designated by dashed black line. .256 


\section{Chapter 1 - Ecology of Fish Communities in Altered Reservoir Ecosystems with Special Emphasis on Reservoir Walleye Fisheries}

Few large river systems in the present day remain in their free-flowing state. Most have been impounded for one or more reasons related to human needs such as flood control, navigation, water supply, and electric power generation (Baxter 1977; Ney et al. 1990). Consequently, the resulting reservoir ecosystems are subjected to challenges that may deviate from those present in natural systems (Baxter 1977; Ney et al. 1990; Miranda et al. 2010). These unique challenges may include unnatural water level fluctuations, altered temperature and dissolved oxygen profiles, and various other changes to the physical and chemical nature of the water body (Baxter 1977; Ploskey 1986; Ney et al. 1990; Gido et al. 2002; Miranda et al. 2010). Reservoirs, which often have a strong linkage to an extensive watershed, are heavily influenced by any activity or impact within the watershed (Miranda and Bettoli 2010).

Within the Appalachian region, acidification is one of the most significant anthropogenic impacts to watersheds (Herlihy et al. 1990; Herlihy et al. 1993). Acidification via precipitation and mine drainage has impacted many watersheds and likewise some reservoirs in this region, especially in West Virginia (Core 1959; Poe 1971; Herlihy et al. 1990; Herlihy et al. 1993; McClurg et al. 2007). Acidification often leads to extirpation of species, including sportfishes, such as Walleye, that are important top predators and recreationally valuable to anglers. Although substantial research has examined acidification of natural lakes and streams, little research exists on the impacts and recovery processes of fish communities and recreational fisheries in acidified reservoirs. Responses of fish communities and recreational fisheries to reservoir stressors such as acidification and subsequent recovery, are important for researchers to document and utilize for future management actions. 


\section{Reservoir Ecosystems}

Reservoirs are typically constructed to serve the needs of hydroelectric power generation, for flood control purposes, or for water storage (Ney et al. 1990). Despite their

intended construction, reservoirs are extremely important to recreationists including fishermen, boaters, swimmers, etc. (Miranda et al. 2010). Estimates from 2016 indicated that over 24 million anglers (83\% of freshwater anglers) in the United States utilized reservoirs, and freshwater anglers spent over \$29 billion on fishing (USFWS and USDOC 2018). Reservoirs are comparatively young aquatic ecosystems, with most having been constructed during the twentieth century (Miranda et al. 2010). As such, researchers and managers are continuing to gain knowledge on and improve management of reservoir fisheries.

Reservoirs often differ from natural lakes in at least part of their physical, chemical, and biological properties largely because of the effects of inflowing rivers and anthropogenic manipulation of flows (Kimmel and Groeger 1984). Reservoirs exhibit substantial variation in morphology and characteristics dependent on the topography of the region and purpose of the reservoir (Miranda and Bettoli 2010). For instance, reservoirs built in steep terrain are often longer and narrower in morphology, while those constructed in low-lying terrain often have a dendritic shape due to numerous tributaries (Dodds 2002; Hayes et al. 1999). Given the departure in characteristics and management response from natural systems, and the inherent variation between reservoirs, continued research into ecology of reservoirs and their fisheries are vital for resource managers.

Given their large watersheds, reservoirs are strongly tied to activities within contributing tributaries (Vanni et al. 2005; Miranda and Bettoli 2010). Natural processes and anthropogenic activities within the watershed inevitably impact the downstream reservoir (Kimmel and Groeger 1984; Ney et al. 1990; Vanni et al. 2005; Miranda and Bettoli 2010). Upstream watershed activities influence factors in reservoirs such as nutrients, sediment, and water quality (Kimmel 
and Groeger 1984; Ney et al. 1990; Vanni et al. 2005; Miranda and Bettoli 2010). For instance, land use development within a watershed can have significant impacts on the downstream reservoir (Vanni et al. 2005). Land use within a watershed significantly effects the resulting water quality and fish community composition of a downstream reservoir (Miranda and Bettoli 2010). Various watershed activities such as deforestation, agriculture, mining, and urban development cause disturbance and may impact the downstream movement of nutrients, sediment, detritus, and potentially pollutants into a reservoir (Vanni et al. 2005; Miranda and Bettoli 2010). The occurrence of these watershed activities can ultimately impact such factors as primary productivity, water quality, habitat, and species composition of reservoirs (Miranda and Bettoli 2010).

Watersheds with high levels of disturbance from practices such as agriculture, timbering, or urbanization will often lead to increased sedimentation and nutrient levels in downstream reservoirs (Beaulac and Reckhow 1982; Field et al. 1996; Arbuckle and Downing 2001; Jones and Knowlton 2005; Knoll et al. 2003; Jones et al. 2004). Excess sedimentation or nutrient levels can negatively impact reservoir habitat or cause water quality issues (Burford et al. 2007; Soares et al. 2008; Juracek 2014). In contrast, forested watersheds and wooded riparian zones contribute more coarse woody debris to reservoirs than do watersheds or riparian zones dominated by agriculture or urban areas (Miranda and Bettoli 2010). Coarse woody habitat provides essential cover to many species and can impact species composition in reservoirs (Sass et al. 2006). Therefore, land use practices that reduce coarse woody habitat can significantly impact reservoir fish communities. Industry operations within watersheds can also impact receiving reservoirs. In West Virginia, heavily mined watersheds resulted in the acidification of major reservoirs downstream (Core 1959; Poe 1971). Acidification from upstream mining practices impaired water quality and significantly reduced species richness and fish abundance in these reservoirs (Core 1959; Poe 1971). 
The resulting reservoir characteristics that can be strongly influenced by watershed activities have a major effect on the fish communities that reservoirs support (Miranda and Bettoli 2010). Therefore, reservoir management should be viewed from a watershed based scale rather than a localized scale (Miranda and Bettoli 2010). Without incorporating factors within the entire watershed, important drivers of reservoir dynamics could be missed. Understanding how these watershed activities and associated reservoir characteristics impact fish communities is integral in the management of reservoir fisheries.

\section{Longitudinal Patterns}

Watershed complexities produce reservoirs that are more spatially heterogenous than natural lakes (Lodge et al. 1988; Irwin and Noble 1996). Specifically, the influence of incoming tributaries in reservoirs usually creates a noticeable longitudinal gradient of abiotic and biotic conditions (Kimmel and Groeger 1984; Thornton et al. 1990; Gido et al. 2002). Reservoirs will typically show an upstream to downstream gradient from lotic conditions to lentic conditions (Kimmel and Groeger 1984; Hayward and Van den Avyle 1986; Thornton et al. 1990; Gido et al. 2002). Consequently, biotic and abiotic characters of reservoirs often vary with some predictability along this gradient (Eggleton et al. 2005). For instance, upstream portions of a reservoir may be more riverine in character, based on the biotic and abiotic conditions compared to downstream areas (Kimmel and Groeger 1984; Thornton et al. 1990; Gido et al. 2002). As such, upstream reaches of reservoirs will often support fish and invertebrate species more indicative of a river ecosystem (Gido et al. 2002). In contrast, fish communities often begin to represent lacustrine conditions in lower reaches of reservoirs (closer to the dam) (Gido et al. 2002). 
Longitudinal biological gradients of reservoirs are driven by spatial patterns of abiotic characteristics. In riverine reaches of reservoirs, river flow is typically more influential compared to areas downstream (Gido et al. 2002; Okada et al. 2005; Soares et al. 2008; Miranda and Bettoli 2010). With this increase in river flow influence comes differences in water quality and physical habitat. Whereas downstream reaches of reservoirs often thermally stratify, riverine reaches are typically uniform in temperature and dissolved oxygen due to the continued mixing of water from river current (Miranda and Bettoli 2010). Consequently, dissolved oxygen levels may be higher in riverine areas during summer compared to downstream lacustrine habitats. In terms of physical habitat, there is typically a higher percentage of hard substrate available in riverine reaches (Miranda and Bettoli 2010). As in a riverine environment, current carries fine sediments from these upstream reaches, leaving coarser substrates as benthic habitat (Wood and Armitage 1997). There are also often longitudinal differences in macrohabitats such as aquatic vegetation. Specifically, macrophyte growth is expected to be less in riverine reaches

compared to lacustrine reaches (Hayes et al. 1999). Given these variations in water quality and habitat characteristics, fish communities in reservoirs often vary spatially. Fish communities in upstream riverine reaches are typically dominated by species that prefer lotic habitat while downstream lacustrine areas may be dominated by species favoring lentic habitat (Gido et al. 2002; Prchalova 2008; Miranda and Bettoli 2010). Understanding this spatial heterogeneity is vital to effective management of reservoir fish communities.

Physical Habitat

Reservoirs are distinct from natural lakes in their physical habitat characteristics and aging patterns (Kimmel and Groeger 1986; Miranda 2017). Reservoirs face unique habitat limitations due to the nature of their creation and subsequent linkage to large watersheds 
(Miranda 2017). Habitat limitations in reservoirs are usually the direct result of the unnatural processes stemming from the inundation of formerly terrestrial habitats (Miranda et al. 2010). Specifically, reservoirs often lack habitat structure and diversity due to pre-impoundment timbering, post-impoundment woody decay, sedimentation of hard substrates, and limited aquatic vegetation (Wills et al. 2004; Santos et al. 2008).

Reservoirs are often lacking in submerged, physical habitat, such as coarse woody debris, due to physical removal during reservoir construction, decomposition over time, or limited woody deposits from the riparian zone (Agosthino et al. 1999; Wills et al. 2004; Miranda 2017). Lack of woody cover can impact biological communities. Woody cover provides habitat for forage species (e.g., invertebrates, small fishes, etc.) and predatory fishes alike (Sass et al. 2006). Species that favor physical structure for spawning or foraging could see reductions in abundance due to a lack of structure (Sass et al. 2006). For instance, Yellow Perch (Perca flavescens) often drape their eggs over woody debris in littoral areas (Thorpe 1977). Without woody debris or vegetation, eggs are laid on bare substrate and have a reduced survival rate compared to eggs deposited on structure (Nelson 1978). Woody debris also provides cover for juvenile fishes and may provide areas for fish to forage (Wills et al. 2004; Sass et al. 2006). As a result of the lack of woody habitat in reservoirs, many management agencies implement habitat enhancement programs to increase the available physical habitat for fish and anglers alike (Miranda 2017).

Sedimentation is another process that alters and homogenizes habitat within reservoirs (Miranda and Bettoli 2010). Specifically, sedimentation can ultimately convert formerly heterogenous substrate with a variety of hard and soft substrates, into entire benthic areas composed of silt and muck (Miranda and Bettoli 2010; Krogman and Miranda 2016). Reservoirs are subjected to continued depositional filling from both inorganic and organic inputs from feeder tributaries (Miranda et al. 2010). This continuous sedimentation in reservoirs can alter 
the biota. Specifically, fishes and invertebrates that require hard substrates at some point in their life history (e.g., lithophilic spawners) will likely experience population declines over time (Miranda and Bettoli 2010). For others, sedimentation may limit available spawning sites. For example, Walleyes require hard substrate to successfully spawn and in reservoirs with extensive sedimentation, this may leave only the very upstream reaches of a reservoir with suitable habitat (Bozek et al. 2011). Excessive sedimentation can also alter fish community composition in reservoirs. Sedimentation leads to homogenization of littoral habitats and therefore provides a less diverse array of habitats for species to inhabit (Gido et al. 2000; Miranda and Bettoli 2010; Krogman and Miranda 2016).

Reservoirs also often lack aquatic vegetation due to changes in water quality, lack of an established seed bank, and unnatural water level fluctuations (Smart et al. 1996). Although reservoirs can support excessive levels of aquatic vegetation in certain situations, often reservoir conditions make establishment of sufficient aquatic vegetation difficult (Miranda and Bettoli 2010). In some reservoirs, excessive suspension of sediments and resulting turbidity can reduce vegetation growth (Smart et al. 1996). More commonly, the formerly terrestrial origin of inundated soils and the subsequent lack of an established seed bank inhibit establishment of aquatic vegetation in reservoirs (Smart et al. 1996; Miranda and Bettoli 2010). The development of an established seed bank to support aquatic vegetation communities can naturally take hundreds of years (Doyle and Smart 1993; Smart et al. 1996; Miranda and Bettoli 2010). In contrast, reservoirs are relatively new, with most having been in existence less than 100 years (Smart et al. 1996; Miranda and Bettoli 2010). Additionally, the frequent and large water level fluctuations common to many reservoirs can prevent establishment of vegetation (Smart et al. 1996). An intermediate level of aquatic vegetation is often desired, as it can benefit the biotic community (Wiley et al. 1984; Smart et al. 1996; Miranda 2017). Certainly, an intermediate level of vegetation increases the diversity of available habitats which in turn can increase the diversity 
of species supported (Dibble et al. 1996; Smart et al. 1996). For fish, aquatic vegetation can represent important spawning habitat, nursery habitat, or foraging habitat (Dibble et al. 1996). Without sufficient vegetation, some species that rely on this habitat for spawning, shelter, or forage may see reductions in abundance (Dibble et al. 1996).

\section{Water Quality}

Water that is trapped within a reservoir undergoes various physical and chemical changes (Miranda 2017). The extent of these changes can vary substantially dependent on the function of the reservoir and how long water is retained (Miranda 2017). Under some circumstances, these changes can significantly impact reservoir fish communities (Miranda 2017). Specifically, the most important water quality characteristics impacted after impoundment are dissolved oxygen and temperature (Miranda and Bettoli 2010).

Reservoirs often exhibit water quality limitations in the form of dissolved oxygen and temperature stratification, particularly during the warm, summer months. During warm, summer months, water temperature and dissolved oxygen concentrations will often stratify, particularly in the deepest, lacustrine areas of the reservoir (Coutant 1985; Soares et al. 2008). The reservoir will separate into an epilimnion and hypolimnion. The epilimnion is comprised of warm water temperatures and higher dissolved oxygen, while the hypolimnion is composed of cooler water temperatures and lower dissolved oxygen (Dodds 2002). Problems arise for fishes in this situation that require relatively cool water for optimal growth but also require suitable dissolved oxygen levels. For instance, Hale (1999) described growth suppression in crappies in late summer due to unsuitable dissolved oxygen concentrations at depths with optimal water temperatures. Crappies were forced to inhabit shallower areas with adequate dissolved oxygen but these areas in turn had water temperatures too warm for growth (Hale 1999). This situation 
has been termed the "temperature-DO" squeeze (Coutant 1985). Traditional "coolwater" species such as Muskellunge, Smallmouth Bass, and Walleye could face similar situations. For instance, Walleyes have been documented as preferring relatively cool water temperatures (22 C; Kitchell et al. 1977). In reservoirs that strongly stratify, dissolved oxygen levels may be limited in depths that sustain these cool temperatures during warmer months (Bozek et al. 2011). In these situations, Walleyes must choose whether to occupy unsuitable water temperatures or dissolved oxygen conditions (Bozek et al. 2011). Fishes could face reductions in growth, condition, and other physiological constraints if forced to occupy either unsuitable water temperatures or dissolved oxygen concentrations (Miranda and Bettoli 2010).

\section{Water Level Fluctuations}

Reservoir water level fluctuations can influence a variety of physical, chemical, and biological reservoir characteristics (Wetzel 1990; Geraldes and Boavida 2005). Water level fluctuations can significantly impact available habitat for a variety of organisms and life stages (Ploskey 1986). In particular, the littoral zone of reservoirs is often highly affected by water level fluctuations (Furey et al. 2004; Fischer and Ohl 2005; Zohary and Ostrovsky 2011; Miranda 2017). Water level fluctuations often lead to barren littoral areas, with little vegetation growth (Smart et al. 1996; Miranda and Bettoli 2010). Specifically, the frequent and substantial fluctuations in water provide a harsh environment for growth of vegetation (Smart et al. 1996; Miranda 2017). Small decreases in water levels can also decrease cover and change substrate composition (Irwin and Noble 1996). For instance, Beauchamp et al. (1994) found that 20 percent of available rocky substrate was exposed during a 2-meter drawdown event. In another study, Gasith and Gafny (1990) found that substrate available for fishes changed from rocky to sandy during decreased water levels. Similarly, Dibble (1993) found that gravel habitat was 
exposed during drawdown events. Additionally, beneficial woody cover that may be present in littoral areas may be exposed and unusable during drawdown events (Zohary and Ostrovsky 2011). Often times, the dewatering of these important habitats can be poorly timed and impact life stages dependent on these areas (Hayes et al. 1999).

Dewatering of shoreline areas can disrupt biotic communities normally inhabiting littoral zones (Hayes et al. 1999). Dewatering can be especially impactful on invertebrate communities and early life stages of fishes (Ploskey 1986; Zoharty and Ostrovsky 2011). Invertebrates colonizing littoral areas may not be mobile enough to escape dewatering events or constant fluctuations may simply prevent colonization of these areas by invertebrates (Ploskey 1986; Zoharhy and Ostrovsky 2011). Benthic invertebrates can be impacted by exposure and loss of habitat (Ploskey 1986; Furey et al. 2006). Additionally, for fishes that spawn in shallow littoral areas, such as Walleye and Yellow Perch, dewatering can cause stranding of eggs and larvae, resulting in mortality (Hassler 1970; Heman et al. 1969; Priegel 1970; Krieger et al. 1983; Ploskey 1986). Yellow Perch typically drape eggs over woody debris or vegetation in shallow, littoral areas (Thorpe 1977). Decreased water levels after spawning occurs could lead to dewatering of eggs (Krieger et al. 1983). Similarly, Walleyes typically spawn in shallow water, and if water levels are reduced after spawning, areas where eggs have settled may become exposed (Johnson 1961; Priegel 1970; Chevalier 1977). Therefore, it is evident that poorly time or managed water level fluctuations can have adverse impacts on aquatic communities.

If managed correctly, water level fluctuations can be beneficial to reservoir fish communities (Groen and Schroeder 1978; Ploskey 1986; Willis 1986; Sammons and Bettoli 2000). Well timed fluctuations can inundate additional habitat during critical periods such as during and after spawning. Increased spawning success of some species has been associated with inundation of additional habitat (Groen and Schroeder 1978; Ploskey 1986; Willis 1986; Sammons and Bettoli 2000). Specifically, species that spawn on vegetation are often benefited 
by springtime water level increases (Groen and Schroeder 1978; Ploskey 1986). Additionally, increased recruitment has been associated with high water levels during extensive periods after spawning (Willis 1986; Sammons and Bettoli 2000). Specifically, refuge provided by flooded vegetation has been correlated with increased survival of young of year of several species (Willis 1986; Sammons and Bettoli 2000). Increases in water levels may also increase available forage for some species, specifically those that feed on invertebrates (Ploskey 1986; Willis 1986). Consequently, well timed water level increases may lead to increased growth rates for some fishes (Ploskey 1986). In some circumstances, water level drawdowns can benefit reservoir fishes (Ploskey 1986; Willis 1986). Large drawdowns in water level may function to concentrate prey for fishes, especially piscivores (Groen and Schroeder 1978; Ploskey 1986). Some studies have suggested that appropriately timed drawdowns could be conducted to improve foraging conditions for piscivores, thereby increasing growth (Ploskey 1986; Willis 1986).

Given the potential for both positive and negative effects of water level fluctuations and the variety of factors they can influence, it is apparent that knowledge of water regime impacts is important for management of reservoir fisheries. Although poorly timed and mismanaged water level fluctuations can be detrimental to reservoir fisheries, well timed and properly managed fluctuations can in some cases be beneficial (Groen and Schroeder 1978; Ploskey 1986; Willis 1986). Resource managers should be cognizant that water level management can be a vital tool for reservoir fisheries management (Jenkins 1970; Willis 1986).

\section{Fish Communities}

The reservoir characters previously mentioned can be important in structuring of fish communities. Due to the diversity of habitats and longitudinal gradient of characteristics, 
reservoirs often support a wide variety of fish species (Gido et al. 2009). However, most species commonly found in reservoirs are also generalists that occupy a wide distribution (Miranda and Bettoli 2010). Specialized species native to the original riverine system are often absent from reservoirs due a lack of suitable habitat (Gido et al. 2009; Clavero and Hermoso 2011). Hildebrand (1979) noted some riverine species disappear or remain at substantially different abundances after the formation of reservoirs. However, reservoirs often support both lotic and lentic species, especially in systems that retain strong longitudinal gradients from riverine to lacustrine habitat (Gido et al. 2009). However, riverine species that persist in reservoirs may be larger species or riverine species with more plastic habitat requirements (Smith and Petrere Jr. 2008; Gido et al. 2009; Clavero and Hermoso 2011). In contrast, lacustrine areas of reservoirs are often dominated by species with a preference for lentic habitats (Gido et al. 2002; Gido et al. 2009).

As a result of the varying fish communities supported in reservoirs, and the potential spatial separation of these assemblages, managers may need to utilize a diversity of actions to manage fisheries. Additionally, although dominant reservoir species are often generalists, possibly not common to the pre-impoundment river system, they may represent important sportfish for recreational anglers. Therefore, effective management of these species is often important to resource agencies. Additionally, some of these sportfish may have been common to the pre-impoundment river, such as Smallmouth Bass or Walleye, and have adapted to reservoir conditions. Some sportfish, such as Walleye and Smallmouth Bass, are also often species that are sensitive to additional environmental perturbations (Magnuson et al. 1984). Therefore, these species not only represent important species to recreational anglers, but also those that are indicators of the health of the aquatic environment. 


\section{Acidification and Recovering Aquatic Ecosystems}

Acidification of aquatic ecosystems results from acid precipitation or acid mine drainage (Herlihy et al. 1990; Herlihy et al. 1993). Acidification of freshwater environments has a negative impact on aquatic communities. Notably, stream impairment due to acidification results in loss of species from impacted areas and lower fitness of individuals that remain (Haines 1981; Magnuson et al. 1984; Baker et al. 1990; Tremblay and Richard 1993; Schorr and Backer 1996; McClurg et al. 2007). Acidification chronically impacts fisheries, such as reductions in species richness, fish abundance, reduced reproduction, and reduced growth (Haines 1981; Magnuson et al. 1984; Schofield and Driscoll 1987; Baker et al. 1990; Schorr and Backer 1996; McCormick and Leino 1999; McClurg et al. 2007). Acid-intolerant species may experience decreases in reproductive success, growth, and possibly extirpation (Haines 1981; Magnuson et al. 1984; Baker et al. 1990; Tremblay and Richard 1993; Schorr and Backer 1996; McCormick and Leino 1999; McClurg et al. 2007). Extremely acidic conditions can be lethal to some fishes, especially the early life stages (Haines 1981; Baker et al. 1990; McCormick and Leino 1999; McClurg et al. 2007). Acidification can also impact fish communities by significantly altering productivity and forage availability (Haines 1981; Baker et al. 1990; McClurg et al. 2007).

Several studies have found significant effects of acidification on fish populations (Beamish 1976; Haines 1981; Rahel and Magnuson 1983; Pauwels and Haines 1986; Wales and Beggs 1986; Tremblay and Richard 1993; Baldigo and Lawrence 2000; Schorr and Backer 1996; McClurg et al. 2007; Cravotta et al. 2010; Williams and Turner 2015). Previous studies that examined acidification effects on lentic ecosystems primarily focused on acid precipitation (Beamish 1976; Rahel and Magnuson 1983; Wales and Beggs 1986; Eaton et al. 1992;

Tremblay and Richard 1993). Additionally, most of these studies have focused on lentic systems outside of the Appalachian region (Beamish 1976; Rahel and Magnuson 1983; Pauwels and Haines 1986; Wales and Beggs 1986; Eaton et al. 1992; Tremblay and Richard 1993). 
Nevertheless, these studies provide information on response of fish communities to acidification. Most of these studies concluded that species such as Smallmouth Bass, Walleyes, along with some darters (Percidae) and shiners (Cyprinidae) were among the first to disappear after acidification (Beamish 1976; Rahel and Magnuson 1983; Tremblay and Richard 1993). In contrast, White Suckers and Brown Bullheads were often tolerant of acidic conditions and the last species to remain in extremely acid lakes (Beamish 1976; Rahel and Magnuson 1983; Tremblay and Richard 1993; Wales and Beggs 1986; Pauwels and Haines 1986).

Most studies examining the effects of acid mine drainage on aquatic organisms have been conducted in lotic habitats (Schorr and Backer 2006; McClurg et al. 2007; Cravotta et al. 2010; Williams and Turner 2015). Similar to the value of the studies of acidification on lakes, these lotic studies provide valuable information on the response of fish species and communities to acid mine drainage pollution. In streams impacted by acid mine drainage, most studies concluded that there were significant decreases in species richness and overall fish abundance (Schorr and Backer 2006; McClurg et al. 2007; Cravotta et al. 2010; Williams and Turner 2015). Streams treated to reduce the impacts of acid mine drainage experienced improvements to fish community health. Although acid intolerant species returned to treated streams in these studies, most were smaller stream species with little parallel to reservoir ecosystems. Most notably in these studies, species richness and fish abundance substantially increased following treatment of acid mine drainage (Schorr and Backer 2006; McClurg et al. 2007; Cravotta et al. 2010; Williams and Turner 2015).

There has been little published research on the impacts and recovery of reservoir fish communities from acidification. Some research was conducted decades ago on reservoir fisheries impacted by acid mine drainage in West Virginia (Core 1959; Poe 1971). Although the response of fish communities to acidification in reservoirs may ultimately be similar to that in streams and natural lakes, it would be beneficial to document instances of acidification and 
recovery within reservoir ecosystems. Additionally, for resource managers within impacted waterbodies, understanding the magnitude of impact from acidification and the conservation and recreational benefits from recovery provide benchmarks from which to base future management activities and goals.

\section{Ecology of Walleye in the context of Reservoir Systems}

The Walleye (Sander vitreus) is a commercially and recreationally popular North American sportfish (Schmalz et al. 2011). Walleyes are members of the family Percidae, which also includes Sauger, Yellow Perch, and many species of darters (Jenkins and Burkhead 1994). In physical appearance, Walleyes are characterized by completely spinous 1 st dorsal fins and partially spinous $2^{\text {nd }}$ dorsal and anal fins, large canine teeth, luminous eyes with a tapetum lucidum, and white tipped caudal fins (Etnier and Starnes 1993). They have a native range encompassing large portions of Canada and the United States from the Rocky Mountains in the west to the Appalachian Mountains in the east (Billington et al. 2011). Walleyes have been extensively introduced due to their popularity (Billington et al. 2011). Areas of introduction include the Pacific drainages, Atlantic slope drainages, and some Gulf of Mexico drainages (Billington et al. 2011). They are typically described as a coolwater species, but have adapted well to a variety of habitats (Kitchell et al. 1977; Bozek et al. 2011). Walleyes inhabit freshwater rivers, streams, lakes, and reservoirs (Bozek et al. 2011). Walleyes exhibit substantial plasticity, persisting in both lotic and lentic environments (Bozek et al. 2011). Kitchell et al. (1977) posited that Walleyes evolved to successfully occupy habitats intermediate of those dominated by warmwater centrarchids and coldwater salmonids. Additionally, Walleyes have scotopic vision allowing them to be successful predators in high turbidity or nocturnal environments, 
differentiating them from other predatory freshwater fishes (Bozek et al. 2011). Overall, the Walleye is a widely-distributed successful top predator in North America (Bozek et al. 2011).

\section{Spawning and Early Life Stages}

Across their range, Walleyes spawn in the spring months, the timing of which can vary widely based on latitude (Eschmeyer 1950; Scott and Crossman 1973; Becker 1983; Jenkins and Burkhead 1994; Bozek et al. 2011). Spawning can occur from March-June dependent on latitude, and may begin under the ice in the northern range (Eschmeyer 1950; Scott and Crossman 1973; Becker 1983; Jenkins and Burkhead 1994; Bozek et al. 2011). Spawning will often occur earlier in the southern limits of Walleye's range and later in the northern limits corresponding to differences in monthly water temperatures (Bozek et al. 2011). In West Virginia, Walleye spawning typically occurs from mid-March-early April (WVDNR, unpublished data). Spawning timing is thought to be linked to both water temperature and photoperiod (Eschmeyer 1950; Priegel 1970; Scott and Crossman 1973; Bozek et al. 2011). Photoperiod determines the maturation of egg and sperm while water temperature dictates when spawning activity actually occurs (Bozek et al. 2011). The water temperature at which spawning begins varies, but typically ranges from $5-10^{\circ} \mathrm{C}$ (Bozek et al. 2011). Despite the importance of water temperature, photoperiod ultimately dictates the temporal limits of when spawning takes place (Bozek et al. 2011). For instance, in some waters if unseasonably cold water temperatures linger, Walleyes may eventually spawn at cooler temperatures than usual (Rawson 1957; Hokanson 1977). Additionally, if waters warm rapidly in early spring, Walleyes may end up spawning at warmer than usual temperatures (Rawson 1957; Hokanson 1977). As such, spawning has been documented at temperatures as low as approximately $2^{\circ} \mathrm{C}$ (Priegel 1970; 
Hokanson 1977) and as warm as approximately $16^{\circ} \mathrm{C}$ (Corbett and Powles 1986; Hokanson 1977; Priegel 1970).

Walleyes are considered a simple lithophilic species, given that they broadcast their eggs over hard substrates (e.g., gravel, cobble) and do not build a nest or provide any parental care (McEIman 1983). In reservoirs, Walleye populations are typically classified as either river spawners or lake spawners (Colby et al. 1979; Jennings et al. 1996; Bozek et al. 2011). Therefore, Walleye spawning in reservoirs may occur in lentic, main lake areas or within large feeder tributaries to the reservoir (Pflieger 1997; Chalupnicki et al. 2010; Bozek et al. 2011; Martin et al. 2011). In lentic areas, Walleyes typically choose rocky, windswept shorelines to broadcast their eggs, while in rivers they usually deposit eggs in areas of current with hard substrate (Eschemeyer 1950; Palmer et al. 2005; Raabe 2006; Hamilton 2009; Martin et al. 2011). In some reservoirs, both lake spawners and river spawners occur (Jennings et al. 1996; Palmer et al. 2005). Researchers suggest that this variation in spawning strategy could simply be a learned behavior or be a heritable trait (Olson et al. 1978; Jennings et al. 1996; Palmer et al. 2005). Spawning success in main lake areas typically is dependent on suitable habitat in the form of rocky, windswept shorelines (Johnson 1961; Auer and Auer 1990; Martin et al. 2011). Likewise, for successful spawning to occur in feeder tributaries, sufficient rocky substrate and current is optimal (Hanson 2006; Hartman 2009). In some reservoirs, spawning may not occur successfully due to a lack of suitable spawning habitat (Johnson 1961).

Walleyes typically spawn at night, with male Walleyes flanking females, and depositing milt over areas where females deposit eggs (Etnier and Starnes 1993). After fertilization and loss of adhesiveness, eggs eventually settle into the substrate (Scott and Crossman 1973). Likely due in part to the lack of nest preparation or parental care, egg mortality is usually high in Walleyes (Colby et al. 1979). Reported egg survival rates vary widely in the literature, due to numerous factors (e.g., habitat, predation, etc.) that can increase or decrease survival (Colby et 
al. 1979). Survival rates as low as $<1 \%$ and as high as $>60 \%$ have been reported in the literature (Eschemeyer 1950; Johnson 1961; Forney 1976; Roseman et al. 1996). Fertilized eggs that survive typically hatch within 10-27 days (Niemuth et al. 1959; Johnson 1961; Priegel 1960; Bozek et al. 2011). Egg hatching times depend greatly on water temperatures during incubation, with warmer water temperatures correlated with shorter incubation periods (Scott and Crossman 1973). Upon hatching, larval Walleyes are quite small, only 6-9 mm in total length (Summerfelt et al. 2011). Larval Walleyes are poor swimmers, and upon hatching are still not capable of swimming, but instead move with water currents (Walburg 1971). Due to their limited swimming ability, larval Walleyes are reliant on currents to carry them to suitable habitat after hatching (Becker 1983; Mion et al. 1998; Jones et al. 2003). Too little water current may strand them in areas without suitable habitat or food, whereas too much current could be fatal due to physical trauma or transport to unsuitable areas (Mion et al. 1998). Newly hatched Walleyes have limited yolk to subsist on and thus rely on feeding shortly after hatching (Bozek et al. 2011). Consequently, hatch timing and juxtaposition near abundant forage is critical for survival at these early life stages (Jones et al. 2003).

\section{Diet and Foraging}

Walleyes undergo ontogenetic diet shifts, primarily during their first year of life (Chipps and Graeb 2011). Walleyes initially begin feeding on small zooplankton as larvae, with survival highly correlated with larval transportation to areas with available zooplankton (Mion et al. 1998; Jones et al. 2003). Walleyes feed on small zooplankton for the first several weeks of their life before switching to benthic macroinvertebrates (Mathias and Li 1982; Hoxmeier et al. 2004; Galarowicz et al. 2006). Subsistence on benthic invertebrates persists until Walleyes reach a size at which they switch to piscivory, targeting small fishes (Chipps and Graeb 2011). Even 
after switching to fish, prey size continues to increase with increasing Walleye size (Chipps and Graeb 2011). Walleyes are gape limited and require larger prey for sustenance as their body size increases (Chipps and Graeb 2011). Onset of piscivory in Walleyes can vary considerably, with some studies suggesting it can occur as early as $20 \mathrm{~mm}$, where others suggest $40 \mathrm{~mm}$ or larger (Colby et al. 1979; Mathias and Li 1982; Galarowicz et al. 2006; Hartman 2009). Chipps and Graeb (2011) suggest that the onset of piscivory is somewhat determined by both gape limitations and availability of fish that fit within this limitation. In rare instances, Walleyes have been documented to continually subsist on invertebrates as adults where forage fish are unavailable (Colby et al.1979). Walleyes initially forage on small bodied fishes that conform to their gape limit, which is likely to be other age-0 fishes such as shiners (Notropis sp.), Yellow Perch, Gizzard Shad, or other available small-sized forage fish (Kocovsky and Carline 2001; Bozek et al. 2011; Chipps and Graeb 2011). Several studies have reported that Walleyes prefer soft-rayed fishes (Forney 1974; Knight et al. 1984; Hartman and Margraf 1992; Bozek et al. 2011), although they also feed heavily on some spiny-rayed fishes, especially Yellow Perch (Forney 1974; Colby et al. 1979; Hartman and Margraf 1992; Hartman and Margraf 1993; Jackson et al 1993; Kocovsky and Carline 2001; Pierce et al. 2006). Species such as Yellow Perch are documented as being especially important when soft-rayed species are not available or are in low abundances (Forney 1974; Hartman and Margraf 1992; Hartman and Margraf 1993; Jackson et al. 1993; Kocovsky and Carline 2001).

Reservoirs often provide Walleyes with a diversity of forage options, although the species and size spectrum of available prey will depend largely on the characteristics of each watershed. For instance, where some reservoirs have abundant soft-rayed prey such as Gizzard Shad, Ciscoes, or Rainbow Smelt, other systems may lack these species and spinyrayed prey such as Yellow Perch and Centrarchids may be more important (Forney 1974; Hartman and Margraf 1992; Santucci and Wahl 1993; Kocovsky and Carline 2001). Still some 
reservoirs may lack a diverse size spectrum of prey and force Walleyes to feed on smaller species (Colby et al. 1979; Lyons and Magnuson 1987). Limitations in preferred prey or a diverse size spectrum of prey could negatively impact condition or growth (Henderson et al. 2004; Kaufmann et al. 2009).

Age and Growth

Walleye age and growth have been researched extensively. Walleye age and growth are dependent on a variety of factors, including latitude, water temperature, habitat, competition, and forage (Colby et al. 1979; Kocovsky and Carline 2001; Quist et al. 2003; Bednarski et al. 2010; Bozek et al. 2011). Walleyes in the northern portion of their range typically grow slower and live longer, while southern Walleyes grow faster and have shorter lifespans (Carlander 1997; Craig 2000; Quist et al. 2003; Bozek et al. 2011). Latitudinal differences in growth are directly related to growing degree days, or the length of the growing season (Bozek et al. 2011). There are also sex-based differences in Walleye growth (Quist et al. 2003; Bozek et al. 2011). Specifically, female Walleyes grow faster and have larger maximum sizes compared to male Walleyes (Bozek et al. 2011). Additionally, diet has been shown to influence Walleye growth (Colby et al. 1979; Hartman and Margraf 1992; Henderson et al. 2004; Kaufmann et al. 2009). Studies suggest that available prey type and size spectrum of available prey may impact condition and growth in Walleyes (Hartman and Margraf 1992; Santucci and Wahl 1993;

Carlander 1997; Henderson et al. 2004; Kaufmann et al. 2009). Specifically, if there is a lack of preferred prey or optimal size prey, condition and growth may be limited (Santucci and Wahl 1993; Carlander 1997; Henderson et al. 2004; Kaufmann et al. 2009).

Growth in reservoirs is typically reported to be similar to growth in natural systems, but certain reservoir characteristics may increase or decrease growth. For instance, reservoirs may 
support a variety of optimal prey items, such as Gizzard Shad, that allows for faster growth in resident Walleyes (Hartman and Margraf 1992; Santucci and Wahl 1993; Quist et al. 2003). However, other aspects of reservoirs, such as thermal stratification, may cause less than optimal growth conditions (Bozek et al. 2011). Growth in reservoirs will ultimately depend on other factors that are determined by the characteristics of each reservoir.

\section{Habitat and Water Quality}

The Walleye is typically considered a coolwater species, preferring habitat with lower maximum water temperatures and adequate dissolved oxygen (Hokanson 1977; Kitchell et al. 1977; Colby et al. 1979; Jenkins and Burkhead 1994). In reservoirs, optimal conditions are most often found in mesotrophic waters (Scott and Crossman 1973; Colby et al. 1979; Jenkins and Burkhead 1994). Walleyes have been reported to prefer a water temperature of approximately $22{ }^{\circ} \mathrm{C}$ for optimal foraging and growth (Kitchell et al. 1977; Bozek et al. 2011). For spawning activity, lower water temperatures from $5-10^{\circ} \mathrm{C}$ are required (Hokanson 1977; Etnier and Starnes 1993; Jenkins and Burkhead 1994; Bozek et al. 2011). If Walleyes are forced to occupy unsuitable water temperatures, there could be impacts to condition, growth rate, and potentially reproduction (Kokovsky and Carline 2001). Walleyes will seek out preferred water temperatures, sometimes despite unsuitability of other water quality parameters (e.g., dissolved oxygen) (Fitz and Holbrook 1978).

Besides water temperature, other water quality parameters are often important to persistence and success of Walleye populations in reservoir ecosystems. Walleyes prefer dissolved oxygen concentrations above $5.0 \mathrm{mg} / \mathrm{L}$, a minimum level for optimal egg incubation (Oseid and Smith Jr. 1971; McMahon et al. 1984). Low dissolved oxygen levels may limit hatching success and survival of larval Walleyes (Colby et al. 1979; Auer and Auer 1990). Given 
oxygen requirements for Walleye eggs, substrate and water movement that facilitates higher dissolved oxygen is often critical for hatching success (Raabe 2006). Additionally, in reservoirs that experience stratification, Walleyes may be limited in depth of water occupied and perhaps alter their location to areas of higher dissolved oxygen (Colby et al. 1979).

Walleyes are sensitive to $\mathrm{pH}$ levels. Specifically, low $\mathrm{pH}$ can be detrimental to successful reproduction in Walleyes (Lynch and Corbett 1980; Hulsman et al. 1983; Rahel and Magnuson 1983). Studies have found that $\mathrm{pH}$ values lower than 6.0 leads to increased egg and larval mortality (Hulsman et al. 1983). In some acidified lakes, a $\mathrm{pH} \leq 5.5$ results in Walleye reproductive failure (Rahel and Magnuson 1983). In the Cheat River watershed, WV, Walleyes were initially abundant but continued acidification due to acid mine drainage eventually extirpated the species from the watershed (Core 1959).

Habitat requirements of Walleyes change throughout each life stage associated with different survival needs (Bozek et al. 2011). While adult habitat has been extensively studied, relatively limited research has been conducted on age-0 Walleye habitat use (Bozek et al. 2011). Age-0 Walleye habitat use shifts as young grow larger (Etnier and Starnes 1993; Bozek et al. 2011). Initially, age-0 Walleyes occupy pelagic habitats, but as their first year progresses they become demersal, progressively occupying deeper waters as they become negatively phototactic (Etnier and Starnes 1993; Bozek et al. 2011). However, habitat use of age-0 Walleyes can vary with food and habitat availability (Bozek et al. 2011). Adult Walleyes are usually demersal, but specific habitat use shifts seasonally in concordance with spawning and foraging (Colby et al. 1979).

Walleyes can successfully reproduce in both lentic and lotic environments, provided there is rocky substrate with adequate dissolved oxygen through either wave action or river current (Jenkins and Burkhead 1994; Bozek et al. 2011). Spawning habitat is critical for sustained natural reproduction and recruitment in aquatic systems. Walleyes may either spawn 
in lentic or lotic habitats, with some habitat similarities and differences (Bozek et a. 2011). In lentic environments, such as main lake areas of reservoirs, Walleyes will spawn on rocky, windswept shorelines (Becker 1983; Bozek et al. 2011; Martin et al. 2011). Rocky substrate is considered critical, as it provides areas for eggs to settle, while being oxygenated as well as protected from predators and abiotic stressors such as wave action or siltation (Bozek et al. 2011; Martin et al. 2011). Walleyes have been documented as spawning on alternative habitats in lentic environments, but the success of reproduction is variable. Walleyes have been documented in other studies as spawning on root wads, vegetation, muck-detritus bottom, and fine sand in some systems (Eschemeyer 1950; Johnson 1961; Priegel 1970; Auer and Auer 1990; Ickes et al. 1999), however, there is some evidence that spawning on rocky substrate increases egg survival (Johnson 1961; Auer and Auer 1990). Depth of spawning activity for Walleyes is in relatively shallow, nearshore areas (Jenkins and Burkhead 1994; Bozek et al. 2011). Studies have documented higher survival of eggs on rocky substrates and lower survival on fine sand or silty substrates (Johnson 1961; Auer and Auer 1990; Hamilton 2009; Bozek et al. 2011). Likewise, while some wave activity is beneficial via oxygenation, excessive wave activity can damage eggs or carry them to unsuitable areas (Eschemeyer 1950; Johnson 1961; Raabe 2006; Bozek et al. 2011). Too little wave activity could lead to a lack of oxygenation (Bozek et al. 2011). When spawning in rivers, such as feeder tributaries of reservoirs, Walleyes similarly spawn on rocky substrates where some current is present (Jenkins and Burkhead 1994; Bozek et al. 2011). They also typically choose relatively shallow water, similar to lentic spawning areas (Jenkins and Burkhead 1994; Bozek et al. 2011). Additionally, like lake spawning areas, rocky substrates offer protection from predation, transport damage, and siltation, while allowing for adequate oxygenation (Dustin and Jacobson 2003; Ivan et al. 2010; Bozek et al. 2011). Similar to wave activity for lake spawners, some river flow is needed for oxygenation of eggs, but excessive flow could be detrimental to eggs (Jones et al. 2003; Bozek et al. 2011). 
Foraging habitat varies to some extent seasonally, likely as a function of water temperature and forage fish availability. Overall, adult Walleyes are considered demersal, usually orienting themselves close to the bottom (Bozek et al. 2011). Walleyes are negatively phototactic as adults, which likely influences their affinity for deep water and benthic habitats (Bozek et al. 2011). Walleyes will become more pelagic under certain conditions, typically when stratification occurs and a strong temperature-oxygen thermocline develops (Williams 2001; Clark-Kolaks 2008; Kirby et al. 2017). Physical habitat preferences have been reported to be hard substrates with structure in the form of boulders, submerged vegetation, or large woody debris (Holt et al. 1977; Ryder 1977; Schlagenhaft and Murphy 1985; Paragamian 1989; Kerr et al. 1997; Williams 2001; Clark-Kolaks 2008). However, foraging habitat appears to be somewhat plastic, as Walleyes will follow abundant forage fish into a variety of habitats (Raby et al. 2017).

In reservoirs, Walleye habitat varies widely and is often significantly impacted by water level fluctuations. Specifically, water level fluctuations can significantly impact spawning habitat and have significant consequences on Walleye recruitment (Priegel 1970; Raabe 2006). Optimal spawning habitat can be limited or unavailable, dependent on the timing and magnitude of water level fluctuations during this period (Johnson 1961; Priegel 1970). Dewatering of optimal rocky habitat during reservoir fluctuations can force Walleyes to spawn on less suitable substrates such as sand and muck (Johnson 1961; Priegel 1970). Additionally, if spawning occurs in shallow water habitats and water levels are subsequently reduced, stranding and mortality of eggs could occur (Priegel 1970). In either situation, water level fluctuations and their impact on spawning habitat and success can lead to increases in recruitment failure that can be detrimental to Walleye populations (Priegel 1970; Raabe 2006). 


\section{Migration and Movement}

Walleyes rely on migrations and movements to locate areas necessary for spawning and foraging (Hanson 2006). Walleyes may undertake large scale seasonal migrations, or smaller scale diel movements. Walleyes make diel movements related to habitat shifts between diurnal and nocturnal periods (Colby et al. 1979; Hanson 2006). In lakes and reservoirs, Walleyes have been documented to move from deeper, main lake areas during the day, to shallower, cove areas at night, presumably to forage (Williams 2001; Kirby et al. 2017). Walleyes also are known to make potentially large migrations to spawning grounds in late winter or early spring (Bozek et al 2011). Some of these migrations have been over $200 \mathrm{~km}$ in length (Eschmeyer and Crowe 1955; Hanson 2006). After spawning, Walleyes likewise usually make post-spawn migrations to foraging areas (Palmer et al. 2005). Finally, Walleyes may make additionally movements to areas used for overwintering habitat (DePhilip et al. 2005). There have been significant sex-based differences in migrations and movement reported in Walleyes (Wang et al. 2007; Raby et al. 2017). Specifically, females are often more apt to make post-spawn movements away from spawning grounds compared to males (Wang et al. 2007; Raby et al. 2017). Motivations for movement may be to find preferred water quality conditions (e.g., water temperature, dissolved oxygen, etc.), pursue abundant forage resources, or a combination of both (Wang et al. 2007; Raby et al. 2017).

\section{Walleye in West Virginia Reservoirs}

In recent years, interest in Walleye fisheries has increased among West Virginia anglers. Subsequently, fisheries managers have increased management efforts for these fisheries across West Virginia waters. Walleyes are native to West Virginia, but were historically inhabitants of riverine environments in the state (Zipfel 2006). Damming of river systems and 
water quality impairment (often acid mine drainage) resulted in the loss or reduction of Walleye fisheries in many areas of West Virginia (WVDNR, unpublished data). Stocking of Walleyes and water quality improvements have resulted in reestablished Walleye populations in many West Virginia reservoirs (WVDNR, unpublished data). Still, many West Virginia reservoirs have limitations that create challenges for management of Walleye fisheries. West Virginia reservoirs often lack adequate spawning habitat, limiting success of natural reproduction. In these waters, continued stocking is necessary to maintain Walleye populations. In other reservoirs, forage limitations or competing populations of Centrarchids (e.g., Largemouth Bass) make establishment of consistent and/or harvestable Walleye fisheries difficult. However, in some West Virginia reservoirs, Walleye populations appear to be improving and angler interest increasing. To better manage Walleye fisheries, WVDNR biologists developed a statewide management plan to address management efforts such as stocking and regulations (WVDNR 2015). Further research will be important to adaptively manage these fisheries.

\section{Cheat Lake, WV}

The Lake Lynn Hydro Project (commonly referred to as Cheat Lake) was created by damming the Cheat River in Monongalia County, WV in 1926 (Core 1959). The river was impounded to serve the needs of a hydroelectric generating facility located near the mouth of the Cheat River. The resulting reservoir has an area of 700 ha and stretches approximately 21 kilometers long. An operating license issued by the Federal Energy Regulatory Commission (FERC) in 1994 mandated that target reservoir water level changes be maintained throughout the year in order to help enhance recreation and minimize impacts to aquatic life (Wellman et al. 2008). Lake elevations must be maintained in three different ranges depending on time of year. From May through October, lake levels must be held between 264.5 and 265.1 meters (full pool) 
above sea level to enhance lake recreation. From November through March, lake levels can fluctuate between 261.2 and 265.1 meters to maximize hydropower generation. Finally, during the month of April lake levels must be held between 263 and 265.1 meters in an attempt to improve spawning success of Walleye and Yellow Perch. Despite best efforts to institute fluctuation restrictions to minimize impacts to aquatic life, it is still possible that seasonal fluctuations could affect fish populations. Specifically, concerns existed that current water level fluctuations in March and April could negatively impact Walleye and Yellow Perch spawning success.

In addition to potential existing impacts from water level fluctuations, the Cheat Lake ecosystem is currently in recovery from decades of impairment due to upstream acid mine drainage. Since the creation of the reservoir, the Cheat River watershed has been significantly impacted by acid mine drainage. Water quality reached a low in the 1970's when pH levels in main Cheat Lake averaged less than 5.0 (WVDNR unpublished data). Some remediation efforts of acid mine drainage in the watershed began in the 1980's (Rick Buckley OSMRE, personal communication). However, a large increase in mine drainage treatment began in the 1990s with the coordination of multiple government agencies and non-profit organizations (Rick Buckley OSMRE, personal communication). Funding for the abatement of abandoned mine lands and other funding opportunities have made possible the extensive mitigation work that has been completed throughout the watershed. As a result of decades of acid mine drainage treatment throughout the watershed, water quality has improved within Cheat Lake. However, periodic depressions in $\mathrm{pH}$ during the early 2000s highlighted the continued risk of impact from acidic sources.

Biomonitoring surveys suggest improvement in the Cheat Lake fish community in recent years. Biological improvements are likely the result of efforts to remediate upstream pollution from acid mine drainage. In addition, after likely being extirpated from Cheat Lake due to poor 
water quality (Core 1959), the Walleye (Sander vitreus) population of Cheat Lake has seen recent improvements as a result of management efforts from the West Virginia Division of Natural Resources (WVDNR). Improved water quality and stocking efforts have led to a resurgent Walleye fishery within Cheat Lake. However, natural reproduction is limited, and little is known about the life history of Walleye in Cheat Lake and how current water level regimes and other environmental influences affect the Walleye population.

This dissertation research evaluated recovery of the fish community within Cheat Lake after decades of acidification, with specific focus on the ecology and population characteristics of the reestablished Walleye population. In the research chapters that follow, I examine 1). The long-term recovery of the fish community of Cheat Lake after decades of acidification; 2). The population characteristics of the reestablished Walleye population; 3). The distribution and space use patterns of Walleye within Cheat Lake; 4). The environmental correlates associated with large scale movements of Walleye within Cheat Lake; 5) and in the last chapter I synthesize the findings of this dissertation into possible management actions and recommendations for the future management of the Cheat Lake fish community. 


\section{References}

Agosthino, A. A., L. E. Miranda, L. M. Bini, L. C. Gomes, S. M. Thomaz and H. I. Suzuki. 1999. Patterns of colonization in neotropical reservoirs, and prognoses on aging. Pages 227265 in J. G. Tundisi and M. Straskraba, editors. Theoretical reservoir ecology and its applications. Backhuys Publishers, Leiden

Arbuckle, K. E. and J. A. Downing. 2001. The influence of watershed land use on lake N:P in a predominantly agricultural landscape. Limnology and Oceanography 46: 970-975

Auer, M. T. and N. A. Auer 1990. Chemical suitability of substrate for walleye egg development in the lower Fox River, Wisconsin. Transactions of the American Fisheries Society, 119: $871-876$

Baker, J. P., D. P. Bernard, S. W. Christensen, M. J. Sale, J. Freda, K. Heltcher, D. Marmorek, L. Rowe, P. Scanlon, G. Suter, W. Warren-Hicks, and P. Welbourn. 1990. Biological effects of changes in surface water acid-base chemistry. NAPAP Report 13. in National Acid Precipitation Assessment Program, Acidic Deposition: State of Science and Technology. Volume II, 1990.

Baldigo, B. P. and G. B. Lawrence. 2000. Composition of fish communities in relation to stream acidification and habitat in the Neversink River, New York. Transactions of the American Fisheries Society 129: 60-76.

Baxter, R. M. 1977. Environmental effects of dams and impoundments. Annual Review of Ecology and Systematics 8: 255-283.

Beamish, R. J. 1976. Acidification of lakes in Canada by acid precipitation and the resulting effects on fishes. Water, Air, and Soil Pollution 6: 501-514. 
Beauchamp, D. A. 1994. Spatial and temporal dynamics of piscivory: implications for food web stability and the transparency of Lake Washington. Lake and Reservoir Management 9: $151-154$.

Beaulac, M. N. and R. H. Reckhow. 1982. An examination of nutrient export relationships. Water Research Bulletin 18: 1013-1024.

Becker, G. C. 1983. Fishes of Wisconsin. University of Wisconsin Press, Madison.

Bednarski, M. S., J. Hendricks, D. L. Higginbotham, and D. L. Peterson. 2010. Growth rates of stocked walleyes in several Georgia reservoirs. Proceedings of Annual Conference of Southeastern Fish and Wildlife Agencies. 64: 136-140.

Billington, N., C. C. Wilson, and B. L. Sloss. 2011. Distribution and population genetics of walleye and sauger. Pages 105-132 in B. A. Barton, editor. Biology, Management, and Culture of Walleye and Sauger. American Fisheries Society, Bethesda, Maryland

Bott, T. L., J. K. Jackson, M. E. McTammany, J. D. Newbold, S. T. Rier, B. W. Sweeney, and J. M. Battle. 2012. Abandoned coal mine drainage and its remediation: impacts on stream ecosystem structure and function. Ecological Applications 22: 2144-2163.

Bozek, M. A., D. A. Baccante, and N. P. Lester. 2011. Walleye and sauger life history. Pages 233-301 in B. A. Barton, editor. Biology, Management, and Culture of Walleye and Sauger. American Fisheries Society, Bethesda, Maryland.

Bozek, M. A., T. J. Haxton, and J.K. Raabe. 2011. Walleye and sauger habitat. Pages 133-197 in B.A. Barton, editor. Biology, Management and Culture of Walleye and Sauger. American Fisheries Society, Bethesda, Maryland.

Bruton, M. N. 1985. Effects of suspensoids on fish. Hydrobiologia 125: 221-241. 
Burford, M.A., S.A. Johnson, A.J. Cook, T.V. Packer, B.M. Taylor, and E. R. Townsley. 2007. Correlations between watershed and reservoir characteristics, and algal blooms in subtropical reservoirs. Water Research 41: 4105-4114.

Carlander, K. D. 1997. Handbook of Freshwater Biology, volume 3. lowa State University Press, Ames.

Chalupnicki, M. A., Johnson, J. H., McKenna, J. E., and D. E. Dittman. 2010. Habitat selection and spawning success of walleye in a tributary to Owasca, New York. North America Journal of Fisheries Management 30: 170-178.

Chevalier, J. R. 1977. Changes in walleye (Stizostedion vitreum vitreum) population in Rainy Lake and factors in abundance. Journal of the Fisheries Research Board of Canada 34: $1696-1702$.

Chipps, S. R. and B. D. S. Graeb. 2011. Feeding ecology and energetics. Pages 303-320 in B. A. Barton, editor. Biology, Management and Culture of Walleye and Sauger. American Fisheries Society, Bethesda, Maryland.

Clark-Kolaks, S. 2008. Distribution and movement of walleye (Sander vitreus) in Monroe Reservoir, Indiana 2008 and 2009. Fish Research Final Report, Indiana Fisheries section, Indiana Department of Natural Resources, Division of Fish and Wildlife.

Clavero, M. and V. Hermoso. 2011. Reservoirs promote the taxonomic homogenization of fish communities within river basins. Biodiversity and Conservation 20: 41-57.

Colby, P. J., R. E. McNicol, and R. A. Ryder. 1979. Synopsis of biological data on the walleye Stizostedion v. vitreum. FAO Fisheries Synopsis 119, Rome.

Corbett, B. W. and P. M. Powles. 1986. Spawning and larval drift of sympatric walleyes and white suckers in an Ontario stream. Transactions of the American Fisheries Society 115: $41-46$. 
Core, E. L. 1959. Biological Investigations of Cheat Lake. West Virginia University, Morgantown, WV.

Coutant, C. C. 1985. Striped bass, temperature, and dissolved oxygen: a speculative hypothesis for environmental risk. Transactions of the American Fisheries Society 114: 31-61.

Craig, J. F. 2000. Percid Fishes: Systematics, Ecology and Exploitation. Blackwell Science, Oxford, UK.

Cravotta III, C. C., R. A. Brightbill, and M. J. Langland. 2010. Abandoned mine drainage in the Swatara Creek basin, southern anthracite coalfield, Pennsylvania, USA: stream water quality trends coinciding with the return of fish. Mine Water and the Environment 29: 176-199.

de Oliveira, E. F., C. V. Minte-Vera, and E. Goulart. 2005. Structure of fish assemblages along spatial gradients in a deep subtropical reservoir (Itaipu Reservoir, Brazil-Paraguay border). Environmental Biology of Fishes 72: 283-304.

DePhilip, M.M., J.S. Diana, and Smith, D. 2005. Movement of walleye in an impounded reach of the Au Sable River, Michigan, USA. Environmental Biology of Fishes 72: 455-463.

Dibble, E. C., K. J. Killgore, and S. L. Harrel. 1996. Assessment of fish-plant interactions. American Fisheries Society Symposium 16: 357-372.

Dodds, W. K. 2002. Freshwater Ecology: Concepts and Environmental Applications. Academic Press, San Diego.

Doyle, R. D. and R. M. Smart. 1993. Potential use of native aquatic plants for long-term control of problem aquatic plants in Guntersville Reservoir, Alabama. Report 1. Establishing native plants. Technical Report A-93-6. U.S. Army Corps of Engineers, Environmental Laboratory, Vicksburg, Mississippi, USA. 
Dustin, D. and P. C. Jacobson. 2003. Evaluation of walleye spawning habitat improvement projects in streams. Minnesota Department of Natural Resources Investigational Report 502, St. Paul.

Eaton, J. G., W. A. Swenson, J. H. McCormick, T. D. Simonson, and K. M. Jensen. 1992. A field and laboratory investigation of acid effects on largemouth bass, rock bass, black crappie, and yellow perch. Transactions of the American Fisheries Society 121: 644658.

Edens, D. L. 1975. A comparative study of nutrients and water quality in Cheat Lake tributaries. Master's Thesis. West Virginia University, Morgantown, WV.

Eggleton, M. A., R. Ramirez, C. W. Hargrave, K. B. Gido, J. R. Masoner, G. D. Schnell, and W. J. Matthews. 2005. Predictability of littoral-zone fish communities through ontogeny in Lake Texoma, Oklahoma-Texas, USA. Environmental Biology of Fishes 73: 21-36

Eschmeyer, P. H. 1950. The life history of the walleye, Stizostedion vitreum vitreum, in Michigan. Michigan Department of Conservation, Bulletin of the Institute of Fisheries Research 3, Ann Arbor.

Eschemeyer, P.H. and W.R. Crowe. 1955. The movement and recovery of tagged walleyes in Michigan, 1929-1953. Michigan Department of Natural Resources, Research Report 8.

Etnier, D. A. and W. C. Starnes. 1993. Fishes of Tennessee. University of Tennessee Press, Knoxville.

Field, C. K., P. A. Siver, and A. M. Lott. 1996. Estimating the effects of changing land use patterns on Connecticut lakes. Journal of Environmental Quality 25: 325-333.

Fischer, P. and U. Ohl. 2005. Effects of water-level fluctuations on the littoral benthic fish community in lakes: a mesocosm experiment. Behavioral Ecology 16:741-746. 
Fitz, R. B. and J. A. Holbrook II. 1978. Sauger and walleye in Norris Reservoir, Tennessee. Pages 82-88 in R. L. Kendall, editor. Selected Coolwater Fishes of North America. American Fisheries Society, Special Publication 11, Bethesda, Maryland

Forney, J. L. 1974. Interactions between yellow perch abundance, walleye predation, and survival of alternate prey in Oneida Lake, New York. Transactions of the American Fisheries Society 103: 15-24.

Forney, J. L. 1976. Year-class formation in the walleye population of Oneida Lake, New York, 1966-73. Journal of the Fisheries Research Board of Canada 33: 783-792.

Freund, J.G. and J.T. Petty. 2007. Response of Fish and Macroinvertebrate Bioassessment Indices to Water Chemistry in a Mined Appalachian Watershed. Environmental Management 39: 707-720.

Furey, P. C., R. N. Nordin, and A. Mazumder, 2004. Water drawdown affects physical and biogeochemical properties of littoral sediments of a reservoir and a natural lake. Lake and Reservoir Management 20: 280-295.

Galarowicz, T. L., J. A. Adams, and D. H. Wahl. 2006. The influence of prey availability on ontogenetic diet shifts of a juvenile piscivore. Canadian Journal of Fisheries and Aquatic Sciences 63: 1722-1733.

Gasith, A. and S. Gafny. 1990. Effects of water level fluctuation on the structure and function of the littoral zone. Pages 156-171 in M. M. Tilzer, C. Serruya, editors. Large Lakes: Ecological Structure and Function. Berlin (Germany): Springer-Verlag.

Geraldes, A. M. and M. J. Boavida. 2005. Seasonal water level fluctuations: implications for reservoir limnology and management. Lakes and Reservoir Research and Management 10: 59-69. 
Gido, K. B. and W. J. Matthews. 2000. Dynamics of the offshore fish assemblage in a Southwestern reservoir (Lake Texoma, Oklahoma-Texas). Copeia 2000: 917-930.

Gido, K. B., C. W. Hargrave, W. J. Matthews, G. D. Schnell, D. W. Pogue, and G. W. Sewell. 2002. Structure of littoral-zone fish communities in relation to habitat, physical, and chemical gradients in a southern reservoir. Environmental Biology of Fishes 63: 253-263.

Gido, K. B., J. F. Schaefer, and J. A. Falke. 2009. Convergence of fish communities from the littoral zone of reservoirs. Freshwater Biology 54:1163-1177.

Groen, C. L., and T. A. Schroeder. 1978. Effects of water level management on walleye and other coolwater fishes in Kansas reservoirs. Pages 278-283 in R. L. Kendall, editor. Selected Coolwater Fishes of North America. American Fisheries Society, Special Publication 11, Bethesda, Maryland

Haines, T. A. 1981. Acidic precipitation and its consequences for aquatic ecosystems: a review. Transactions of the American Fisheries Society 110: 669-707.

Hale, R. S. 1999. Growth of white crappies in response temperature and dissolved oxygen conditions in a Kentucky reservoir. North American Journal of Fisheries Management 19: $591-598$.

Hall, R. P. 1966. Distribution of sediments at Cheat Lake, West Virginia. Master's Thesis. West Virginia University, Morgantown, WV.

Hamilton, M. T. 2009. Determining spawning occurrence and reproductive potential of Shenango River Lake Walleye. Master's Thesis, Youngstown State University, Youngstown. 
Hanson, J. R. 2006. Seasonal Movement Patterns of Walleye (Sander vitreus) in Muskegon River and Muskegon Lake, Michigan. Master's thesis, University of Michigan, Ann Arbor.

Hartman, K. J., and F. J. Margraf. 1992. Effects of prey and predator abundances on prey consumption and growth of walleyes in Western Lake Erie. Transactions of the American Fisheries Society 121:245-260.

Hartman, K. J., and F. J. Margraf. 1993. Evidence of predatory control of yellow perch (Perca flavescens) recruitment in Lake Erie, U.S.A. Journal of Fish Biology 43: 109-119.

Hartman, G. F. 2009. A biological synopsis of walleye (Sander vitreus). Canadian Manuscript Report of Fisheries and Aquatic Sciences 2888. Fisheries and Oceans Canada Science Branch, Pacific Region, Nanaimo, British Columbia

Hassler, T. G. 1970. Environmental influences on early development and year-class strength of northern pike in lakes Oahe and Sharpe, South Dakota. Transactions of the American Fisheries Society 99: 369-375.

Hayes, D. B., W. W. Taylor, and P. A. Soranno. 1999. Natural Lakes and Large Impoundments. Pages 493-515 in C. C. Kohler and W. A. Hubert, editors. Inland Fisheries Management in North America. American Fisheries Society, Bethesda, Maryland.

Hayward, R. S. and M. J. Van den Avyle. 1986. The nature of zooplankton spatial heterogeneity in a nonriverine impoundment. Hydrobiologia 131: 261-271.

Heman, M. L., R. S. Campbell, and L. C. Redmond. 1969. Manipulation of fish populations through reservoir drawdown. Transactions of the American Fisheries Society 98: 293304. 
Henderson, B. A., N. Collins, G. E. Morgan, and A. Vaillancourt. 2003. Sexual size dimorphism of walleye (Stizostedion vitreum vitreum). Canadian Journal of Fisheries and Aquatic Sciences 60: 1345-1352.

Herlihy, A. T., P. R. Kaufmann, and M. E. Mitch. 1990. Regional estimates of acid mine drainage impact on streams in the mid-Atlantic and southeastern United States. Water, Air, and Soil Pollution 50: 91-107.

Herlihy, A. T., P. R. Haufmann, M. R. Church, P. J. Wigington, J. R. Webb, and M. J. Sale. 1993. The effects of acidic deposition on streams in the Appalachian Mountain and Piedmont Region of the Mid-Atlantic United States. Water Resources Research 29: 2687-2703.

Hildebrand, S.G. 1979. Potential environmental impacts of hydroelectric development: an overview. Pages 322-392 in Hydropower: A National Energy Resource. 1979 Engineering Foundation Conference Proceedings, Easton, MD. Superintendent of Documents, U. S. Government Printing Office, Washington, D. C.

Hivick, F. R. 1972. Biological factors contributing to the distribution of certain aquatic plants in Cheat Lake. Master's Thesis. West Virginia University, Morgantown, WV.

Hokanson, K. E. F. 1977. Temperature requirements of some percid fishes and adaptations to the seasonal temperature cycle. Journal of the Fisheries Research Board of Canada $34: 1524-1550$.

Holt, C. S., G.D. Grant, G.P. Oberstar, C.C. Oakes, and D.W Bradt. 1977. Movement of walleye, Stizostedion vitreum, in Lake Bemidji, Minnesota as determined by radio-biotelemetry. Transactions of the American Fisheries Society 106: 163-169.

Hoxmeier, R. J. H., D. H. Wahl, R. C. Brooks, and R. C. Heidinger. 2006. Growth and survival of age-0 walleye (Sander vitreus): interactions among walleye size, prey availability, 
predation, and abiotic factors. Canadian Journal of Fisheries and Aquatic Sciences 63: 2173-2182.

Hulsman, P. F., P. M. Powles, and J. M. Gunn. 1983. Mortality of walleye eggs and rainbow trout yolk-sac larvae in low-pH waters of the LaCloche Mountain area, Ontario. Transactions of the American Fisheries Society 112: 680-688.

Ickes, B. S., A. G. Stevens, and D. L. Pereira. 1999. Seasonal distribution, habitat use, and spawning locations of walleye (Stizostedion vitreum vitreum) and sauger, $(S$. canadense) in pool 4 of the upper Mississippi River, with special emphasis on winter distribution related to a thermally altered environment. Minnesota Department of Natural Resources, Investigational Report 482, St. Paul.

Irwin, E. R. and R. L. Noble. 1996. Effects of reservoir drawdown on littoral habitat: assessment with on-site measures and Geographic Information Systems. American Fisheries Society Symposium 16: 324-331.

Ivan, L. N., E. S. Rutherford, C. Risenf, and J. A. Taylor. 2010. Density, production and survival of walleye (Sander vitreus) eggs in the Muskegon River, Michigan. Journal of Great Lakes Research 36: 328-337.

Jackson, J. J., D. W. Willis, and D. G. Fielder. 1993. Changes in walleye food habits throughout Lake Oahe, South Dakota, in August 1991. Journal of Freshwater Ecology 25: 331-340.

Janicki, A. J. 1980. Analysis of the crustacean plankton community of acidic Cheat Lake. Doctoral Dissertation. West Virginia University, Morgantown, WV.

Jenkins, R. M. 1970. The influence of engineering design and operation and other environmental factors on reservoir fishery resources. Water Resources Bulletin 6: 110119. 
Jenkins, R. E. and N. M. Burkhead. 1994. Freshwater fishes of Virginia. American Fisheries Society, Bethesda, Maryland, USA.

Jennings, M. J., J. E. Claussen, and D. P. Philipp. 1996. Evidence for heritable preferences for spawning habitat between two walleye populations. Transactions of the American Fisheries Society 125: 978-982.

Johnson, F. H. 1961. Walleye egg survival during incubation on several types of bottom in Lake Winnibigoshish, Minnesota, and connecting waters. Transactions of the American Fisheries Society $90: 312-322$.

Jones, J. R. and M. F. Knowlton. 2005. Suspended solids in Missouri reservoirs in relation to catchment features and internal processes. Water Research 39: 3629-3635.

Jones, M. L., J. K. Netto, J. D. Stockwell, and J. B. Mion. 2003. Does the value of newly accessible spawning habitat for walleye (Stizostedion vitreum) depend on its location relative to nursery habitat? Canadian Journal of Fisheries and Aquatic Sciences 60: 1527-1538.

Jones, J. R., M. F. Knowlton, D. V. Obrecht, and E. A. Cook. 2004. Importance of landscape variables and morphology on nutrients in Missouri reservoirs. Canadian Journal of Fisheries and Aquatic Sciences 61: 1503-1512.

Juracek, K.E. 2014. Geomorphic changes caused by the 2011 flood at selected sites along the lower Missouri River and comparison to historical floods: U.S. Geological Survey Professional Paper 1798.

Kaufman, S. D., J. M. Gunn, and G. E. Morgan. 2009. The role of ciscoes as prey in the trophy growth potential of walleyes. North American Journal of Fisheries Management 29: 468477. 
Kerr, S. J., B. W. Corbett, N. J. Hutchinson, D. Kinsman, J. H. Leach, D. Puddister, L. Stanfield, and N. Ward. 1997. Walleye habitat: a synthesis of current knowledge with guidelines for conservation. Percid Community Synthesis, Walleye Habitat Working Group. Ontario Ministry of Natural Resources, Peterborough.

Kimmel, B. L. and A. W. Groeger. 1986. Limnological and ecological changes associated with reservoir aging. Pages 103-109 in G. E. Hall and M. J. Van Den Avyle, editors. Reservoir Fisheries Management: Strategies for the 80s. American Fisheries Society, Southern Division Reservoir Committee, Bethesda, Maryland.

Kirby, L. J., S. L. Johnson, and N. H. Ringler. 2017. Diel movement and home range estimation of Walleye (Sander vitreus) within a no-take urban fishery. Journal of Freshwater Ecology 32: 49-64.

Kitchell, J. F., M. G. Johnson, K. Minns, K. H. Loftus, L. Grieg, and C. H. Olver. 1977. Percid habitat: the river analogy. Journal of the Fisheries Research Board of Canada 34: 19361940.

Knight, R. L., F. J. Margraf, and R. F. Carline. 1984. Piscivory by walleyes and yellow perch in western Lake Erie. Transactions of the American Fisheries Society 113: 677-693.

Knoll, L. B, M. J. Vanni, and W. H. Renwick. 2003. Phytoplankton primary production and photosynthetic parameters in reservoirs along a gradient of watershed land use. Limnology and Oceanography 48: 608-617.

Kocovsky, P. M. and R. F. Carline. 2001. Dynamics of the unexploited walleye population of Pymatuning Sanctuary, Pennsylvania, 1997-1998. North American Journal of Fisheries Management 21: 178-187.

Krieger, D. A., J. W. Terrell, and Nelson, P. C. 1983. Habitat suitability information: Yellow Perch. US Fish and Wildlife Service, Washington, D. C. 
Krogman, R. M. and L. E. Miranda. 2016. Rating US reservoirs relative to fish habitat condition. Lake and Reservoir Management 32:51-60.

Lynch, J. A. and E. S. Corbett. 1980. Acid precipitation-a threat to aquatic ecosystems. Fisheries 5: 8-10.

Lyons, J. and J. J. Magnuson. 1987. Effects of walleye predation on the population dynamics of small littoral zone fishes in a northern Wisconsin lake. Transactions of the American Fisheries Society 116: 29-39.

Magnuson, J. J., J. P. Baker, and E. J. Rahel. 1984. A critical assessment of effects of on acidification on fisheries in North America. Philosophical Transactions of the Royal Society B 305: 501-516.

Martin, D. R., L. A. Powell, and K. L. Pope. 2012. Habitat selection by adult walleye during spawning season in irrigation reservoirs: A patch occupancy modeling approach. Environmental Biology of Fishes 93: 589-98.

Mathias, J. A. and S. Li. 1982. Feeding habits of walleye larvae and juveniles: comparative laboratory and field studies. Transactions of the American Fisheries Society 111: 722735.

McClurg, S. E., J. T. Petty, P. M. Mazik, and J. L. Clayton. 2007. Stream ecosystem response to limestone treatment in acid impacted watersheds of the Allegheny Plateau. Ecological Applications 17:1087-1104.

McCormick, J. H. and R. L. Leino. 1999. Factors contributing to first-year recruitment failure of fishes in acidified waters with some implications for environmental research. Transactions of the American Fisheries Society 128: 265-277. 
McEIman, J. F. 1983. Comparative embryonic ecomorphology and reproductive guild classification of walleye Stizostedion vitreum and white sucker Catostomus commersoni. Copeia 1983: 246-250.

McMahon, T. E., J. W. Terrell, and P. C. Nelson. 1984. Habitat suitability information: walleye, U.S. Fish and Wildlife Service FWS/OBS 82/10.56, Washington, D. C.

Merovich, G. T., J. M. Stiles, J. T. Petty, J. Fulton, and P. F. Ziemkiewicz. 2007. Water chemistry based classification of streams and implications for restoring mined Appalachian watersheds. Environmental Toxicology and Chemistry 26:1361-1369.

Mion, J. B., R. A. Stein, and E. A. Marschall. 1998. River discharge drives survival of larval walleye. Ecological Applications 8: 88-103.

Miranda, L. E. 2017. Reservoir fish habitat management. Lightning Press, Totowa, New Jersey. $176 \mathrm{pp}$.

Miranda, L. E. and P. W. Bettoli. 2010. Large Reservoirs. Pages 545-586 in W. A. Hubert and M. C. Quist, editors. Inland Fisheries Management in North America, $3^{\text {rd }}$ edition, American Fisheries Society, Bethesda, Maryland.

Miranda, L. R., M. Spickard, T. Dunn, K. M. Webb, J. N. Aycock, and Hunt, K. 2010. Fish habitat degradation in U.S. reservoirs. Fisheries 35:175-184.

Nelson, W.R. and C. H. Walburg 1977. Population dynamics of yellow perch (Perca flavescens), sauger (Stizostedion canadense) and walleye (S. vitreum vitreum) in four main stem Missouri River reservoirs. Journal of the Fisheries Research Board of Canada 34: 17481763. 
Ney, J. J., C. M. Moore, M. S. Tisa, J. J. Yurk, and R. J. Neves. 1990. Factors affecting the sport fishery in a multiple-use Virginia reservoir. Lake and Reservoir Management 6: 2132.

Niemuth, W., W. Helm, and V. Hacker. 1959. The walleye, its life history, ecology, and management. Wisconsin Conservation Department Publication 227, Madison.

Okada, E. K., A. A. Agostinho, and L. C. Gomes. 2005. Spatial and temporal gradients in artisanal fisheries: a case study of the Itaipu Reservoir, Brazil. Canadian Journal of Fisheries and Aquatic Sciences 62: 714-724.

Olson, D. E., D. H. Schupp, and V. Macins. 1978. An hypothesis of homing behavior of walleye as related to observed patterns of passive and active movements. Pages 52-57 in R. L. Kendall, editor. Selected Coolwater Fishes of North America. American Fisheries Society, Special Publication 11, Bethesda, Maryland.

Oseid, D. M. and L. L. Smith, Jr. 1971. Survival and hatching of walleye eggs at various dissolved oxygen levels. Progressive Fish-Culturist 33: 81-85.

Palmer, G. C., B. R. Murphy, and E. M. Hallerman. 2005. Movements of walleyes in Claytor Lake and the upper New River, Virginia, indicate distinct lake and river populations. North American Journal of Fisheries Management 25: 1448-1455.

Paragamian, V. L. 1989. Seasonal habitat use by walleye in a warmwater river system, as determined by radiotelemetry. North American Journal of Fisheries Management 9: 392401.

Pauwels, S. J. and T. A. Haines. 1986. Fish species distribution in relation to water chemistry in selected Maine lakes. Water, Air, and Soil Pollution 30: 477-488. 
Pflieger, W. L. 1997. The Fishes of Missouri, revised edition. Missouri Department of Conservation, Jefferson City.

Pierce, R. B., C. M. Tomcko, and M. T. Negus. 2006. Interactions between stocked walleyes and native yellow perch in Lake Thirteen, Minnesota: a case history of percid community dynamics. North American Journal of Fisheries Management 26: 97-107.

Ploskey, G. R. 1986. Management of the physical and chemical environment: effects of waterlevel changes on reservoir ecosystems, with implications for fisheries management. Pages 86-97 in G. E. Hall and M. J. Van den Avyle, editors. Reservoir Fisheries Management: Strategies for the 80s. American Fisheries Society, Bethesda, Maryland.

Poe, T. R. 1971. Evaluation of the Tygart Reservoir fishery in relation to physical and chemical conditions. Master's Thesis, West Virginia University, Morgantown.

Prchalova, M., J. Kubecka, M. Vasek, J. Peterka, J. Seda, T. Juza, M. Riha, O. Jarolim, M. Tuser, M. Kratochvil, M. Cech, V. Drastik, J. Frouzova, and E. Hohausova. 2008. Distribution patterns of fishes in a canyon-shaped reservoir. Journal of Fish Biology 73: $54-78$.

Priegel, G. R. 1970. Reproduction and early life history of the walleye in the Lake Winnebago region. Wisconsin Department of Natural Resources Technical Bulletin 45, Madison.

Quist, M. C., C. S. Guy, R. D. Schultz and J. L. Stephen. 2003. Latitudinal comparisons of walleye growth in North America and factors influencing growth of walleyes in Kansas reservoirs. North American Journal of Fisheries Management 23: 677-692.

Raabe, J. K. 2006. Walleye (Sander vitreus) spawning habitat selection and dynamics in a north-temperate lake. Master's thesis, University of Wisonsin-Stevens Point, Stevens Point. 
Raby, G. D., C. S. Vandergoot, T. A. Hayden, M. D. Faust, R. T. Kraus, J. M. Dettmers, S. J. Cooke, Y. Zhao, A. T. Fisk, and C. C. Krueger. 2018. Does behavioural thermoregulation underlie seasonal movements in Lake Erie walleye? Canadian Journal of Fisheries and Aquatic Sciences 75: 488-496.

Rahel, F. J. and J. J. Magnuson. 1983. Low pH and the absence of fish species in naturally acidic Wisconsin Lakes: inferences for cultural acidification. Canadian Journal of Fisheries and Aquatic Sciences 40: 3-9.

Rawson, D. S. 1957. The life history of the yellow walleye (Stizostedion vitreum) in Lac La Ronge, Saskatchewan. Transactions of the American Fisheries Society 86: 15-37.

Roseman, E. F., W. W. Taylor, D. B. Hayes, R. C. Haas, R. L. Knight, and K. O. Paxton. 1996. Walleye egg deposition and survival on reefs in Western Lake Erie (USA). Annales Zoologici Fennici 33: 341-351.

Ryder, R. A. 1977. Effects of ambient light variations on behavior of yearling, subadult, and adult walleyes (Stizostedion vitreum vitreum). Journal of the Fisheries Research Board of Canada 34: 1481-1491.

Sammons, S. M. and P. W. Bettoli. 2000. Population dynamics of a reservoir sport fish community in response to hydrology. North American Journal of Fisheries Management 20: $791-800$.

Santucci Jr., V. J., and D. H. Wahl. 1993. Factors influencing survival and growth of stocked walleye (Stizostedion vitreum) in a centrarchid-dominated impoundment. Canadian Journal of Fisheries and Aquatic Sciences 50: 1548-1558.

Sass, G. G., C. M. Gille, J. T. Hinke, and J. F. Kitchell, 2006. Whole-lake influences of littoral structural complexity and prey body morphology on fish predator-prey interactions. Ecology of Freshwater Fish 15: 301-308. 
Schlagenhaft, T. W. and B. R. Murphy. 1985. Habitat use and overlap between adult largemouth bass and walleye in a west Texas reservoir. North American Journal of Fisheries Management 5: 465-470.

Schmalz, P.J., A.H. Fayram, D.A. Isermann, S.P. Newman, and C. J. Edwards. 2011. Harvest and exploitation. Pages 375-402 in B.A. Barton, editor. Biology, Management, and Culture of Walleye and Sauger. American Fisheries Society, Bethesda, Maryland.

Schofield, C. L. and C. T. Driscoll. 1987. Fish species distribution in relation to water quality gradients in the North Branch of the Moose River Basin. Biogeochemistry 3: 63-85.

Schorr, M. S. and J. C. Backer. 2006. Localized effects of coal mine drainage on fish assemblages in a Cumberland Plateau stream in Tennessee. Journal of Freshwater Ecology 21: 17-24.

Scott, W. B. and E. J. Crossman. 1973. Freshwater fishes of Canada. Fisheries Research Board of Canada Bulletin 184, Ottawa.

Smart, R. M., G. O. Dick, and R. D. Doyle. 1998. Techniques for establishing native aquatic plants. Journal of Aquatic Plant Management 36: 44-49.

Smith, W. S., and M. Petrere, Jr. 2008. Spatial and temporal patterns and their influence on fish community at Itupararanga Reservoir, Brazil. Revista de Biologica Tropical 56: 20052020.

Soares, M. C. S., M. M. Marinho, S. M. F. O. Azevedo, C. W. C. Branco, and V. L. M. Huszar, 2008. The effects of water retention time and watershed features on the limnology of two tropical reservoirs in Brazil. Lakes \& Reservoirs: Research and Management 13: 257269. 
Sotak, M. J. 1968. Fish distribution and acid mine pollution in the Monongahela River main stem of West Virginia. Master's Thesis, West Virginia University, Morgantown.

Summerfelt, R. C., J. A. Johnson, and C. P. Clouse. 2011. Culture of walleye, sauger, and hybrid walleye. Pages 451-470 in B. Barton, editor, Biology, Management, and Culture of Walleye, Sauger, and Hybrid Walleye. American Fisheries Society Special Publication, Bethesda, Maryland,.

Thornton, K. W., B. L. Kimmel, and F. E. Payne, editors. 1990. Reservoir Limnology Ecological Perspectives. John Wiley and Sons, New York.

Thorpe, J. E. 1977. Synopsis of biological data on the perch, Perca fluviatilis Linnaeus, 1758 and Perca flavescens Mitchill, 1804. FAO Fisheries Synopsis 113.

Tremblay, S. and Y. Richard. 1993. Effects of acidity on fish communities of southwestern Quebec (Canada). Water, Air, and Soil Pollution 66: 315-331.

USFWS and USDOC (U.S. Fish and Wildlife Service and U.S. Department of Commerce. 2018. 2016 national survey of fishing, hunting, and wildlife related recreation. U.S. Fish and Wildlife Service and U.S. Department of Commerce, Bureau of the Census. Government Printing Office, Washington, D. C.

Vanni, M. J., K. Arend, M. T. Bremigan, D. B. Bunnell, J. E. Garvey, M. J. Gonzalez, W. H. Renwick, P. A. Soranno, and R. A. Stein. 2005. Linking landscapes and food webs: effects of omnivorous fish and watersheds on reservoir ecosystems. BioScience 55: $155-167$.

Volkmar, R. D. 1972. Phytoplankton primary productivity in Cheat Lake. Master's Thesis. West Virginia University, Morgantown, WV. 
Walburg, C. H. 1971. Loss of young fish in reservoir discharge and year-class survival in Lewis and Clark Lake, Missouri River. Pages 441-448 in G. E. Hall, editor. Reservoir Fisheries and Limnology, American Fisheries Society, Special Publication 8, Bethesda, Maryland.

Wales, D. L. and G. L. Beggs. 1986. Fish species distribution in relation to lake acidity in Ontario. Water, Air, and Soil Pollution 30: 601-609.

Wang, H. Y., E. S. Rutherford, H. A. Cook, D. W. Einhouse, R. C. Haas, T.B. Johnson, R. Kenyon, B. Locke, and M. W. Turner. 2007. Movement of walleyes in Lakes Erie and St. Clair inferred from tag return and fisheries data. Transactions of the American Fisheries Society 136: $539-551$.

Wellman, D., F. Jernejcic, and J. Hedrick. 2008. Biological monitoring of aquatic communities of Cheat Lake, and Cheat River downstream of the Lake Lynn hydrostation, 2008. Final FERC Project Report to Allegheny Energy Supply, LLC.

Welsh, S. A. and S.A. Perry. 1997. Acidification and fish occurrence in the upper Cheat River drainage, West Virginia. Journal of the American Water Resources Association 33: 423429.

Wetzel, R. G. 1990. Reservoir ecosystems: Conclusions and speculations, Pages 227-238 in K. W. Thornton, B. L. Kimmel, and F. E. Payne, editors. Reservoir Limnology: Ecological Perspectives. Wiley, New York.

Wiley, M. J., R. W. Gorden, S. W. Waite, and T. Powless. 1984. The relationship between aquatic macrophytes and sport fish production in Illinois ponds: a simple model. North American Journal of Fisheries Management 4: 111-119. 
Williams, J. D. 2001. Walleye movement, distribution, and habitat use in Laurel River Lake, Kentucky. Proceedings of the Annual Conference of Southeastern Association of Fish and Wildlife Agencies 55: 257-269.

Williams, K. M. and A. M. Turner. 2015. Acid mine drainage and stream recovery: effects of restoration on water quality, macroinvertebrates, and fish. Knowledge and Management of Aquatic Ecosystems 416: 1-12.

Willis, D. W. 1986. Review of water level management of Kansas reservoirs. Pages 110-114 in G. E. Hall and M. J. Van Den Avyle, editors. Reservoir Fisheries Management: Strategies for the 80s. American Fisheries Society, Southern Division, Reservoir Committee, Bethesda, Maryland.

Wills, T. C., M. T. Bremigan, and D. B. Hayes. 2004. Variable effects of habitat enhancement structures across species and habitats in Michigan reservoirs. Transactions of the American Fisheries Society 133: 399-411.

Wood, P. J. and P. D. Armitage. 1997. Biological effects of fine sediment in the lotic environment. Environmental Management 21: 203-17.

Zipfel, K.J. 2006. The distribution and status of native walleye (Sander vitreus) stocks in West Virginia. Master's Thesis. Ohio University, USA.

Zohary, T. and I. Ostrovsky, 2011. Ecological impacts of excessive water level fluctuations in stratified freshwater lake. Inland Waters 1: 47-59. 


\section{Chapter 2 - Long-term recovery of a fish community in an acid impacted hydropower reservoir}

\section{Abstract}

Cheat Lake, a hydropower reservoir in northern West Virginia, has been impacted by acid mine drainage since the formation of the reservoir in 1926. As a result, several fish species were extirpated or nearly so from the reservoir, and fish species richness and abundance were limited. Surveys from 1952-1977 indicated only 15 species present, with Brown Bullheads (Ameiurus nebulosus) and White Suckers (Catostomus commersonii) accounting for the large majority of fishes collected ( $56 \%$ and $26 \%$ mean relative abundance). Due to successful efforts to improve water quality within the watershed, the fish community of Cheat Lake has substantially changed over the last few decades. To assess these changes and to monitor for potential impacts from hydropower operations, biomonitoring has been conducted regularly on Cheat Lake since 1990 using boat electrofishing and gill netting surveys. Data from these surveys were analyzed to determine if significant changes have occurred to the Cheat Lake fish community over time. Since 1990, 18,387 fishes representing 44 species have been collected in Cheat Lake. The mean annual relative abundance of captured fishes from the period of 20112015 was over 4 times greater than the mean annual relative abundance captured during the period of 1990-2001. Abundances of many individual species increased dramatically. The acid sensitive Smallmouth Bass (Micropterus dolomieu) saw an increase in mean annual abundance from 2.9 fish/hr. from 1990-2001 to 38.5 fish/hr. from 2005-2015. Statistical analyses of fish community data using non-metric multidimensional scaling and generalized linear models suggest that the fish community has significantly changed over time. These changes are primarily due to increases in abundance of several species that comprise the fish community, and decreases in pollution tolerant species such as Brown Bullhead. The fish community of Cheat Lake exhibits significant spatial differences in community structure across reservoir zones 
(i.e., riverine, transitional, lacustrine, and embayment zones). Species such as Smallmouth Bass, Channel Catfish (Ictalurus punctatus), Walleye (Sander vitreus), Golden Redhorse (Moxostoma erythrurum), Silver Shiner (Notropis photogenis), and Emerald Shiner (Notropis atherinoides) have increased in abundance and distribution throughout the reservoir.

Additionally, fish species richness has significantly increased over time dependent on lake zone. Changes to the fish community have coincided with water quality improvement efforts throughout the watershed. Continuation of water quality improvement efforts are critical to the conservation of this valuable resource.

\section{Introduction}

Long-term biological monitoring is critically important for documenting trends in aquatic communities, such as temporal changes in environmental conditions (McClelland et al. 2012; Bennett et al. 2015; Marhadja et al. 2017; Starks et al. 2018). Data from long-term monitoring programs provide valuable insights on the natural and anthropogenic influences on temporal population change (McClelland et al. 2012; Bennett et al. 2015). Without long-term monitoring, it is often difficult to make science based management decisions (Walters 2001; Walters and Martrell 2004; Walters et al. 2005; McClelland et al. 2012; Bennett et al. 2015). However, published long-term monitoring research is often uncommon for aquatic ecosystems (Gutreuter et al. 1995; McClelland et al. 2012; Ross 2013; Bennett et al. 2015). Long-term biological monitoring can be especially important in systems negatively impacted by anthropogenic activities (Nielsen et al. 2009; Magurran et al. 2010; Ward-Campbell et al. 2017). This is especially true for systems where mitigation efforts are occurring, as long-term monitoring can be critical to accurately estimate any improvements that occur. Long-term monitoring programs 
are also critical for evaluating success or failure of management actions in place to improve conditions (McClelland et al. 2012).

Long-term monitoring can be critical for documenting decline and/or recovery of fish faunas influenced by environmental or anthropogenic stressors (McClelland et al. 2012; McCain et al. 2016). This is particularly true for fishes affected by stream acidification in the Appalachians of the eastern United States, a region where acid mine drainage and acid precipitation have long stressed fish assemblages and populations (Herlihy et al. 1993; Schorr and Backer 1996; Wigington et al. 1996; Van Sickle et al. 1996; Bott et al. 2012). The Cheat River watershed of northern West Virginia has experienced depressed water quality for over a century as a result of acid precipitation and acid mine drainage (Core 1959; Welsh and Perry 1997; Thorne and Pitzer 2004; Freund and Petty 2007; Merovich et al. 2007). Similarly, Cheat Lake, a reservoir in the lower Cheat River watershed, has also experienced the effects of acidification (Core 1959). In recent years, the Cheat River watershed and Cheat Lake have seen substantial water quality improvements likely owing to mitigation efforts throughout the watershed (Thorne and Pitzer 2004; McClurg et al. 2007).

Biomonitoring of the fisheries resources of Cheat Lake, WV, a hydropower reservoir, began in 1990 in response to needs for biological information necessary for the renewed issuance of a Federal Energy Regulatory Commission (FERC) license. Ultimately, the renewal license required for biomonitoring of the fish community of Cheat Lake for potential impacts caused by hydropower operations and acidification from acid mine drainage (Wellman et al. 2008). Additionally, the renewal license required restrictions on seasonal water level fluctuations. Specifically, lake elevations are to be maintained between 264.5-265.1 m (868$870 \mathrm{ft}$. ) from May $1^{\text {st }}$ to October $31^{\text {st }}$ to enhance recreational activities (Wellman et al. 2008). Elevations are permitted to fluctuate between $261.2-265.1 \mathrm{~m}\left(857-870 \mathrm{ft}\right.$.) from November $1^{\text {st }}$ to March $31^{\text {st }}$ to maximize power generation. Finally, lake elevation is restricted to $263-265.1 \mathrm{~m}$ 
(863-870 ft.) during April in an effort to limit potential impacts from fluctuations on Walleye and Yellow Perch (Perca flavescens) spawning (Wellman et al. 2008).

Several studies have been conducted on the water quality and biological communities of Cheat Lake and its tailwaters intermittently since its creation in the late 1920's (Core 1959; Stilson 1969; Hivick 1972; Wellman et al. 2008). Water quality data have been collected several times each decade since 1929 (Core 1959; Stilson 1969; Hivick 1972; Wellman et al. 2008). Previous studies concluded that Cheat Lake water quality was extremely acidic and artificially oligotrophic as a result of impacts from acid mine drainage (Core 1959; Volkmar 1972; Edens 1975; Janicki 1980). Studies on the zooplankton and phytoplankton communities revealed severely impaired and simplistic communities supporting only a few tolerant taxa (Volkmar 1972; Janicki 1980). The first major survey of the fish community was conducted in the 1950's (Core 1959). This study concluded that the fish community was significantly impaired from AMD impact. With the enactment of the Clean Water Act (CWA) in 1972 and the Surface Mining Control and Reclamation Act (SMCRA) of 1977, steps began to be taken nationwide to reduce pollution of waterways. Specifically, SMCRA required acid mine drainage to be treated and also helped provide funds to reclaim abandoned mine sites (Thorne and Pitzer 2004). Although a handful of projects were completed in the 1980's to remediate abandoned mine lands, more intensive efforts did not occur until after a large mine blowout occurred in the watershed in 1994 (Cline 1999; Steelman and Carmin 2002; Thorne and Pitzer 2004). Several agencies and nonprofit organizations have contributed to acid mine drainage abatement projects within the watershed. Over 200 land reclamation and water treatment projects have been completed since 1994 (Rick Buckley OSMRE, personal communication). Not every reclamation project treated water quality directly, but even those that did not, often benefited water quality indirectly (Rick Buckley OSMRE, personal communication). Since 2000, greater than 5 million dollars have been invested towards Cheat River restoration, including funds from EPA Section 319 nonpoint 
source funding and matching funds from the Office of Surface Mining Reclamation and Enforcement (Capacasa 2016). Between 2000 and 2013, over 1.7 million pounds of AMD pollution were reduced within the watershed (Capacasa 2016). In addition, over 100 miles of streams are directly treated for acidification within the watershed via the WVDNR limestone fines program (WVDNR, unpublished data).

The primary goal of this study was to evaluate spatial and temporal changes that have occurred to the Cheat Lake fish community. Specifically, we sought to determine if overall fish abundance, species-specific abundance, species richness and fish community structure has changed temporally and spatially in comparison to improving water quality conditions longitudinal variations in reservoir characteristics.

\section{Methods}

Study area

Cheat Lake, a 700 ha hydropower reservoir located in northern West Virginia, has been impacted by stream acidification since construction in 1926 . The reservoir, created by damming the Cheat River near the West Virginia-Pennsylvania border, supports a hydroelectric generating facility. The reservoir maintains a somewhat riverine shape, with moderate sinuosity and steep slopes throughout portions of the reservoir (Figure 2.1). The reservoir is approximately $21 \mathrm{~km}$ in length and has a maximum depth of $24 \mathrm{~m}$ near the dam. The reservoir is dimictic, experiencing seasonal stratification of water temperature and dissolved oxygen. Downstream of Cheat Lake, the Cheat River (hereafter Lower Cheat River) flows for approximately $5.3 \mathrm{~km}$ into the Monongahela River in Point Marion, PA. 
For this study, we subdivided Cheat Lake into four zones: riverine, transitional (middle main lake), lacustrine (lower main lake), and embayment (Figure 2.1). Separation of these zones was based on characteristics defining reservoir morphology including bathymetry and water chemistry. The transitional and lacustrine zones are typically $2.5-3.0$ times wider in cross section than that of the narrow riverine and embayment zones (Figure 2.1). Hydrologically, river flow strongly regulates the riverine section, but has a reduced influence going downstream from transitional to the lacustrine zones. The embayments, with narrow connections to the main lake, are least influenced by the Cheat River flow. During winter, the formation and persistence of ice cover reflects the influence of river flow, with the embayment and lacustrine zones more likely to maintain ice cover longer than the transitional and riverine zones. Additionally, bathymetry varies greatly across the different zones. The riverine and transitional zones are much shallower than both the lacustrine and embayment zones. There are also notable habitat differences between the zones. The riverine zone is dominated by sand and coarser substrates and usually lacks aquatic vegetation. In contrast, the other zones have substrates primarily composed of silt/clay particles and also have areas of aquatic vegetation growth. Specifically, the transitional zone and embayment zone have more aquatic vegetation present than both the lacustrine and riverine zones. Finally, there are also historic and current water chemistry differences between the zones. Historically, the embayment zone was more suitable for aquatic life compared to the other zones due to reduced influence of acidification. The embayment areas are largely separated from the main lake and were historically buffered by incoming tributaries therefore creating more suitable water chemistry conditions (i.e., higher $\mathrm{pH}$ ). Also, the zones often differ in water temperature and dissolved oxygen, particularly during warm, summer months. The riverine zone usually has cooler, more oxygenated water and does not typically experience stratification. The transitional zone usually has subsurface water temperature and dissolved oxygen levels comparable to the lacustrine and embayment zones, but stratification is often less 
severe. The lacustrine and embayment zones experience the greatest amount of stratification, with lower hypolimnetic oxygen levels often near zero during warm, summer months.

\section{Water Quality Monitoring}

Data on water quality were collected intermittently prior to 1997, associated with periodic studies on the ecosystem of Cheat Lake (Core 1959; Stilson 1969; Hivick 1972; Volkmar 1972; Edens 1975; Janicki 1980; WVDNR unpublished data). Given Cheat Lake's historic impairment from AMD, $\mathrm{pH}$ data were of particular interest for our study, and included measurements at varying intensities in 1956, 1965, 1968, 1969, 1971, 1977, and 1990. Monitoring of pH in Cheat Lake also was conducted multiple times a year (6-13 samples per year) during biomonitoring surveys that occurred from 1997-2015. Additionally, beginning in 1997, $\mathrm{pH}$ values were recorded daily at the hydrostation on Cheat Lake from March through November of each year. Beginning in 2004, a YSI model 600 XLM continuous monitor was placed at the head of Cheat Lake that recorded $\mathrm{pH}$ values hourly. Utilizing available data, minimum and mean $\mathrm{pH}$ values were summarized for both the main lake and embayments.

\section{Pre-Biomonitoring Fish Surveys}

From 1952-1977, periodic fish surveys were conducted on Cheat Lake (Core 1959; WVDNR unpublished data). Surveys utilized a variety of gear including experimental gill nets, fyke nets, and boat electrofishing. Records and reports from these surveys provide little detail on dimensions of gear and sampling effort. Due to this lack of detail, data from these studies are purely qualitative, providing relative estimates of species presence/absence and proportional relative abundance. Surveys were conducted in 1952, 1955, and 1956 utilizing gill netting and 
fyke netting in Cheat Lake. Survey locations and gear dimension/sampling effort were either vague or not provided (Core 1959; WVDNR 1972, unpublished data). Data from the 1955 and 1956 surveys included information on presence and proportional relative abundance of fish species. Data from the 1952 survey only included species captured and anecdotal notes on dominant species. Surveys were also conducted by WVDNR in 1973, 1974, and 1977 using experimental gill nets and boat electrofishing (WVDNR 1973; WVDNR 1974; WVDNR 1977, unpublished data). Again, little information was provided on gear dimensions or sampling effort. However, survey locations were provided in these reports. Data from 1974 included information on presence and proportional relative abundance of fish species. Data from 1973 and 1977 only provided species captured and anecdotal notes on dominant species.

\section{Biomonitoring Fish Surveys}

Biomonitoring fish surveys were conducted on Cheat Lake using night-time boat electrofishing and gill netting. Biomonitoring electrofishing surveys were conducted at least twice yearly during spring (May/June) and fall (September/October) in 1990, 1997, 1998, 2001, 2005,2008 , and yearly from 2011-2015. During the years of $1990,1998,2001$, and 2008 , a

summer (July/August) survey was also done. Biomonitoring gill net surveys were conducted at least twice yearly (spring and fall) during the same years except for 2013 and 2015 when gill netting was not conducted. A summer survey was completed in 1990, 1998, and 2001. Biomonitoring surveys were conducted at stations located in each lake zone (Riverine, Main Lake, Embayments; Figure 1). Main lake stations were further designated as either lower main lake (L1 \& L2) or middle main lake (L3) for some analyses. Electrofishing surveys were conducted during night-time hours using pulsed-DC electrofishing (4-6 A). Electrofishing effort changed during the biomonitoring period. In 1990, two distance based transects (160 m per 
transect) were conducted at each site. However, these transects were recorded as requiring on average 15 min of effort for each 160 m transect. From 1997-2001, two 15 minute transects were electrofished per site. From 2005-2015, one 10 minute transect was electrofished per site. Additionally, only 6 stations were surveyed from 1990-2001, while 8 stations were surveyed from 2005-2015. Due to changes in total effort, electrofishing data were standardized by catchper-unit-effort (fish/hour) for analytical purposes. Gill net surveys were conducted using

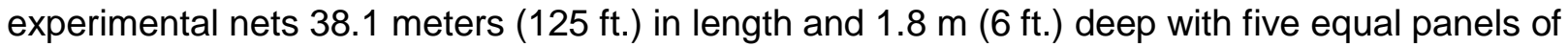
19 (0.75), 25 (1.0), 38 (1.5), 51 (2.0), and 64 (2.5) mm bar mesh (inches in parentheses). In 1990, 1997, 1998, and 2001, straight mesh nets (38 mm mesh) of the same length and depth were also used. At each station, two nets (one experimental and one straight mesh from 19902001) were deployed before dusk and retrieved after dawn the following day resulting in soak times of approximately 12 hours. The two nets at each station were set approximately 100 meters apart and were set perpendicular to the shoreline.

Captured fishes were identified to species and were measured (total length) to the nearest millimeter. During fall surveys fishes were also weighed to the nearest gram. Some juvenile game fishes (i.e., sunfishes) and non-game fishes (i.e., minnows or darters) of similar length were grouped into length bins (i.e., 10-20 $\mathrm{mm}$ ) by species, counted, and batch weighed. Small, non-game fishes were often fixed in $10 \%$ formalin, and processed in the laboratory.

\section{Data Analysis}

Data were analyzed using a combination of summary statistics, ordination techniques, and generalized linear mixed models. We calculated species richness, overall catch-per-unit-

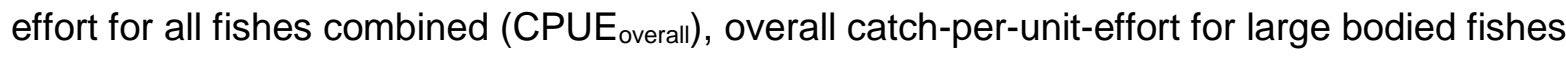

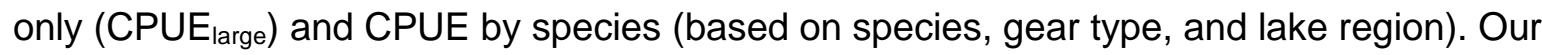


estimate of overall catch per unit effort for large bodied fishes (CPUE $E_{\text {large }}$ ) excluded small bodied fishes including minnows and darters (Chick et al. 2004). We used CPUE $E_{\text {large }}$ for our overall fish abundance statistical analyses. Small bodied species such as minnows and darters were excluded in abundance analyses to minimize bias and variance of overall fish abundance associated with the potential for highly variable catch rates due to benthic lifestyles or other capture difficulties (Chick et al. 1999; Flotemesch and Blocksom 2005; Ruetz III et al. 2007; Koryak et al. 2009). Boat electrofishing capture efficiencies for small minnow species and darters are often low due to habitat use of these species (benthic lifestyle of darters), behavioral traits (shoaling behavior of shiners), and physiological adaptations (reduced or absent air bladder in darters) (Chick et al. 1999; Flotemesch and Blocksom 2005; Ruetz III et al. 2007; Koryak et al. 2009). Data for small-bodied species were included in community analyses using non-metric multidimensional scaling (NMDS) and multivariate generalized linear models, because these data were predicted to represent changes to community structure. We also calculated proportional relative abundance by species to make qualitative comparisons between historic data (pre-1990) and biomonitoring data. Proportional relative abundance was calculated as the percent composition of a species for an individual sampling event. Temporal and spatial differences in measurements of overall $\mathrm{CPUE}_{\text {large }}$ and species richness were analyzed using generalized linear mixed model analysis (McCain et al. 2016). We visually evaluated the spatial and temporal change in fish communities in Cheat Lake using non-metric multidimensional scaling (NMDS). We statistically tested spatial and temporal changes in fish communities with multivariate generalized linear models using the mvabund package in $R$ (Wang et al. 2012). Rare species (present in $<5 \%$ of all samples; Starks et al. 2018) were removed from community analyses due to sensitivity of analyses to rare species.

Due to inconsistency and relative ineffectiveness of the method in Cheat Lake during biomonitoring months, gill net data were excluded from statistical analyses. Limitations due to 
debris build up, low catch rates, and steep shorelines, resulted in inconsistent sampling effectiveness for most species of fish. Some species, such as Yellow Perch and Walleye which were captured more effectively during other studies in colder months, had highly variable catch rates during the warmer biomonitoring months. Catfishes were a group of fish consistently captured using gill nets, however, frequent surveys with zero catch complicate analysis options. Therefore, temporal patterns in Brown Bullhead and Channel Catfish abundance were visually assessed using graphically plotted catch-per-unit effort (fish/net-night) over time. Additionally, summaries of species captured and abundances from gill net data were included for descriptive purposes.

We calculated CPUE as an estimate of overall fish abundance for each sample and for each species captured. We also calculated species richness for each sample. We tested for

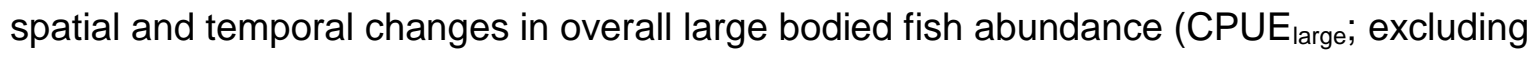
minnows and darters) and species richness using generalized linear mixed model analysis in $\mathrm{R}$ (McCain et al. 2016). Specifically, we used the packages glmer.nb and glmer in R, to model fish abundance with a negative binomial distribution and species richness as a Poisson distribution (McCain et al. 2016). A log-link function was utilized for both the fish abundance and species richness models (McCain et al. 2016). The generalized linear mixed model for fish abundance specified both temporal (year) and spatial (lake zone) fixed effects, and an interaction effect between year and lake zone. Like the model for overall fish abundance, the model for species richness utilized the same model structure. Both models incorporated survey site as a random effect to account for potential spatiotemporal autocorrelation. Significance level for fixed effects was set at $\alpha=0.05$ (McCain et al. 2016).

For analyses of fish community changes across space and time, we used multivariate statistical techniques including NMDS and multivariate generalized linear models (mvabund; McCain et al. 2016). Multivariate statistical analyses were conducted in PRIMER 7 (NMDS) and 
R (mvabund) (Primer-E Ltd., Ivybridge, UK, R version 3.3.0, R Core Team 2014). To visually examine spatiotemporal changes in fish community structure we used NMDS. Non-metric multidimensional scaling is a visual ordination technique that identifies patterns in community structure and relies on the use of a species resemblance matrix across sampling sites (Bennett et al. 2015; McCain et al. 2016). We generated our species resemblance matrix using BrayCurtis distances derived from a species abundance matrix from Cheat Lake sampling sites (Bennett et al. 2015; McCain et al. 2016). We examined the change in species presence/absence community structure from 1952-2015 using annual presence/absence data from each sampling year. We also analyzed changes in community structure using species abundance data from 1990-2015. Species abundances (CPUE) were square root transformed to help normalize data and decrease bias associated with abnormally high abundances during specific sampling periods (McClelland et al. 2012; Bennett et al. 2015). Specifically, we were interested in identifying patterns in community structure associated with sampling year and different lake zones. Graphical results from NMDS were limited to two dimensional plots and sites were represented by both sample year and lake zone. Sites were plotted using the values from the Bray-Curtis similarity matrix. Distances in plot space between sites are determined by the similarity in fish communities (McClelland et al. 2012). Sites close together in space have more similar fish communities, while sites further apart in space have increasingly dissimilar fish communities (Clarke and Warwick 2001; McClelland et al. 2012). In addition to plotting sites based on fish community similarity, we also used Pearson correlations between species abundances and NMDS axes to visually illustrate which species contribute most to differences in fish community patterns (Bennett et al. 2015).

We used multivariate generalized linear models (multivariate GLM) to statistically test for temporal (sampling year) and spatial (lake zone) effects on fish community structure. Traditionally, distance based approaches (i.e., Analysis of Similarity (ANOSIM), Permutational 
Analysis of Variance (PERMANOVA)) have often been used to assess differences in community structure, however, these approaches have been shown to confound location and dispersion effects (Warton et al. 2012; McCain et al. 2016). Instead, we incorporated a model based approach using package mvabund in $\mathrm{R}$, which utilizes multivariate generalized linear models that specify a quadratic mean-variance relationship (Warton 2011; Wang et al. 2012; McCain et al. 2016). For our fish abundance data, we used a GLM and specified a negative binomial distribution with a log-link function (McCain et al. 2016). Our model structure incorporated fixed effects of sampling year, lake zone, and an interaction term of year and lake zone. We examined residual plots which did not indicate a noticeable pattern suggesting that the negative binomial distribution was appropriate (McCain et al. 2016).

\section{Results}

\section{Water Quality}

Water quality data for Cheat Lake were summarized for the time period of 1952-2015. Both mean and minimum $\mathrm{pH}$ values were on average lower in the main lake section compared to the embayments (Figure 2.2) representing some degree of refuge from acidity in the embayments. Annual main lake mean $\mathrm{pH}$ values averaged only 4.5 prior to 1990 (Figure 2.2), and annual main lake minimum $\mathrm{pH}$ values averaged only 3.9 during this same time period (Figure 2.2). Annual main lake mean pH in 1990 still indicated acid impairment but showed some improvement in water quality compared to previous years with an overall mean $\mathrm{pH}$ of 5.8 and minimum $\mathrm{pH}$ of 4.1 (Figure 2.2). Annual main lake mean $\mathrm{pH}$ since 1997 has remained 
greater than 6.0 (overall mean of 6.7 ) and average main lake annual minimum pH was 5.9 (Figure 2.2).

In contrast, annual mean pH of the embayments averaged 6.3 prior to 1990 (Figure 2.2) and annual minimum $\mathrm{pH}$ values in the embayments averaged 5.18 during this same time period (Figure 2.2). Like the main lake section, the embayments also experienced increases in $\mathrm{pH}$ over time. Annual mean $\mathrm{pH}$ in the embayments in 1990 was 6.7 , while minimum $\mathrm{pH}$ in the embayments during this year was 5.7 (Figure 2.2). Since 1997, the mean annual pH has averaged 7.1 and minimum annual $\mathrm{pH}$ has averaged 6.5 (Figure 2.2).

Fish Abundance, Catch-Per Unit Effort, and Species Richness

From 1990-2015, a total of 18,387 fishes representing 44 species were captured using both boat electrofishing and gill netting (Table 2.1). A total of 16,198 fishes from 39 species were collected using electrofishing and 2,189 fishes from 27 species were collected using gill nets (Table 2.1). Considering separate years, the lowest electrofishing CPUE $E_{\text {overall }}$ during our study was in 1990 (118 fish/hr.), and the lowest gill net CPUE was 3.0 fish/net-night in 1998 (Table 2.2). The highest electrofishing CPUE $_{\text {overall }}$ (681 fish/hr.) occurred in 2015 and the highest gill net CPUE (12 fish/net-night) occurred in both 2005 and 2012 (Table 2.2). Yearly species richness ranged from 27 species in 1990, 2011, 2012, and 2013, to 33 species in 2008 . The highest average CPUE $\mathrm{Everall}_{\text {for }}$ both electrofishing and gill netting occurred in the riverine zone

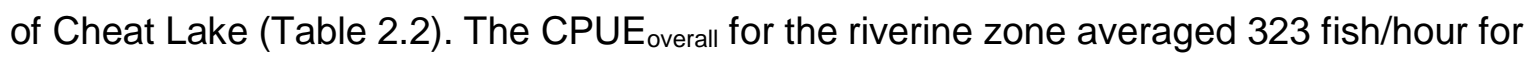
electrofishing and 13 fish per net-night for gill netting (Table 2.2). The embayments of Cheat Lake had the second highest average CPUE $_{\text {overall }}$ with an average of $301 \mathrm{fish} /$ hour (electrofishing) and 6 fish/net-night (gill netting). The main lake zone (lower and middle lake sites combined) had the lowest average CPUE $_{\text {overall }}$ with an average of $258 \mathrm{fish} /$ hour (electrofishing) and 5 fish/net-night (gill netting). 
There were 22 species used for statistical analysis of fish abundance (CPUE $\left.E_{\text {large }}\right)$ after excluding minnows and darters. Results from the generalized linear mixed model suggest a significant increase in fish abundance (CPUE ${ }_{\text {large }}$ ) occurred from 1990-2015 (Table 2.5). In addition to there being a significant effect of time, fish abundance was also significantly affected by lake region (Table 2.5). There was also a significant interactive effect of time and lake region on fish abundance (Table 2.5), suggesting that fish abundance changed differently over time depending on lake region. Specifically, there were 2.5 times as many fish sampled per hour on average from 2001-2008 compared to 1990-1998 (Figure 2.4). Additionally, there were over 4 times as many fish collected per hour from 2011-2015 compared to 1990-1998 (Figure 2.4). Abundance of fishes was greater on average in the main lake zone compared to both the embayments and riverine zones (Figure 2.4). Also, abundance of fishes showed larger increases in both the riverine zone (6.5 times higher in 2011-2015 vs. 1990-1998) and the main lake zone (6.1 times higher in 2011-2015 vs. 1990-1998) compared to increases observed in the embayments (2.2 times higher in 2011-2015 vs. 1990-1998; Figure 2.4). These differences in abundance over time by lake zone are demonstrated in plotted model predicted values (Figure 2.6).

Statistical results also suggest that there was a significant interactive effect of time and lake region on species richness (Table 2.5) suggesting that species richness changed differently over time dependent on lake region. Examination of the plotted model predicted values for species richness illustrates this interactive effect (Figure 2.4). Specifically, while species richness does not substantially increase over time in the embayment zone, species richness shows considerably greater rates of increase in each of the other zones (Figure 2.4). Total yearly species richness since biomonitoring began has ranged from 27-34 species per sampling year. Species richness has seen a notable increase over time in the riverine zone, middle main lake zone, and lower main lake zone (Figure 2.3). The riverine zone had lows of 8 
and 9 species captured by electrofishing during 1990 and 1997, respectively (Figure 2.3). However, in later years (i.e., 2005-2015) yearly species richness has exceeded 20 species (Figure 2.3). Gill net species richness in the riverine zone experienced lows of 5,7 , and 4 species captured in 1990, 1997, and 1998, respectively. In 2005 and later surveys, no fewer than 12 species per year were captured with gill nets in the riverine zone. Species richness in the embayment zone has remained relatively consistent over time (Figure 2.3). Additionally, several species were collected during the biomonitoring period for the first time in Cheat Lake. New species collected during the time period from the start of biomonitoring (1990) to the most recent collection (2015) include Banded Darter, Fantail Darter, Greenside Darter, Mimic Shiner, Muskellunge, Popeye Shiner, Spotted Bass, Silver Shiner, Walleye, and White Bass. These were species absent in the historical surveys (1952-1977) and in the original 1990 biomonitoring survey, but that appeared in subsequent years.

\section{Multivariate Community Analyses}

Fish community data revealed patterns of presence and abundance of particular species lakewide and across lake region. Species captured in Cheat Lake can be generally separated into non-game/forage species (non-sportfish) and sportfish species. Across space and time, the most abundant forage species in Cheat Lake captured by electrofishing (in order of overall abundance) included Emerald Shiner, Mimic Shiner (Notropis volucellus), Brook Silverside (Labidesthes sicculus), Logperch (Percina caprodes), Golden Redhorse, Silver Shiner, and Gizzard Shad (Dorosoma cepedianum) (Appendix 2.1). Emerald Shiner was the most abundant forage species collected lakewide, with a mean electrofishing CPUE of $55.93 \mathrm{fish} / \mathrm{hr}$. (Appendix 2.1). However, there were differences in dominant forage species across lake region. In main lake sites, Emerald Shiner was still the most abundant forage species with a mean 
electrofishing CPUE of 78.7 fish/hour (Table 2.3). In embayment sites, Brook Silverside was the most abundant forage species collected with a mean electrofishing CPUE of 49.2 fish/hour (Table 2.3). In riverine sites, Mimic Shiner was the most abundant forage species collected with a mean electrofishing CPUE of 94.09 fish/hour (Table 2.3). The most abundant sportfish species captured in Cheat Lake (in order of overall abundance) included Bluegill (Lepomis macrochirus), Green Sunfish (Lepomis cyanellus), Smallmouth Bass, Largemouth Bass (Micropterus salmoides), Pumpkinseed (Lepomis gibbosus), Spotted Bass (Micropterus punctulatus), Rock Bass (Ambloplites rupestris), Yellow Perch, White Bass (Morone chrysops), Black Crappie (Pomoxis nigromaculatus), Channel Catfish, and Walleye (Appendix 2.1). Bluegill was the most abundant sportfish collected lakewide, with a mean electrofishing CPUE of 66.3 fish/hour (Appendix 2.1). Similar to forage species, there were differences in dominant sportfish species across lake region. Bluegill were also the most abundant sportfish species in both the embayment and main lake sites with mean electrofishing CPUE of 110.48 fish/hour and 73.41 fish/hour, respectively (Table 2.3). In riverine sites, Smallmouth Bass were the most abundant sportfish collected with a mean electrofishing CPUE of 58.19 fish/hour (Table 2.3).

The most abundant species captured by gill nets included Channel Catfish $(18.5 \%$ of total catch), Gizzard Shad (13.3\%), Golden Redhorse (10.7\%), White Bass (9.1\%), and Yellow Perch (8.0\%) (Appendix 2.2). Species relative abundances captured by gill nets varied by lake zone. In the embayment zone the most abundant species captured included Black Crappie (19.4\% of catch), Gizzard Shad (16.1\%), and Channel Catfish (10.4\%). In the main lake, Yellow Perch were the most abundant species captured (14.8\%), followed by Brown Bullhead (10.1\%), Gizzard Shad (9.4\%), and Channel Catfish (9.2\%). The strong contribution of Brown Bullhead was heavily skewed by greater abundances in 1990 and 1997. Finally, riverine zone gill net catches were dominated by Channel Catfish (28\% of catch), Gizzard Shad (14.7\%), Golden 
Redhorse (13.9\%), and White Bass (13.2\%). Complete gill net CPUE information can be found in Appendix 2.2.

Although several species appeared to increase in abundance over time according to gill net CPUE, gill nets were not very effective at consistently capturing most species of fish. However, catfish species within the lake were routinely captured. The two most abundant catfish species within the lake, Channel Catfish and Brown Bullhead, both displayed contrasting changes in abundance over time. Plotted values of gill net CPUE over time illustrate decreasing abundance of Brown Bullhead over time (Figure 2.6). While never extremely abundant during the biomonitoring period, Brown Bullhead were nearly 16 times less abundant in the 2010s (mean CPUE of 0.05 fish/net-night) compared to the 1990 s (mean CPUE of 0.79 fish/net-night) (Appendix 2.2; Figure 2.6). Channel Catfish displayed the opposite trend, with plotted values of gill net CPUE suggesting increasing abundance over time (Table 2.7). An average of over 6 times as many Channel Catfish were captured in the 2010s (mean CPUE 2.1 fish/net-night) compared to the 1990s (mean CPUE 0.33 fish/net-night) (Appendix 2.2; Figure 2.6).

Results from NMDS suggest significant spatial and temporal differences in fish community structure of Cheat Lake. Specifically, fish community composition showed significant differences in similarity across lake zones (embayment, lower, middle, and riverine) and across study years (1990-2015) based on electrofishing data. Non-metric multi-dimensional scaling showed visible separation between early electrofishing surveys (1990-2001) and more recent surveys (2005-2015). In general, spatial orientation of sites moves from bottom-left to top-right in NMDS space from early to recent surveys (Figures 2.10). The earliest survey years (1990 and 1997) are especially distant from more recent surveys, possibly indicating large differences in fish communities. Plotting of Pearson correlations of select species in NMDS space revealed trends in abundance of several species over time which likely influenced dissimilarities of fish communities between years. Brown Bullhead was the only species with a visible correlation to 
early study years, designated by its placement on the far bottom-left of the plot (Figure 2.10). The placement of Brown Bullhead in NMDS space near early sampling years indicates abundance of Brown Bullhead contributed to the dissimilarity between early sampling years and later sampling years. In contrast, a number of sportfish and forage species (Channel Catfish, Emerald Shiner, Gizzard Shad, Green Sunfish, Largemouth Bass, Pumpkinseed, Smallmouth Bass, Spotted Bass, Walleye, White Bass, and Yellow Perch) showed varying degrees of correlation toward more recent study years (Figures 2.10). The orientation of these species in NMDS space suggests that changes in their abundance contributed to differences in fish communities between early study years and later study years.

Although NMDS results suggest significant differences in lake fish communities over time, fish communities were also distinguishable by lake zone in NMDS space. The NMDS results plotted by lake zone show riverine fish communities oriented bottom-right in NMDS space, embayment and lower lake communities oriented top-left in NMDS space, and middle lake communities positioned in between (Figure 2.9). Essentially, NMDS orientation of fish communities in Cheat Lake move in a downstream direction from bottom-right to top-left in NMDS space (Figure 2.9). As with the NMDS results plotted by year, plotting of Pearson correlations of select species in NMDS space revealed trends in abundance of several species by lake zone. Species such as Largemouth Bass, Spotted Bass, Bluegill, Green Sunfish, Brook Silverside, and Gizzard Shad oriented more towards Embayment and Lower Lake zone sites (Figure 2.9). In contrast, species such as White Bass, Walleye, Channel Catfish, Yellow Perch, Smallmouth Bass, Logperch, Emerald Shiner, Mimic Shiner, and Golden Redhorse oriented more toward Riverine zone sites (Figure 2.9). Orientation of certain species towards a specific lake zone suggests that their abundance influenced differences in fish communities between zones. Visible separation of samples by both year and lake zone suggests that both factors influenced NMDS orientation of samples. 
Supporting the NMDS results, multivariate GLM (mvabund) results indicated significant differences in fish community composition by year and lake zone from electrofishing data (Table 2.6). Univariate tests indicated that eighteen species significantly influenced the observed changes in fish communities across space and/or time (Table 2.6). Fourteen species significantly influenced differences in fish communities over time (Table 2.6). Smallmouth Bass contributed the most to differences in fish communities over time, accounting for over $20 \%$ of the observed deviance (Table 2.6). Supporting this, Smallmouth Bass mean CPUE was over 13 times higher from 2011-2015 compared to mean CPUE in the 1990s (Table 2.3; Figure 2.5). Largemouth Bass (17\%), Bluegill (12.5\%), Smallmouth Bass (11.7\%), and Green Sunfish (10.3\%) accounted for the largest percentage of observed deviance across lake region (Table 2.6). Largemouth Bass were most abundant in embayment areas, with mean embayment site CPUE over 20 times higher than mean riverine site CPUE and 1.28 times higher than main lake site CPUE (Table 2.3). Bluegill were also most abundant in embayment areas, with mean embayment site CPUE over 8 times higher than mean riverine site CPUE and 1.33 times higher than mean main lake site CPUE (Table 2.3). Smallmouth Bass were most abundant in riverine areas, with mean riverine site CPUE over 7 times higher than mean embayment site CPUE and 2.62 times higher than mean main lake CPUE (Table 2.3). Green Sunfish were most abundant in main lake sites, with mean main lake site CPUE over 21 times higher than mean riverine site CPUE and 1.26 times higher than mean embayment site CPUE (Table 2.3).

Multivariate GLM results also suggested a significant interactive effect between lake zone and year on fish community structure changes (Table. 2.6). Specifically, five species significantly contributed to fish community changes when considering time and lake zone together (Table 2.6). These species and their contribution to percent deviance included Black Crappie (14.8\%), Green Sunfish (9.8\%), Smallmouth Bass (9.2\%), Largemouth Bass (8.6\%), and Yellow Perch (8.5\%) (Table 2.6). This indicates that abundance of these species did not 
change equally across lake region. For instance, although Black Crappie abundance increased in each lake region over time, these changes were most notable in the main lake zone. Black Crappie abundance was negligible in this zone in the 1990s (mean main lake CPUE of 0.06 fish/hour) but increased substantially by the 2011-2015 time period (mean main lake CPUE of 11 fish/hour). Likewise, Green Sunfish abundance increased most notably over time in the main lake and embayment zones. Abundance of Green Sunfish was comparably low in these zones in the 1990s (mean embayment CPUE of 4.11 fish/hour and mean main lake CPUE of 1.61 fish/hour) but increased dramatically by the 2011-2015 time period (mean embayment CPUE of 77.4 fish/hour and mean main lake CPUE of 110 fish/hour). Smallmouth Bass increased in abundance over time in all lake zones, but increases were most substantial in the main lake and riverine zones. Abundance of Smallmouth Bass was comparably low in the 1990s in the main lake zone (mean CPUE of 1.81 fish/hour) and riverine zone (8.56 fish/hour), but increased dramatically by the 2011-2015 time period (mean make lake CPUE of $30 \mathrm{fish} /$ hour and mean riverine CPUE of 68.2 fish/hour). Largemouth Bass continually increased in abundance in both the embayment and main lake zones, but increases were greatest in the main lake zone. Largemouth Bass mean CPUE increased from 4.78 fish/hour in the $1990 \mathrm{~s}$ to 45.4 fish/hour in the 2011-2015 time period in the main lake zone. Finally, although Yellow Perch abundance did not increase in the embayment zone over time, increases in abundance were substantial in both the main lake and riverine zones. Yellow Perch abundance increased from lows of 1.02 fish/hour mean main lake CPUE and 4 fish/hour mean riverine CPUE in the 1990s to highs of 21.6 fish/hour mean main lake CPUE and 22 fish/hour mean riverine CPUE from 2011-2015.

Historical vs. Recent Fish Community Structure

Many new species were collected in the biomonitoring period compared to the historic data period. During the historic data period, only 15 species were collected (Table 2.4). The 
most abundant species captured were Brown Bullhead (56\% mean relative abundance) and White Sucker (26\% mean relative abundance) (Table 2.4). No other species comprised on average any more that $7 \%$ relative abundance (Table 2.4). Largemouth Bass, Bluegill, Black Crappie, Rock Bass, and Green Sunfish comprised 7\%, 4\%, 3\%, 2\%, and 1\%, respectively (Table 2.4). All other species captured during this period (Northern Hogsucker (Hypentelium nigricans), Channel Catfish, Golden Redhorse, Pumpkinseed, Common Carp (Cyprinus carpio), Yellow Bullhead (Ameiurus natalis), Logperch, Johnny Darter (Etheostoma nigrum)) comprised less than $1 \%$ of the catch on average. During the biomonitoring period 44 species were collected (Table 2.3). In contrast to surveys during the historic period, during the biomonitoring period, abundance was more evenly distributed among species (no species comprised more than $10 \%$ of the catch, on average). Where Brown Bullhead and White Sucker were quite common from 1952-1977, during the biomonitoring period these two species were quite uncommon ( $2 \%$ and $1 \%$ average relative abundance, respectively).

\section{Discussion}

Due largely to acidic conditions, Cheat Lake once supported only limited aquatic life (Core 1959; WVDNR unpublished data). However, due to improvements in water quality, notably $\mathrm{pH}$, and a reduction in acidic conditions, fish communities within the lake have seen dramatic changes. Specifically, results from this study indicate that fish community structure in Cheat Lake has changed significantly over time since initiation of biomonitoring in 1990. Changes in the fish community coincided with improvements in water quality in the postSMCRA era. Specifically, increases in overall fish abundance in Cheat Lake and increases in abundance of individual species suggest improved water quality and/or habitat conditions. The $\mathrm{pH}$ conditions of Cheat Lake have dramatically improved over time and past studies have shown how acidic conditions can lead to reduction or extirpation of many species (Haines 1981; 
Magnuson et al. 1984; Baker et al. 1990; Tremblay and Richard 1993; Schorr and Backer 1996; McCormick and Leino 1999; McClurg et al. 2007). Many species intolerant to low pH (i.e., Smallmouth Bass, Walleye, cyprinids, etc.) have shown substantial increases in abundance in Cheat Lake. In contrast, those species tolerant to acidic conditions that were once dominant (Brown Bullhead, White Sucker), now represent only a small fraction of the fish community. Although fish abundance has increased lakewide, increases have been particularly noticeable in the riverine and main lake zones. These are also areas that have been most impacted by AMD in the past. This is in contrast to the embayments which have been partially buffered from acidification due to clean water inputs from incoming tributaries. Therefore, it is expected that the riverine and main lake areas would experience the greatest improvement in water quality over time. These changes in the fish community have been possible due to more favorable conditions resulting from acid mine drainage treatment within the Cheat River watershed. However, much of the observed improvements in water quality are dependent on continuous treatment of acid mine drainage within the watershed. Interruptions or discontinuation of water treatment would almost certainly result in increased acidic conditions and the return of impaired fish communities.

Statistical results provide supporting evidence that Cheat Lake fish populations have changed positively over time. Statistical results showed that early fish surveys (1990-2001) supported higher abundances of tolerant bullhead species and lower abundances of other sportfish and forage species. Over time, fish communities have seen increases in important sportfish and forage species, and thus fish communities from recent surveys (2005-2015) are significantly different than fish communities from early surveys (1990-2001). Many species have significantly increased in abundance since biomonitoring began. Based on multivariate generalized linear model analysis of electrofishing catch data, the following species significantly contributed to changes in fish community structure through increases in abundance: 
Smallmouth Bass, Green Sunfish, White Bass, Spotted Bass, Channel Catfish, Gizzard Shad, Rock Bass, Emerald Shiner, Yellow Perch, Pumpkinseed, Silver Shiner, Largemouth Bass, Black Crappie, and Walleye. Additionally, gill net data suggest that Channel Catfish have significantly increased in abundance while Brown Bullhead have significantly decreased.

Continuing improvements to the fishery resources of Cheat Lake are likely at least partly a result of improvements in water quality in the Cheat River watershed. Improvements in water quality are the result of AMD abatement projects in the Cheat River watershed upstream of Cheat Lake (McClurg et al. 2007). Several species that have increased in abundance are known to be particularly sensitive to acidic conditions. In particular, species such as Walleye, Smallmouth Bass, Emerald Shiner, and Silver Shiner are known to be sensitive to acidification (Butler et al. 1973; Beamish et al. 1975; Hulsman et al. 1983; Kelso 1988) and are thus good indicators of improved water quality conditions. Smallmouth Bass are known to be one of the first species to be lost when acidification occurs (Beamish et al. 1975), therefore their changes in abundance provide a particularly good indication of the improvements that have occurred. Smallmouth Bass were entirely absent from historic fish surveys in Cheat Lake (1952-1977), and abundance was low (2.97 fish/hr.) in early biomonitoring surveys (1990-2001). However, abundance increased substantially (38.5 fish/hr.) in later surveys (2005-2015).

Increase in Walleye abundance can be partially attributed to the continuance of the WVDNR stocking program. Stocking of Walleye fingerlings in Cheat Lake has provided critical supplementation to the limited natural reproduction. However, Walleyes have likely benefited from increases in spring $\mathrm{pH}$ as Walleye eggs and larvae are sensitive to acidic conditions (Hulsman et al. 1983). Thus, increases in $\mathrm{pH}$ have likely benefited natural recruitment of Walleye in Cheat Lake. Capture of young of year Walleyes in recent years in which stocking did not occur or was limited indicates increased success of natural reproduction. Increases in 
natural reproduction have likely benefited from stocking success which has helped increase the spawning population of Walleyes in Cheat Lake.

Some species have been documented as tolerating acidic conditions better than other fish, yet they have also seen increases in abundance in Cheat Lake. In particular, Yellow Perch, Pumpkinseed, and Rock Bass have in some studies been noted as moderately tolerant of acidic conditions (Wales and Beggs 1986; Schofield and Driscoll 1987; Tremblay and Richard 1993). However, for Rock Bass other studies have suggested this species to be sensitive to acidification (Schofield and Driscoll 1987). Even Yellow Perch and Pumpkinseed which have been suggested to be moderately tolerant have been documented to be extirpated by acidification (Magnuson et al. 1984). These species could be indirectly benefiting from reduced acidification via increases in lake productivity, available forage, or habitat changes (e.g., increased vegetated habitat). Yellow Perch could have benefited from increases in aquatic vegetation habitat which provides essential shelter for juvenile Yellow Perch (Dibble et al. 1996). Two species that are known to be especially tolerant to low $\mathrm{pH}$, Brown Bullhead and White Sucker, have went from dominating the Cheat Lake fish community to being nearly absent from surveys. Whereas these species have no competitors in acidic conditions, with improving water quality competition from other more sensitive species likely leads to a reduction in abundance of these tolerant species. Channel Catfish replaced Brown Bullhead as the most dominant catfish species in Cheat Lake following improved water quality. Likewise, Golden Redhorse have replaced White Sucker as the most dominant sucker species. Both Channel Catfish and Golden Redhorse are more sensitive to acidic conditions than Brown Bullhead and White Sucker, but with good water quality these species have successfully replaced their tolerant counterparts.

In addition to fish abundance, species richness has also significantly increased over time. Specifically, from 1952-1977, only 15 species were captured. Since 1990, a total of 44 species have been captured. Species richness has also increased since biomonitoring began in 
1990. However, increases in species richness have not changed equivalently across lake zones. Specifically, increases in species richness have been greater in riverine and main lake zones, compared to the embayment zone. When looking at graphical results, it is apparent that although species richness has steadily increased over time in riverine and main lake zones, species richness in the embayments has remained relatively stable. This could be due in part to the embayments experiencing some sheltering from acidic conditions due to clean water inputs from incoming tributaries.

Better water quality in the embayments has been apparent over time with these areas consistently experiencing higher $\mathrm{pH}$ than the main lake and riverine areas. Annual mean and minimum $\mathrm{pH}$ has been higher in embayment areas than in main lake and riverine zones for most of the existence of Cheat Lake. It was not until recent years that $\mathrm{pH}$ in these areas became comparable. The embayments (Morgans Run and Rubles Run) both are fed by tributaries with good water quality. These AMD free tributaries likely help buffer the embayment areas from the lower $\mathrm{pH}$ values experienced in the riverine and main lake zones. Increases in richness over time with improving $\mathrm{pH}$ conditions are not surprising, given that many species of fish were at one time extirpated from Cheat Lake.

Other studies have also documented the disappearance of species from acidified waters (Beamish et al. 1975; Beamish 1976; Magnuson et al. 1984; Schofield and Driscoll 1987; Mills et al. 2000; Schorr and Backer 2006) and some studies have also documented the eventual return of species with improving conditions (Mills et al. 2000; Willams and Turner 2015). Since biomonitoring began, several species were documented for the first time since prior to the 1952 fish survey. Species documented for the first time in recent history include Popeye Shiner (Notropis ariommus), Mimic Shiner, Silver Shiner, Emerald Shiner, White Bass, Walleye, Muskellunge (Esox masquinongy), Greenside Darter (Etheostoma blennioides), and Banded Darter (Etheostoma zonale). Some of these species may have been introduced by anglers, 
while others may have emigrated into Cheat Lake from clean water refuges (i.e., tributaries). Regardless of the source, the occurrence of these species provides further indication of improved water quality.

Although increases in $\mathrm{pH}$ and improvements in water quality over time are likely the main contributing factor to observed changes in fish community composition, there are possible indirect effects from water quality improvements that have likely benefited Cheat Lake fisheries. Most notably, increases in productivity and forage as a result of $\mathrm{pH}$ increases have likely contributed to changes in fish community composition and fish abundance. Many man-made reservoirs undergo a "trophic upsurge" for several years after construction as a result of released nutrients (Miranda and Bettoli 2010). As a result of this trophic upsurge there are often dramatic increases in animal biomass and growth within reservoirs (Miranda and Bettoli 2010; Turgeon et al. 2016). For most of its existence, productivity of Cheat Lake was dramatically limited due to acidic conditions (Core 1959; Volkmar 1972; Janicki 1980). Studies on phytoplankton and zooplankton communities of Cheat Lake during the 1970s when acidic conditions were prevalent suggested extremely simple communities indicative of artificially oligotrophic conditions (Volkmar 1972; Janicki 1980). With treatment of mine drainage and increases in $\mathrm{pH}$ within Cheat Lake, productivity as a result has increased resulting in what could be viewed as a delayed trophic upsurge. Additionally, acidification has been shown to depress or hinder growth of many aquatic plants (Gorham and Gordon 1963; Roberts et al. 1985; Jackson and Charles 1988). The ability for a greater diversity of plants to grow and be available as habitat is another potential pathway for changes in fish community structure. Also, improvements in water quality have likely led to increases in available macroinvertebrates which serve as important forage to fishes (Mills and Schindler 1986). Increased productivity and other secondary impacts of improved water quality has important effects throughout the food chain (zooplankton, macroinvertebrates, forage fish) and abiotic habitat (aquatic vegetation). Thus, 
this increase in productivity and subsequent effects has likely contributed to the dramatic increase in fish abundance and fish growth in recent years in Cheat Lake.

In addition to water quality as a driver of fish community changes, stability of water level management since biomonitoring began has also likely benefited the fisheries of Cheat Lake. Beginning in 1994, lake level fluctuations were restricted to $2.1 \mathrm{~m}$ (7 ft.) in April with the intent to benefit Walleye and Yellow Perch spawning. Also, lake level fluctuations were restricted to 0.6 $\mathrm{m}(2 \mathrm{ft})$ from May-October to accommodate recreational use of the lake and to benefit spawning of other fishes such as Centrarchids. Cheat Lake does not see the drastic swings in lake levels that many other West Virginia reservoirs experience as most other West Virginia reservoirs are intended for flood control purposes. These relatively stable water levels have potentially contributed to improved natural reproduction of some species. Other studies have identified lake levels as important drivers in recruitment and year class strength of multiple species (Martin et al. 1981; Miranda et al. 1984; Noble 1986; Kallemeyn 1989; Jude 1992; Reinart et al. 1997; Sammons and Bettoli 2000). Species in these studies (Largemouth Bass, Spotted Bass, Black Crappie, White Crappie, White Bass, Yellow Perch, Buffalo, Walleye) generally responded to stable or high water levels with increased recruitment and year class strength (Martin et al. 1981; Miranda et al. 1984; Noble 1986; Kallemeyn 1989; Jude 1992; Reinart et al. 1997; Sammons and Bettoli 2000). In contrast, years with low water levels usually correlated with poor recruitment and low year class strength (Martin et al. 1981; Miranda et al. 1984; Noble 1986; Kallemeyn 1989; Jude 1992; Reinart et al. 1997; Sammons and Bettoli 2000). High water levels provide access to more littoral habitat which in turn provides greater area for spawning, juvenile fish foraging, and shelter for young fish (Sammons and Bettoli 2000). Limiting water level fluctuations in Cheat Lake to $0.6 \mathrm{~m}$ from May-October likely benefits some species, particularly those that spawn during this time period. However, the current Cheat Lake water level fluctuation rules for winter months and April still allow for the possibility of impacts to spawning 
of some fishes, particularly Walleye and Yellow Perch. During Cheat Lake Walleye stocking assessment surveys in early spring (March/April), Yellow Perch eggs have often been seen dewatered after spawning occurred and lake levels were dropped (WVDNR unpublished data). Additionally, other work on Cheat Lake Walleyes (see Chapter 5) has suggested that Walleyes spawn in relatively shallow water near the head of the lake and the potential exists for egg dewatering to occur for this species as well.

In addition to significant temporal changes, our results suggest that Cheat Lake fish communities are also inherently different spatially. Fish community composition was significantly different across lake zones suggesting fish communities in different areas of Cheat Lake are significantly different from one another. These spatial differences are likely the result of differences in habitat of these zones and typically followed an upstream to downstream longitudinal gradient from riverine habitat to lacustrine habitat. For instance, the riverine zone has characteristics more closely resembling lotic (pronounced flow, rockier habitat, little to no thermal stratification, etc.) environments compared to the other zones of Cheat Lake. In contrast, the embayment and main lake zones have characteristics more indicative of lentic habitat (limited flow, deeper water, soft sediment bottom, thermal stratification, etc.). Correlated with these habitat differences by reservoir zone, fish communities also varied by reservoir zone. These longitudinal differences in fish communities have been documented in other studies (Beamesderfer and Rieman 1991; Agostinho et al. 1999; Michaletz and Gale 1999; Gido et al. 2002; De Oliveira et al. 2005; Miranda and Bettoli 2010). In other studies, species typically associated with riverine zones favor flowing water and harder substrates for a portion of their life history (Miranda and Bettoli 2010). Species associated with lacustrine zones are typically lake adapted species that may be more pelagic or better adapted to areas with little flow and soft sediment (Miranda and Bettoli 2010). In our study, species with significantly greater abundance within the riverine zone included Smallmouth Bass, Mimic Shiner, Golden Redhorse, and Rock 
Bass. Except for Mimic Shiner, these species are those typically associated with lotic habitats in other systems (Lee 1980; Jenkins and Burkhead 1994). Although Mimic Shiner were more abundant in the riverine zone within Cheat Lake, other studies have suggested they prefer vegetated, lentic habitats (Willis and Magnuson 2000). Species significantly more abundant in the main lake or embayment zones in our study included Largemouth Bass, Bluegill, Green Sunfish, Pumpkinseed, Black Crappie, and Spotted Bass. These species are those often associated with lentic habitats in other systems (Lee 1980; Jenkins and Burkhead 1994). These stark longitudinal differences in fish community structure has influenced management strategies in other reservoirs (Buynak et al. 1989; Miranda and Bettoli 2010). Alternative management strategies such as stratification of sampling regimes, differences in habitat management, and differences in harvest regulations by zone have been considered or implemented in other systems (Buynak et al. 1989; Miranda and Bettoli 2010). Some of these management strategies have been utilized for Cheat Lake (habitat management considerations by zone, sampling patterns for different species, etc.). Additionally, this information is important for anglers to consider when targeting particular species of fish.

In summary, our results suggest that the fisheries resources of Cheat Lake have drastically improved over time largely due to improved water quality and possibly in part to stable hydrological conditions. Cheat Lake fish communities continue to see increases in abundance of several important sportfish species and the forage species that support these sportfish. This study has also confirmed that fish communities are significantly different across lake zones in Cheat Lake. In particular, fish communities in the riverine zone of Cheat Lake, where conditions are more lotic, are significantly different from main lake and embayment sites that are more lentic. Dominant species in the riverine zone are those that favor lotic conditions such as Smallmouth Bass and Rock Bass, while dominant species in main lake and embayment zones are those that favor lentic conditions such as Largemouth Bass and Bluegill. Cheat Lake 
at one point was considered a dead fishery by anglers and biologists alike, and fisheries management was not attempted due to the limitations created by poor water quality. Not only have the fisheries of Cheat Lake rebounded with improved water quality, fish communities are in the best condition that they have likely ever been since the creation of the reservoir over 90 years ago. Given the healthy populations of a variety of sportfish, Cheat Lake represents a quality resource for anglers. However, given the fragile nature of AMD mitigation funding and hydrological dynamics with the lake, future monitoring is critical for ensuring the persistence of quality fishery resources within the lake. 


\section{References}

Agosthino, A. A., L. E., Miranda, L. M. Bini, L. C. Gomes, S. M. Thomaz and H. I. Suzuki. 1999. Patterns of colonization in neotropical reservoirs, and prognoses on aging. Pages 227265 in J. G. Tundisi and M. Straskraba, editors. Theoretical Reservoir Ecology and its Applications. Backhuys Publishers, Leiden.

Baker, J. P., D. P. Bernard, S. W. Christensen, M. J. Sale, J. Freda, K. Heltcher, D. Marmorek, L. Rowe, P. Scanlon, G. Suter, W. Warren-Hicks, and P. Welbourn. 1990. Biological effects of changes in surface water acid-base chemistry. NAPAP Report 13. In: National Acid Precipitation Assessment Program, Acidic Deposition: State of Science and Technology. Volume II, 1990.

Baker, J. P., J. Van Sickle, C. J. Gagen, D. R. DeWalle, W. E. Sharpe, R. F. Carline, B. P. Baldigo, P. S. Murdoch, D. W. Bath, W. A. Krester, H. A. Simonin, and P. J. Wigington Jr. 1996. Episodic acidification of small streams in the northeastern United States: effects of fish populations. Ecological Applications 6: 422-437.

Baldigo, B. P. and G. B. Lawrence. 2000. Composition of fish communities in relation to stream acidification and habitat in the Neversink River, New York. Transactions of the American Fisheries Society 129: 60-76.

Beamesderfer, R. C. and B. E. Rieman. 1991. Abundance and distribution of northern squawfish, walleyes, and smallmouth bass in John Day Reservoir, Columbia River. Transactions of the American Fisheries Society 120: 439-447.

Beamish, R. J. 1976. Acidification of lakes in Canada by acid precipitation and the resulting effects on fishes. Water, Air, and Soil Pollution 6: 501-514. 
Beamish, R. J., W. L. Lockhart, J. C. Van Loon, and H. H. Harvey. 1975. Long-term acidification of a lake and resulting effects on fishes. Ambio 4: 98-102.

Bennett, M. G. and J. P. Kozak. 2016. Spatial and temporal patterns in fish community structure and abundance in the largest U.S. river swamp, the Atchafalaya River floodplain, Louisiana. Ecology of Freshwater Fish 25: 577-589.

Bolker, B.M., M.E. Brooks, C.J. Clark, S.W. Geange, J.R. Poulsen, M. Henry, H. Stevens, and J.-S.S. White. 2008. Generalized linear mixed models: a practical guide forecology and evolution. Trends in Ecology and Evolution 24: 127-135.

Bott, T. L., J. K. Jackson, M. E. McTammany, J. D. Newbold, S. T. Rier, B. W. Sweeney, and J. M. Battle. 2012. Abandoned coal mine drainage and its remediation: impacts on stream ecosystem structure and function. Ecological Applications 22: 2144-2163.

Butler, R. L., E. L. Cooper, J. K. Crawford, D. C. Hales, W. G. Kimmel, and C. C. Wagner. 1973. Fish and food organisms in acid mine waters of Pennsylvania. US Environmental Protection Agency Ecological Research Series EPA-R3-73-032. US Govt Printing Office, Washington D.C.

Buynak, G. L., L. E. Kornman, A. Surmont, and B. Mitchell. 1989. Longitudinal differences in electrofishing catch rates and angler catches of black bass in Cave Run Lake, Kentucky. North American Journal of Fisheries Management 9: 226-230.

Chick, J. H., C. R. Ruetz III, and J. C. Trexler. 2004. Spatial scale and abundance patterns of large fish communities in freshwater marshes of the Florida Everglades. Wetlands 24: $652-664$.

Chick, J. H., S. Coyne, and J. C. Trexler. 1999. Effectiveness of airboat electrofishing for sampling fishes in shallow, vegetated habitats. North American Journal of Fisheries Management 19: 957-967. 
Clarke, K. R. and R. M. Warwick. 2001. Change in marine communities: an approach to statistical analysis and interpretation, $2^{\text {nd }}$ edition. Primer-E, Plymouth, England.

Cline, S. A. 1999. An assessment of organizational effectiveness: a study of West Virginia watershed associations. Master's thesis, West Virginia University, Morgantown, WV.

Clovis, J. F. 1971. Aquatic vascular plant distribution in Cheat Lake (Lake Lynn), West Virginia. Castanea 36: 153-163.

Core, E. L. 1959. Biological investigations of Cheat Lake. West Virginia University, Morgantown, WV.

Cravotta III, C. C., R. A. Brightbill, and M. J. Langland. 2010. Abandoned mine drainage in the Swatara Creek basin, southern anthracite coalfield, Pennsylvania, USA: stream water quality trends coinciding with the return of fish. Mine Water and the Environment 29: 176-199.

de Oliveira, E. F., C. V. Minte-Vera, and E. Goulart. 2005. Structure of fish assemblages along spatial gradients in a deep subtropical reservoir (Itaipu Reservoir, Brazil-Paraguay border). Environmental Biology of Fishes 72: 283-304.

Dibble, E. C., K. J. Killgore, and S. L. Harrel. 1996. Assessment of fish-plant interactions. American Fisheries Society Symposium 16: 357-372.

Eaton, J. G., W. A. Swenson, J. H. McCormick, T. D. Simonson, and K. M. Jensen. 1992. A field and laboratory investigation of acid effects on largemouth bass, rock bass, black crappie, and yellow perch. Transactions of the American Fisheries Society 121: 644658.

Edens, D. L. 1975. A comparative study of nutrients and water quality in Cheat Lake tributaries. Master's Thesis. West Virginia University, Morgantown, WV. 
Flotemersch, J. E. and K. A. Blocksom. 2005. Electrofishing in boatable rivers: does sampling design affect bioassessment metrics? Environmental Monitoring and Assessment 102: 263-283.

Freund, J.G. and J.T. Petty. 2007. Response of fish and macroinvertebrate bioassessment indices to water chemistry in a mined Appalachian watershed. Environmental Management 39: 707-720.

Gido, K. B., C. W. Hargrave, W. J. Matthews, G. D. Schnell, D. W. Pogue, and G. W. Sewell. 2002. Structure of littoral-zone fish communities in relation to habitat, physical, and chemical gradients in a southern reservoir. Environmental Biology of Fishes 63: 253-263.

Gorham, E. and A. G. Gordon. 1963. Some effects of smelter pollution upon aquatic vegetation near Sudbury, Ontario. Canadian Journal of Botany 41: 371-378.

Gutreuter, S., R. Burkhardt, and K. Lubinski. 1995. Long term resource monitoring program procedures: fish monitoring. National Biological Service, Environmental Management Technical Center, Onalask, Wisconsin, July 1995. LTRMP 95-P002-1.

Haines, T. A. 1981. Acidic precipitation and its consequences for aquatic ecosystems: a review. Transactions of the American Fisheries Society 110: 669-707.

Hall, R. P. 1966. Distribution of sediments at Cheat Lake, West Virginia. Master's Thesis. West Virginia University, Morgantown, WV.

Herlihy, A. T., P. R. Haufmann, M. R. Church, P. J. Wigington, J. R. Webb, and M. J. Sale. 1993. The effects of acidic deposition on streams in the Appalachian Mountain and Piedmont Region of the Mid-Atlantic United States. Water Resources Research 29: 2687-2703. 
Hivick, F. R. 1972. Biological factors contributing to the distribution of certain aquatic plants in Cheat Lake. Master's Thesis. West Virginia University, Morgantown, WV.

Hulsman, P. F., P. M. Powles, and J. M. Gunn. 1983. Mortality of walleye eggs and rainbow trout yolk-sac larvae in low-pH waters of the LaCloche Mountain area, Ontario. Transactions of the American Fisheries Society 112: 680-688.

Jackson, S. T. and D. F. Charles. 1988. Aquatic macrophytes in Adirondack (New York) lakes: patterns of species composition in relation to environment. Canadian Journal of Botany 66: $1449-1460$.

Janicki, A. J. 1980. Analysis of the crustacean plankton community of acidic Cheat Lake. Doctoral Dissertation. West Virginia University, Morgantown, WV.

Jenkins, R. E. and N. M. Burkhead. 1994. Freshwater fishes of Virginia. American Fisheries Society, Bethesda, Maryland, USA.

Jude, D. J. and J. Pappas. 1992. Fish utilization of Great Lakes coastal wetlands. Journal of Great Lakes Research 18: 651-672.

Kallemeyn, L. W. 1987. Correlations of regulated lake levels and climatic factors with abundance of young-of-the-year walleye and yellow perch in four lakes in Voyageurs National Park. North American Journal of Fisheries Management 7: 513-521.

Kelso, J. R. M. 1988. Fish community structure, biomass, and production in the Turkey Lakes watershed, Ontario. Canadian Journal of Fisheries and Aquatic Sciences 45: 115-120.

Koryak, M., P. S. Bonislawsky, D. D. Locy, and B. A. Porter. 2009. Typical channel fish assemblage of the recovering lower Allegheny River navigation system, Pennsylvania, USA. Journal of Freshwater Ecology 24: 509-517.

Lee, D. S., C. R. Gilbert, C. H. Hocutt, R. E. Jenkins, D. E. McCallister, and J. R. Stauffer Jr., editors. 1980. Atlas of North American freshwater fishes. North Carolina State Museum of Natural History, Raleigh. 
Littell, R.C., G. Milliken, W.W. Stroup, R. Wolfinger, and O. Schabenberger. 2006. SAS for Mixed Models, 2nd ed. SAS Institute, Cary, NC.

Magnuson, J. J., J. P. Baker, and E. J. Rahel. 1984. A critical assessment of effects of on acidification on fisheries in North America. Philosophical Transactions of the Royal Society B 305: 501-516.

Magurran, A. E., S. E. Baillie, S. T. Buckland, J. M. Dick, D. A. Elston, E. M. Scott, R. I. Smith, P. J. Somerfield, and A. D. Watt. 2010. Long-term datasets in biodiversity research and monitoring: assessing change in ecological communities through time. Trends in Ecology and Evolution 25: 574-582.

Marhadja, B., M. J. Farruggia, B. Schreier, and T. Sommer. 2017. Evidence of a shift in the littoral fish community of the Sacramento-San Joaquin Delta. PLoS ONE 12: e0170683. doi: 10.1371 /journal.pone.0170683.

Martin, D. B., L. J. Mengel, J. F. Novotny, and C. H. Walburg. 1981. Spring and summer water levels in a Missouri River reservoir: effects of age-0 fish and zooplankton. Transactions of the American Fisheries Society 110: 370-381.

McCain, J. S. P., D. C. Schneider, and H. K. Lotze. 2016. Long-term shift in coastal fish communities before and after the collapse of Atlantic cod (Gadus morhua). ICES Journal of Marine Science 73: 1415-1426.

McClelland, M. A., G. G. Sass, T. R. Cook, K. S. Irons, N. N. Michaels, T. M. O'Hara, and C. S. Smith. 2012. The long-term Illinois River fish population monitoring program. Fisheries 37: $340-50$.

McClurg, S. E., J. T. Petty, P. M. Mazik, and J. L. Clayton. 2007. Stream ecosystem response to limestone treatment in acid impacted watersheds of the Allegheny Plateau. Ecological Applications 17:1087-1104. 
McCormick, J. H., and R. L. Leino. 1999. Factors contributing to first-year recruitment failure of fishes in acidified waters with some implications for environmental research. Transactions of the American Fisheries Society 128: 265-277.

Merovich, G. T., J. M. Stiles, J. T. Petty, J. Fulton, and P. F. Ziemkiewicz. 2007. Water chemistry based classification of streams and implications for restoring mined Appalachian watersheds. Environmental Toxicology and Chemistry 26:1361-1369

Michaletz, P. H. and C. M. Gale. 1999. Longitudinal gradients in age-0 gizzard shad density in large Missouri reservoirs. North American Journal of Fisheries Management 19: 765773.

Mills, K. H. and D. W. Schindler. 1986. Biological indicators of lake acidification. Water, Air, and Soil Pollution 30: 779-789.

Mills, K. H., S. M. Chalanchuk, and D. J. Alan. 2000. Recovery of fish populations in Lake 223 from experimental acidification. Canadian Journal of Fisheries and Aquatic Sciences 57: 192-204.

Miranda, L. E., W. L. Shelton, and T. D. Bryce. 1984. Effects of water level manipulation on abundance, mortality, and growth of young-of-year largemouth bass in West Point Reservoir, Alabama-Georgia. North American Journal of Fisheries Management 4: 314320.

Miranda, L.E. and P. W. Bettoli. 2010. Large reservoirs. Pages 545-586 in W. Hubert and M. Quist, editors. Inland Fisheries Management in North America, $3^{\text {rd }}$ edition. American Fisheries Society, Bethesda, Maryland.

Ney, J. J., C. M. Moore, M. S. Tisa, J. J. Yurk, and R. J. Neves. 1990. Factors affecting the sport fishery in a multiple-use Virginia reservoir. Lake and Reservoir Management 6: 2132. 
Nielsen, S. E., D. L. Haughland, E. Bayne, and J. Schieck. 2009. Capacity of large-scale, longterm biodiversity monitoring programmes to detect trends in species prevalence. Biodiversity Conservation 18: 2961-2978.

Noble, R. L. 1986. Predator-prey interactions in reservoir communities. Pages 137-143 in G. E. Hall and M. J. Van Den Avyle, editors. Reservoir Fisheries Management: Strategies for the 80s. Reservoir Committee, Southern Division, American Fisheries Society, Bethesda, Maryland.

Palmer, M. A., E. S. Bernhardt, W. H. Schlesinger, K. N. Eshleman, E. Foufoula-Georgiou, M. S. Hendryx, A. D. Lemly, G. E. Likens, O. L. Loucks, M. E. Power, P. S. White, and P. R. Wilcock. 2010. Mountaintop mining consequences. Science 327: 148-149.

Pauwels, S. J. and T. A. Haines. 1986. Fish species distribution in relation to water chemistry in selected Maine lakes. Water, Air, and Soil Pollution 30: 477-488.

Pegg, M. A. and M. A. McClelland. 2004. Spatial and temporal patterns in fish communities along the Illinois River. Ecology of Freshwater Fish 13: 125-135.

Ploskey, G. R. 1986. Effects of water-level changes on reservoir ecosystems, with implications for fisheries management. Pages 86-97 in G. E. Hall and M. J. Van Den Avyle, editors. Reservoir Fisheries Management: strategies for the 80's. American Fisheries Society, Southern Division, Reservoir Committee, Bethesda, Maryland.

Rahel, F. J., and J. J. Magnuson. 1983. Low pH and the absence of fish species in naturally acidic Wisconsin lakes: inferences for cultural acidification. Canadian Journal of Fisheries and Aquatic Sciences 40: 3-9.

Reinert, T. R., G. R. Ploskey, and M. J. Van Den Avyle. 1995. Effects of hydrology on black bass reproductive success in four southeastern reservoirs. Proceedings of the Annual Conference of Southeastern Association of Fish and Wildlife Agencies 49: 47-57. 
Roberts, D. A., R. Singer, and C. W. Boylen. 1985. The submersed macrophyte communities of Adirondack lakes (New York, U.S.A.) of varying degrees of acidity. Aquatic Botany 21: 219-235.

Ross, S. 2013. Ecology of North American Freshwater Fishes. Oakland, CA: University of California Press.

Ruetz III, C. R., D. G. Uzarski, D. M. Krueger, and E. S. Rutherford. 2007. Sampling a littoral fish assemblage: comparison of small-mesh fyke netting and boat electrofishing. North American Journal of Fisheries Management 27: 825-831.

Sammons, S. M. and P. W. Bettoli. 2000. Population dynamics of a reservoir sport fish community in response to hydrology. North American Journal of Fisheries Management 20: 791-800.

Schofield, C. L. and C. T. Driscoll. 1987. Fish species distribution in relation to water quality gradients in the North Branch of the Moose River Basin. Biogeochemistry 3: 63-85.

Schorr, M. S. and J. C. Backer. 2006. Localized effects of coal mine drainage on fish assemblages in a Cumberland Plateau stream in Tennessee. Journal of Freshwater Ecology 21: 17-24.

Schwartz, F. J. 1991. Depth and storage capacity changes in Cheat Lake, West Virginia, during the 64-year period 1026 - 1990. The Journal of the Elisha Mitchell Scientific Society 107: 115-122.

Starks, T. A., A. W. Rodger, D. King, and M. Skoog. 2018. Assessing temporal shifts in lotic fish community structure in the upper Red River basin, Oklahoma. Journal of Freshwater Ecology 33: 129-138. 
Stauffer, J. R., J. M. Boltz, and L. R. White. 1995. The Fishes of West Virginia. Academy of Natural Sciences, Philadelphia.

Steelman, T. A. and J. Carmin. 2002. Community-based watershed remediation: connecting organizational resources to social and substantive outcomes. Pages 145-178 in D. Rahm, editor. Toxic Waste and Environmental Policy in the $21^{\text {st }}$ Century United States. McFarland, Jefferson, North Carolina

Stilson, W. P. 1969. Seasonal changes of water quality in a reservoir containing acid mine drainage. Master's Thesis, West Virginia University, Morgantown, WV

Thorne, B. and K. Pitzer. 2004. An update on the Cheat River restoration. Proceedings of the American Society of Mining and Reclamation 2004: 1894-1905.

Tremblay, S. and Y. Richard. 1993. Effects of acidity on fish communities of southwestern Quebec (Canada). Water, Air, and Soil Pollution 66: 315-331.

Turgeon, K., C. T. Solomon, C. Nozais, and I. Gregory-Eaves. 2016. Do novel ecosystems follow predictable trajectories? Testing the trophic surge hypothesis in reservoirs using fish. Ecosphere 7: e01617. https://doi.org/10.1002/ecs2.1617

Van Sickle, J., J. P. Baker, H. A. Simonin, B. P. Baldigo, W. A. Kretser, and W. E. Sharpe. 1996. Episodic acidification of small streams in the northeastern United States: fish mortality in field bioassays. Ecological Applications 6: 408-421.

Volkmar, R. D. 1972. Phytoplankton primary productivity in Cheat Lake. Master's Thesis. West Virginia University, Morgantown, WV.

Wales, D. L. and G. L. Beggs. Fish species distribution in relation to lake acidity in Ontario. Water, Air, and Soil Pollution 30: 601-609. 
Walters, C. J. 2001. Adaptive management of renewable resources. The Blackburn Press, Caldwell, New Jersey.

Walters, C. J. and S. J. Martell. 2004. Fisheries Ecology and Management. Princeton University Press, Princeton, New Jersey.

Walters, C. J., V. Christensen, S. J. Martell, and J. F. Kitchell. 2005. Possible ecosystem impacts of applying MSY policies from single-species assessment. ICES Journal of Marine Science 62: 558-568.

Wang, Y., U. Naumann, S. T. Wright, and D. I. Warton. 2012. mvabund - an R package for model-based analysis of multivariate abundance data. Methods in Ecology and Evolution 3: $471-474$.

Ward-Campbell, B. W., K. Cottenie, N. E. Mandrak, and R. McLaughlin. 2017. Fish assemblages in agricultural drains are resilient to habitat change caused by drain maintenance. Canadian Journal of Fisheries and Aquatic Sciences 74: 1538-1548.

Warton, D. I., S. T. Wright, and Y. Wang. 2012. Distance-based multivariate analyses confound location and dispersion effects. Methods in Ecology and Evolution 3: 89-101.

Wellman, D., F. Jernejcic, and J. Hedrick. 2008. Biological monitoring of aquatic communities of Cheat Lak, and Cheat River downstream of the Lake Lynn hydrostation, 2008. Final FERC Project Report to Allegheny Energy Supply, LLC

Welsh, S. A. and S. A. Perry. 1997. Acidification and fish occurrence in the upper Cheat River drainage, West Virginia. Journal of the American Water Resources Association 33: 423429.

Wigington, P. J., J. P. Baker, D. R. DeWalle, W. A. Kretser, P. S. Murdoch, H. A. Simonin, J. Van Sickle, M. K. McDowell, D. V. Peck, and W. R. Barchet. 1996. Episodic acidification 
of small streams in the northeastern United States: episodic response project. Ecological Applications 6: 374-388.

Williams, K. M. and A. M. Turner. 2015. Acid mine drainage and stream recovery: effects of restoration on water quality, macroinvertebrates, and fish. Knowledge and Management of Aquatic Ecosystems 416: 1-12.

Willis, T. V. and J. J. Magnuson. 2000. Patterns in fish species composition across the interface between streams and lakes. Canadian Journal of Fisheries and Aquatic Sciences 57: 1042-1052.

Zuellig, R. E. and H. J. Crockett. 2013. Assessing the use of existing data to compare plains fish assemblages collected from random and fixed sites in Colorado. US Geological Survey Open-File Report 2013-1115, 9 p., http://pubs.usgs.gov/of/2013/1115/.

Zuellig, R. E. and T. S. Schmidt. 2012. Characterizing invertebrate traits in wadeable streams of the contiguous US: differences among ecoregions and land uses. Freshwater Science 31: 1042-1056. 
Table 2.1. Temporal trends in total catch for electrofishing and gill net surveys in Cheat Lake by region.

\begin{tabular}{clcccccccccccc}
\hline & & \multicolumn{1}{c}{ Total Catch } \\
Region & \multicolumn{1}{c}{ Gear } & $\mathbf{1 9 9 0}$ & $\mathbf{1 9 9 7}$ & $\mathbf{1 9 9 8}$ & $\mathbf{2 0 0 1}$ & $\mathbf{2 0 0 5}$ & $\mathbf{2 0 0 8}$ & $\mathbf{2 0 1 1}$ & $\mathbf{2 0 1 2}$ & $\mathbf{2 0 1 3}$ & $\mathbf{2 0 1 4}$ & $\mathbf{2 0 1 5}$ & Total \\
\hline \multirow{2}{*}{ Riverine } & Night Boat Electrofishing & 35 & 92 & 93 & 129 & 957 & 270 & 609 & 560 & 295 & 403 & 591 & 4034 \\
& Biomonitoring Gill Nets & 16 & 16 & 24 & 51 & 225 & 211 & 136 & 220 &. & 146 &. & 1045 \\
\multirow{3}{*}{ Main } & Night Boat Electrofishing & 432 & 526 & 863 & 830 & 356 & 392 & 521 & 733 & 606 & 841 & 748 & 6848 \\
& Biomonitoring Gill Nets & 78 & 73 & 75 & 55 & 74 & 81 & 52 & 113 &. & 83 &. & 684 \\
\multirow{3}{*}{ Lmbayments Total } & Night Boat Electrofishing & 591 & 948 & 548 & 1030 & 294 & 313 & 186 & 246 & 369 & 314 & 477 & 5316 \\
& Biomonitoring Gill Nets & 99 & 78 & 26 & 62 & 74 & 32 & 13 & 40 &. & 36 &. & 460 \\
& Night Boat Electrofishing & 1058 & 1566 & 1504 & 1989 & 1607 & 975 & 1316 & 1539 & 1270 & 1558 & 1816 & 16198 \\
& Biomonitoring Gill Nets & 193 & 167 & 125 & 168 & 373 & 324 & 201 & 373 &. & 265 &. & 2189 \\
\hline
\end{tabular}

Table 2.2. Temporal trends in CPUE for electrofishing (fish/hr.) and gill net (fish/net-night) surveys in Cheat Lake by region.

\begin{tabular}{|c|c|c|c|c|c|c|c|c|c|c|c|c|}
\hline \multirow[b]{2}{*}{ Region } & \multicolumn{12}{|c|}{ CPUE (fish/hr or fish/net-night) } \\
\hline & Gear & 1990 & 1997 & 1998 & 2001 & 2005 & 2008 & 2011 & 2012 & 2013 & 2014 & 2015 \\
\hline \multirow[t]{2}{*}{ Riverine } & Night Boat Electrofishing & 23.3 & 92.0 & 62.0 & 86.0 & 957.0 & 270.0 & 609.0 & 560.0 & 295.0 & 403.0 & 591.0 \\
\hline & Biomonitoring Gill Nets & 2.7 & 4.0 & 4.0 & 8.5 & 18.8 & 17.6 & 11.3 & 18.3 & 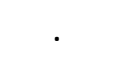 & 12.2 & . \\
\hline \multirow[t]{2}{*}{ Main } & Night Boat Electrofishing & 96.0 & 175.3 & 143.8 & 138.3 & 356.0 & 392.0 & 521.0 & 733.0 & 606.0 & 841.0 & 748.0 \\
\hline & Biomonitoring Gill Nets & 3.3 & 2.0 & 1.1 & 2.2 & 3.5 & 3.6 & 2.5 & 7.4 & . & 6.0 & . \\
\hline \multirow[t]{2}{*}{ Embayments } & Night Boat Electrofishing & 197.0 & 237.0 & 182.7 & 343.3 & 441.0 & 469.5 & 279.0 & 369.0 & 553.5 & 471.0 & 318.0 \\
\hline & Biomonitoring Gill Nets & 8.3 & 9.8 & 2.2 & 5.2 & 9.3 & 4.0 & 1.6 & 5.0 & $\cdot$ & 4.5 & \\
\hline \multirow[t]{2}{*}{ Lake Total } & Night Boat Electrofishing & 117.6 & 182.0 & 143.2 & 189.4 & 602.6 & 365.7 & 493.5 & 577.1 & 476.3 & 584.3 & 681.0 \\
\hline & Biomonitoring Gill Nets & 5.4 & 7.0 & 3.0 & 4.0 & 11.7 & 10.1 & 6.3 & 11.7 & & 8.3 & \\
\hline
\end{tabular}


Table 2.3. Temporal trends in CPUE (fish/hr.) for electrofishing by decade and lake region. Bolded species and values with an asterisk indicate significance in mvabund results. $\mathrm{E}=$ Embayment Zone, $\mathrm{M}=$ Main Lake Zone (Lower Lake and Middle Lake combined), $\mathrm{R}=$ Riverine Zone. 1990s = surveys from 1990, 1997, and 1998; 2000s = surveys from 2001, 2005, and 2008; 2010s = surveys from 2011, 2012, 2013, 2014, and 2015. Standard errors in parentheses.

\begin{tabular}{|c|c|c|c|c|c|c|}
\hline Species & $1990 \mathrm{~s}$ & 2000s & 2010s & $\mathbf{E}$ & $\mathbf{M}$ & $\mathbf{R}$ \\
\hline Banded Darter & $0.00(0)$ & $0.13(0.11)$ & $0.00(0)$ & $0.00(0)$ & $0.09(0.07)$ & $0.00(0)$ \\
\hline Black Crappie* & $0.83(0.46)^{*}$ & $1.19(0.60)^{*}$ & $6.75(1.22)^{*}$ & $4.92(1.03)^{*}$ & $5.20(1.16)^{*}$ & $1.00(0.49)^{*}$ \\
\hline Bluegill* & $46.20(6.56)$ & $73.51(9.68)$ & $77.78(10.78)$ & $110.52(10.46)^{*}$ & $82.92(9.36)^{*}$ & $13.33(3.98)^{*}$ \\
\hline Bluntnose Minnow & $4.82(1.40)$ & $7.32(2.83)$ & $6.23(1.83)$ & $7.87(1.57)$ & $7.16(2.30)$ & $2.91(1.62)$ \\
\hline Brook Silverside & $26.51(6.14)$ & 39.65 (12.89) & $30.53(5.58)$ & $49.20(7.70)$ & $27.78(4.74)$ & $21.00(12.64)$ \\
\hline Brown Bullhead & $0.65(0.25)$ & $0.16(0.12)$ & $0.38(0.19)$ & $0.03(0.04)$ & $0.42(0.14)$ & $0.88(0.33)$ \\
\hline Creek Chub & $0.06(0.08)$ & $0.00(0)$ & $0.00(0)$ & $0.06(0.08)$ & $0.00(0)$ & $0.00(0)$ \\
\hline Channel Catfish* & $0.15(0.09)^{*}$ & $1.79(0.55)^{*}$ & $5.03(1.12)^{*}$ & $0.47(0.21)$ & $1.79(0.38)$ & $5.39(1.63)$ \\
\hline Common Carp & $0.13(0.09)$ & $0.38(0.19)$ & $2.55(0.66)$ & $0.41(0.20)$ & $1.85(0.49)$ & $1.27(0.79)$ \\
\hline Emerald Shiner* & $17.91(5.89)^{*}$ & $5.16(1.18)^{*}$ & $109.20(26.03)^{*}$ & $24.08(9.27)$ & $78.70(25.06)$ & $52.15(13.17)$ \\
\hline Fantail Darter & $0.11(0.12)$ & $0.00(0)$ & $0.00(0)$ & $0.09(0.12)$ & $0.00(0)$ & $0.00(0)$ \\
\hline Flathead Catfish & $0.06(0.04)$ & $0.00(0)$ & $0.00(0)$ & $0.00(0)$ & $0.03(0.02)$ & $0.00(0)$ \\
\hline Freshwater Drum & $0.03(0.04)$ & $0.13(0.11)$ & $0.00(0)$ & $0.16(0.12)$ & $0.00(0)$ & $0.00(0)$ \\
\hline Gizzard Shad* & $0.72(0.32)^{*}$ & $1.57(0.50)^{*}$ & $9.83(1.96)^{*}$ & $4.42(1.05)$ & $8.19(1.89)$ & $2.73(0.90)$ \\
\hline Golden Redhorse* & $3.47(1.00)$ & $9.49(2.16)$ & $8.40(1.42)$ & $2.42(0.90)^{*}$ & $5.30(1.23)^{*}$ & $12.15(2.17)^{*}$ \\
\hline Golden Shiner & $0.09(0.07)$ & $0.03(0.04)$ & $0.90(0.30)$ & $0.45(0.27)$ & $0.49(0.22)$ & $0.36(0.22)$ \\
\hline Greenside Darter & $0.00(0)$ & $0.16(0.12)$ & $0.15(0.15)$ & $0.00(0)$ & $0.29(0.17)$ & $0.00(0)$ \\
\hline Green Sunfish* & $2.24(0.61)^{*}$ & $31.89(4.67)^{*}$ & $62.03(12.13)^{*}$ & $50.11(7.49)^{*}$ & $62.89(11.72) *$ & $2.88(0.68)^{*}$ \\
\hline Hybrid Sunfish & $0.16(0.10)$ & $0.82(0.37)$ & $0.60(0.20)$ & $1.00(0.49)$ & $0.54(0.17)$ & $0.18(0.16)$ \\
\hline Johnny Darter & $0.54(0.22)$ & $0.82(0.23)$ & $1.20(0.29)$ & $1.10(0.28)$ & $1.00(0.26)$ & $0.64(0.26)$ \\
\hline
\end{tabular}




\begin{tabular}{|c|c|c|c|c|c|c|}
\hline Largemouth Bass* & $8.26(1.50)^{*}$ & $11.88(1.97)^{*}$ & $30.15(3.73)^{*}$ & $33.29(3.48)^{*}$ & $25.94(3.22)^{*}$ & $1.64(0.50)^{*}$ \\
\hline Logperch* & $15.52(5.09)$ & $44.25(5.14)$ & $31.64(5.26)$ & $37.04(5.43)^{*}$ & $21.36(2.58)^{*}$ & $33.64(8.14)^{*}$ \\
\hline Mimic Shiner* & $0.06(0.04)$ & $70.80(25.73)$ & 39.08 (16.97) & $1.39(0.65)^{*}$ & $5.18(2.96)^{*}$ & $94.09(34.26)^{*}$ \\
\hline Muskellunge & $0.00(0)$ & $0.00(0)$ & $0.23(0.17)$ & $0.14(0.12)$ & $0.18(0.15)$ & $0.00(0)$ \\
\hline Northern Hogsucker & $0.88(0.27)$ & $0.60(0.28)$ & $0.30(0.18)$ & $0.39(0.20)$ & $0.78(0.26)$ & $0.36(0.17)$ \\
\hline Popeye Shiner & $0.00(0)$ & $1.25(0.51)$ & $0.00(0)$ & $0.00(0)$ & $0.00(0)$ & $0.91(0.51)$ \\
\hline Pumpkinseed* & $5.03(1.01)^{*}$ & $7.10(2.24)^{*}$ & $24.83(5.49)^{*}$ & $3.46(0.67)^{*}$ & $27.12(4.94)^{*}$ & $8.94(4.30)^{*}$ \\
\hline Rainbow Darter & $0.07(0.05)$ & $0.41(0.16)$ & $0.45(0.18)$ & $0.77(0.23)$ & $0.27(0.13)$ & $0.09(0.11)$ \\
\hline River Chub & $0.04(0.04)$ & $0.41(0.25)$ & $0.15(0.10)$ & $0.00(0)$ & $0.04(0.03)$ & $0.45(0.29)$ \\
\hline Rock Bass* & $3.19(0.76)^{*}$ & $11.85(1.73)^{*}$ & $14.55(2.28)^{*}$ & $6.10(1.10)^{*}$ & $5.43(0.68)^{*}$ & $19.42(3.25)^{*}$ \\
\hline Silver Shiner* & $0.00(0)^{*}$ & $4.01(1.01)^{*}$ & $9.38(3.12)^{*}$ & $13.02(4.54)$ & $3.58(1.32)$ & $2.24(0.86)$ \\
\hline Smallmouth Bass* & $2.90(0.75)^{*}$ & $27.80(6.06)^{*}$ & $39.30(3.90) *$ & $6.38(0.96)^{*}$ & $18.46(2.26)^{*}$ & $48.33(6.62)^{*}$ \\
\hline Spotfin Shiner & $0.29(0.14)$ & $5.01(1.01)$ & $1.05(0.56)$ & $0.31(0.17)$ & $2.26(0.66)$ & $2.61(0.90)$ \\
\hline Spotted Bass* & $1.98(1.14)^{*}$ & $16.99(1.97)^{*}$ & $18.45(1.81)^{*}$ & $20.91(2.26)^{*}$ & $14.86(1.88)^{*}$ & $7.12(1.28)^{*}$ \\
\hline Walleye* & $0.00(0)^{*}$ & $1.54(0.68)^{*}$ & $2.93(0.69)^{*}$ & $0.67(0.32)$ & $1.92(0.49)$ & $2.30(0.97)$ \\
\hline White Bass* & $0.16(0.13)^{*}$ & $1.13(0.45)^{*}$ & $9.00(1.83)^{*}$ & $0.82(0.32)$ & 5.88 (1.29) & $5.42(2.15)$ \\
\hline White Sucker & $0.10(0.12)$ & $0.00(0)$ & $0.08(0.07)$ & $0.00(0)$ & $0.14(0.10)$ & $0.00(0)$ \\
\hline Yellow Bullhead & $1.04(0.22)$ & $2.22(0.46)$ & $1.80(0.39)$ & $0.93(0.33)$ & $2.25(0.35)$ & $1.67(0.46)$ \\
\hline Yellow Perch* & $2.70(0.87)^{*}$ & $4.48(1.18)^{*}$ & $17.63(2.80)^{*}$ & 4.06 (1.07) & $11.41(2.37)$ & $12.73(2.81)$ \\
\hline
\end{tabular}


Table 2.4. Mean relative abundance of species captured from 1952-1977.

\begin{tabular}{lc}
\hline \multicolumn{1}{c}{ Species } & Relative Abundance (\% catch) \\
\hline Brown Bullhead & $56 \%$ \\
White Sucker & $26 \%$ \\
Largemouth Bass & $7 \%$ \\
Bluegill & $4 \%$ \\
Black Crappie & $3 \%$ \\
Rock Bass & $2 \%$ \\
Green Sunfish & $1 \%$ \\
Northern Hogsucker & $1 \%$ \\
Channel Catfish & $<1 \%$ \\
Golden Redhorse & $<1 \%$ \\
Pumpkinseed & $<1 \%$ \\
Common Carp & $<1 \%$ \\
Yellow Bullhead & $<1 \%$ \\
Logperch & $<1 \%$ \\
Johnny Darter & $<1 \%$ \\
\hline
\end{tabular}

Table 2.5. Analysis of deviance and variance table from generalized linear mixed model analyses for overall fish abundance and species richness. Asterisk * indicates statistical significance at $\alpha=0.05$.

\begin{tabular}{|c|c|c|c|c|}
\hline & \multicolumn{2}{|c|}{ Large Fish Abundance (CPUE) } & \multicolumn{2}{|c|}{ Species Richness } \\
\hline & Chi-square & $\mathrm{p}$-value & Chi-square & $\mathrm{p}$-value \\
\hline Year & 15.374 & $<0.001^{*}$ & 0.0122 & $<0.726$ \\
\hline Region & 20.542 & $<0.001^{*}$ & 13.322 & $<0.01 *$ \\
\hline Year*Region & 20.411 & $<0.001^{*}$ & 13.286 & $<0.01 *$ \\
\hline
\end{tabular}


Table 2.6. Results of mvabund analysis of fish community composition changes. Species with significant contribution to the parameter deviance are listed with percent contribution provided in parentheses. Asterisk * indicates statistical significance at $\alpha=$ 0.05 .

\begin{tabular}{|c|c|c|c|c|c|}
\hline Parameter & Residuals DF & DF & Deviance & $\mathrm{p}$-value & Significant Species \\
\hline Year & 182 & 1 & 415.7 & $0.001^{*}$ & $\begin{array}{c}\text { Smallmouth Bass (20.2\%), Green Sunfish (12.8\%), } \\
\text { White Bass (8.5\%), Spotted Bass (8.2\%), Channel } \\
\text { Catfish (5.5\%), Gizzard Shad (5.0\%), Rock Bass } \\
(4.9 \%), \text { Emerald Shiner (4.4\%), Yellow Perch } \\
(4.2 \%), \text { Pumpkinseed (4.1\%), Silver Shiner (4.0\%), } \\
\text { Largemouth Bass (3.8\%), Black Crappie (2.5\%), } \\
\text { Walleye (2.4\%) }\end{array}$ \\
\hline Zone & 179 & 3 & 659.5 & $0.002 *$ & $\begin{array}{l}\text { Largemouth Bass (17.0\%), Bluegill (12.5\%), } \\
\text { Smallmouth Bass (11.7\%), Green Sunfish (10.3\%), } \\
\text { Mimic Shiner (9.0\%), Logperch (5.3\%), Golden } \\
\text { Redhorse (5.2\%), Pumpkinseed (4.9\%), Rock Bass } \\
(3.4 \%) \text {, Black Crappie (2.9\%), Spotted Bass (2.8\%) }\end{array}$ \\
\hline Year*Zone & 176 & 3 & 219.9 & $0.006^{*}$ & $\begin{array}{c}\text { Black Crappie (14.8\%), Green Sunfish }(9.8 \%), \\
\text { Smallmouth Bass (9.2\%), Largemouth Bass (8.6\%), } \\
\text { Yellow Perch (8.5\%) }\end{array}$ \\
\hline
\end{tabular}


Figure 2.1. Biomonitoring sampling locations for Cheat Lake.

Figure 2.2. Temporal trends in water quality for main Cheat Lake and embayments (1956 - 2016). Gray bars represent mean annual pH. Black bars overlayed on gray bars represent minimum annual $\mathrm{pH}$. The black line transecting all bars highlights $\mathrm{pH}$ of 6.0.

Figure 2.3. Temporal trends in species richness by lake zone. Black dots represent mean annual species richness. Standard error bars are given.

Figure 2.4. GLMM model predicted values of species richness by lake zone over time (1990-2015). E = Embayment Zone, $L=$ Lower Lake Zone, $M=$ Middle Lake Zone, $R=$ Riverine Zone. Colored lines represent model predicted values of species richness. Colored bands represent $95 \%$ confidence intervals for species richness value predictions.

Figure 2.5. Temporal trends in electrofishing CPUE (fish/hr.) by lake zone for large bodied fishes in Cheat Lake (1990 - 2015). Main lake zone = lower lake and middle lake combined. Standard error bars are given.

Figure 2.6. GLMM model predicted values of fish abundance (CPUE (fish/hr.)) by lake zone over time (1990-2015). E = Embayment Zone, $\mathrm{L}=$ Lower Lake Zone, $\mathrm{M}=$ Middle Lake Zone, $\mathrm{R}$ = Riverine Zone. Colored lines represent model predicted values of CPUE. Colored bands represent $95 \%$ confidence intervals for CPUE value predictions. 
Figure 2.7. Temporal trends in electrofishing CPUE (fish/hr.) for Smallmouth Bass in Cheat Lake (1990-2015). Standard error bars are given.

Figure 2.8. Temporal trends in gill net CPUE (fish/net-night) for Channel Catfish and Brown Bullhead (1990-2015). Standard error bars are given.

Figure 2.9. NMDS results plotted by year using Cheat Lake fish survey presence/absence data from 1952-1977 and 1990-2015.

Figure 2.10. NMDS results plotted by lake zone (Riverine, Middle Lake, Lower Lake, and Embayments) for electrofishing survey CPUE data (fish/hr.) on Cheat Lake.

Figure 2.11. NMDS results plotted by year (1990-2015) for electrofishing survey CPUE data (fish/hr.) on Cheat Lake. 


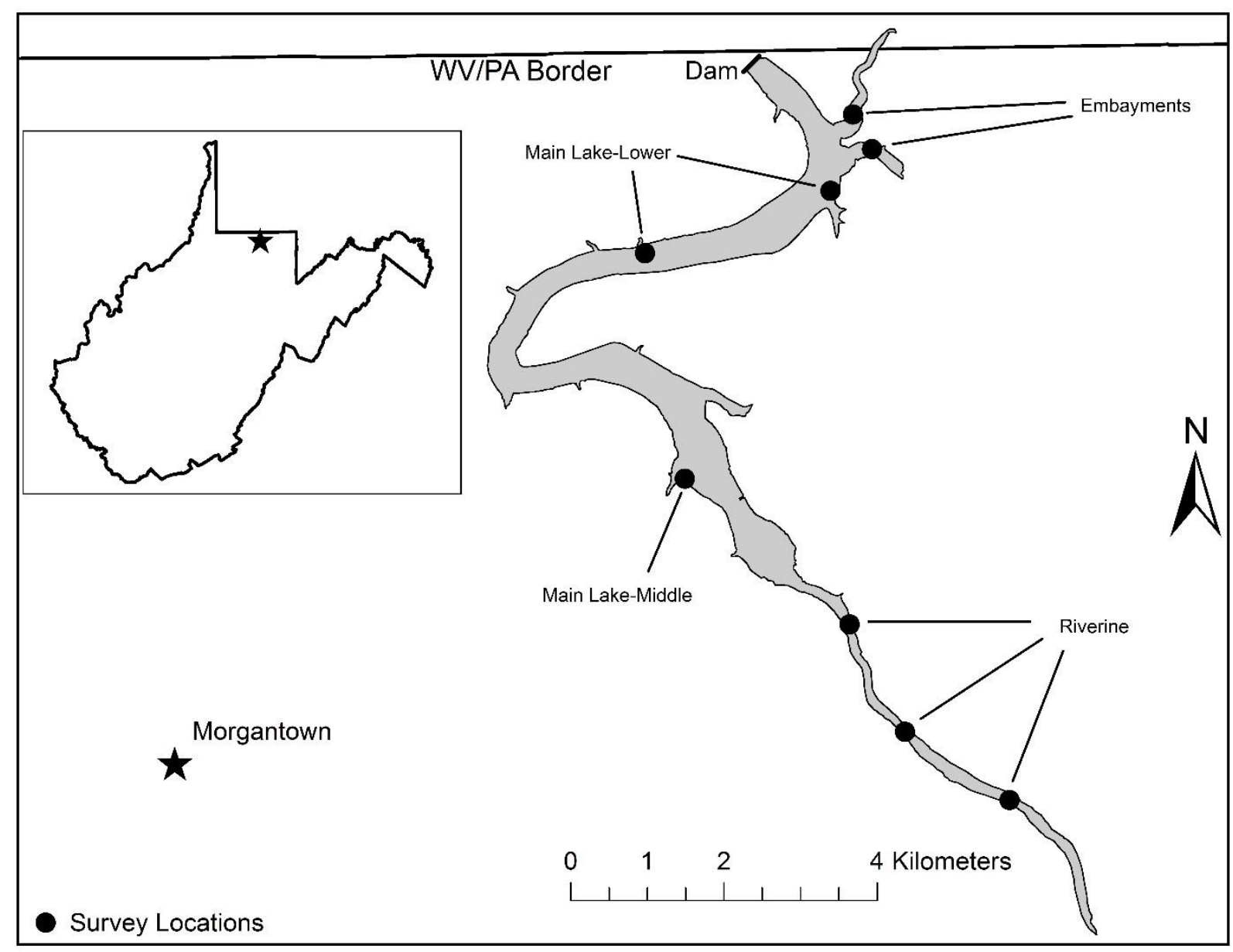



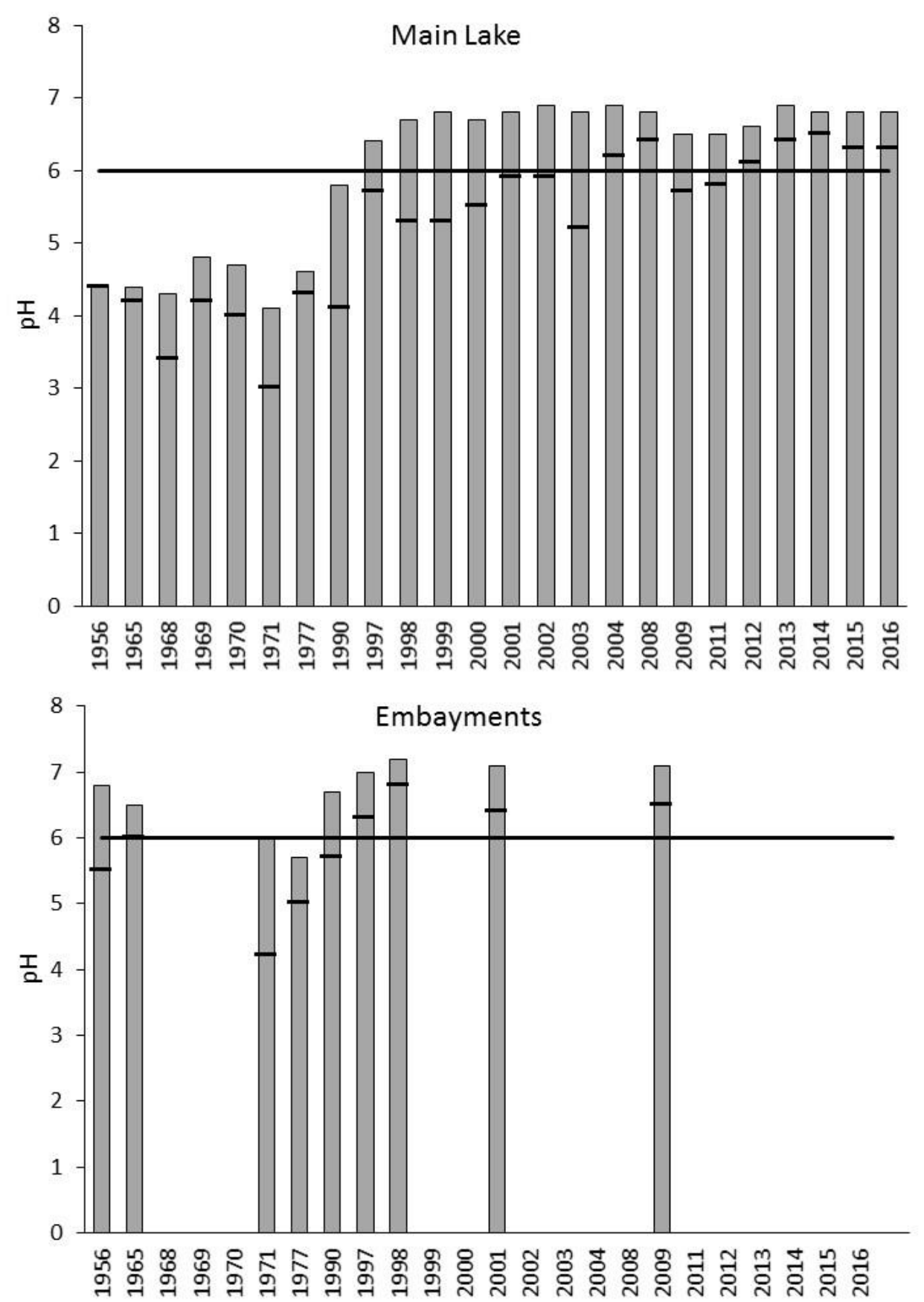

$\square$ mean pH - minimum pH $-\mathrm{pH} 6.0$ 
Embayment Zone

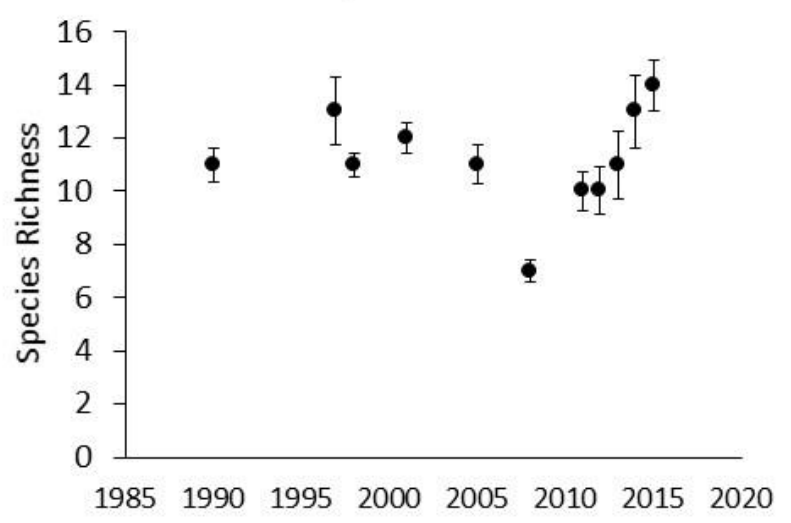

Middle Lake Zone

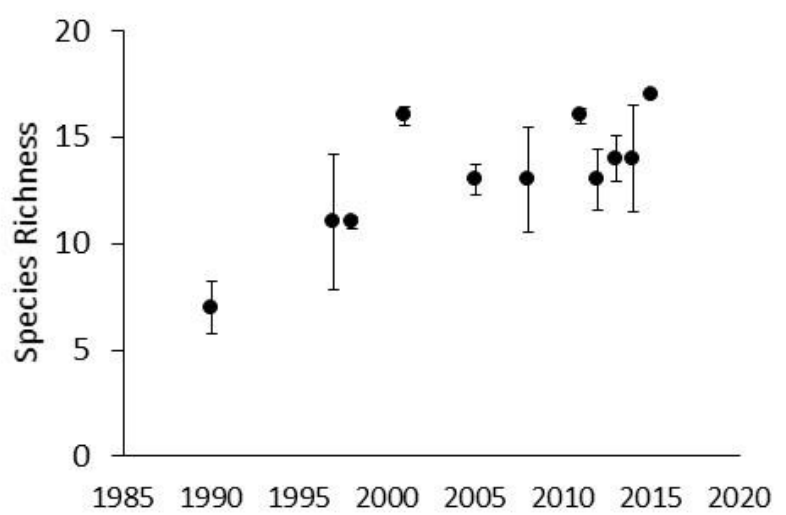

Lower Lake Zone
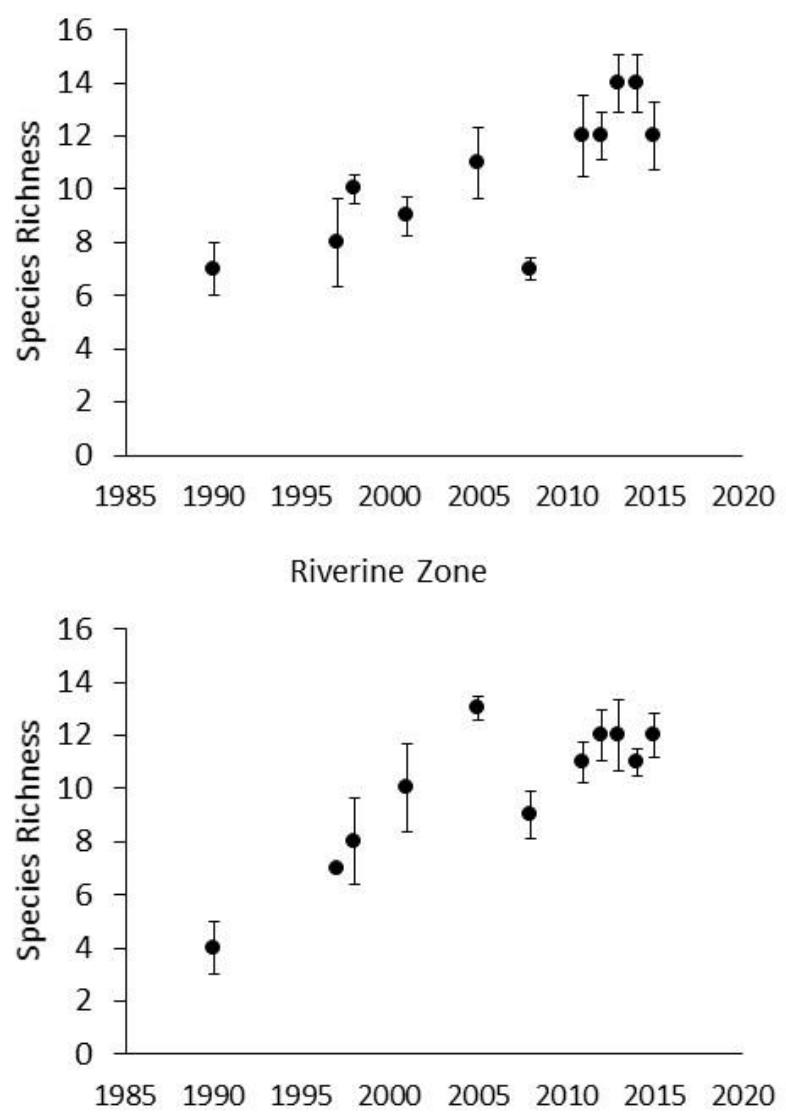


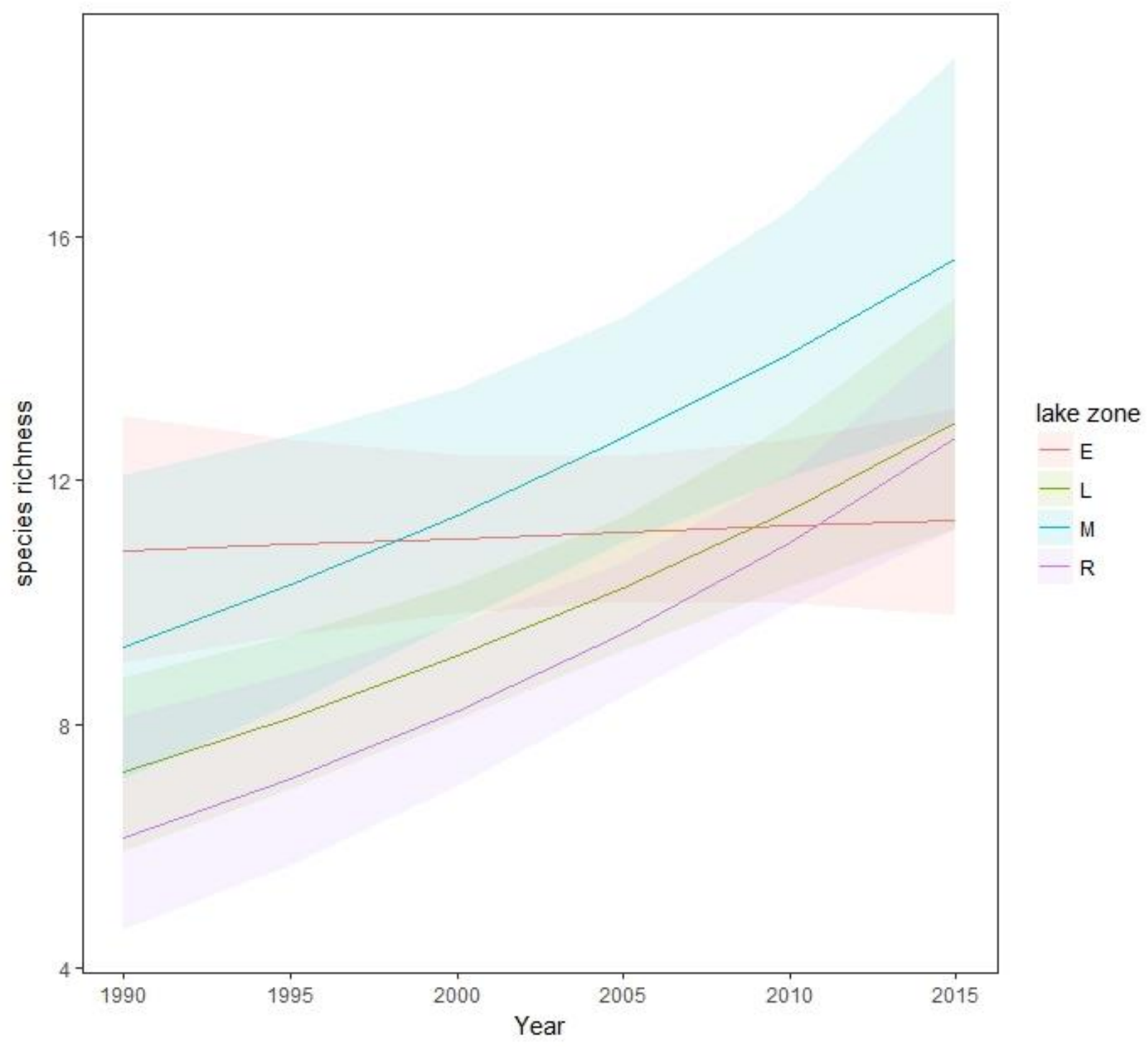



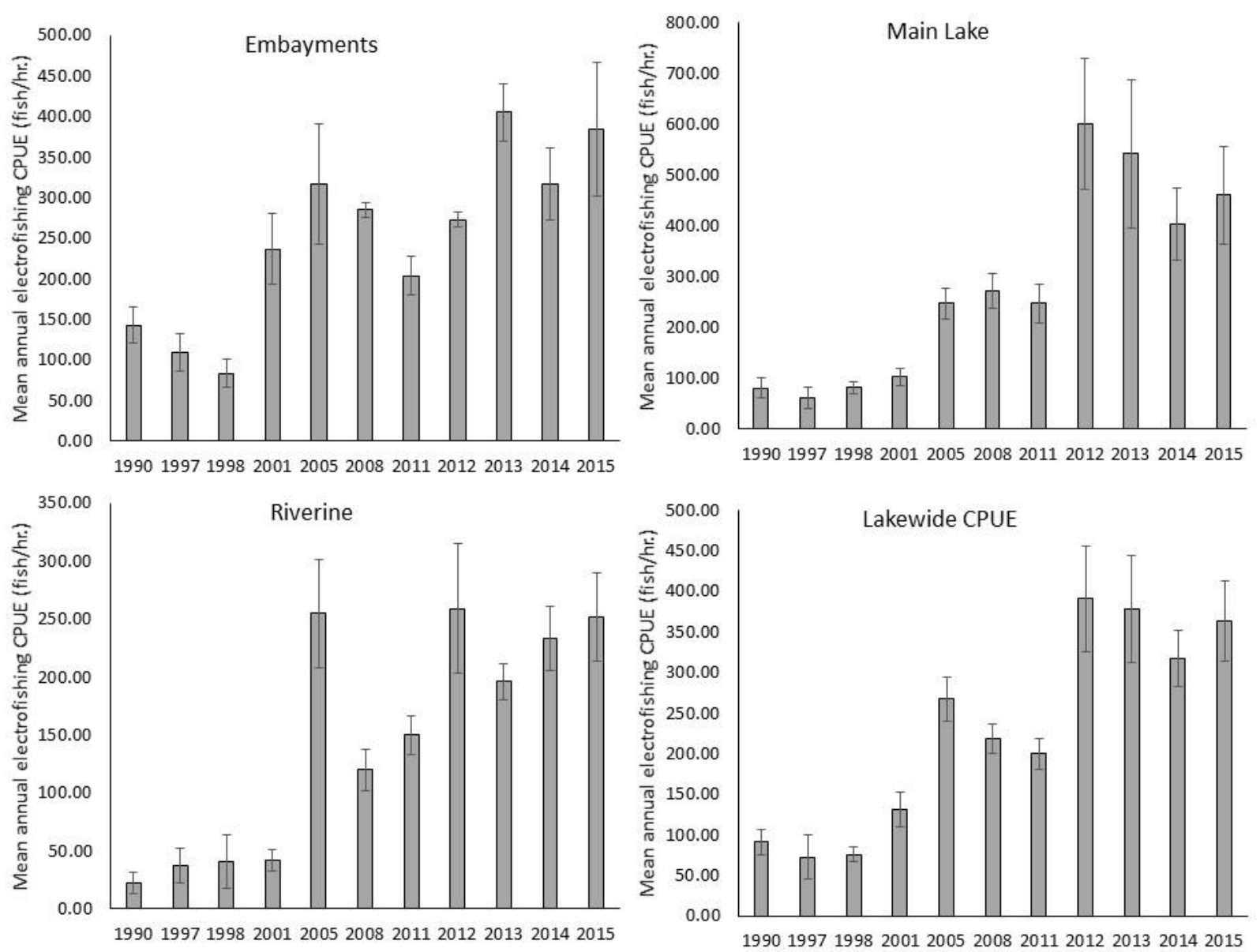


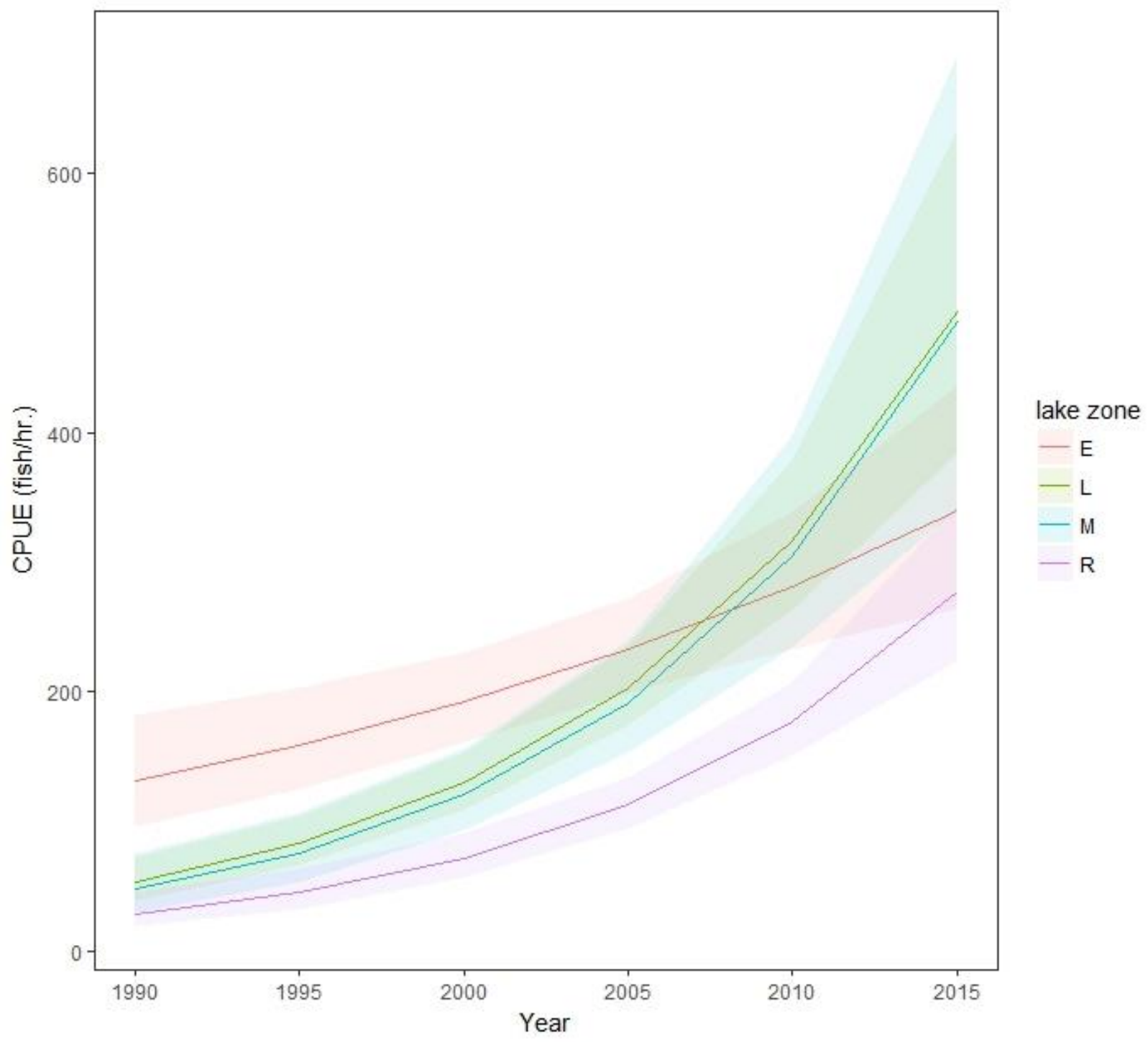




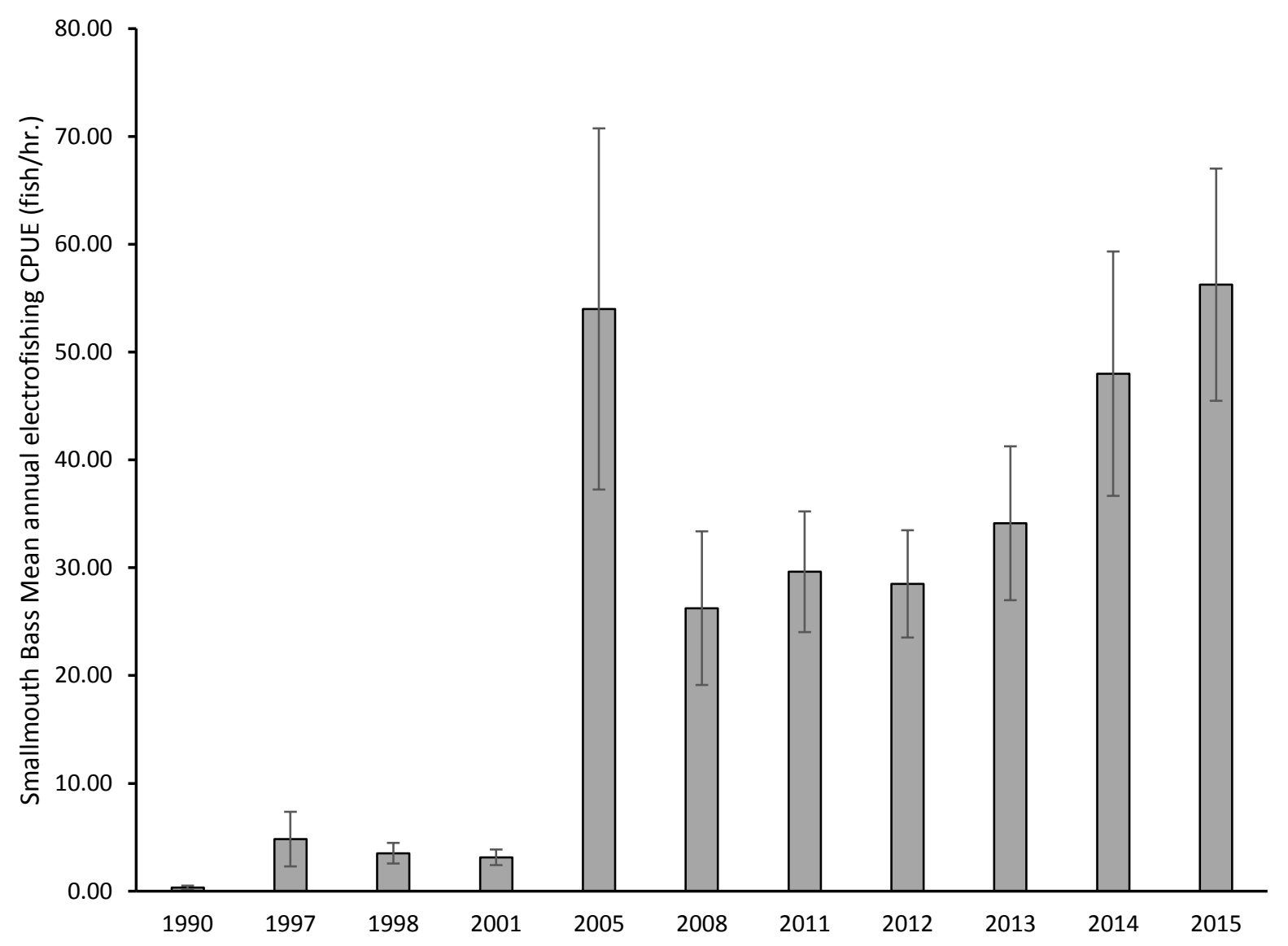




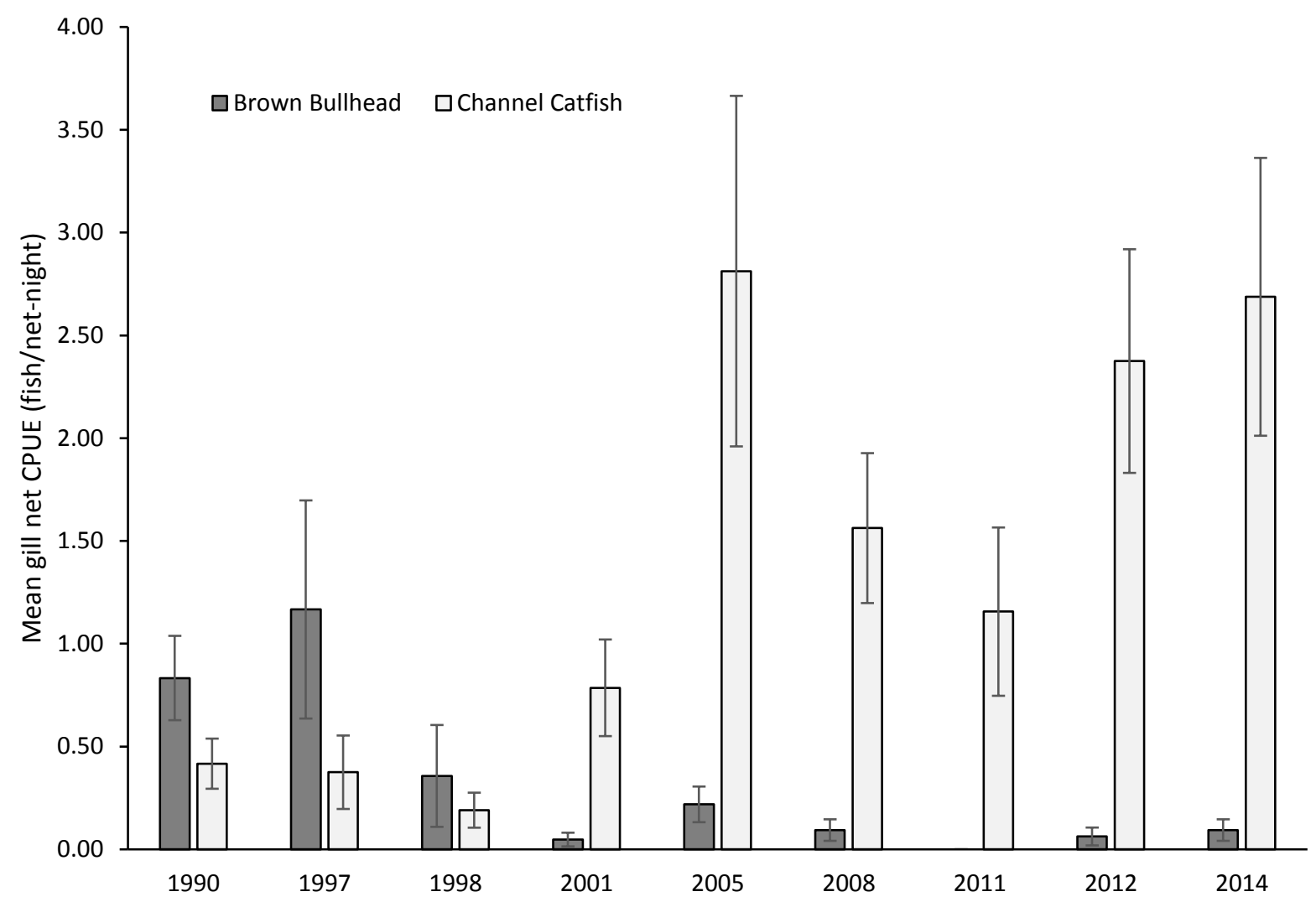



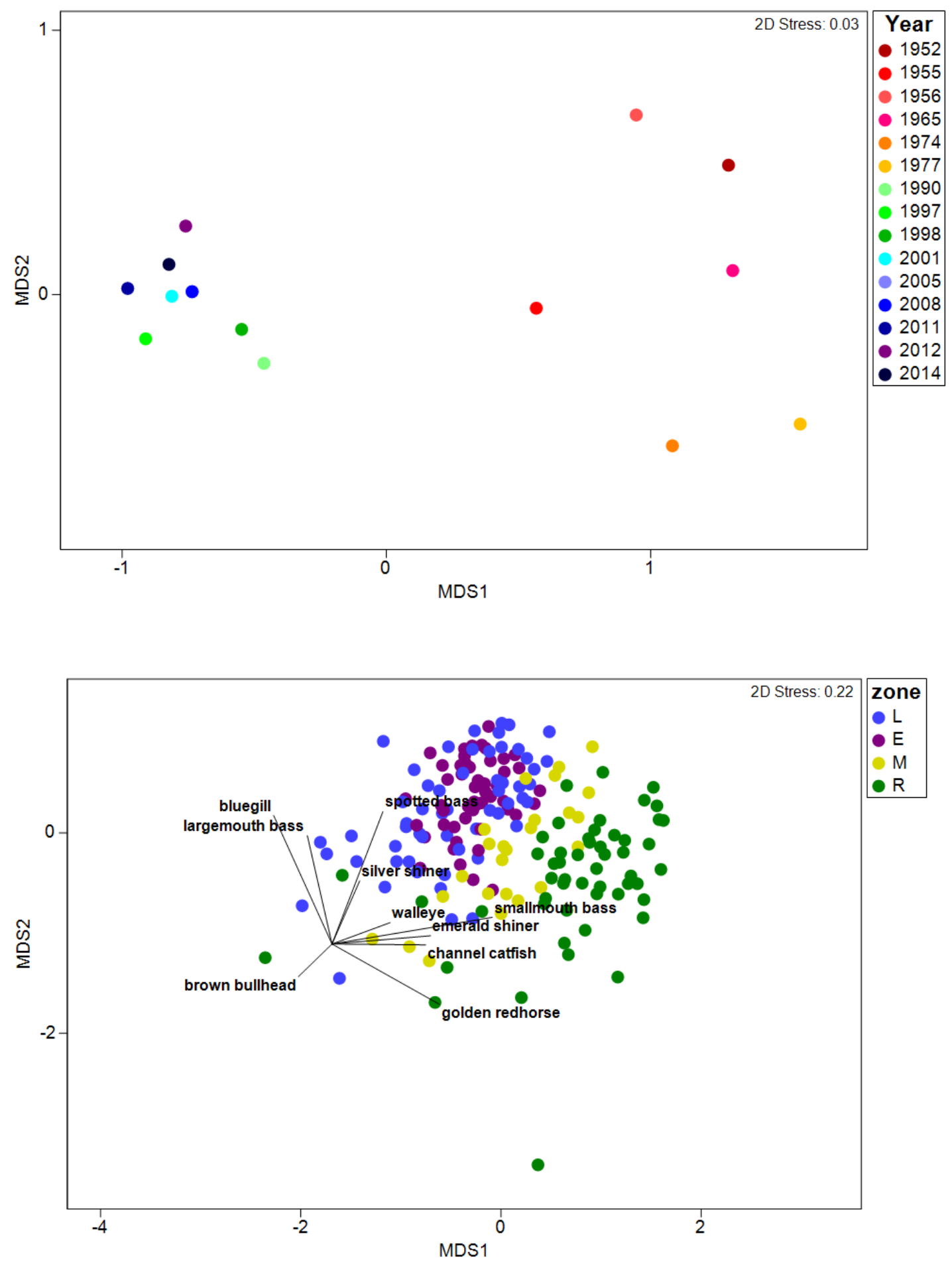


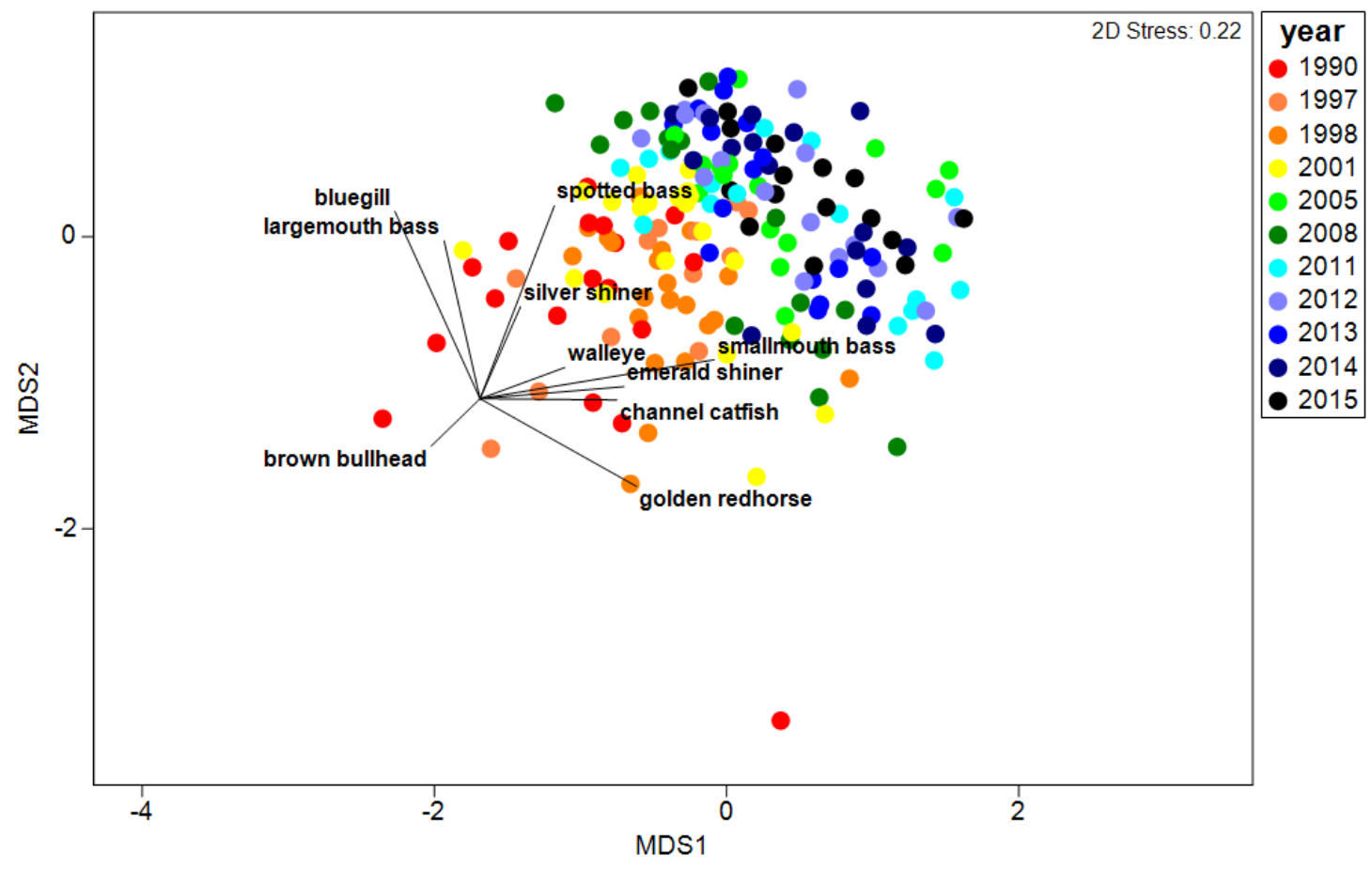


Appendix 2.1. Temporal trends in mean annual CPUE (fish/hr.) by species for Cheat Lake using electrofishing survey data for years sampled.

\begin{tabular}{|c|c|c|c|c|c|c|c|c|c|c|c|c|}
\hline Species & 1990 & 1997 & 1998 & 2001 & 2005 & 2008 & 2011 & 2012 & 2013 & 2014 & 2015 & Total \\
\hline Banded Darter & 0.00 & 0.00 & 0.00 & 0.00 & 0.00 & 0.38 & 0.00 & 0.00 & 0.00 & 0.00 & 0.00 & 0.03 \\
\hline Black Crappie & 2.22 & 0.17 & 0.10 & 0.57 & 3.00 & 0.00 & 3.00 & 6.00 & 6.38 & 13.50 & 4.88 & 3.51 \\
\hline Bluegill & 56.56 & 42.8 & 39.24 & 78.76 & 76.88 & 64.9 & 42.00 & 108.00 & 96.75 & 59.25 & 82.88 & 66.30 \\
\hline Bluntnose Minnow & 4.56 & 6.58 & 3.33 & 6.57 & 13.88 & 1.50 & 10.88 & 7.13 & 3.38 & 3.00 & 6.75 & 6.26 \\
\hline Brook Silverside & 9.11 & 36.5 & 33.90 & 22.19 & 67.50 & 29.25 & 27.38 & 23.63 & 13.13 & 37.88 & 50.63 & 29.87 \\
\hline Brown Bullhead & 1.78 & 0.17 & 0.00 & 0.10 & 0.00 & 0.38 & 0.00 & 0.38 & 0.75 & 0.75 & 0.00 & 0.39 \\
\hline Creek Chub & 0.00 & 0.00 & 0.19 & 0.00 & 0.00 & 0.00 & 0.00 & 0.00 & 0.00 & 0.00 & 0.00 & 0.02 \\
\hline Channel Catfish & 0.11 & 0.33 & 0.00 & 0.86 & 1.88 & 2.63 & 5.63 & 7.13 & 3.00 & 3.00 & 6.38 & 2.71 \\
\hline Common Carp & 0.11 & 0.00 & 0.29 & 0.38 & 0.38 & 0.38 & 3.00 & 0.75 & 3.00 & 3.00 & 3.00 & 1.26 \\
\hline Emerald Shiner & 6.44 & 33 & 14.29 & 0.86 & 1.13 & 13.5 & 159.75 & 59.25 & 31.50 & 157.50 & 138.00 & 53.09 \\
\hline Fantail Darter & 0.00 & 0.33 & 0.00 & 0.00 & 0.00 & 0.00 & 0.00 & 0.00 & 0.00 & 0.00 & 0.00 & 0.04 \\
\hline Flathead Catfish & 0.00 & 0.17 & 0.00 & 0.00 & 0.00 & 0.00 & 0.00 & 0.00 & 0.00 & 0.00 & 0.00 & 0.01 \\
\hline Freshwater Drum & 0.00 & 0.08 & 0.00 & 0.00 & 0.38 & 0.00 & 0.00 & 0.00 & 0.00 & 0.00 & 0.00 & 0.04 \\
\hline Gizzard Shad & 0.56 & 0.00 & 1.62 & 2.10 & 1.88 & 0.75 & 13.88 & 4.13 & 13.13 & 8.63 & 9.38 & 4.98 \\
\hline Golden Redhorse & 1.78 & 1 & 7.62 & 4.86 & 13.88 & 9.75 & 9.00 & 13.13 & 8.25 & 9.00 & 2.63 & 7.39 \\
\hline Golden Shiner & 0.11 & 0.17 & 0.00 & 0.10 & 0.00 & 0.00 & 0.38 & 0.00 & 0.38 & 3.38 & 0.38 & 0.43 \\
\hline Greenside Darter & 0.00 & 0.00 & 0.00 & 0.10 & 0.00 & 0.38 & 0.00 & 0.00 & 0.00 & 0.75 & 0.00 & 0.11 \\
\hline Green Sunfish & 2.11 & 3 & 1.62 & 9.81 & 26.63 & 59.25 & 19.50 & 56.63 & 111.75 & 47.63 & 74.63 & 35.24 \\
\hline Hybrid Sunfish & 0.11 & 0.00 & 0.38 & 0.57 & 0.00 & 1.88 & 0.00 & 0.38 & 1.13 & 1.50 & 0.00 & 0.54 \\
\hline Johnny Darter & 0.44 & 1.08 & 0.10 & 0.57 & 0.00 & 1.88 & 0.38 & 0.75 & 1.50 & 1.13 & 2.25 & 0.85 \\
\hline Largemouth Bass & 11.67 & 4.17 & 8.95 & 7.14 & 18.00 & 10.5 & 23.25 & 40.50 & 30.38 & 35.63 & 21.00 & 18.85 \\
\hline Logperch & 4.56 & 29.42 & 12.57 & 18.76 & 47.25 & 66.75 & 14.63 & 29.63 & 19.44 & 29.25 & 65.25 & 27.98 \\
\hline Mimic Shiner & 0.00 & 0.17 & 0.00 & 3.90 & 186.75 & 21.75 & 71.63 & 63.75 & 10.13 & 7.13 & 42.75 & 34.24 \\
\hline Muskellunge & 0.00 & 0.00 & 0.00 & 0.00 & 0.00 & 0.00 & 0.00 & 0.00 & 0.00 & 1.13 & 0.00 & 0.10 \\
\hline Northern Hogsucker & 0.56 & 1.33 & 0.76 & 0.29 & 1.50 & 0.00 & 0.00 & 0.00 & 0.00 & 1.13 & 0.38 & 0.54 \\
\hline Popeye Shiner & 0.00 & 0.00 & 0.00 & 0.00 & 0.38 & 3.38 & 0.00 & 0.00 & 0.00 & 0.00 & 0.00 & 0.23 \\
\hline Pumpkinseed & 7.11 & 4.08 & 3.90 & 1.43 & 13.13 & 6.75 & 7.88 & 57.38 & 16.13 & 22.13 & 20.63 & 14.17 \\
\hline
\end{tabular}




\begin{tabular}{lcccccccccccc} 
Rainbow Darter & 0.11 & 0.00 & 0.10 & 0.10 & 0.38 & 0.75 & 0.00 & 0.38 & 0.00 & 1.50 & 0.38 & 0.29 \\
River Chub & 0.11 & 0.00 & 0.00 & 0.10 & 1.13 & 0.00 & 0.00 & 0.00 & 0.00 & 0.00 & 0.75 & 0.18 \\
Rock Bass & 1.67 & 4.75 & 3.14 & 7.05 & 18.00 & 10.5 & 9.38 & 11.25 & 13.13 & 18.75 & 20.25 & 10.61 \\
Silver Shiner & 0.00 & 0.00 & 0.00 & 1.90 & 7.13 & 3 & 1.50 & 1.13 & 15.75 & 21.00 & 7.50 & 4.98 \\
Smallmouth Bass & 0.33 & 4.83 & 3.52 & 3.14 & 54.00 & 26.25 & 29.63 & 28.50 & 34.13 & 48.00 & 56.25 & 25.13 \\
Spotfin Shiner & 0.22 & 0.08 & 0.57 & 2.29 & 7.88 & 4.88 & 4.50 & 0.00 & 0.38 & 0.00 & 0.38 & 1.76 \\
Spotted Bass & 0.00 & 4.5 & 1.43 & 9.71 & 23.25 & 18 & 12.75 & 25.88 & 24.00 & 14.63 & 15.00 & 12.90 \\
Walleye & 0.00 & 0.00 & 0.00 & 1.24 & 3.00 & 0.38 & 4.88 & 2.25 & 0.75 & 2.25 & 4.50 & 1.71 \\
White Bass & 0.00 & 0.00 & 0.48 & 0.00 & 3.00 & 0.38 & 8.63 & 14.25 & 5.25 & 7.13 & 9.75 & 4.26 \\
White Sucker & 0.00 & 0.00 & 0.29 & 0.00 & 0.00 & 0.00 & 0.38 & 0.00 & 0.00 & 0.00 & 0.00 & 0.07 \\
Yellow Bullhead & 0.78 & 1.58 & 0.76 & 1.05 & 3.00 & 2.63 & 0.75 & 1.88 & 2.25 & 1.88 & 2.25 & 1.66 \\
Yellow Perch & 4.44 & 1 & 2.67 & 2.95 & 7.50 & 3.00 & 9.00 & 13.13 & 10.50 & 22.88 & 32.63 & 9.76 \\
\hline
\end{tabular}


Appendix 2.2. Temporal trends in mean annual CPUE (fish/net-night) by species for Cheat Lake using gill net survey data for years sampled.

\begin{tabular}{|c|c|c|c|c|c|c|c|c|c|c|}
\hline Species & 1990 & 1997 & 1998 & 2001 & 2005 & 2008 & 2011 & 2012 & 2014 & Total \\
\hline Black Crappie & 1.08 & 0.25 & 0.07 & 0.69 & 0.59 & 0.25 & 0.03 & 0.25 & 0.50 & 0.42 \\
\hline Black Redhorse & 0.00 & 0.00 & 0.00 & 0.00 & 0.00 & 0.06 & 0.00 & 0.00 & 0.00 & 0.01 \\
\hline Bluegill & 0.03 & 0.04 & 0.02 & 0.02 & 0.03 & 0.00 & 0.09 & 0.03 & 0.00 & 0.03 \\
\hline Brown Bullhead & 0.83 & 1.17 & 0.36 & 0.05 & 0.22 & 0.09 & 0.00 & 0.06 & 0.09 & 0.30 \\
\hline Channel Catfish & 0.42 & 0.38 & 0.19 & 0.79 & 2.81 & 1.56 & 1.16 & 2.38 & 2.69 & 1.33 \\
\hline Common Carp & 0.11 & 0.29 & 0.07 & 0.05 & 0.09 & 0.00 & 0.06 & 0.44 & 0.13 & 0.13 \\
\hline Creek Chub & 0.00 & 0.00 & 0.00 & 0.00 & 0.00 & 0.00 & 0.00 & 0.00 & 0.03 & 0.00 \\
\hline Freshwater Drum & 0.00 & 0.04 & 0.00 & 0.00 & 0.00 & 0.00 & 0.00 & 0.00 & 0.00 & 0.00 \\
\hline Gizzard Shad & 0.78 & 1.42 & 0.69 & 0.64 & 0.66 & 1.22 & 0.75 & 2.09 & 0.72 & 0.96 \\
\hline Golden Redhorse & 0.44 & 1.25 & 0.17 & 0.40 & 1.09 & 1.09 & 0.59 & 1.31 & 1.06 & 0.77 \\
\hline Green Sunfish & 0.03 & 0.00 & 0.00 & 0.00 & 0.06 & 0.13 & 0.03 & 0.06 & 0.03 & 0.04 \\
\hline Largemouth Bass & 0.47 & 0.46 & 0.14 & 0.07 & 0.13 & 0.16 & 0.03 & 0.34 & 0.22 & 0.21 \\
\hline Muskellunge & 0.00 & 0.00 & 0.00 & 0.00 & 0.00 & 0.00 & 0.00 & 0.00 & 0.03 & 0.00 \\
\hline Northern Hogsucker & 0.03 & 0.04 & 0.02 & 0.00 & 0.00 & 0.03 & 0.00 & 0.00 & 0.03 & 0.02 \\
\hline Northern Pike & 0.03 & 0.04 & 0.02 & 0.02 & 0.00 & 0.00 & 0.00 & 0.00 & 0.00 & 0.01 \\
\hline Pumpkinseed & 0.17 & 0.33 & 0.17 & 0.05 & 0.31 & 0.09 & 0.06 & 0.25 & 0.19 & 0.17 \\
\hline Rainbow Trout & 0.03 & 0.00 & 0.00 & 0.00 & 0.03 & 0.00 & 0.00 & 0.00 & 0.00 & 0.01 \\
\hline Rock Bass & 0.11 & 0.08 & 0.26 & 0.29 & 1.19 & 1.03 & 0.50 & 0.69 & 0.25 & 0.48 \\
\hline Sauger & 0.00 & 0.00 & 0.00 & 0.00 & 0.00 & 0.03 & 0.00 & 0.00 & 0.00 & 0.00 \\
\hline Smallmouth Bass & 0.00 & 0.04 & 0.00 & 0.05 & 0.63 & 0.59 & 0.22 & 0.47 & 0.28 & 0.24 \\
\hline Spotted Bass & 0.00 & 0.04 & 0.02 & 0.02 & 0.53 & 0.13 & 0.19 & 0.63 & 0.41 & 0.21 \\
\hline Striped Bass & 0.00 & 0.00 & 0.00 & 0.00 & 0.00 & 0.00 & 0.03 & 0.00 & 0.00 & 0.00 \\
\hline Walleye & 0.00 & 0.04 & 0.00 & 0.24 & 0.56 & 0.66 & 0.44 & 0.84 & 0.59 & 0.36 \\
\hline White Bass & 0.00 & 0.29 & 0.10 & 0.21 & 0.81 & 2.09 & 1.69 & 0.72 & 0.28 & 0.65 \\
\hline White Sucker & 0.42 & 0.00 & 0.05 & 0.12 & 0.41 & 0.22 & 0.03 & 0.06 & 0.03 & 0.15 \\
\hline Yellow Bullhead & 0.19 & 0.13 & 0.05 & 0.12 & 0.31 & 0.03 & 0.03 & 0.00 & 0.09 & 0.11 \\
\hline Yellow Perch & 0.19 & 0.63 & 0.57 & 0.17 & 1.19 & 0.66 & 0.34 & 1.03 & 0.63 & 0.58 \\
\hline
\end{tabular}




\section{Chapter 3 - Population characteristics of a reestablished reservoir Walleye population}

\section{Abstract}

Walleyes (Sander vitreus) were believed to be extirpated from Cheat Lake and the Cheat River watershed in West Virginia by 1950 due to acid mine drainage pollution. However, after extensive water quality improvements, reestablishment of Walleyes in Cheat Lake began with stocking efforts in 1999. Despite successfully reestablishing Walleyes into Cheat Lake, little is known about the population characteristics of this fishery. Population characteristics were evaluated via gill net and electrofishing survey catch data, age and growth analysis using sagittal otoliths and from diet information collected on captured fish. From 1990-2015, 193 Walleyes were collected with standardized fall gill net sampling and catch data were analyzed for significant temporal changes. An additional 123 Walleyes were captured for age and growth analysis. Three growth models (von Bertanlanffy, logistic, and Gompertz) were fit to length at age data and compared using Akaike's Information Criterion (AIC). Additionally, fall diets were collected from 46 age-1+ fish captured for age and growth analysis. Walleye gill net CPUE significantly increased over time, which was expected given stocking events. Age and growth analyses of male and female Walleyes using the AIC-selected von Bertalannfy growth models suggest that female Walleyes in Cheat Lake grow quickly and reach large maximum sizes compared to males (female $L \infty=754 \mathrm{~mm}$; male $L \infty=502 \mathrm{~mm}$ ). Both male and female Cheat Lake Walleyes reach quality size $(\geq 380 \mathrm{~mm})$ after two years of growth. Males and females began to show differences in growth rate at age-3, with females continuing to grow steadily and male growth slowing down. Age and growth analysis and fall electrofishing provided evidence of increasing natural reproduction, demonstrated by cohorts belonging to year classes without stocking and collection of young of the year when no stocking occurred. Finally, diet contents of 
captured Walleyes suggest that Yellow Perch (Perca flavescens) are an important prey to Cheat Lake Walleyes. Yellow Perch were present in $67 \%$ of Walleye stomachs and were one of the largest prey items consumed on average. Walleye stocking into Cheat Lake has successfully resulted in reestablishing a Walleye population. Walleye growth and size structure is above average in Cheat Lake, potentially due in part to a diverse forage base that includes Yellow Perch. These findings suggest that the reestablishment of Walleyes to Cheat Lake has created a fishery of fast growing individuals that reach large sizes.

\section{Introduction}

Walleyes are large predators of aquatic ecosystems and are popular sportfish to recreational anglers (Quist et al. 2003; Bednarski et al. 2010). Due to their large size and predatory behavior, Walleyes often have a significant influence on the trophic structure of the aquatic ecosystems they inhabit (Pothoven et al. 2016). However, due to their popularity with anglers, Walleyes are often a heavily pressured sportfish which can influence their abundance and size structure (Johnson et al. 2015). Walleyes are widely distributed throughout North America, including both their native range and systems in which they have been introduced (Bozek et al. 2011). Due to their wide range and popularity, Walleye populations have been studied extensively regarding most aspects of their life history (Bozek et al. 2011). However, despite the extensive research that has been conducted on Walleye populations, there can be regional variations in life history and there exist several geographic areas in which Walleye literature is sparse (Bozek et al. 2011).

Walleyes are becoming an increasingly popular sportfish in West Virginia, but limited research has been conducted on Walleyes in West Virginia waters. However, in recent years Walleye research and management have gained increased focus in West Virginia by the West 
Virginia Division of Natural Resources (WVDNR). In 2016, the WVDNR implemented a new Walleye management plan for West Virginia which includes fishing regulation changes aimed at improving Walleye fisheries. Despite increased angler interest and management focus, many West Virginia reservoirs currently only support limited Walleye fisheries that are often dependent on frequent fry or fingerling stockings (WVDNR, unpublished data). Limitations to sustainable Walleye populations could be related to such things as habitat, water quality, forage availability, or angling pressure, most of which remain unknown for West Virginia waters.

Cheat Lake and the Cheat River watershed historically supported a Walleye population (Core 1959). However, poor water quality as a result of acid mine drainage likely extirpated the native Walleye population (Core 1959). As a result of improving water quality, the WVDNR began stocking Walleye fry into Cheat Lake in 1999 (Table 3.1). To increase the likelihood of stocking success, the WVDNR began stocking fingerling Walleyes in 2001 (Table 3.1). Monitoring has been conducted on the Cheat Lake Walleye population to determine if stocking has been successful and if a naturally reproducing population is achievable. Considering their relative sensitivity to poor water quality and status as a large predator, research into population characteristics of Cheat Lake Walleyes also provides valuable information on the benefits of improving water quality that may be applicable in other systems. Research into population characteristics such as trends in abundance, size structure, growth, and recruitment is necessary to effectively manage a pressured population and is valuable in determining the success of stocking efforts (Bednarski et al. 2010; Johnson et al. 2015). In addition, with knowledge of these population characteristics, comparisons can be made to Walleye populations in other West Virginia reservoirs and across North America. Information gained on this population in a unique environmental situation will provide important knowledge for how Walleye populations respond to environmental improvement and subsequent reintroduction 
efforts. Comparisons with other populations can also provide better perspective as to the health and condition of the Cheat Lake Walleye population.

The primary objective of this study was to evaluate the status and describe the population characteristics of the Cheat Lake Walleye population, with emphasis on abundance, size structure, and growth. Specifically, we were interested in determining the trends in relative abundance of Walleyes in Cheat Lake since management efforts began, what contribution (if any) natural reproduction provides to the fishery, and the current age/size structure of the Cheat Lake Walleye population. We also sought to compare abundance, age, growth, and size structure of Cheat Lake Walleyes to other West Virginia reservoirs and to Walleye populations throughout North America.

\section{Methods}

Study Area

Cheat Lake (700 ha), historically impacted by acidification, is a hydropower reservoir located near the West Virginia-Pennsylvania border in Monongalia County, WV. The reservoir was formed in 1926 after damming the Cheat River for hydroelectric needs (Core 1959). The reservoir is characterized by steep slopes and relatively narrow width over most of its area. The reservoir is approximately $21 \mathrm{~km}$ in length and has a maximum depth of $24 \mathrm{~m}$ near the dam. The reservoir also experiences seasonal stratification of water temperature and dissolved oxygen in its lacustrine zone. The reservoir is largely composed of lacustrine habitat, with substrate that is dominated primarily of soft sediments (silt/clay). However, the headwaters of the lake retain riverine characteristics, with a greater influence from incoming river flow and a rockier (sand/gravel/cobble) substrate. 
Cheat Lake and the Cheat River watershed that feeds it have been significantly impacted by acid mine drainage since the formation of the reservoir (Core 1959; Welsh and Perry 1997; Freund and Petty 2007; Merovich et al. 2007). As a result of poor water quality, Walleye and Yellow Perch were believed to be extirpated by the late 1940's (Core 1959). In recent years, the Cheat River watershed and Cheat Lake have seen substantial water quality improvements owing to mitigation efforts throughout the watershed (McClurg et al. 2007; see Chapter 2). Biomonitoring has indicated improving water quality and fish communities within Cheat Lake, likely as a result of mitigation efforts (see Chapter 2). Since 1999, in response to improving water quality conditions and the popularity of Walleye as a sport fish, the WVDNR initiated and has continued stocking of Walleyes in Cheat Lake.

\section{Fish Collection}

Walleyes were collected from Cheat Lake for estimates of relative abundance and size structure using sinking monofilament, multimesh gill nets during November in the years of 2005, 2008, and annually from 2012-2015. Additional data on Walleye abundance for temporal comparison were available from biomonitoring surveys in 1990, 1997, 1998, 2001, and 2011 in which October sampling with experimental gill nets was conducted. Monitoring sites included six stations positioned throughout Cheat Lake (Figure 3.1). One to two gill nets were set at each site (one per site during November Walleye surveys, two per site during October biomonitoring surveys) perpendicular to the shoreline. Gill nets used were $45.7 \mathrm{~m}$ in length and $1.8 \mathrm{~m}$ deep with six $7.6 \mathrm{~m}$ panels of $38,51,64,38,51$, and $64 \mathrm{~mm}$ bar mesh. Nets were set prior to sunset and retrieved after sunrise the following day resulting in a soak time of approximately 12 hours. We also used fall electrofishing data from biomonitoring surveys from 1990-2015 for evaluation of young-of-the-year (YOY) and evidence of natural reproduction. Fall electrofishing surveys 
were conducted at night, and consisted of 10-15 minute transects per station depending on year. Due to variation in sampling effort, catch per unit effort of YOY Walleyes was calculated as fish per hour. Separate sampling was conducted to collect Walleyes for age, growth and diet analysis. Walleyes were collected for age, growth and diet analysis from 9 October 2013 to 22 November 2013 and from 25 September 2014 to 14 November 2014 using gill nets (of the same dimensions above) and night boat electrofishing. Gill nets were the primary method of capture for age and growth analysis, but electrofishing was used to more effectively capture YOY.

\section{Laboratory Processing}

Walleyes collected for age, growth, and diet analysis were immediately placed on ice to preserve specimens and slow the digestion of stomach contents. Sex was determined from captured fish through dissection and examination of gonads. Sagittal otoliths were removed from captured fish, cleaned of soft tissue, and placed dry into coin envelopes. Otoliths were prepared for aging by cracking them in half perpendicular to their longitudinal axis (Kocovsky and Carline 2001; Bednarski et al. 2010). We sanded otoliths using 400 or 600 grit wet/dry sandpaper and polished them with 1200 and/or 2500 grit sandpaper to improve visibility of annuli (Bednarski et al. 2010; Hilling et al. 2016). Otoliths were then placed in a basin of black modeling clay filled with water with the fractured side up to improve clarity (Taylor 2013). Otoliths were viewed under a dissecting scope at 20-40x magnification. Two readers independently viewed otoliths and counted annuli to estimate age. If readers disagreed on an age, then otoliths were examined by both readers in concert until a consensus age was reached (Kocovsky and Carline 2001).

We collected diet data on age-1+ and older Walleyes that were captured for age and growth analysis. Diet contents were examined by removing stomach contents, identifying 
consumed prey to the lowest practical taxonomic level, counting prey items and recording an approximate total length of prey fish consumed. Empty stomachs were noted and excluded from further analysis. All stomach contents were excised and processed the day of capture eliminating the need for preservation.

\section{Data Analysis}

Relative abundance of Walleyes was estimated via calculation of catch per unit effort (CPUE) or number of Walleyes captured per net-night. Each gill net set represented one netnight of effort. Overall trends in Walleye CPUE were analyzed using a mixed effects model in the nlme package in program $\mathrm{R}$ (Pinheiro et al. 2017). Walleye CPUE data were log +1 transformed to improve normality and homogeneity of variance (Hubert and Fabrizio 2007). Fixed effects included in the model were as follows: time (i.e. sample year), lake region, and an interactive effect of time and lake region. Sampling site was included as a random effect to account for repeated measures at sites over time (Hubert and Fabrizio 2007). We also modeled

the change in Walleye CPUE over time using only data from the stocking period (2001-2015) to determine if any significant changes have occurred in Walleye CPUE since stocking was initiated (excluding data from pre-stocking years).

Size structure of the Cheat Lake Walleye population was evaluated with length frequencies and proportional size distributions (PSD). We used length-group interval guidelines (i.e., $25 \mathrm{~mm}$ intervals) from Neumann et al. (2012) to construct the length-frequency histogram. We used length categories provided by Gabelhouse (1984) to estimate proportional size distributions which were categorized as follows: stock (250-379 mm), quality (380-509 mm), preferred (510-629 mm), memorable (630-759 mm), and trophy ( $\geq 760 \mathrm{~mm})$. Proportional size 
distributions and 95\% confidence intervals were calculated using the Fishery Analysis and Modeling Simulator software (FAMS version 1.64; Slipke and Maceina 2014).

For modeling of Walleye growth in Cheat Lake we fit three different growth models to length at age data and used an information theoretic approach to select the best fitting model (Katsanevakis 2006; Katsanevakis and Maravelias 2008; Taylor 2013; Hilling et al. 2016). Given sexual dimorphism in growth of Walleyes, we analyzed growth separately for males and females (Quist et al. 2003). The three candidate models were fit to Walleye length at age data using a Gauss-Newton algorithm in program R version 3.3.0 (R Core Development Team 2016; Hilling et al. 2016). The three candidate models included the von Bertalanffy growth model, logistic growth model, and Gompertz growth model, and each are described by the following equations:

$$
\begin{array}{ll}
\text { von Bertalanffy: } & \mathrm{L}(\mathrm{t})=\mathrm{L} \infty\left[1-\exp \left(-\mathrm{k}\left(\mathrm{t}-\mathrm{t}_{0}\right)\right)\right] \\
\text { Logistic: } & \mathrm{L}(\mathrm{t})=\mathrm{L} \infty\left[1+\exp \left(-\mathrm{G}\left(\mathrm{t}-\mathrm{t}_{0}\right)\right)\right]^{-1} \\
\text { Gompertz: } & \mathrm{L}(\mathrm{t})=\mathrm{L} \infty \exp \left[-\left(\exp \left(-\mathrm{G}\left(\mathrm{t}-\mathrm{t}_{0}\right)\right)\right)\right]
\end{array}
$$

In each model $L(t)$ represents predicted length at a given age $(\mathrm{t})$. In the von Bertalannfy growth model equation, $L \infty$ represents maximum or asymptotic length, $k$ represents how quickly $L \infty$ is reached, and $t_{0}$ is the theoretical age when length is equal to zero (Quist et al. 2012). The von Bertalanffy growth model assumes that there is a linear decrease in growth rate with increasing fish length (Katsanevakis 2006; Katsanevakis and Maravelias 2008). Both the logistic model and Gompertz model also include a maximum length term $\left(L^{\infty}\right)$ (Hilling et al. 2016). However, the logistic and Gompertz models are sigmoidal curves with different assumptions regarding growth compared to the von Bertalanffy model (Hilling et al. 2016). Specifically, the Gompertz model predicts an exponential decrease in growth rate with age and the logistic model predicts symmetrical growth around an inflection point (Katsanevakis 2006; Quist et al. 2012; Hilling et al. 2016). The Gompertz model is described by the terms to and $\mathrm{G}$ which represent the inflection 
point of the curve and the instantaneous growth rate at to, respectively (Quist et al. 2012; Hilling et al. 2016). In the logistic model, the terms to and G represent the theoretical age when length is zero and the instantaneous growth rate at the origin of the curve, respectively (Quist et al. 2012; Hilling et al. 2016).

Akaike's Information Criterion (AIC) was used to select the best approximating growth model with the most parsimonious fit (Burnham et al. 2011). Specifically, Akaike's Information Criterion with a small sample bias (AICc) was used to rank models in order of decreasing fit (Burnham et al. 2011; Hilling et al. 2016). The AICc was calculated as follows:

$$
\begin{gathered}
A I C=n\left(\log \left(2 \pi \frac{R S S}{n}+1\right)+2 k\right. \\
A I C C=A I C+\frac{(2 k(k+1)}{(n-k-1)}
\end{gathered}
$$

In the AIC calculation, RSS is the residual sum of squares for a given model, $n$ is the number of observations in the sample and $k$ is the number of parameters estimated by the model (Katsanevakis and Maravelias 2008; Hilling et al. 2016). Growth models were ranked in order of decreasing fit using Akaike's Information Criterion with a small sample size bias correction (AICc) using the AICcmodavg package in R (Anderson 2008; Burnham et al. 2011; Mazzerole 2015). The growth model determined to have the smallest AICc value was considered the best approximating model (Burnham et al. 2011). The resulting AICc values were used to calculate $\Delta$ values and AICc weights ( $w i)$ were calculated for each model and used as another measure of evidence for model support (Akaike 1983; Burnham and Anderson 2002; Hilling et al. 2016). Both were calculated as follows:

$$
\Delta_{i}=\mathrm{AlCc}_{i}-\mathrm{AlCc}_{\text {min }}
$$




$$
w i=\frac{\exp (-0.5 \Delta i)}{\sum_{i}^{3}=1 \exp (-0.5 \Delta \mathrm{k})}
$$

Walleye growth was also described as minimum, mean, and maximum length at age. Mean length at age data were used to compare Cheat Lake Walleye growth to North American Walleye growth standards published by Quist et al. (2003). Quist et al. (2003) published mean length at age growth standards for Walleye by developing a North American relative growth index (RGI). The RGI was developed by compiling and analyzing published Walleye length at age data from across North America (42 datasets on male growth; 38 datasets on female growth; Quist et al. 2003). We calculated the RGI for male and female Cheat Lake Walleyes using the equation $R G I=\left(L_{t} / L_{s}\right) \times 100$, where $L_{t}$ was the observed length at age and $L_{s}$ was the predicted age specific standard length (Quist et al. 2003). We calculated mean RGI for male and female Walleyes for each age class. An RGI of 100 indicates growth is similar to the average growth across North America, whereas values $<100$ indicate below average growth and values > 100 indicate above average growth (Quist et al. 2003). Quist et al. (2003) also presented mean length at age values for Walleyes corresponding to the $5^{\text {th }}, 10^{\text {th }}, 25^{\text {th }}, 50^{\text {th }}, 75^{\text {th }}$, $90^{\text {th }}$, and $95^{\text {th }}$ percentiles of the national average for comparison. The age specific standard length estimates for male and female Walleyes (ages 1-8) were developed by Quist et al. (2003) by estimating a von Bertalannfy growth model for North American populations. The standard length equations developed by Quist et al. (2003) were as follows:

Female Walleyes: $L_{s}=652\left(1-e^{-0.266(a g e+0.346)}\right)$

Male Walleyes: $L_{s}=496\left(1-\mathrm{e}^{-0.419(\operatorname{age}+0.083)}\right)$

Age, growth, and CPUE data on Cheat Lake Walleyes were also compared to data collected on Walleye populations from other West Virginia Reservoirs. From 2008-2014, data 
were collected on Walleye populations from five West Virginia reservoirs (Burnsville, East Lynn, Stonecoal, Summersville, and Tygart Reservoirs; WVDNR, unpublished data). Data were collected using six single mesh, sinking monofilament gill nets per station. Nets were $22.9 \mathrm{~m}$ in length, $1.8 \mathrm{~m}$ in depth, with bar mesh sizes of $13 \mathrm{~mm}, 25 \mathrm{~mm}, 38 \mathrm{~mm}, 51 \mathrm{~mm}, 64 \mathrm{~mm}$, and $76 \mathrm{~mm}$ (WVDNR, unpublished data). Estimates of CPUE, age, and growth were calculated for Walleyes captured in these five reservoirs. Due to differences in gill net dimensions compared to Cheat Lake surveys, comparisons are meant to be descriptive and were not statistically tested.

Age data were used to determine year class strength and contribution of natural reproduction or stocking (Goeckler et al. 2003). We calculated the percent frequency of year classes represented from aged Walleyes. Using these percent frequencies we determined if any Walleyes belonged to year classes when no stocking occurred in Cheat Lake, thus providing evidence of natural reproduction (Goeckler et al. 2003). We also examined fall electrofishing data from 1990-2015 and determined the number of young of the year Walleyes collected. Young of year Walleyes collected during years of no stocking would provide evidence of natural reproduction (Jude 1992; Goeckler et al. 2003; Riley et al. 2007; Warren and Bettoli 2014).

Diet data were summarized for Walleyes captured in gill nets from 25 September 2014 to 14 November 2014. Diets were summarized using percent frequency of occurrence (Oi) and mean percent frequency by number $(\mathrm{MNi})$. Frequency of occurrence was calculated as $O_{i}=J_{i} P^{-1}$ $x 100$, where $J_{i}$ represents the number of fish containing a particular prey and $P$ represents the number of fish with food in their stomachs (Chipps and Garvey 2007). Mean percent composition by number was calculated as $M N i=\frac{1}{P} \sum_{j=1}^{P}\left(\frac{N i j}{\sum_{i=1}^{Q} N i j}\right) \times 100$, where $P$ was the total number of fish with food in their stomachs, $Q$ was the total number of prey types, and Nij was the number of prey type $i$ in fish $j$ (Chipps and Garvey 2007). We also summarized diets by the minimum, mean, and maximum total length of prey species consumed. 


\section{Results}

Catch-Per-Unit-Effort (CPUE) and Size Structure

A total of 193 Walleyes were collected during gill net monitoring surveys from 19902015 (Figure 3.2). Mean annual CPUE ranged from zero Walleye per net-night in 1990 and 1998, to 3.7 Walleye per net-night in 2008 (Figure 3.2). Only one Walleye (443 mm TL) was captured prior to when stocking was initiated in Cheat Lake in 1999, resulting in an overall mean CPUE of 0.04 fish/net-night from 1990-1998. Overall mean CPUE after stocking was initiated (2001-2015) was 1.55 fish/net-night. Results from the mixed model analysis suggested that Walleye CPUE has significantly increased with time $\left(F_{1,141}=28.73 ; p<0.0001\right)$. Results from the mixed model analysis using only data from the stocking period (2001-2015) suggested that CPUE estimates over this period have not significantly increased with time $\left(F_{1,105}=3.33 ; p=\right.$ 0.07). Examination of plotted CPUE over time (Figure 3.2) clearly shows that prior to stocking in 1999, Walleyes were nearly non-existent in Cheat Lake, aside from the capture of a lone individual in 1997. After stocking was initiated in 2001, Walleye CPUE immediately increased and has fluctuated with periods of low CPUE followed by spikes in CPUE in 2008, 2014, and 2015 (Figure 3.2). Compared to other West Virginia reservoirs, Cheat Lake has had moderate relative abundance of Walleyes since stocking began. Cheat Lake Walleye CPUE (overall mean $=1.55 \mathrm{fish} /$ net-night; mean annual range $=0.3-3.7 \mathrm{fish} /$ net-night) was higher on average than Walleye CPUE for Burnsville Lake (overall mean = $0.3 \mathrm{fish} / \mathrm{net}$-night; annual range $=0.2-0.4$ fish/net-night), East Lynn Lake (overall mean $=0.3$ fish/net-night; annual range $=0.2-0.6$ fish/net-night), and Stonecoal Lake (overall mean = 0.6 fish/net-night; annual range $=0.2-1.2$ fish/net-night). Cheat Lake Walleye CPUE was lower compared to both Tygart Lake (overall mean $=2.3$ fish/net-night; annual range $=2.3-2.3$ ) and Summersville Lake (overall mean $=2.9$ fish/net-night; annual range = 2.3-3.8). 
Length frequency and proportional size distribution were calculated from a total of 123 Walleyes collected for age and growth analysis. Adult Walleyes were collected with gill nets $(n=95)$, while YOY individuals were collected with boat electrofishing $(n=28)$. Young of the year individuals ranged in length from 163-270 mm (Figure 3.3). Female Walleyes ranged in length from 378-790 mm, whiles males ranged in length from 379-600 mm (Figure 3.3). Likewise, based on the length frequency histogram, females represented most of the Walleyes collected for size classes over $500 \mathrm{~mm}$ (Figure 3.3). Additionally, a gap in sizes represented is apparent from 270-378 $\mathrm{mm}$ in the length frequency histogram, likely related to fast growth in young fishes (Figure 3.3). We also summarized Walleye lengths using length categories developed by Gabelhouse (1984). The Gabelhouse (1984) system categorizes lengths according to five categories including stock $(S)$, quality $(\mathrm{Q})$, preferred $(\mathrm{P})$, memorable $(\mathrm{M})$, and trophy $(\mathrm{T})$. There were 21 individuals (17\%) that were smaller than the stock size (i.e., sub-stock). These individuals were all young of the year. For the remaining fish above stock size, proportional size distributions with $95 \%$ confidence intervals were calculated as: $P S D=92 \pm 5.27, P S D-P=40 \pm$ 9.53, PSD-M = $7 \pm 4.95$, and PSD-T = $1 \pm 1.93$. Incremental PSDs with $95 \%$ confidence intervals were calculated as: PSD S-Q $=8 \pm 8, P S D$ Q-P $=52 \pm 15, P S D P-M=33 \pm 14$, and PSD M-T $=6 \pm 6$. The PSD estimate of 92 indicates $92 \%$ of Walleyes of stock length or greater were quality size ( $\geq 380 \mathrm{~mm}$ ) individuals. Additionally, the PSD-P (preferred size) value indicates $40 \%$ of captured Walleyes of stock length or greater were $\geq 510 \mathrm{~mm}$. Memorable (PSD-M) and trophy (PSD-T) size Walleyes were also represented in the sample $(7 \%$ and $1 \%$ of stock length or greater fish, respectively). 
Age, Growth, and Diet

Otoliths were collected from 123 Walleyes for aging purposes. Two independent readers had an initial agreement rate of $91.1 \%$ for assigned ages. Agreement within one year was $99.2 \%$ and age was agreed upon in all instances after mutual examination by both readers. Age-0+ individuals (young of the year) were not sexed, and were used for both the male and female growth models. Sexual dimorphism in growth of Walleyes is not typically apparent in age-0 fish (Henderson et al. 2003). The convention for age designation of Walleyes followed guidelines by Devries and Frie (1996). Using these guidelines, fish are considered to have completed one year of life on January $1^{\text {st }}$ of each year (Devries and Frie 1996). However, the national average growth calculated by Quist et al. (2003) was based on studies that used back calculation to determine length at age (thus corresponding to length at annulus formation in late spring/early summer), whereas our study was based on length of fishes captured in fall. To account for growth beyond the last annulus in our samples, we added one year to the ages assigned to each individual fish in our samples (Bednarski et al. 2010). This resulted in conservative estimates of growth for our study fish, but improves comparability with the national averages published by Quist et al. (2003).

We aged 123 individuals ranging in length from 163-790 mm, with ages ranging from 114 (ages adjusted +1 year for comparability with Quist et al. 2003). An age frequency plot shows that most individuals were ages $1-5$, with age 5 being the most abundant (Figure 3.4). Based on aging data, male and female Cheat Lake Walleyes reach quality size $(\geq 380 \mathrm{~mm})$ after two years of growth (i.e., age- 1 individuals in the fall; assigned as age-2 for N.A. average comparison) (Table 3.4 and 3.5). Preferred size ( $\geq 510 \mathrm{~mm}$ ) is typically reached by females after four years of growth (i.e., age-3 individuals in fall; assigned as age-4 for N.A. average comparison) (Table 3.4). Memorable size ( $\geq 630 \mathrm{~mm}$ ) is typically reached by females after 6 years of growth (age-5 individuals in the fall; assigned as age- 6 for N.A. comparison) (Table 
3.4). One trophy size ( $\geq 690 \mathrm{~mm}$ ) Walleye was captured measuring $790 \mathrm{~mm}$ in length that was estimated to be an age-8 individual when collected (assigned as age-9 for N.A. average comparison).

Of the four growth models (von Bertalannfy, logistic, and Gompertz) fit to our length at age data, the von Bertalannfy growth model was AICc selected as the best approximating model for both male $\left(w_{i}=0.74\right)$ and female $\left(w_{i}=1.0\right)$ Cheat Lake Walleye growth (Table 3.2). For female growth, there was no support for either the logistic or Gompertz models (Table 3.2), and there was little support (Gompertz $w_{i}=0.19, \Delta \mathrm{AICc}=2.74$; logistic $w_{i}=0.07, \Delta \mathrm{AICc}=$ 4.69) for either of these models for male growth (Table 3.2). The von Bertalannfy growth models for male and female growth indicated large differences in growth rates between sexes (Figure 3.5). Males and females began to show differences in growth rate at age-3, with female growth increasing steadily and male growth beginning to slow down (Figure 3.5). Females grew fast and large in Cheat Lake with an estimated asymptotic length of $754 \mathrm{~mm}$ and a $k$ value of 0.31 (Table 3.3; Figure 3.5). In contrast, males had a much smaller estimated asymptotic length (502 $\mathrm{mm}$ ) and a $k$ value over two times as high than that of females, indicating that asymptotic length is reached quickly in males (Table 3.3; Figure 3.5). While female growth rate did not show much indication of slowing with age, male growth had largely plateaued by age-4 (Figure 3.5).

We compared growth of Cheat Lake Walleyes with average growth compiled from populations across North America (Quist et al. 2003) and from other West Virginia reservoirs (WVDNR, unpublished data). Compared to North American growth standards (Quist et al. 2003) mean lengths at age for female Cheat Lake Walleyes were greater than or equal to the $75^{\text {th }}$ percentile for all ages (Table 3.4). Furthermore, female mean lengths at age were greater than or equal to the $90^{\text {th }}$ percentile for ages 4 and 5, and were at the $95^{\text {th }}$ and above percentile (Quist et al. 2003) for ages 6 and up (Table 3.4). In contrast, male Cheat Lake Walleyes were at the $75^{\text {th }}$ and above percentile at ages 1 and 2 , but were in the $50-75^{\text {th }}$ percentile for ages 3 and up 
(Table 3.5). Cheat Lake Walleyes of all ages (both male and female) had mean RGI values > 100 (Tables 3.4 and 3.5). The VBGM predicted a much larger asymptotic length for female Cheat Lake Walleyes compared to the North American average (Quist et al. 2003; Table 3.6; Figure 3.6). Male Cheat Lake Walleyes also had a larger predicted asymptotic length than the North American average, but only slightly (Quist et al. 2003; Table 3.6; Figure 3.7). Female Cheat Lake Walleyes were also predicted to attain larger maximum length on average than female Walleyes from five other WV reservoirs (Table 3.6; Figure 3.8). Male Cheat Lake Walleyes were predicted to attain larger maximum lengths on average for all but one WV reservoir (East Lynn Lake) of comparison (Table 3.6; Figure 3.8).

Examination of year class frequency of aged Walleyes shows that most sampled fish were from year classes 2009-2014 (Figure 3.10). The most abundant year class in our sample was 2010 , accounting for $28 \%$ of aged Walleyes (Figure 3.10 ). Two of the most abundant year classes, 2010 and 2012, were from successful fingerling stocking years (Table 3.1; Figure 3.10). However, beginning in 2008, Walleyes belonging to non-stocking year classes started to contribute to the population (Table 3.1; Figure 3.10). No stockings occurred in 2008, 2011, or 2013, yet contributions from these year classes steadily increased (Figure 3.10). Additionally, although stocking occurred in 2014 , it is unlikely that stocked fish contributed much to the population due to low numbers stocked ( $<7$ fingerlings/hectare), high initial fingerling mortality observed (> 50\%) and poor stocking conditions (high, turbid water and substantial decrease in water temperature; WVDNR, unpublished data). Therefore, fish representing the 2014 year class could be largely naturally reproduced. Additionally, young of the year Walleyes were captured in fall electrofishing surveys during years 2011 (0.4/hr.), $2013(1.1 / \mathrm{hr}$.), 2014 (3.0/hr.) and 2015 (7.7/hr.). No stockings occurred during 2011, 2013, or 2015, and very limited success was expected from 2014 stockings. This provides additional evidence of successful natural reproduction of Walleyes in Cheat Lake. 
Diets of 46 age- $1+$ Walleyes $(379-690 \mathrm{~mm}$ TL, mean $=493, \mathrm{SD}=89.3)$ collected from September $25^{\text {th }}$ to November $15^{\text {th }}, 2014$ were examined for prey species consumed, size of prey, and prey abundance. Thirteen Walleyes (28.2\%) had empty stomachs and $33(71.7 \%)$ had prey in stomachs. Approximately $67 \%$ of Walleyes had consumed Yellow Perch (Perca flavescens) (Table 3.7). Other prey species consumed in order of decreasing frequency of occurrence included Gizzard Shad (Dorosoma cepedianum) (12\%), Emerald Shiner (Notropis atherinoides) (9\%), Lepomis sp. (9\%), and Micropterus sp. (3\%) (Table 3.7). Yellow Perch were the prey with the largest maximum size consumed by Walleyes $(229 \mathrm{~mm}$ ) (Table 3.7). Gizzard Shad and Yellow Perch were the largest prey items consumed on average (mean prey lengths of $121 \mathrm{~mm}$ and $110 \mathrm{~mm}$, respectively) (Table 3.7).

\section{Discussion and Management Implications}

Although Walleyes were once extirpated from Cheat Lake, WV, due to water quality impairment, improvements in water quality since the 1990's have created more favorable conditions (see Chapter 2). The results of our study show that the Walleye stocking program in Cheat Lake has resulted in successfully reestablishing a Walleye fishery. Walleye CPUE went from near zero prior to stocking, to immediate and persistent abundance within the reservoir (Figure 3.2). Our results on age and growth of Cheat Lake Walleyes suggest that growth is faster than average, especially in females (Quist et al. 2003). Female Cheat Lake Walleyes can attain large maximum sizes on average compared to other North American populations (Quist et al. 2003; Figure 3.6). This could be due in part to a diverse forage base, with Yellow Perch and Gizzard Shad being important to diets of Cheat Lake Walleyes. Our data also provide evidence of successful and potentially increasing natural reproduction. Given the lack of knowledge on the population characteristics of this reestablished fishery, this data gathered on abundance, age, growth, and diet provide valuable information for future management of this fishery. 
Additionally, information gained on this population of Walleyes reestablished after years of water quality degradation provides a valuable case study to other similar situations elsewhere.

Temporal monitoring data suggest that Walleye relative abundance in Cheat Lake has increased significantly since WVDNR began stocking Walleyes in 1999 (Figure 3.2). Walleyes used to be common within Cheat Lake and the Cheat River watershed as evidenced from past reports (Core 1959; WVDNR unpublished data). However, fisheries surveys were conducted extensively on Cheat Lake from the 1950's through the 1970's and no Walleyes were collected during this timeframe (Core 1959; WVDNR unpublished data). Likewise, Core (1959) stated that Walleyes were likely extirpated from Cheat Lake by the late 1940's due largely to acid mine drainage pollution. With improving water quality in the Cheat River watershed due to mitigation of acid mine drainage pollution, WVDNR began stocking Walleyes in Cheat Lake in 1999 (Table 3.1). Temporal monitoring was conducted on the Cheat Lake fish community and Walleye population from 1990-2015. Prior to the initiation of Walleye stocking, Walleyes were still effectively absent from the reservoir. Gill net CPUE was near zero ( 0.04 Walleye/net-night) from 1990-1998, with one adult Walleye captured (443 mm TL) in 1997 (Figure 3.2). Walleyes had not been stocked when this individual was captured. The origin of this fish is unknown, but could be evidence of a small, remnant population of Walleyes or perhaps more likely was the result of an angler introduction. Given the lack of Walleyes captured for decades in the lake, and the propensity for anglers to introduce sportfish, it seems more likely this fish was the result of an angler introduction. After stocking was initiated in Cheat Lake, Walleye gill net CPUE immediately increased and has averaged 1.55 fish/net-night during the post-stocking time period (2001-2015; Figure 3.2). Although Walleye CPUE has significantly increased over time, this significant change can be attributed to the differences in Walleye abundance before and after stocking. Walleye CPUE in gill net surveys has not significantly increased over time since stocking began. During this time, Walleye relative abundance has fluctuated with periods of 
relatively low abundance, followed by peaks in abundance in 2008 (3.7 fish/net-night), 2014 (2.8 fish/net-night), and 2015 (3.3 fish/net-night). The last two years (2014 and 2015) of monitoring showed consecutive peaks in relative abundance and it remains to be seen if an upward trend in abundance will persist or if it will continue to fluctuate between low and high CPUE numbers. Given continued improvements in water quality, increases in forage within Cheat Lake (see Chapter 2), and evidence of natural reproduction, it is possible that future overall mean Walleye abundance will increase.

Compared to relative abundance estimates from other studies, gill net CPUE of Walleyes in Cheat Lake is still quite low (Li et. al 1996; Munger and Kraal 1997; Porath et al. 2003; Ward et al. 2007; Isermann 2007; Katt et al. 2011; Bethke and Staples 2015). However, standard gill net surveys in these other states (e.g., Minnesota, Nebraska, South Dakota, etc.) typically utilize much longer gill nets and longer soak times ( $\geq 76$ m, > 12 hours; Li et. al 1996; Munger and Kraal 1997; Porath et al. 2003; Ward et al. 2007; Isermann 2007; Katt et al. 2011; Bethke and Staples 2015) compared to the shorter gill nets and soak times used in our study and other WV reservoirs ( $\leq 45 \mathrm{~m},<12$ hours). Additionally, the steep slopes of Cheat Lake and WV reservoirs could reduce effectiveness compared to lakes and reservoirs in other states. Nevertheless, compared to five other WV reservoirs, Cheat Lake had moderate Walleye abundance with gill net CPUE higher than 3 of the 5 populations (WVDNR, unpublished data).

We estimated size structure, age, and growth for 123 Walleyes ranging in length from 163-790 mm (mean $439 \mathrm{~mm}$ ). Size structure estimates indicated high abundance of quality length (> $380 \mathrm{~mm}$ ) and preferred length (> $510 \mathrm{~mm}$ ) Walleyes in Cheat Lake (Figure 3.3). Additionally, both memorable (>630 $\mathrm{mm}$ ) and trophy length $(>760 \mathrm{~mm}$ ) fish were present in samples. Additionally, Cheat Lake Walleyes exhibited fast growth and large maximum lengths, especially for females, when compared to average growth based on other North American populations (Quist et al. 2003; Figure 3.6). Age and growth analysis indicates that Cheat Lake 
Walleyes show substantial differences in growth between males and females (Figure 3.5). Although male Walleyes typically don't exceed $502 \mathrm{~mm}$ total length, female Walleyes grow substantially larger. The largest female Walleye captured was $790 \mathrm{~mm}$ and the estimated female maximum length from growth models was $754 \mathrm{~mm}$. Fast growth and large maximum sizes of Walleyes could be attributed to a number of factors including climate, forage availability, and density (Kocovsky and Carline 2001; Quist et al. 2003; Bednarski et al. 2010; Bozek et al. 2011). The milder climate found in West Virginia compared to northern latitudes with abundant Walleye populations could provide beneficial growing conditions in the form of a longer growing season, similar to conditions found in other studies (Kocovsky and Carline 2001; Quist et al. 2003; Bednarski et al. 2010; Bozek et al. 2011). Additionally, Cheat Lake has a diverse forage base that includes Yellow Perch, Gizzard Shad, and several species of shiners (Notropis sp.). Adequate forage of optimal size has been shown in other studies to benefit Walleye growth (Hartman and Margraf 1992; Quist et al. 2003; Bozek et al. 2011). Finally, density has also been suggested to impact Walleye growth (Kocovsky and Carline 2001; Bozek et al. 2011). Cheat Lake Walleyes are only moderately abundant compared to other West Virginia reservoirs. This relatively low density of Walleyes within Cheat Lake could be another factor contributing to fast growth.

Although it is apparent that fry and fingerling stockings have been critical to the reestablishment of the Cheat Lake Walleye fishery, this study provides evidence of increasing natural reproduction. Aged individuals belonging to year classes when no stocking occurred (i.e., 2008, 2011, 2013), and collection of young of the year in increasing numbers during fall electrofishing surveys during non-stocking years (i.e., 2011, 2013, 2015) have shown that natural reproduction is occurring and potentially increasing in Cheat Lake. The occurrence and potential increase in natural reproduction has likely resulted, in part, from successfully establishing an adult population from stocking, and improved spawning conditions (i.e., $\mathrm{pH}$ of 
Cheat Lake headwaters during spring). Walleyes were extirpated from Cheat Lake by the late 1940's due to acid mine drainage pollution and therefore a viable population did not exist to allow for natural reproduction. Stocking efforts successfully reestablished Walleyes in the reservoir allowing for a potential spawning population to develop. Also, early life stages of Walleyes have been shown to be sensitive to acidic conditions (Hulsman et al. 1983; Rahel and Magnuson 1983). Waters with $\mathrm{pH}<6.0$ during spawning periods can lead to significantly increased mortality of eggs and larvae and ultimately the extirpation of Walleye populations (Hulsman et al. 1983; Rahel and Magnuson 1983). As recently as 1990, pH values in Cheat Lake frequently decreased to less than 5.0 (see Chapter 2). Although conditions continued to improve, early spring $\mathrm{pH}$ values regularly experienced depressions in which $\mathrm{pH}$ fell below 6.0 as recently as 2011 (see Chapter 2). However, since 2012, pH values in Cheat Lake have not reached levels less than 6.0 due to increasing acid mine drainage abatement occurring within the watershed (see Chapter 2). The reestablishment of Walleyes via stocking and these improving water quality conditions within Cheat Lake appear to have led to successful natural reproduction within Cheat Lake.

The results from our examination of diets of Cheat Lake Walleyes were similar to those found in other studies (Forney 1974; Hartman and Margraf 1992; Kocovsky and Carline 2001; Pothoven et al. 2016). Age 1+ Walleyes consumed a variety of prey fish, including Yellow Perch, Gizzard Shad, Emerald Shiner, Lepomis sp. and Micropterus sp. (Table 3.7). Specifically, diet examination of Walleyes indicated that Yellow Perch are an important forage species in Cheat Lake. Yellow Perch occurred in $67 \%$ of diets collected in Cheat Lake and were also one of the largest prey items encountered in stomach contents (Table 3.7). Yellow Perch have been shown to be important, but not necessarily preferred forage for Walleyes in many waters of the midwestern and northern United States (Forney 1974; Swenson 1977; Lyons and Magnuson 1987; Hartman and Margraf 1992; Kocovsky and Carline 2001). In some waters 
Yellow Perch are a primary prey selected by Walleyes (Forney 1974; Swenson 1977; Lyons and Magnuson 1987), whereas in others they act as an important secondary prey source (Hartman and Margraf 1992; Kocovsky and Carline 2001). Gizzard Shad and Emerald Shiners have also been shown in previous studies to be important prey for Walleyes (Hartman and Margraf 1992; Kocovsky and Carline 2001). Gizzard Shad were the second most common prey item in Cheat Lake Walleye diets (12.1\%), whereas Emerald Shiners were found in diets but at a lower frequency (6.1\%). Young Gizzard Shad abundance in Cheat Lake is variable and it is possible that during years of high juvenile Gizzard Shad abundance that Walleyes increase foraging on this species (Hartman and Margraf 1992). Additionally, it is important to note that diets were only sampled in fall months and possibly differ at other times of the year. We also only examined diets from a relatively small sample size of stomachs with food present $(n=33)$. To obtain a more representative sample of Walleye diets, a higher sample size during multiple seasons would be beneficial. Increased abundance of large Walleyes and fast growth of females suggests that good foraging and habitat conditions exist in Cheat Lake. The large population of Yellow Perch, and increasing abundance of important prey such as Gizzard Shad, Emerald Shiners, Silver Shiners, and Mimic Shiners may provide Cheat Lake Walleyes with a unique forage base for West Virginia conducive to fast and persistent growth.

The results of this study provide valuable information on the population characteristics of a reestablished Walleye fishery in Cheat Lake, WV. Results from this study will be beneficial for the future management of this reestablished Walleye fishery. Additionally, these results provide a unique example of the response of Walleyes to reestablishment after extirpation from environmental stressors. Currently, it appears the Walleye population is exceptionally healthy compared to other West Virginia reservoir populations. Cheat Lake Walleyes grow fast, attain large sizes, have abundant forage, and are showing evidence of natural reproduction. However, abundance is moderately low at times, and it is unknown how dependent this population will be 
on stocking efforts in the future. Additionally, angling pressure on this population remains unknown, but from opportunistic angler interviews pressure still appears to be low. Additional pressure and success of anglers could alter the current dynamics of this population. Future research on angler effort and harvest of Walleyes in Cheat Lake would significantly improve the ability to manage this population. Additionally, continued improvement and sustainability of this population will be dependent on adequate spawning and habitat conditions and/or stocking success. Walleyes were originally extirpated from Cheat Lake due to acidic conditions and acid mine drainage still persists in the watershed despite continued mitigation efforts. There have been no $\mathrm{pH}$ depressions since 2011, but if acidic conditions were to return, future natural reproduction of Walleyes could be significantly reduced. Additionally, spawning success of Walleyes in Cheat Lake could be impacted by water level fluctuations which can lead to egg and/or larval mortality (Bozek et al. 2011; see Chapter 5). Also, the fast growth and good condition of Cheat Lake Walleyes are dependent on adequate prey availability and foraging conditions. Forage availability for Walleyes could be impacted from worsening water quality or reduced recruitment of forage species owing to spring water level fluctuations (specifically for Yellow Perch). Future management efforts should focus on further monitoring of Walleye population characteristics, investigation of angler pressure on Cheat Lake Walleyes and continued work to ensure good water quality persists into the future. 


\section{References}

Anderson, D. R. 2008. Model Based Inference in the Life Sciences: a Primer on Evidence. New York, Springer.

Anderson, R. O. and R. M. Neumann. 1996. Length, weight, and associated structural indices. Pages 477-481 in B. R. Murphy and D.W. Willis, editors. Fisheries Techniques, Second edition, American Fisheries Society, Bethesda, Maryland.

Bednarski, M. S., J. Hendricks, D. L. Higginbotham and D. L. Peterson. 2010. Growth rates of stocked walleyes in several Georgia reservoirs. Proceedings of Annual Conference of Southeastern Fish and Wildlife Agencies 64: 136-140.

Bethke, B. J. and D. F. Staples. 2015. Changes in relative abundance of several Minnesota fishes from 1970 to 2013. Transactions of the American Fisheries Society 144: 68-80.

Bozek, M. A., D. A. Baccante, and N. P. Lester. 2011. Walleye and sauger life history. Pages 233-301 in B. A. Barton, editor. Biology, Management, and Culture of Walleye and Sauger. American Fisheries Society, Bethesda, Maryland.

Bozek, M. A., T. J. Haxton and J.K. Raabe. 2011. Walleye and sauger habitat. Pages 133-197 in B.A. Barton, editor. Biology, Management and Culture of Walleye and Sauger. American Fisheries Society, Bethesda, Maryland.

Burnham, K.P. and D.R. Anderson. 2002. Model Selection and Multimodel Inference: a Practical Information-theoretic Approach, Second Edition. Springer, New York, New York.

Burnham, K. P., D. R. Anderson, and K. P. Huyvaert. 2011. AIC model selection and multimodel inference in behavioral ecology: some background, observation, and comparisons. Behavioral Ecology and Sociobiology 65:23-35.

Core, E. L. 1959. Biological investigations of Cheat Lake. West Virginia University, Morgantown, WV. 
Devries, D. R. and R. V. Frie. 1996. Determination of age and growth. Pages 483-512 in B. R. Murphy and D. W. Willis, editors. Fisheries Techniques, Second Edition. American Fisheries Society, Bethesda, Maryland.

Forney, J. L. 1974. Interactions between yellow perch abundance, walleye predation, and survival of alternate prey in Oneida Lake, New York. Transactions of the American Fisheries Society 103: 15-24.

Freund, J.G. and J.T. Petty. 2007. Response of fish and macroinvertebrate bioassessment indices to water chemistry in a mined Appalachian watershed. Environmental Management 39: 707-720.

Gabelhouse, D. W. 1984. A length-categorization system to assess fish stocks. North American Journal of Fisheries Management 4:273-285.

Goeckler, J. M., M. C. Quist, J. A. Reinke, and C. S. Guy. 2003. Population characteristics and evidence of natural reproduction of Blue Catfish in Milford Reservoir, Kansas. Transactions of the Kansas Academy of Science 106: 149-154.

Gustafson, K. A. 1988. Management briefs: approximating confidence intervals for indices of fish population size structure. North American Journal of Fisheries Management 8:139_ 141.

Hartman, K. J., and F. J. Margraf. 1992. Effects of prey and predator abundances on prey consumption and growth of walleyes in Western Lake Erie. Transactions of the American Fisheries Society 121: 245-260.

Henderson, B. A., N. Collins, G. E. Morgan and A. Vaillancourt. 2003. Sexual size dimorphism of walleye (Stizostedion vitreum vitreum). Canadian Journal of Fisheries and Aquatic Sciences 60: 1345-1352.

Hilling, C. D., S. A. Welsh, and D. M. Smith. 2016. Age, growth and fall diet of channel catfish in Cheat Lake, West Virginia. Journal of Fish and Wildlife Management 7: 304-314. 
Hubert, W. H. and M. C. Fabrizio. 2007. Relative abundance and catch per unit effort. Pages 279-325 in C. Guy and M. Brown, editors. Analysis and Interpretation of Freshwater Fisheries Data. American Fisheries Society, Bethesda, Maryland.

Hulsman, P. F., P. M. Powles, and J. M. Gunn. 1983. Mortality of walleye eggs and rainbow trout yolk-sac larvae in low-pH waters of the LaCloche Mountain area, Ontario. Transactions of the American Fisheries Society 112: 680-688.

Isermann, D. A. 2007. Evaluating Walleye length limits in the face of population variability: case histories from western Minnesota. North American Journal of Fisheries Management 27: 551-568.

Johnson, J. J., J. X. He, and D. G. Fielder. 2015. Rehabilitation stocking of walleyes and lake trout: restoration of reproducing stocks in Michigan waters of Lake Huron. North American Journal of Aquaculture 77: 396-408.

Jude, D. J. 1992. Evidence for natural reproduction by stocked Walleyes in the Saginaw River tributary system, Michigan. North American Journal of Fisheries Management 12: 386395.

Katsanevakis, S. 2006. Modelling fish growth: model selection, multi-model inference and model selection uncertainty. Fisheries Research 81: 229-235.

Katsanevakis, S. and C. D. Maravelias. 2008. Modelling fish growth: multi-model inference as a better alternative to a priori using von Bertalanffy equation. Fish and Fisheries 9: 178187.

Katt, J. D., B. C. Peterson, K. D. Koupal, K. W. Shoenebeck and W. W. Hoback. 2011. Changes in relative abundance of adult Walleye and egg density following the addition of Walleye spawning habitat in a midwest irrigation reservoir. Journal of Freshwater Ecology 26: $51-58$. 
Kocovsky, P. M., and R. F. Carline. 2001. Influence of extreme temperatures on consumption and condition of walleyes in Pymatuning Sanctuary, Pennsylvania. North American Journal of Fisheries Management 21: 198-207.

Kocovsky, P. M., and R. F. Carline. 2001. Dynamics of the unexploited walleye population of Pymatuning Sanctuary, Pennsylvania, 1997-1998. North American Journal of Fisheries Management 21: 178-187.

Li, J. Y. Cohen, D. H. Schupp, and I. R. Adelman. 1996. Effects of walleye stocking on population abundance and fish size. North American Journal of Fisheries Management 16: 830-839.

Lyons, J. and J. J. Magnuson. 1987. Effects of walleye predation on the population dynamics of small littoral-zone fishes in a northern Wisconsin lake. Transactions of the American Fisheries Society 116: 29-39.

Mazzerolle, M. J. 2015. AlCcmodavg: model selection and multimodel inference based on (Q)AIC(c). R package version 2.0-3. Available: http://CRAN.R-

\section{project.org/package=AICcmodavg}

McClurg, S. E., J. T. Petty, P. M. Mazik, and J. L. Clayton. 2007. Stream ecosystem response to limestone treatment in acid impacted watersheds of the Allegheny Plateau. Ecological Applications 17:1087-1104.

Merovich, G. T., J. M. Stiles, J. T. Petty, J. Fulton, and P. F. Ziemkiewicz. 2007. Water chemistry based classification of streams and implications for restoring mined Appalachian watersheds. Environmental Toxicology and Chemistry 26:1361-1369.

Munger, C. R and J. E. Kraal. 1997. Evaluation of length and bag limits for Walleyes in Meredith Reservoir, Texas. North American Journal of Fisheries Management 17: 438-445.

Neumann, R. M., C. S. Guy and D. W. Willis. 2012. Length, weight, and associated indices. Pages 637-676 in A. V. Zale, D. L. Parrish and T. M. Sutton, editors. Fisheries Techniques, $3^{\text {rd }}$ edition. American Fisheries Society, Bethesda, Maryland. 
Pinheiro, J. D. Bates, S. DebRoy, D. Sarkar, and R Core Team. 2014. nlme: Linear and nonlinear mixed effects models. R package version 3.1-118. http://CRAN.Rproject.org/package=nlme.

Porath, M. T., E. J. Peters, and D. L. Eichner. 2003. Impact of Alewife introduction on Walleye and White Bass condition in Lake McConaughy, Nebraska, 1980-1995. North American Journal of Fisheries Management 23: 1050-1055.

Pothoven, S. A., C. P. Madenjian, and T. O. Hook. 2017. Feeding ecology of walleye (Percidae, Sander vitreus), a resurgent piscivore in Lake Huron (Laurentian Great Lakes) after shifts in the prey community. Ecology of Freshwater 26: 676-685.

Quist, M. C., C. S. Guy, R. D. Schultz and J. L. Stephen. 2003. Latitudinal comparisons of walleye growth in North America and factors influencing growth of walleyes in Kansas reservoirs. North American Journal of Fisheries Management 23: 677-692.

Quist, M. C., M. A. Pegg and D. R. DeVries. 2012. Age and growth. Pages 677-731 in A. V. Zale, D. L. Parrish and T. M. Sutton, editors. Fisheries Techniques, $3^{\text {rd }}$ edition. American Fisheries Society, Bethesda, Maryland.

R Development Core Team. 2016. R: A language and environment for statistical computing. $R$ Foundation for Statistical Computing, Vienna, Austria. ISBN 3-900051-07-0, URL http://www.R-project.org.

Rahel, F. J. and J. J. Magnuson. 1983. Low pH and the absence of fish species in naturally acidic Wisconsin Lakes: inferences for cultural acidification. Canadian Journal of Fisheries and Aquatic Sciences 40: 3-9.

Riley, S. C., J. X. He, J. E. Johnson, T. P. O’Brien, and J. S. Schaeffer. 2007. Evidence of widespread natural reproduction by Lake Trout Salvelinus namaycush in the Michigan waters of Lake Huron. Journal of Great Lakes Research 33: 917-921.

Slipke, J. W. and M. J. Maceina. 2014. Fishery Analysis and Modeling Simulator (FAMS). Version 1.64. American Fisheries Society, Bethesda, Maryland. 
Swenson, W. A. 1977. Food consumption of walleye (Stizostedion vitreum vitreum) and sauger (S. canadense) in relation to food availability and physical conditions in Lake of the Woods, Minnesota, Shagawa Lake, and Western Lake Superior. Journal of the Fisheries Research Board of Canada 34: 1643-1654.

Taylor, N. 2013. Assessment of age, diet, and growth of yellow perch (Perca flavescens) in Cheat Lake, West Virginia. Master's Thesis, West Virginia University, Morgantown.

Ward, M. J., D. W. Willis, B. H. Miller, S. R. Chipps. 2007. Walleye consumption and long-term population trends following Gizzard Shad introduction into a western South Dakota reservoir. Journal of Freshwater Ecology 22: 339-345.

Warren, L. H. and P. W. Bettoli. 2014. Evidence of natural reproduction by Muskellunge in middle Tennessee rivers. Southeastern Naturalist 13: 506-514.

Welsh, S. A. and S.A. Perry. 1997. Acidification and fish occurrence in the upper Cheat River drainage, West Virginia. Journal of the American Water Resources Association 33: 423429. 
Table 3.1. Number of Walleyes stocked in Cheat Lake since reintroduction began in 1999.

\begin{tabular}{ccc}
\hline & Fry & Fingerlings \\
\hline 1999 & $1,700,000$ & \\
2000 & $1,000,000$ & \\
2001 & & 50,000 \\
2004 & & 50,000 \\
2005 & & 43,812 \\
2006 & & 46,362 \\
2007 & 33,346 \\
2009 & 6,800 \\
2010 & & 87,712 \\
2012 & & 31,775 \\
2014 & & 5,000 \\
\hline
\end{tabular}

Table 3.2. AICc model selection results for candidate growth models for Cheat Lake Walleyes.

\begin{tabular}{ccccc}
\hline Model & $\mathbf{K}$ & AIC $_{\mathbf{c}}$ & $\mathbf{\Delta A I C}_{\mathbf{c}}$ & $\mathbf{W}_{\mathbf{i}}$ \\
\hline & $\frac{\text { Females }}{4}$ & & & \\
VBGM & 4 & 838.38 & 0 & 1 \\
Gompertz & 4 & 860.71 & 22.33 & 0 \\
Logistic & Males & & & \\
& 4 & 668.65 & 0 & 0.74 \\
VBGM & 4 & 671.39 & 2.74 & 0.19 \\
Gompertz & 4 & 673.34 & 4.69 & 0.07 \\
Logistic & & & &
\end{tabular}

Table 3.3. Parameter estimates for von Bertalanffy (VBGM), Gompertz, and logistic growth models for Cheat Lake, WV Walleye growth.

\begin{tabular}{|c|c|c|c|c|c|}
\hline \multirow[b]{2}{*}{ Model } & \multirow[b]{2}{*}{ Parameter } & \multicolumn{2}{|c|}{ Females } & \multicolumn{2}{|c|}{$\underline{\text { Males }}$} \\
\hline & & Estimate & SE & Estimate & SE \\
\hline \multirow[t]{3}{*}{ VBGM } & $L_{\infty}$ & 753.968 & 32.968 & 501.532 & 9.671 \\
\hline & k & 0.313 & 0.037 & 0.746 & 0.113 \\
\hline & $t_{0}$ & -0.172 & 0.102 & 0.184 & 0.122 \\
\hline Gompertz & $L_{\infty}$ & 696.86 & 21.971 & 494.094 & 8.168 \\
\hline
\end{tabular}




\begin{tabular}{llcccc} 
& $\mathbf{k}$ & 0.516 & 0.044 & 1.044 & 0.141 \\
& $\mathbf{t}_{\mathbf{0}}$ & 1.159 & 0.073 & 0.752 & 0.054 \\
Logistic & $\mathbf{L}^{\infty}$ & 665.592 & 17.591 & 490.291 & 7.569 \\
& $\mathbf{k}$ & 0.736 & 0.054 & 1.376 & 0.17 \\
& $\mathbf{t}_{\mathbf{0}}$ & 1.787 & 0.099 & 1.1 & 0.047 \\
\hline
\end{tabular}

Table 3.4. Summary of length at age data for Cheat Lake Walleyes (Females).

\begin{tabular}{cccccc}
\hline Age & $\mathbf{n}$ & Mean TL $(\mathbf{m m})$ & Mean RGI & SD & Percentile \\
\hline 1 & 28 & 227 & 131 & 15.1 & $75-90$ \\
2 & 11 & 399 & 133 & 3.7 & $75-90$ \\
3 & 13 & 475 & 120 & 4.6 & $75-90$ \\
4 & 14 & 547 & 120 & 6.7 & $90-95$ \\
5 & 14 & 586 & 117 & 9.4 & $90-95$ \\
6 & 2 & 687 & 125 & 0.7 & $95-100$ \\
7 & 2 & 673 & 116 & 2.4 & $95-100$ \\
8 &. &. &. &. &. \\
9 & 1 & 790 & 132 &. & $\mathrm{n} / \mathrm{a}$ \\
\hline
\end{tabular}

Table. 3.5. Summary of length at age data for Cheat Lake Walleyes (Males).

\begin{tabular}{cccccc}
\hline Age & $\mathbf{n}$ & Mean TL $(\mathbf{m m})$ & Mean RGI & SD & Percentile \\
\hline 1 & 28 & 227 & 131 & 16.1 & $75-90$ \\
2 & 8 & 393 & 137 & 3.6 & $75-90$ \\
3 & 2 & 409 & 114 & 7.9 & $50-75$ \\
4 & 1 & 424 & 104 &. & $50-75$ \\
5 & 15 & 477 & 105 & 9.4 & $50-75$ \\
6 & 6 & 488 & 106 & 6.0 & $50-75$ \\
7 & 1 & 480 & 101 &. & $50-75$ \\
8 &. &. &. &. &. \\
9 & 2 & 560 & 115 & 5.2 & $\mathrm{n} / \mathrm{a}$ \\
10 & 2 & 502 & 103 & 2.6 & $\mathrm{n} / \mathrm{a}$ \\
11 &. &. &. &. &. \\
12 &. &. &. &. &. \\
13 &. &. &. &. &. \\
14 & 1 & 600 & 121 &. & $\mathrm{n} / \mathrm{a}$ \\
\hline
\end{tabular}


Table 3.6. von Bertalanffy growth parameters for Walleyes in Cheat Lake, North American average (Quist et al. 2003) and for five other West Virginia reservoirs.

\begin{tabular}{|c|c|c|c|}
\hline & $L_{\infty}$ & k & $\mathbf{t}_{0}$ \\
\hline \multicolumn{4}{|c|}{ Females } \\
\hline Cheat Lake, WV & 754 & 0.313 & -0.172 \\
\hline N.A. average (Quist et al. 2003) & 652 & 0.266 & -0.346 \\
\hline East Lynn Lake, WV & 690 & 0.41 & 0.20 \\
\hline Burnsville Lake, WV & 682 & 0.33 & -0.11 \\
\hline Stonecoal Lake, WV & 655 & 0.36 & -0.31 \\
\hline Tygart Lake, WV & 644 & 0.15 & -1.02 \\
\hline Summersville Lake, WV & 422 & 0.68 & 0.16 \\
\hline \multicolumn{4}{|c|}{ Males } \\
\hline Cheat Lake, WV & 502 & 0.746 & 0.184 \\
\hline N.A. average (Quist et al. 2003) & 496 & 0.419 & -0.083 \\
\hline East Lynn Lake, WV & 558 & 0.67 & 0.37 \\
\hline Burnsville Lake, WV & 500 & 0.65 & 0.16 \\
\hline Stonecoal Lake, WV & 494 & 0.73 & -0.01 \\
\hline Tygart Lake, WV & 416 & 0.43 & -0.56 \\
\hline Summersville Lake, WV & 372 & 1.23 & 0.47 \\
\hline
\end{tabular}

Table 3.7. Summary of diet contents from Cheat Lake Walleyes $(n=33)$.

\begin{tabular}{lcccc}
\hline Prey Species & Oi & MNi & Prey size range $(\mathbf{m m})$ & Mean prey size $(\mathbf{m m})$ \\
\hline Yellow Perch & 66.7 & 48.1 & $76-229$ & 110 \\
Gizzard Shad & 12.1 & 23.1 & $84-132$ & 121 \\
Emerald Shiner & 9.1 & 19.2 & $71-98$ & 87 \\
Lepomis sp. & 9.1 & 5.8 & $40-76$ & 58 \\
Micropterus sp. & 3.0 & 3.8 & 104 & 104 \\
\hline
\end{tabular}


Figure 3.1. Walleye gill net sampling locations in Cheat Lake, WV.

Figure 3.2. Temporal changes in CPUE (Walleyes/net-night) of Fall Walleye gill net surveys for Cheat Lake. Error bars represent one standard error. Black dashed line represents the first year of Walleye stocking in 1999.

Figure 3.3. Sex-specific length frequency distribution (25-mm bins) of Cheat Lake, WV Walleyes $(\mathrm{n}$ (females) $=57, \mathrm{n}$ (males) $=38, \mathrm{n}$ (immature $)=28$ ) collected for age and growth analysis.

Figure 3.4. Age frequency distribution (adjusted +1 year for comparison with Quist et al. 2003 growth standards) of Cheat Lake, WV Walleyes ( $n=123)$ collected for age and growth analysis during fall of 2013 and 2014.

Figure 3.5. The von Bertalanffy growth model fit to length at age data for 123 Cheat Lake Walleyes (ages 1-14). Female growth model is represented by black line and female mean length at age represented by circles. Male growth model is represented by blue line and male mean length at age represented by triangles. The von Bertalannfy model parameters for males and females are provided.

Figure 3.6. Comparison between growth rates of female Cheat Lake, WV Walleyes to the average North American growth rate (Quist et al. 2003) using von Bertalanffy growth models. 
Figure 3.7. Comparison between growth rates of male Cheat Lake, WV Walleyes to the average North American growth rate (Quist et al. 2003) using von Bertalanffy growth models.

Figure 3.8. Comparison between growth rates of female Cheat Lake, WV Walleyes to the Walleye growth rates in five other West Virginia reservoirs (East Lynn, Burnsville, Stonecoal, Tygart, and Summersville Lakes) using von Bertalanffy growth models.

Figure 3.9. Comparison between growth rates of male Cheat Lake, WV Walleyes to the Walleye growth rates in five other West Virginia reservoirs (East Lynn, Burnsville, Stonecoal, Tygart, and Summersville Lakes) using von Bertalanffy growth models.

Figure 3.10. Year class frequency of Walleyes collected for age and growth analysis $(n=123)$ during fall of 2013 and 2014. Years when fingerlings were stocked are represented by black bars. Years without Walleye stockings are represented by crosshatched bars. 


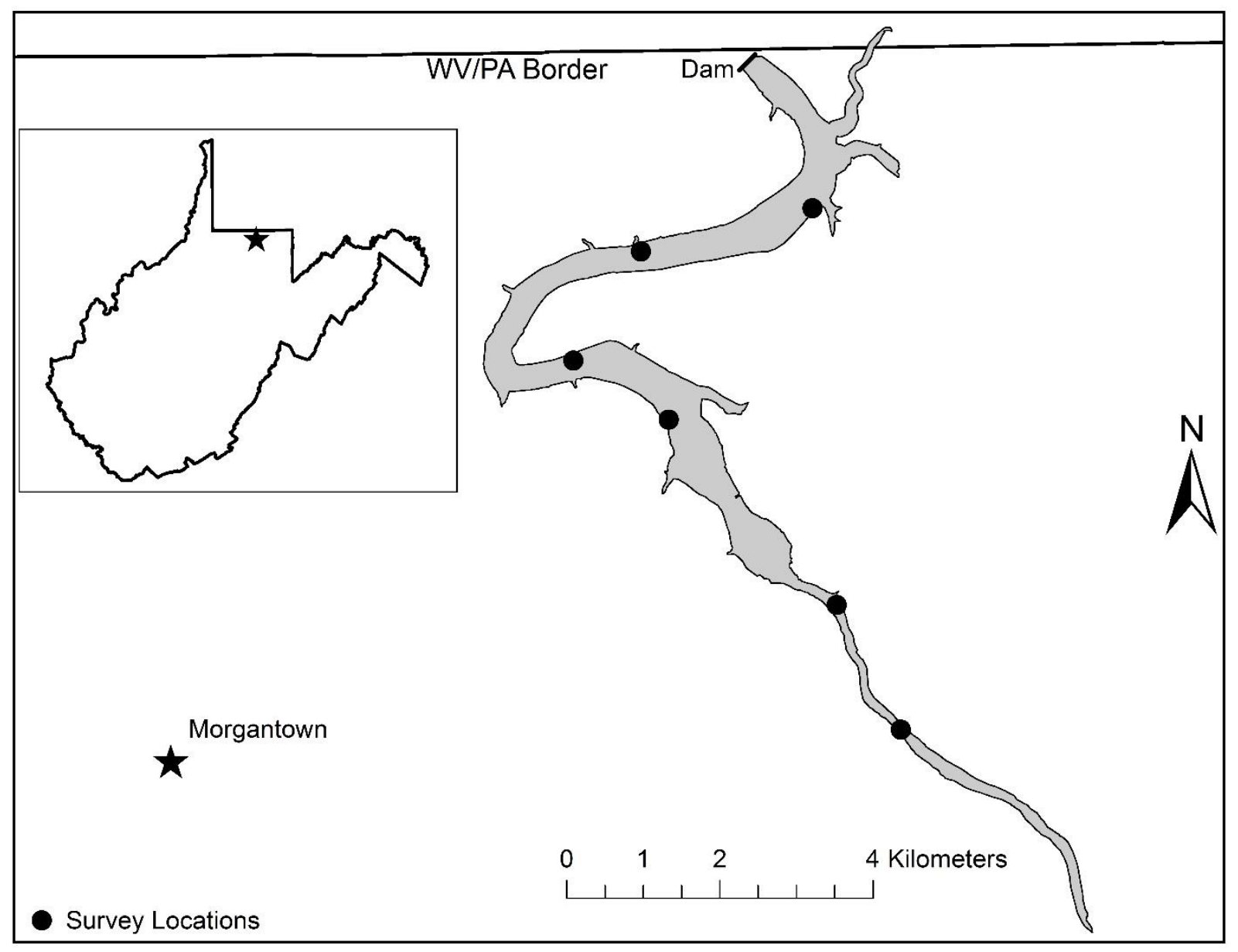




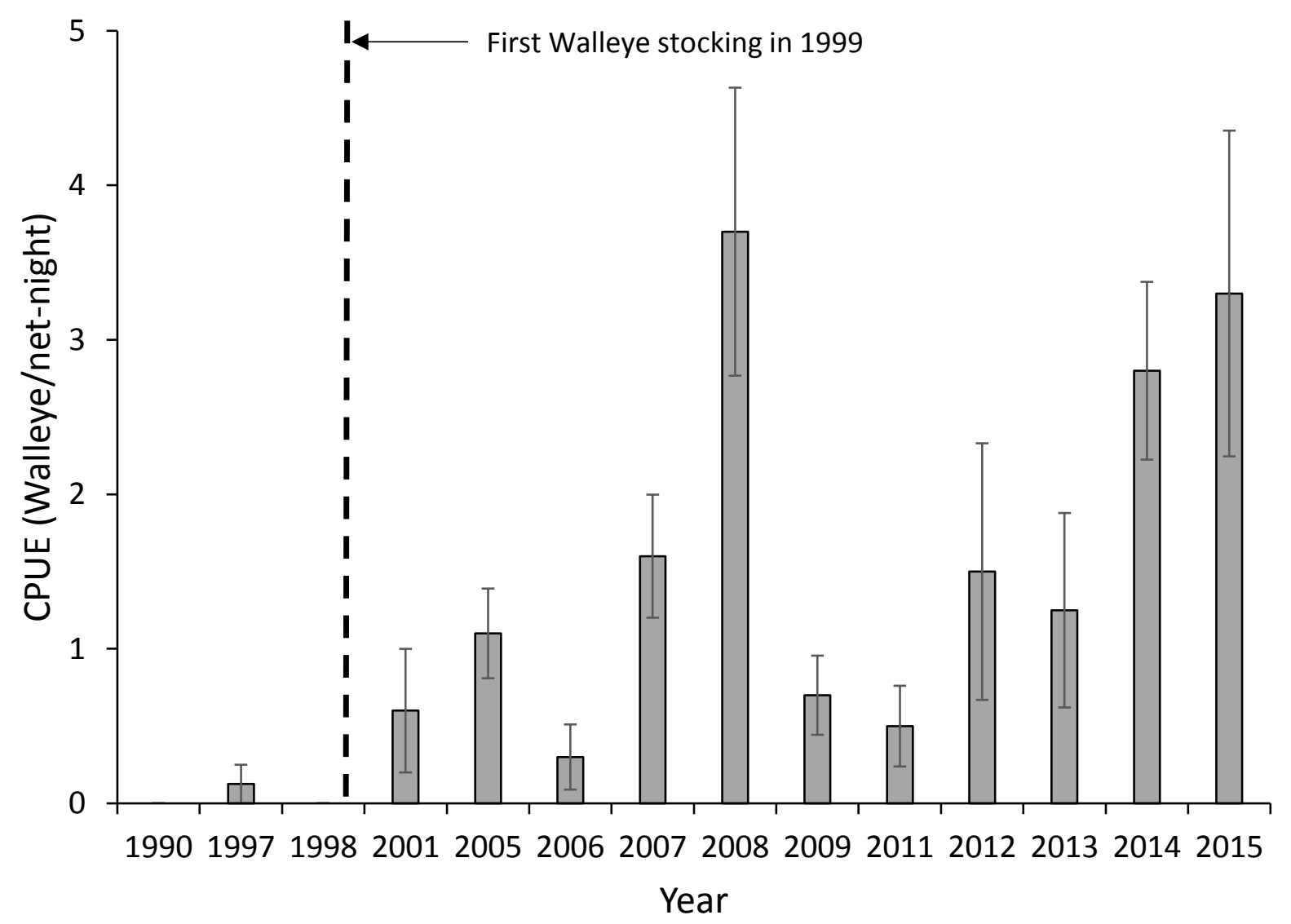




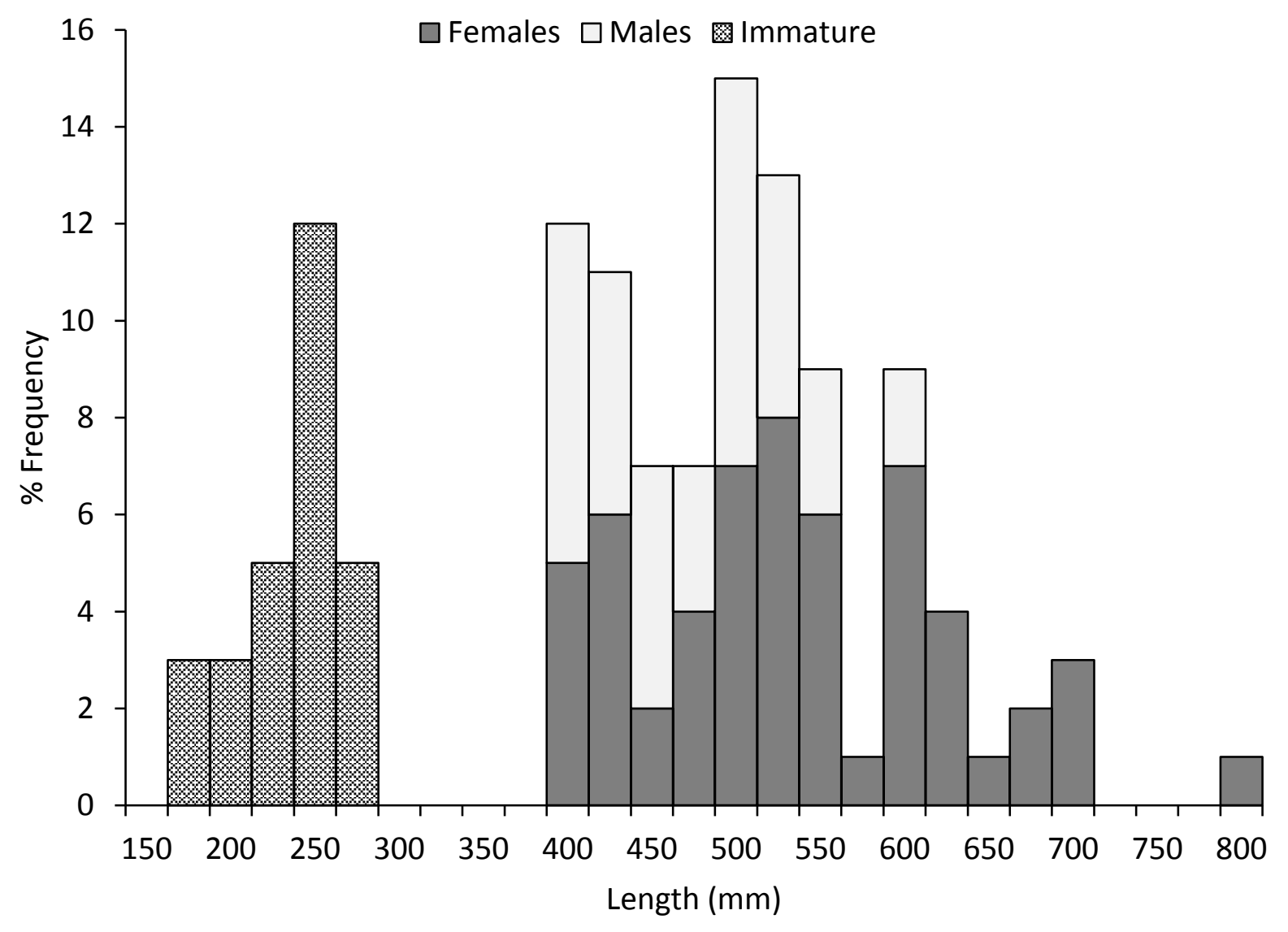




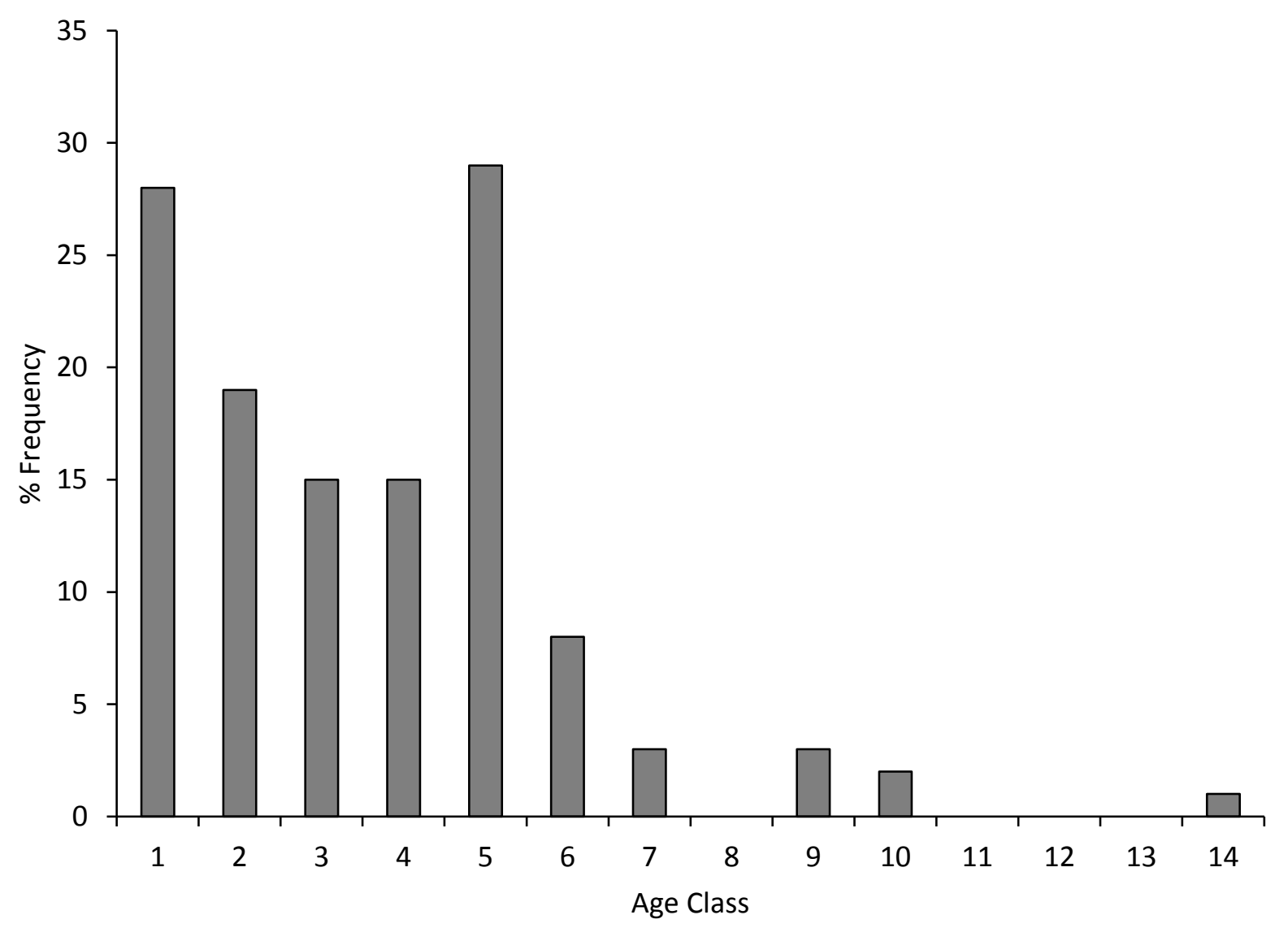




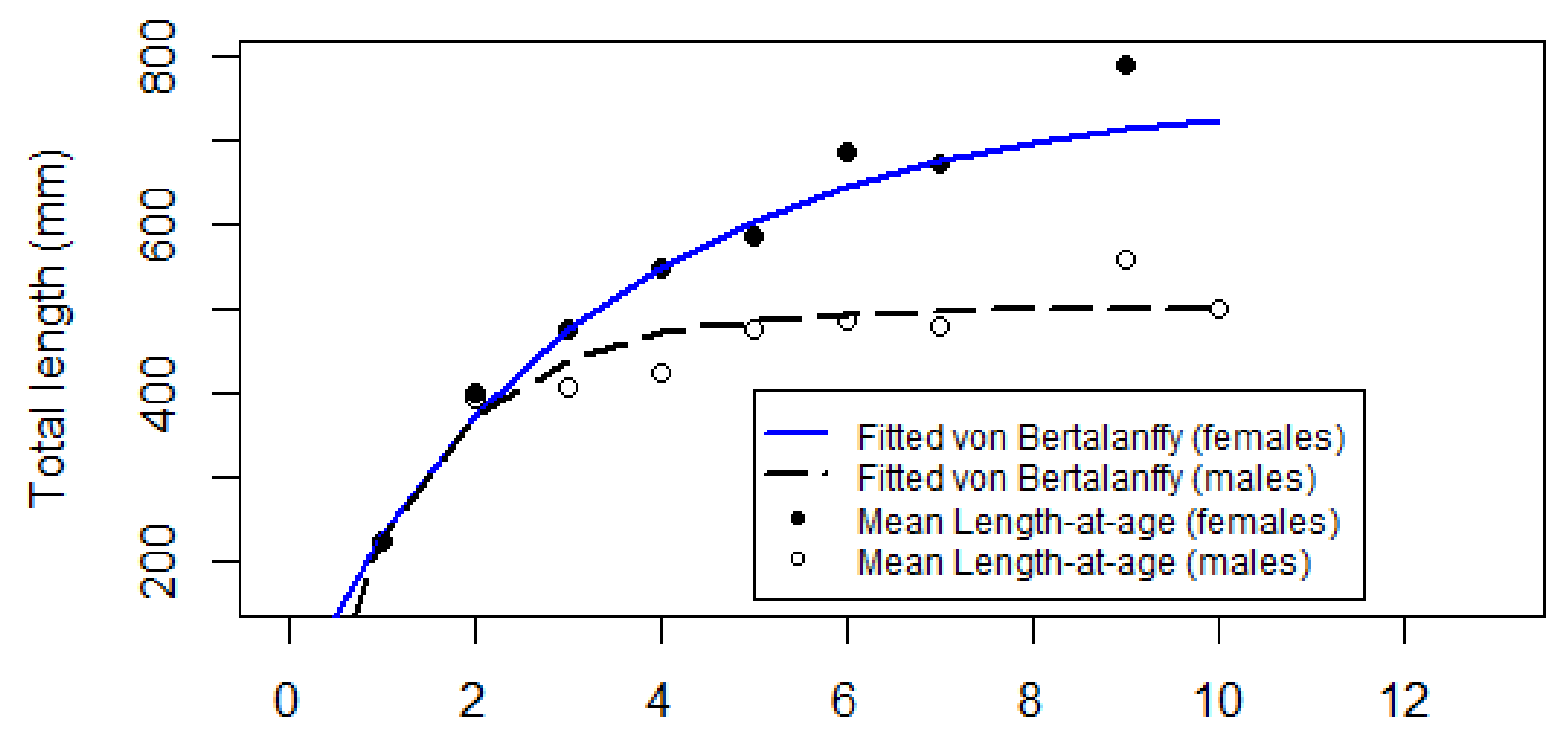

Age (yrs)

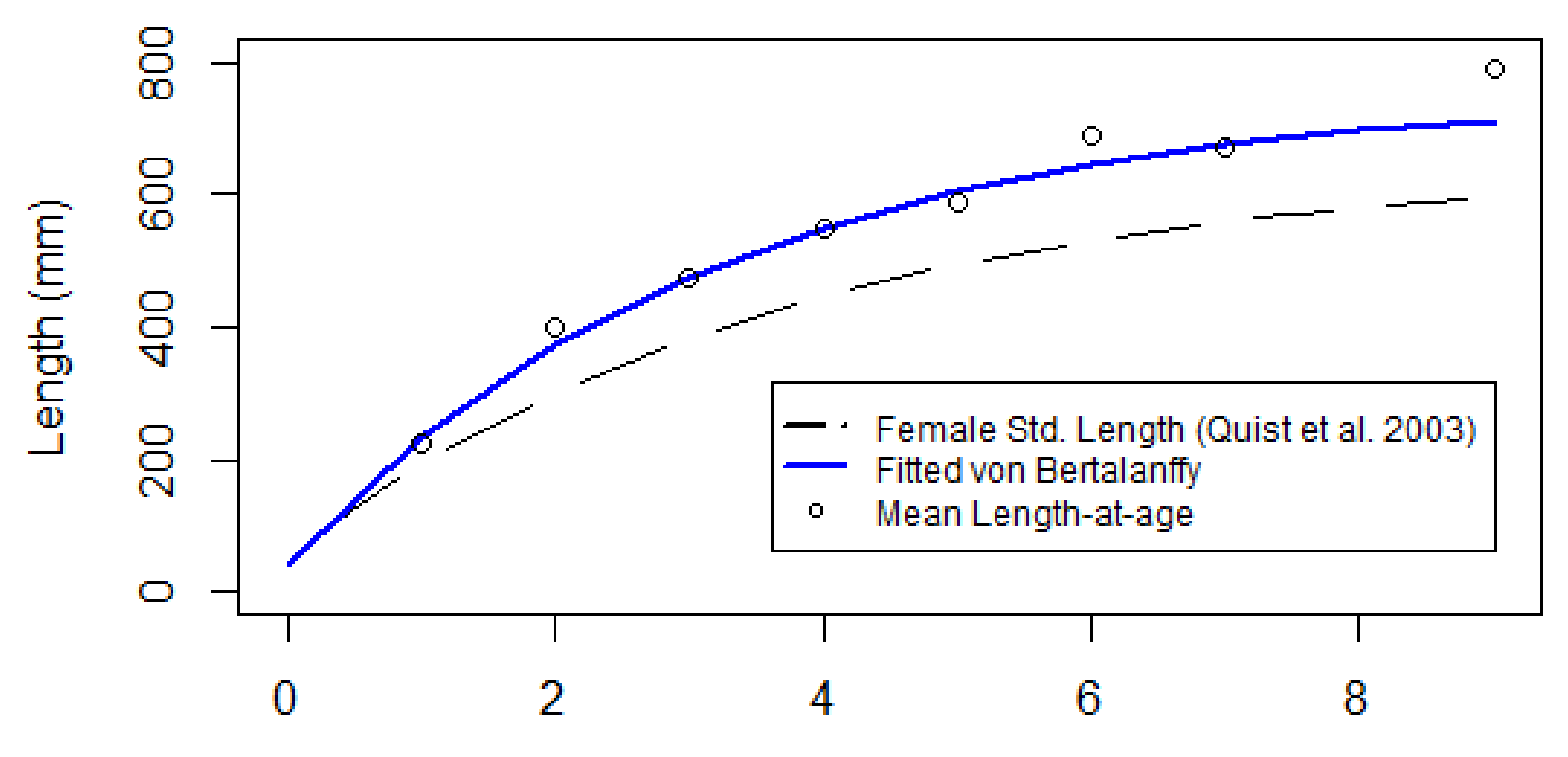

Age (yrs) 


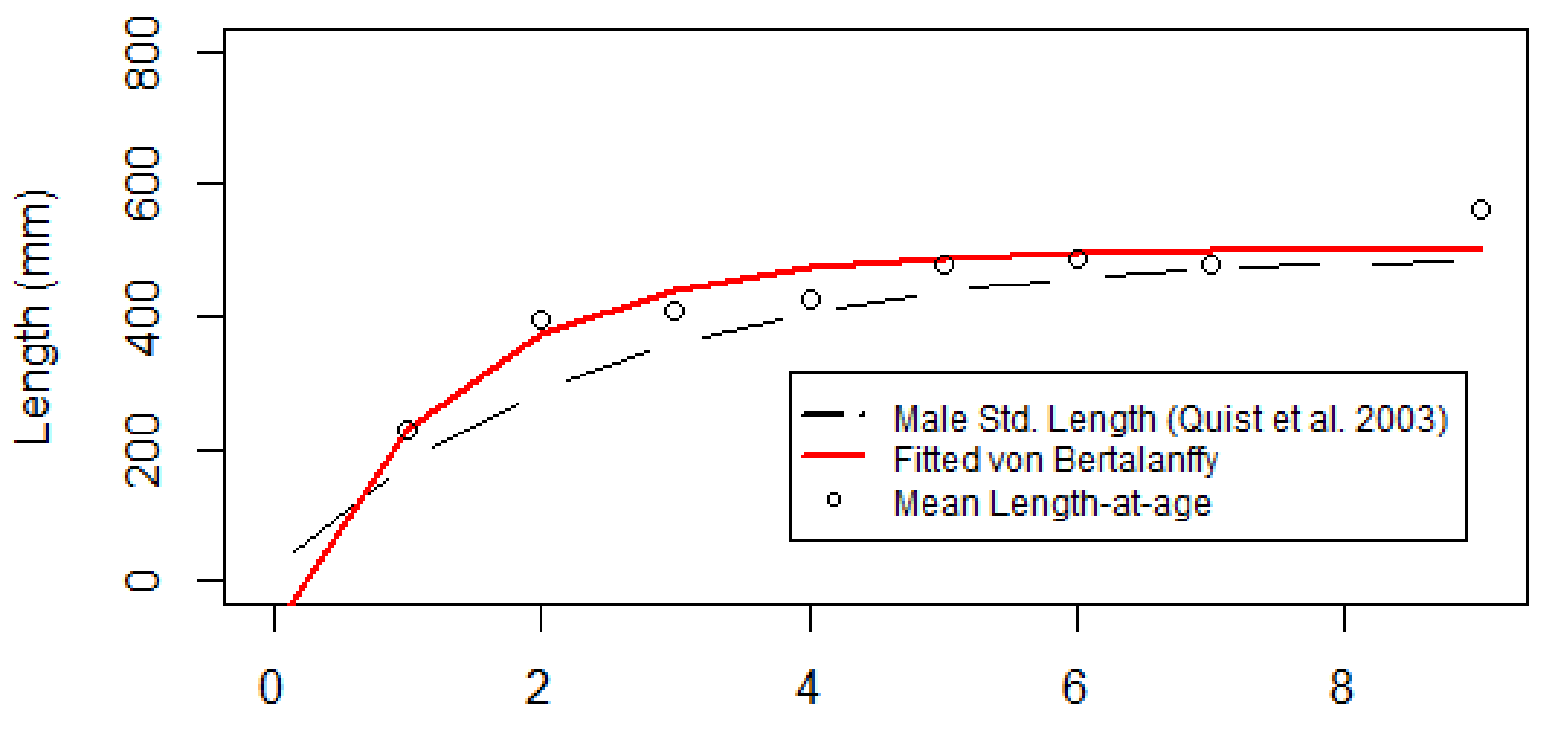

Age (yrs) 


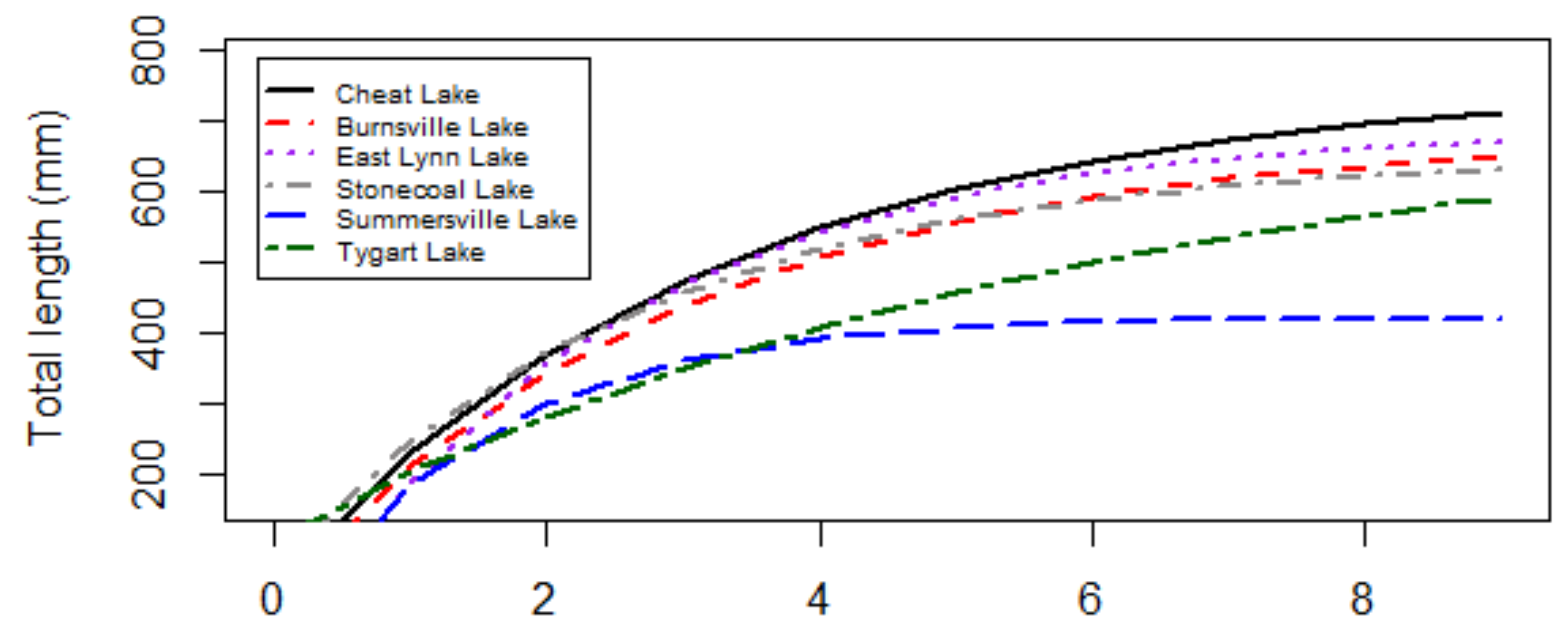

Age (yrs)

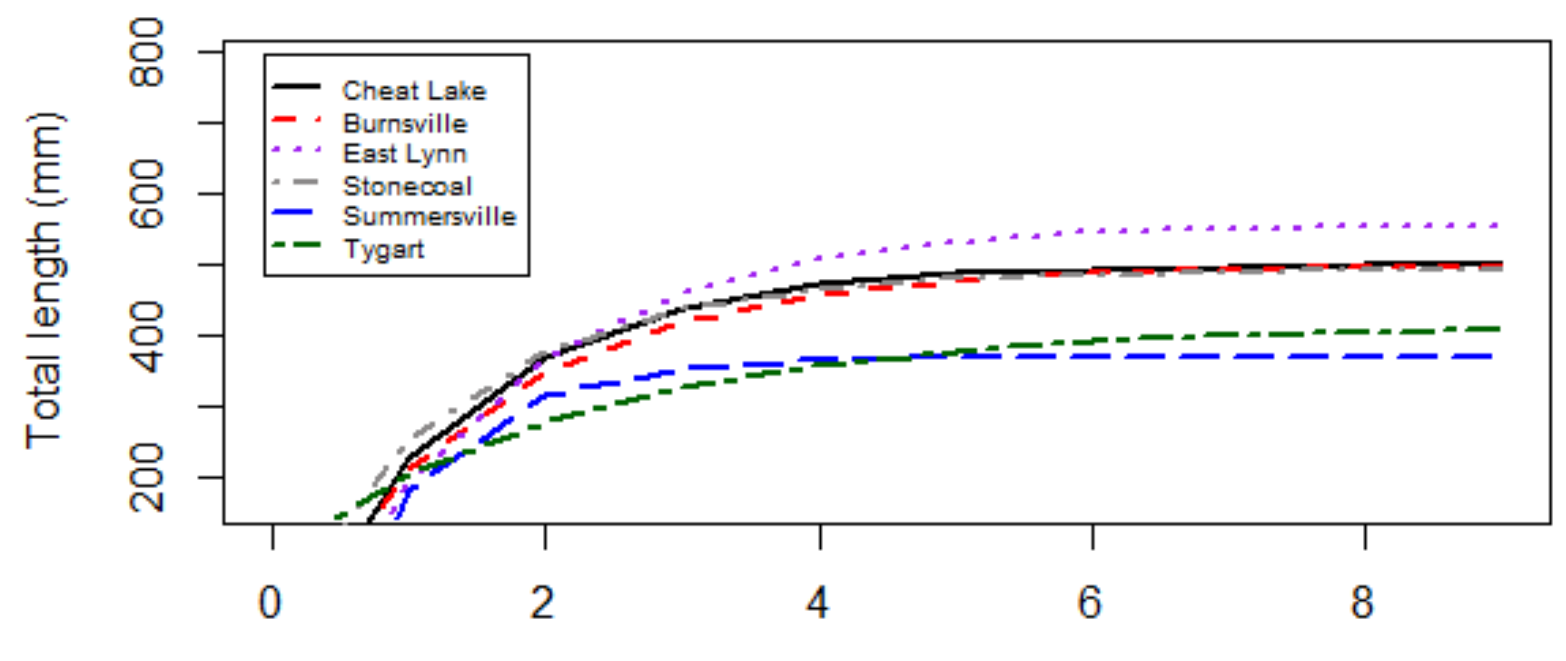

Age (yrs) 


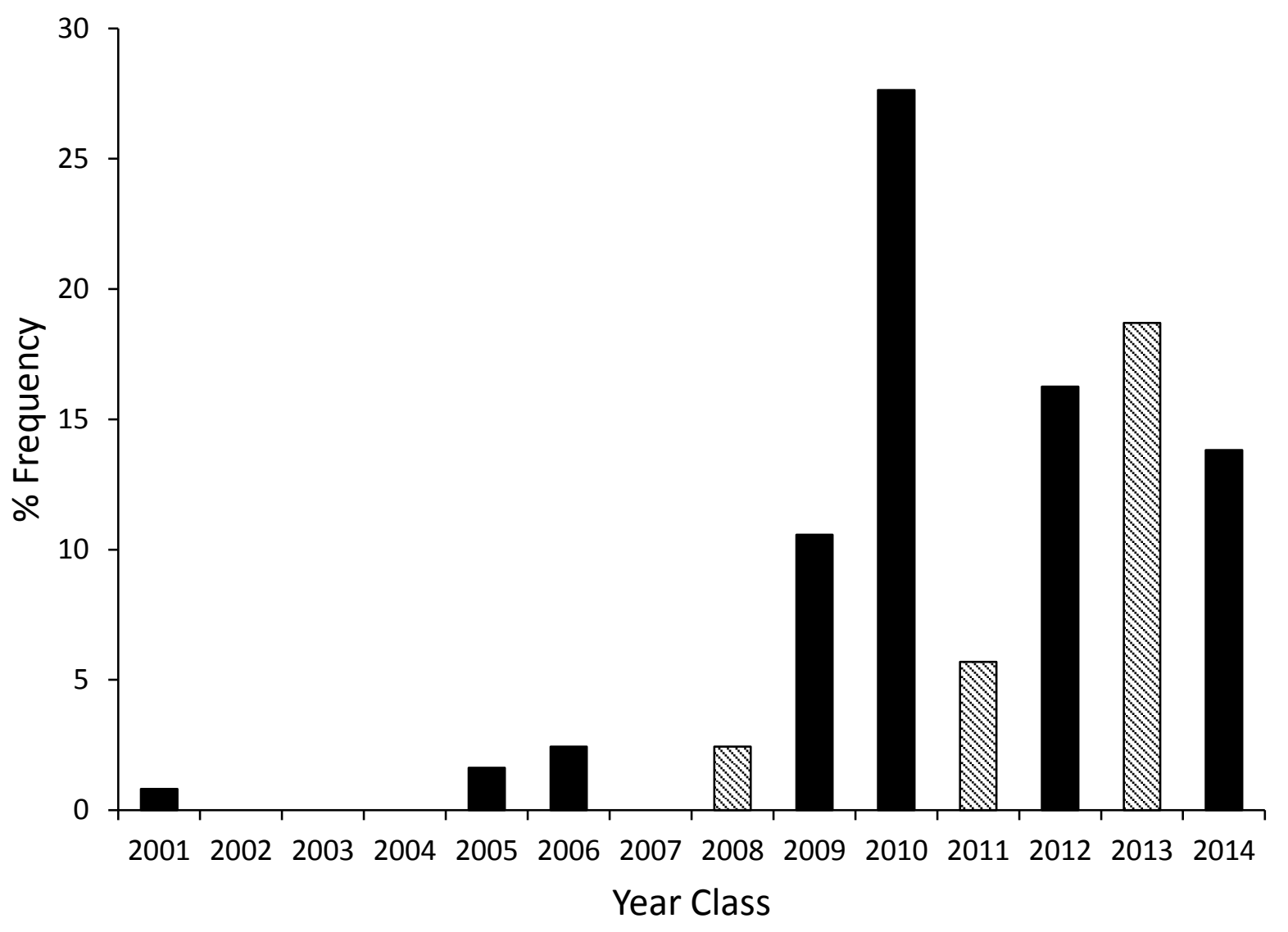




\section{Chapter 4 - Seasonal distribution and space use patterns of Walleyes in a hydropower reservoir}

\section{Abstract}

Knowledge and understanding of the ecology and spatial distribution of sportfishes, such as Walleye (Sander vitreus), are critical for fisheries management. Recently, a Walleye population was reestablished in Cheat Lake, a 700 ha hydropower reservoir in northern West Virginia, where movement patterns and spatial distribution of this species had not been described. From 2012-2015, seasonal movements and distribution of telemetered Walleyes in Cheat Lake were monitored using a stationary acoustic receiver array. Walleye locations were analyzed for seasonal changes in distribution and space use patterns as measured through seasonal distribution, home range, core range, and lake residency. Walleye movements and distributions varied seasonally and by sex. Overall, the most heavily used area of Cheat Lake by Walleyes were main lake habitats compared to riverine habitats (59.1\% of overall time). Seasonally, riverine habitats were most heavily used from March-August (47.6\%), with the highest proportion of use occurring in March (62.1\%). In contrast, main lake habitat was most heavily used from September-February $(73.9 \%)$, with the highest proportion of use occurring in January (87.9\%). Additionally, male Walleyes were more likely to occupy riverine habitats compared to female Walleyes. Most Walleyes demonstrated seasonal shifts in core range and linear home range. Additionally, male Walleyes were more likely to have more than one core range compared to females. Number of monthly range shifts were higher than average from March-May, and October-November. Also, as indicated by residency index, male Walleyes were more likely to emigrate from Cheat Lake into the incoming river upstream compared to females. Overall, distribution and space use patterns indicated that Walleyes were overall more likely to experience range shift or changes in distribution in spring and fall months. These 
temporal patterns of distribution were likely associated with spawning activity in spring and movement to overwintering habitats in fall. Knowledge of these spatial patterns will inform management efforts, as well as provide anglers with beneficial knowledge in targeting this improving fishery.

\section{Introduction}

Understanding the spatial ecology of top predators in reservoir ecosystems is a critical component to conservation and management of reservoir fisheries (Craig 2000; Lucas and Baras 2000; Quist et al. 2003; Landsman et al. 2011; Daly et al. 2014). Top predators such as Walleyes are important in structuring fish communities and are also often popular sportfish (Craig 2000; Quist et al. 2003; Pothoven et al. 2016). Spatial distribution and home range of such species often varies seasonally depending on habitat needs associated with spawning, foraging, and overwintering (Williams 2001; DePhilip et al. 2005; Palmer et al. 2005; Foust and Haynes 2007; Bozek et al. 2011). Home and core range can also vary individually within a population or have sex based differences (Palmer et al. 2005; Bozek et al. 2011; Hayden et al. 2014). Knowledge of the seasonal distribution and spatial ecology of top predators can greatly benefit reservoir fisheries management through understanding of spatial trophic structure and spatial vulnerability of populations to fishing pressure (Craig 2000; Quist et al. 2003; Pothoven et al. 2016).

Given the economic importance of recreational and commercial Walleye fisheries (Schmalz et al. 2011), managers need information on the extensive movements and seasonal shifts in distribution of Walleyes in conjunction with spawning, foraging, and overwintering (Paragamian 1989; DePhillip et al. 2005; Hanson 2006; Bozek et al. 2011). Several tagging 
studies have examined the spatial ecology of Walleyes (Eschemeyer and Crowe 1955; Crowe 1962; Paramagian 1989; DePhillip et al. 2005; Palmer et al. 2005; Hanson 2006; Hayden et al. 2014). Past studies have focused mostly on Walleye movements and distribution in northern or midwestern states (Holt et al. 1977; Paramagian 1989; Williams 2001; DePhillip et al. 2005; Hanson 2006; Bozek et al. 2011). Although much is known about Walleye life history including spatial ecology (Bozek et al. 2011), as with many species, movement patterns and spatial ecology can have substantial variation between waterbodies and regions (Bozek et al. 2011). Research on Walleye movement suggests that movement can vary seasonally and with changing environmental conditions (Paragamian 1989; Williams 2001; DePhillip et al. 2005; Palmer et al. 2005; Hanson 2006; Bozek et al. 2011). Most studies on Walleye distribution and habitat use have focused on activity during spawning with less focus on non-spawning periods (Paragamian 1989; DePhillip et al. 2005; Palmer et al. 2005; Hanson 2006; Bozek et al. 2011). Although Walleye movement has been extensively studied in several regions such as the Great Lakes and the Midwest, little research has been conducted in Appalachian reservoirs (Williams 2001; Palmer et al. 2005). Additionally, a substantial portion of research on Walleye spatial ecology has employed manual tracking techniques. Recently, researchers have used continuous acoustic monitoring of Walleyes with stationary acoustic receivers (Hanson 2006; Phillips 2014; Hayden et al. 2014; Peat et al. 2015; Raby et al. 2018).

Cheat Lake is a hydropower reservoir in northern West Virginia that historically supported Walleye but has been impacted by acidification. For over a century, Cheat Lake was severely impacted by acid mine drainage from abandoned mine lands (Core 1959; Welsh and Perry 1997; Freund and Petty 2007; Merovich et al. 2007). As a result, Walleyes were reportedly extirpated from the reservoir in the late 1940's (Core 1959). Abatement of acid mine drainage pollution, beginning in the 1980's, has led to improved water quality in the reservoir and throughout the watershed (McClurg et al. 2007). In response to improved water quality, the 
WVDNR began stocking Walleyes in 1999 and have continued on a bi-annual basis. Given the success of stockings and recent evidence of natural reproduction, more information on the life history of Walleyes in Cheat Lake, including movements and distribution, would be beneficial to the future management of the population. Information gained on both spawning and nonspawning seasonal locations and movements would further enhance management opportunities of the fishery. Therefore, there is a need for research investigating seasonal distribution and space use patterns of Walleyes within Cheat Lake. With knowledge of seasonal distribution and other spatial behavior, managers can better predict potential impacts to the population by environmental conditions and fishing pressure. Increased knowledge of Walleye distribution, home range, and residency would provide beneficial information to both managers and anglers.

The goal of this study was to determine the seasonal home and core range, lake residency, and seasonal distribution of Walleyes in a West Virginia hydropower reservoir. Specifically, one objective was to determine what reservoir areas were utilized, and if distributions changed temporally or differed between males and females. Additionally, we sought to determine residency of Cheat Lake Walleyes, how Walleyes may emigrate from the system, and if there were temporal or sex based differences in residency.

\section{Methods}

\section{Study Area}

Cheat Lake, formed in 1926, is a hydropower reservoir on the lower Cheat River, northern West Virginia. The reservoir has a surface area of $700 \mathrm{ha}$, is approximately $21 \mathrm{~km}$ in length and has a maximum depth of $24 \mathrm{~m}$ near its dam. The reservoir serves the needs of a hydroelectric generating facility at its dam. The reservoir experiences daily and seasonal water level fluctuations due to hydropower operations. Fluctuations are restricted to $0.6 \mathrm{~m}$ from May - 
October and are at their maximum during November - March when levels can fluctuate $3.9 \mathrm{~m}$. Fluctuations are restricted to $2.1 \mathrm{~m}$ during April in an attempt to protect spawning habitat and activities of Walleye and Yellow Perch.

For this study, we designated three spatial zones of Cheat Lake for comparisons of Walleye movements and distribution: the riverine zone, middle main lake zone, and lower main lake zone (including embayments) (Figure 4.1). Additionally, we recognized the Cheat River upstream of the reservoir as a separate zone (Figure 4.1). Separation of these zones was based on various factors including reservoir morphology, bathymetry, and water chemistry differences. Specifically, based on morphology, there is a distinct morphological difference between the riverine zone, middle lake zone, and lower lake zone. The riverine zone is relatively narrow in cross section, whereas the middle and lower lake zones are typically $2.5-3$ times the width of the riverine zone (Figure 4.1). There is also a distinct difference in hydrological characteristics between the three zones. The riverine zone is heavily influenced by the incoming Cheat River in terms of river current. In contrast, the middle and lower lake zones are much more lacustrine in character as river current is spread out. This is apparent by the typical pattern of overwinter ice formation in the middle and lower lake zones but absence of ice in the riverine zone. Additionally, throughout most of the middle and lower lake zones, average depths are greater than that occurring within the riverine zone. The lower lake zone and middle lake zone also differed in characteristics. Specifically, the middle lake zone is more of a transitional area between the riverine habitat of the riverine zone and the lacustrine habitat of the lower lake zone. The middle lake zone typically has bathymetric and morphological characteristics intermediate of the riverine and lower lake zones.

Fish Collection and Tagging 
Fifty-two Walleyes (30 males, 20 females, 2 undetermined, 432-708 mm TL) were collected and implanted with acoustic transmitters in the months of October-February, in 2011, 2012, and 2013. Walleyes were collected using boat electrofishing and gill nets from all 3 reservoir zones. Prior to transmitter implantation, each Walleye was measured for total length $(\mathrm{mm})$ and weighed $(\mathrm{g})$. After anesthetization (MS-222, tricaine methanesulfonate, $100 \mathrm{mg} / \mathrm{L}$ ), acoustic transmitters (Sonotronics CTT-83-3-I) were surgically-implanted into the abdominal cavity of each Walleye (Hart and Summerfelt 1975). Acoustic transmitters were $62 \mathrm{~mm}$ in length, $16 \mathrm{~mm}$ in diameter, weighed $10 \mathrm{~g}$ in water and had an estimated battery life of 3 years. Each fish was tagged with a numerically coded external t-bar anchor tag. Each anchor tag displayed contact information in the event of angler caught fish. Additional information was included on each tag recommending the release of the fish due to the 21-day hold time of MS222. Fish were placed in a V-shaped trough during surgery, ventral side up, and the gills were continuously irrigated with water. Surgical instruments were sterilized prior to surgery and betadine was applied to the incision site as an antiseptic. To insert the transmitter, an incision of approximately $20-30 \mathrm{~mm}$ was made and 3-4 sutures of non-absorbable monofilament were used to close the incision (Ethicon). Surgical procedures lasted less than 7 minutes. After surgery, fish were placed in a livewell to recuperate and were monitored until swimming upright and behaving normally (usually a period of 5-10 minutes). To reduce tag-induced behavior, transmitter weight was never more than $2 \%$ of the fish weight (Winter 1996). We also included a recovery period of 4 weeks prior to data collection to monitor for abnormal behavior associated with gear-induced and post-surgery stress or injury (Gilroy et al. 2010). When possible Walleyes were sexed by examination of the gonads through the surgical incision or by expulsion of milt for males. Some Walleyes that were initially difficult to sex were later recaptured via fish surveys or anglers and sex was verified. 


\section{Telemetry}

Movements and locations of tagged Walleyes were monitored from January 2012-April 2015. Some manual tracking of Walleyes was conducted to determine fine scale range and distribution. However, tagged Walleyes were predominantly monitored year-round using an array of stationary receivers (Sonotronics omni-directional submersible receivers) deployed throughout Cheat Lake (Figure 4.1). An attempt was made to position receivers relatively equidistant from each other to maximize effective coverage. Receivers were either attached to buoys or tethered to the shoreline via root systems. Receivers were attached to buoys or the shoreline using $9.5 \mathrm{~mm}$ steel cable and were anchored in place using two, $20 \times 20 \mathrm{~cm}$ cinder blocks. Receivers attached to the shoreline were dropped approximately 20-30 m away from and perpendicular to the shoreline. At most, 10 acoustic receivers were active within the reservoir, with an additional receiver placed approximately $1 \mathrm{~km}$ upstream of Cheat Lake (upstream of $1^{\text {st }}$ riffle/run complex). The receiver located $12 \mathrm{~km}$ upstream of the dam was added in November 2012. The two receivers located within the large embayments near the dam were lost in December 2013. The mean distance between each receiver was approximately $2.4 \mathrm{rkm}$. Tag detection range of acoustic receivers can be influenced by thermal stratification, acoustic noise (bridges) and sinuosity (Shroyer and Logsdon 2009). Tag detection range varied seasonally in Cheat lake due to thermal stratification. Specifically, thermal stratification reduces the effective range of receivers (Shroyer and Logsdon 2009). Range detection tests determined that the average detection range of acoustic receivers during periods of thermal stratification was 200-500 m. During periods without stratification, range of receivers was between 400900m. 


\section{Data Analysis}

Telemetry data were retrieved from stationary receivers. Data were processed using Sonotronics SURsoftDPC software, and exported to Microsoft Excel for further data processing and analysis. Acoustic telemetry data can produce false detections due to background noise (sonar units, other disturbances) and multiple tagged fish close to a receiver at once (Pincock 2011). Possible false detections were eliminated from the dataset by omitting single detections from individual fish within a 24 hour period (Harasti et al. 2015). Additionally, records of individual fish occurring in multiple locations simultaneously $(<0.01 \%$ of detections) were eliminated from the dataset. Due to the large number of detections per individual fish that often include hours or days of continuous relocations at the same receiver, data were transformed into a manageable format for analysis. Data were transformed to reflect arrival and departure dates/times and direction of travel for individual fish for each receiver (Rosenblatt and Heithaus 2011).

Overall and temporal distribution and range of tagged Walleyes were summarized from processed telemetry data. Due to the potential bias of using number of detections at a receiver from unequal detection range of receivers and seasonal changes in detectability, fish locations were instead summarized by the amount of time each fish spent at a receiver (Walsh et al. 2012; Ramsden et al. 2016). Specifically, the number of overall days each fish spent at each receiver was determined (Ramsden et al. 2016). Calculations of overall days spent near a receiver were transformed for each individual into percent time spent near a specific receiver or percent time spent in a lake zone. Tagged fish were determined to be in the area of a receiver when two or more consecutive detections were recorded within an hour (Walsh et al. 2012). If fish were absent for more than one hour then location was determined to be averaged over the location prior to and after the absence (Cowley et al. 2008). Calculation of percent time spent near a receiver allowed us to determine proportional use of lake zones by individual fish and 
also proportional use of lake zones by month for all fish. When referencing distribution seasonally, we defined seasons as the following: winter (December-February), spring (MarchMay), summer (June-August), and fall (September-November). Proportional use of receivers or lake zones were examined for differences across months. Comparisons were also made to determine if there were differences in proportional use of receivers or lake zones by fish sex.

Due to the linear set up of our array system and coarse detail of locations due to relocation data from receivers, we did not utilize traditional home range calculation techniques (Vokoun 2003; Walsh et al. 2012). Instead, we adopted the approach used by Walsh et al. (2012) by calculating probability intervals using Pareto cumulative frequency density plots. This method calculates a utilization distribution that is based on the probability of an individual fish using a particular area (Vokoun 2003; Walsh et al. 2012). As described by Walsh et al. (2012), receiver area boundaries were designated as mid-points between receivers. Sections that encompassed $50 \%$ of the receiver areas used by a fish were considered the core-use area (Walsh et al. 2012). Similarly, sections that encompassed $95 \%$ of the receiver areas used by a fish were considered the home range of the fish (Walsh et al. 2012). Home range length for individual fish was described as the distance between the furthest downstream and furthest upstream areas encompassed in the home range of a fish (Walsh et al. 2012).

We examined spatial distribution of Walleyes in several ways utilizing core range calculations. Overall core range was calculated for each individual. Number of overall core use areas was calculated and analyzed using a Kruskal-Wallis test to determine if there were sexbased differences $(\alpha=0.05)$. We also used a Kruskal-Wallis test to determine if there were sexbased differences in lake zone occupied in the overall core use areas $(\alpha=0.05)$. Specifically, Walleye core range was labeled as either including the riverine zone and/or Cheat River or not including these zones. We also calculated monthly core range for each Walleye. Using these calculations we determined the frequency that receiver areas were included in core use areas 
across months. Using monthly core range calculations, the lake zone encompassed by the core use area was determined for each month. Additionally, we calculated changes in core range shifts. During months when tagged Walleyes shifted lake zones in core range (e.g., core range shift from the middle main lake to riverine zone), a "1" was assigned for that month. If no shift occurred then a "0" was assigned. This binary setup allowed us to determine what months had the highest frequency of core range shifts among tagged Walleyes. Repeated measures binomial logistic regression (package "Ime4" in program R, Bates et al. 2015) was used to determine if there was a significant effect $(\alpha=0.05)$ of sex and/or month on core range shifts.

We also evaluated changes in monthly Walleye movement by comparing linear range expansion and contraction. Following Topping et al. (2006), we took the number of receivers by which individual fish were detected each month and calculated a yearly mean for number or receivers visited. To get an estimate of monthly range deviations, we took the yearly mean for each fish and subtracted it from the number of receivers fish visited each month (Topping et al. 2006). Positive deviations from the mean number of receivers visited indicated range expansion, while negative deviations indicated range contraction (Topping et al. 2006). A linear mixed effects model (package "Ime4" in program R, Bates et al. 2015) was used to test for significant effects of month and/or sex $(\alpha=0.05)$ in monthly range deviations (Topping et al. 2006).

Lake residency of tagged fish in our study was affected by both emigration downstream of the lake (via dam spillway or turbine passage) or emigration upstream of the lake into Cheat River. Downstream movement via the dam spillway or turbine passage resulted in permanent emigration from the lake (and possibly mortality in some instances), whereas upstream movement into Cheat River allowed for later immigration back into the lake. We evaluated potential environmental factors (river discharge, lake elevation, water temperature) and temporal patterns associated with permanent emigration over or through the dam. Due to the 
relatively small number of fish that escaped via the dam, we did not conduct statistical analysis on these movements, but simply described associated environmental conditions and temporal patterns through simple summary statistics (e.g., mean, standard errors, etc.) or with a graphical approach. We also calculated a residency index for Walleyes. Residency index was calculated as the number of days fish were present within the lake divided by the total number of days the fish was at liberty. Calculation of this index provided an indication of what proportion of time fish remained in the lake boundaries vs time spent upstream in Cheat River. Both an overall residency index (including the entire tagged life of a fish) and a monthly residency index were calculated. We tested for sex based differences in overall residency of tagged Walleyes using a Kruskal-Wallis test $(\alpha=0.05)$. We also tested for effects of month and/or sex on differences in residency using a linear mixed effects model $(\alpha=0.05)$.

Environmental data, referenced for comparisons to telemetry data, included water temperature $\left({ }^{\circ} \mathrm{C}\right)$, lake elevation, and river discharge data acquired from the U.S. Geological Survey Water Watch website (http://water.usgs.gov/waterwatch). Additionally, water temperature and river discharge data were taken from the Albright gauging station on the Cheat River. The Albright gauging station is approximately $24 \mathrm{rkm}$ upstream from the head of Cheat Lake. Lake elevation data were taken from a monitoring gauge at the Cheat Lake hydrostation.

\section{Results}

From January 2012-April 2015 a total of 40 Walleyes (19 males; 19 females; 2 unknown) provided data on seasonal distribution and range (Table 4.2; Table 4.3). Three of 19 females were immature during part of their monitoring period and six of the 19 females were believed to be immature during their entire monitoring period. The number of fish monitored per year included 6 individuals in 2012, 31 individuals in 2013, 20 individuals in 2014, and 15 
individuals in 2015. Twelve of the fish originally tagged did not provide data on seasonal distributions due to either mortality, emigration over the dam within 30 days of tagging or transmitter failure. Fish that were tagged in winter of 2014 did not provide summer-winter movement data as acoustic receivers were removed from the reservoir the following spring.

A total of 2,769,936 detections were recorded for 40 acoustically-tagged Walleyes (Table 4.2). The most detections for an individual fish was 188,272 (fish \#80; Table 4.2). The mean number of detections (averaged over all fish) was $69,248(\mathrm{SE}=7461)$. A total of 1,216 days were monitored for fish movement during the monitoring period. The mean number of days that fish were monitored was 589 days $(S E=45.3)$, and the most days monitored for an individual fish was 919 days for fish \#40 (Table 4.2). Temporal distribution of Walleyes showed substantial individual variation, but proportional use of lake zones was similar for many individuals (Table 4.1). Distribution often varied by month or season for individuals. Although Walleyes used all lake zones, the middle main lake zone was used most frequently overall by both male and female Walleyes (females: mean $=71.6 \%$, SE $=5.80 \%$; males: mean $=50.7 \%$, SE $=5.14 \%$; Table 4.1; Figure $4.5 \& 4.6$ ). The lower main lake zone was the overall least used area for males $($ mean $=5.09 \%$, SE $=2.61 \%$; Table 4.1; Figure 4.5), while the Cheat River was the overall least used area for females (mean $=4.96 \%$, SE $=2.44 \%$; Table 4.1 ; Figure 4.5$)$. The riverine zone and Cheat River were used substantially by males and accounted for an overall average of $30.7 \%(\mathrm{SE}=4.58 \%)$ and $13.4 \%(\mathrm{SE}=3.65 \%)$ of time, and for a combined overall mean of $44.2 \%(\mathrm{SE}=5.45 \%$; Table 4.1; Figure 4.5). For males, the riverine zone and Cheat River were used most heavily during spring and summer (March-September, mean = 72.0\%), and use decreased substantially in fall and winter (October-February, mean $=14.5 \%$ ) (Figure 4.5). For females, the riverine zone and Cheat River were primarily used in spring (March-April, mean $=35.2 \%$, , and use was substantially lower in other months (May-February, mean = 9.0\%) (Figure 4.6). In contrast to the riverine zone and Cheat River, males primarily used the 
middle main lake zone in fall and winter (October-February, mean $=80.6 \%$,), while use of this zone decreased from March-September (mean = 21.8\%) (Figure 4.5). Females utilized the middle main lake zone heavily during all months, but use was particularly high from MayFebruary (mean $=73.9 \%$ ), and was lower in March and April (mean = 56.8\%) (Figure 4.6). Use of the lower main lake zone was comparatively low for both males and females during all months, but females did utilize this zone more frequently than the riverine zone and Cheat River from June-February (Figures 4.5 \& 4.6).

Core, home, and total linear range of tagged Walleyes varied across individuals, although similarities in space use patterns were apparent in different groups of tagged fish. Walleyes could be grouped by number of overall core areas, including those individuals that occupied one core use area, and those that occupied two separate core use areas (Table 4.2). Specifically, 60\% (24 fish) of tagged Walleyes occupied one overall core use area, whereas $40 \%$ (16 fish) occupied two overall separate core use areas (Table 4.2). There was a significant difference in the number of core use areas between male and female Walleyes (Kruskal-Wallis: d.f. $=1, H=7.05, p$ value $=0.008)$. Specifically, most females $(84.2 \%)$ only had one core use area, whereas most males (57.9\%) had two core use areas (Table 4.2). Most Walleyes had a core range encompassing or including the middle main lake zone ( $90 \%$ of fish or 36 individuals; Table 4.2; Figure 4.2). The riverine zone and Cheat River were included in the core use areas by fewer Walleyes (20\% or 8 fish and $15 \%$ or 6 fish, respectively; Table 4.2 ; Figures 4.3 \& 4.4). The lower main lake was included in the core range by the fewest proportion of fish (10\%, 4 fish Table 4.2). Additionally, inclusion of the riverine and/or Cheat River zones in Walleye core use areas significantly differed between sexes (Kruskal-Wallis: d.f. $=1, \mathrm{H}=11.86$, p value $<0.001$ ). Specifically, only one female (5.3\% of females) utilized riverine habitats as part of its core use area, whereas, 11 males (57.9\%) utilized riverine habitats as part of their core range. Home range of tagged Walleyes also varied individually. Some Walleyes utilized nearly the entire lake 
as part of their overall home range $(16.4 \mathrm{~km})$ while one fish had the smallest overall home range that only included two receivers $(2.1 \mathrm{~km})$. Total linear range of Walleyes likewise varied individually. The largest linear range encompassed nearly the entire reservoir and the lower Cheat River (19.6 km), while the smallest linear range only included three receivers $(3.7 \mathrm{~km})$. The mean total linear range for Walleyes was approximately $14.3 \mathrm{~km}(\mathrm{SE}=0.75)$.

Residency of tagged Walleyes varied individually, with significant sex-based differences. Overall residency of tagged Walleyes also varied, with some tagged fish never leaving the reservoir, while others temporarily exited the reservoir by swimming upstream into the Cheat River. Overall, 21 of the 40 tracked Walleyes (52.5\% of tagged fish) at some point exited the reservoir via the Cheat River resulting in a residency index of less than 1 (Table 4.2). There was a significant difference in residency between male and female Walleyes (Kruskal Wallis: d.f. = 1, $H=4.48, p$ value $=0.03$; Figure 4.9). Male Walleyes were more likely leave the lake for Cheat River (mean residency index $=0.81, \mathrm{SE}=0.05$ ) and have a lower residency than female Walleyes (mean residency index $=0.95, \mathrm{SE}=0.01$; Figure 4.9). Specifically, male Walleyes spent an average of 58 days per year $(S E=14.72$, range $=0-160$ days per year $)$ in Cheat River, while females spent an average of 15 days per year $(\mathrm{SE}=9.75$, range $=0-157$ days per year) in the river.

In addition to overall space use patterns, examination of monthly space use patterns provided insight into Walleye movements and distribution. Examination of monthly core range shifts, residence time, and linear range change, all revealed similar patterns in Walleye distribution and space use in Cheat Lake. Logistic regression results suggested that core range shifts differed significantly across months and by sex (Table 4.6; Figure 4.7). Specifically, logistic regression results suggested that Walleye range shifts were significantly different in the months of March, April, May, October, and November, and that male range shifts were significantly different that female range shifts $(p<0.05$; Table 4.6). Male Walleyes, on average, 
experienced more core range shifts (monthly mean $=5.2, \mathrm{SE}=1.1)$ than females (monthly mean $=3.5, \mathrm{SE}=0.71)$. The largest peak in core range shifts occurred in spring (March-May) and fall (October-November) (Figure 4.7). The monthly mean number of core range shifts by lake zone was $8.7(\mathrm{SE}=1.6)$, whereas the mean number of core range shifts were greater than the mean from March - May and October-November (Figure 4.7). The highest number of average core range shifts was in March (19 individuals with core range shifts; Figure 4.7). The middle main lake zone, on average, occurred most frequently in the monthly core ranges of tagged Walleyes (Tables 4.4 \& 4.5). However, in March and April, the riverine zone occurred most frequently, on average, in the core ranges of tagged Walleyes (Tables $4.4 \& 4.5$ ). Additionally, when combining use of the riverine zone and Cheat River, there was a small peak in use of these areas in the month of July (Table 4.4). In July, the riverine zone and Cheat River combined occurred more frequently than the middle main lake zone in the core ranges of tagged Walleyes (Table 4.4).

Monthly residency index also revealed patterns in Walleye distribution. Based on the linear mixed model analysis, residency index significantly differed across months $(F=7.57$; $d f=$ 11, 330; $p<0.001)$ and between males and females $(F=5.77 ; d f=1,29 ; p=0.02)$. Specifically, males were more likely to leave Cheat Lake (and have a lower residency index) than females (Figure 4.9). April had the lowest mean residency index of all months (mean for both sexes combined $=0.75$, male mean $=0.60$, female mean $=0.88$, due to more Walleyes leaving the lake for the Cheat River (Figure 4.9). The monthly residency indices from April-September were significantly low compared to other months, due to increased use of Cheat River during this time period (Figure 4.9). January had the highest residency index (mean $\mathrm{RI}=1.0$ ), as no Walleyes utilized Cheat River during this month (Figure 4.9).

The monthly change in receiver use (i.e., linear range) of tagged Walleyes was consistent with those of monthly core range and residency index. Linear mixed model analysis 
suggested that linear range change significantly differed across months $(F=2.83$; $d f=11,330$; $p<0.01)$ but was not significantly different between males and females $(F=0.43 ; d f=1,29, p=$ 0.52). The only months with evidence for mean linear range expansion were February-April and October (Figure 4.8). The mean deviation in linear range for these months was $>0$, indicating an expansion of linear range and increased movement for tagged Walleyes during these months. However, linear range expansion was significantly different only during the month of March $(p<0.001)$. Nevertheless, this metric provides an indication of increased movement during spring and fall months.

A total of 12 individuals (23.1\% of tagged Walleyes) passed over or through the dam during the study. Most dam passage events occurred in November or December (75\%). Four individuals were caught by anglers in the tailwater pool shortly after passing over the dam. Two individuals (March and December) likely passed through the dam turbines as lake elevation was decreasing and hydropower generation was occurring. These fish were considered as likely deceased from the passage event as the transmitters were continuously detected near the turbine outflow for several months without movement. No other tagged fish that exited via the dam were continuously detected in the tailwater, potentially indicating survival. The ten fish that potentially survived passage of the dam (including the four caught by anglers) passed during high water events (mean lake elevation $869.8 \mathrm{ft}$ elevation \pm 0.122 standard error; river discharge 12,168 cfs \pm 2186.2 ) when lake elevation was increasing (mean daily lake elevation increase $1.6 \mathrm{ft} . \pm 0.55$ standard error). In contrast, the two fish that likely died during passage, passed during comparatively lower water periods (862.9 ft. elevation \pm 2.135 ; river discharge 2675 cfs \pm 5) when lake elevation was decreasing from hydropower operations (mean daily lake elevation decrease $-1.8 \mathrm{ft} . \pm 1.475$ standard error). 


\section{Discussion}

Walleyes often demonstrated range shifts and movement patterns during periods associated with spawning, post-spawn/summer, and fall/winter. Most Walleyes made upstream movements and range shifts from lake to riverine environments in conjunction with spawning season. After spawning, a portion of the tagged individuals, largely females, migrated back to main lake areas, while many males remained in riverine habitats. Some individuals displayed shifts in range toward riverine habitats during peak summer, possibly in relation to increasing water temperatures and declining oxygen conditions in the main lake. By fall, most individuals remaining in riverine habitats made return trips and range shifts to the main lake where overwintering occurred. Distribution and spatial patterns demonstrated by Cheat Lake Walleyes could have important implications for future management and recreational angling of this emerging fishery.

Examining overall Walleye distribution patterns over the calendar year, it appeared that tracked fish largely favored middle main lake habitats where depths and water quality characteristics (dissolved oxygen, water temperature, flow, etc.) were intermediate compared to upstream and downstream habitats. On average, male Cheat Lake Walleyes spent over $50 \%$ of their time and females spent over $71 \%$ of their time in the middle main lake zone. Other studies have reported Walleyes primarily utilizing lacustrine reservoir habitats during non-spawning periods (Williams 2001; Palmer et al. 2005, Hanson 2006). Bathymetry, water temperature, dissolved oxygen, and habitat could be described as intermediate compared to the lower main lake zone and the riverine zone. The middle main lake zone has shallow flats juxtaposed next to deep water areas, two large coves, and the most abundant and diverse forage of all areas of the lake. Walleyes have been reported to select for shallow flats and coves to forage on at night (Swenson and Smith 1976; Fitz and Holbrook 1978; Ickes et al. 1999; Haxton et al. 2015). This habitat is most prevalent in the middle main lake zone. Although the middle main lake zone 
does stratify, stratification can be weaker compared to the lower main lake zone. The middle main lake zone has an abundance of fishes common to Walleye diets, including Yellow Perch, Gizzard Shad, Emerald Shiner, Logperch, Golden Redhorse, and sunfish species (see Chapter 2). In contrast, the lower main lake and riverine zones do not support the combination of abundance and diversity of forage opportunities. Additionally, the lower main lake zone, although providing deep water with cool summer temperatures, tends to strongly stratify. It could be difficult for Walleyes to locate preferred water temperatures with suitable dissolved oxygen. The lower main lake also has sharply sloped banks, leading to limited littoral zone areas on which to forage. Therefore, it is possible the heavy use of the middle main lake zone is tied to foraging opportunities, habitat, or a combination thereof which has been suggested in previous studies on Walleye distribution (DePhilip et al. 2005; Hanson 2006; Wang et al. 2007; Raby et al. 2018).

Core and home range size of tracked fish were similar throughout the year, although we documented temporal shifts in areas used by Walleyes. There was individual variation in size of home and core range with some individuals occupying relatively small areas $(<5 \mathrm{~km})$ and other individuals occupying the entire reservoir (>19 km). Other studies have noted a wide range in individual range variation (Williams 2001; Palmer et al. 2005; Golding et al. 2007; Clark-Kolaks 2008; Phillips 2014; Kirby et al. 2017). Total ranges of Walleyes in Cheat Lake were small compared to what has been reported in some other studies when considering distance traveled (e.g., river kilometers) (DePhilip et al. 2005; Palmer et al. 2005; Phillips 2014). However, this is largely due to the small size of Cheat Lake $(20.9 \mathrm{rkm})$ and limited monitoring area of Cheat River compared to other water bodies where telemetry studies have taken place. Several Walleyes occupied the entirety of Cheat Lake and also utilized some of the upstream Cheat River. These fish had total linear ranges of at least $19.6 \mathrm{rkm}$ based on the distance between the Cheat River receiver and the most downstream receiver in Cheat Lake. However, due to a lack 
of receiver coverage we are unsure how far upstream fish traveled into the Cheat River, so it is possible these fish had much larger linear ranges than realized. When considering proportion of lake area occupied, Walleyes in Cheat Lake had similar total ranges as what has been reported in other studies, with some Walleyes only occupying a very small percentage of the reservoir and other Walleyes utilizing the entire reservoir (Williams 2001; DePhillip et al. 2005; Palmer et al. 2005; Hanson 2006; Foust and Haynes 2007; Clark-Kolaks 2008; Kirby et al. 2017). As previously eluded to, the middle main lake zone was most frequently included in core use areas of tracked fish. A total of $90 \%$ of tracked fish utilized the middle main lake zone as part of their overall core range, reinforcing the importance of this area to Cheat Lake Walleyes. Walleyes differed in that individual fish either occupied one or two overall core use zones. This suggests that fish with only one core use zone had a more overall restricted high use range, while fish with two core use zones exhibited more plasticity or temporal variations in areas of high use. Other studies have only eluded to multiple core use areas of Walleyes via description of temporal changes in range and distribution (DePhilip et al. 2005; Palmer et al. 2005; Hanson 2006; Raby et al. 2018), but have not specifically quantified them, so comparisons with other populations are difficult.

Walleyes exhibited temporal variations in core ranges and use of lake zone. In spring months and to a lesser extent in mid-summer, fish shifted core use areas from the middle main lake to the riverine zone and Cheat River. Spring month range shifts were most likely a factor of pre-spawning and spawning activity. These spawning related range shifts are typical of what occurs in other systems (Ickes et al. 1999; DePhilip et al. 2005; Palmer et al. 2005; Hanson 2006; Phillips 2014). The small peak in range shifts evident in mid-summer (July) could potentially be related to challenging physicochemical conditions with the main lake areas during summer months. Specifically, water temperatures were highest in July and dissolved oxygen concentrations were also strongly stratified during this time period (WVDNR unpublished data). 
This could result in an oxygen-temperature squeeze (Coutant 1985; Williams 2001; ClarkKolaks 2008; Bozek et al. 2011) forcing some Walleyes to make range shifts in search of cooler, more oxygenated water which is most likely to be found near the inflow of Cheat River. Movements in search of optimum water temperature conditions have been suggested in other studies (Ickes et al. 1999; DePhilip et al. 2005; Wang et al. 2007; Hayden et al. 2014; Raby et al. 2018). However, only a small number of Walleyes made this mid-summer habitat shift, indicating that other main lake residents chose to remain in stratified main lake habitats. Cheat Lake typically experiences fall turnover in September (WVDNR unpublished data) which is also when tagged fish began to increase use of the middle lake zone. Once water temperatures cooled and fall months arrived, nearly all Walleyes shifted core use areas again to occupying primarily the middle main lake zone. Use of the middle lake zone peaked during late fall/early winter. Walleyes may retreat to the main lake zone during this period to locate deeper water or concentrated prey (Paragamian 1989; DePhillip et al. 2005; Hanson 2006). Convergence of Walleyes into deeper waters in the fall has been commonly reported in other studies (Paragamian 1989; Williams 2001; DePhilip et al. 2005; Potter et al. 2009).

In general, there were two groups of Walleyes in our study: lake resident fish, that spent most their time in main lake habitats, and riverine resident fish that spent a substantial portion of their time in riverine habitats in addition to overwintering in main lake habitats. Lake resident fish typically occupied main lake core ranges during all time periods except for months associated with spawning. Riverine resident fish occupied riverine core ranges during all time periods except fall and winter, in which most of these fish switched to occupying main lake habitats. Riverine resident fish also were more likely to emigrate from Cheat Lake via the Cheat River upstream, resulting in lower residency indices for these fish. Although both males and females were often lake resident fish, riverine resident fish were much more likely to be males. Other Walleye movement studies have reported a similar segregation of Walleyes occupying 
lacustrine or riverine environments (Williams 2001; DePhilip et al. 2005; Palmer et al. 2005; Wang et al. 2007; Hayden et al. 2014). In most of these studies, differences in overall distribution were often tied to variations in post-spawning movements between males and females, or genetically induced behavior (DePhilip et al. 2005; Palmer et al. 2005; Hayden et al. 2014). However, many studies have not quantified core and home ranges for individuals, but instead have qualitatively described seasonal movements. Additionally, in most of these studies, fish had left spawning areas by late spring (Ickes et al. 1999; Palmer et al. 2005; Hanson 2006; Hayden et al. 2014; Raby et al. 2017). In our study, it was not uncommon for fish to remain near spawning areas until fall. DePhilip et al. (2005) did have similar results to our study in the Au Sable River, Michigan. In their study, some Walleyes did not outmigrate from spawning areas to the downstream reservoir until fall. DePhilip et al. (2005) postulated that some Walleyes delayed return to the reservoir to take advantage of optimal foraging conditions. Palmer et al. (2005) found that lake resident fish spawned in riverine habitats but subsequently returned to main lake habitats, while river resident fish spawned and remained in riverine habitats. Differences in their study were thought to be the result of genetic differentiation (Palmer et al. 2005). In our study, nearly all individuals occupied the main lake at some point during a given year (almost always to overwinter) but differences existed in ranges occupied in post-spawn and summer periods.

Sex-based differences in distribution and movement patterns were apparent in our study. Other studies have noted the apparent link between Walleye sex and seasonal distribution (DePhilip et al. 2005; Wang et al. 2007; Hayden et al. 2014; Raby et al. 2018). In particular, other studies have reported a dichotomy in post-spawn distributions between males and females (DePhilip et al. 2005; Wang et al. 2007; Hayden et al. 2014; Raby et al. 2018). Several theories have been posited to why males and females segregate. Other researchers have suggested theories related to maximizing spawning success for males, occupation of 
preferred water temperatures, and optimal foraging theory (DePhilip et al. 2005; Wang et la. 2007; Hayden et al. 2014; Raby et al. 2018).

It is possible that sex-based differences in distribution in our study were related to differences in spawning behavior between males and females. Some authors have suggested that male Walleyes extend time spent on spawning grounds to maximize their potential spawning attempts with as many females as possible (Hayden et al. 2014; Raby et al. 2018). Males often spawn with multiple females whereas females typically deposit all of their eggs in a short timeframe (Colby et al. 1979). By extending time spent on spawning grounds, males may increase their interaction with females and increase their spawning attempts (Hayden et al. 2014; Raby et al. 2018). However, this theory does not explain the residence of males past the month of April in riverine habitats.

Another possible explanation for sex-based differences in distribution is related to variations in habitat needs between males and females. Other researchers have suggested that females are more likely to search out optimal habitat (e.g., water temperature) conditions compared to males after spawning to maximize their energy intake (Wang et al. 2007; Raby et al. 2018). In many waters, as surface water temperatures warm, deep waters in main lake areas could provide thermal refugia for female Walleyes, potentially optimizing growth potential and body condition. In Cheat Lake, deeper main lake areas do offer cool water temperatures compared to the uniform temperatures found throughout the riverine zone. However, in Cheat Lake, the riverine zone still consistently offers Walleyes summertime water temperatures within their preferred range. Additionally, during summer, stratification of main lake areas negates the ability to find cool waters as oxygen levels are often depleted. In summer, some females displayed a propensity to make forays from the main lake back into the riverine zone. Potentially, these fish were searching for cooler, more oxygenated water that the incoming Cheat River provides during summer periods. However, only a small number of females 
displayed this behavior, suggesting other main lake residents were able to find suitable habitat without making movements into the riverine zone.

Researchers have also suggested that some Walleyes (especially females) migrate to areas after spawning that offer optimal foraging opportunities in terms of preferred prey (DePhilip et al. 2005; Wang et al. 2007; Bowlby and Hoyle 2011; Hayden et al. 2014; Raby et al. 2018). Of all the reasons presented, this seems the most likely for Cheat Lake Walleyes. Although the riverine zone supports prey fish for Walleyes, a higher proportion of these fish will be smaller shiner species (e.g., Mimic Shiner, Emerald Shiner, etc.), Logperch, and riverine centrarchids (e.g., Smallmouth Bass, Rock Bass). In contrast, the main lake offers a greater diversity of prey fish and a greater size spectrum of potential prey. Specifically, the middle main lake supports a strong population of Yellow Perch, and Cheat Lake Walleyes have demonstrated a strong propensity to prey on Yellow Perch (see Chapter 2).

Most Walleyes increased their use of upstream riverine habitats and the incoming Cheat River during spring. Range shifts during spring months provided evidence that Walleyes used the headwaters of Cheat Lake and the Cheat River for spawning. Given Cheat Lake is an ecosystem recovering from decades of acidification, identification of available spawning habitat for a once extirpated species such as the Walleye is important. Cheat Lake experiences seasonal changes in lake level fluctuations which can impact Walleye spawning (Johnson 1961; Priegel 1970; Chevalier 1977). Lake area utilized for spawning was a relatively small area (approximately $1 \mathrm{rkm}$ ) just downstream of the incoming Cheat River. This limited spawning area creates an inherent risk of disruption to spawning activity. Poorly timed lake level decreases in spring could lead to spawning failure for fish utilizing this area. Some Walleyes are evidently utilizing the Cheat River to spawn and as summer habitat. These Walleyes are protected from lake level fluctuations, but if larval Walleyes subsequently drift downstream to the main lake, they would still be susceptible to changing water levels given their poor swimming ability 
(Walburg 1971). Additionally, should acidification issues arise again in the future, this area would be the first to receive acidic water from upstream prior to it having a chance to dilute in the larger body of the main lake. Acidic conditions are not conducive to successful Walleye reproduction (Hulsman et al. 1983; Rahel and Magnuson 1983), so protection of suitable water quality especially around spawning habitat is critical. Evidence of spawning being restricted to the upper portion of the lake should improve the ability of researchers to monitor the impacts of lake level fluctuations on spawning activity in future years. However, this seasonal clustering of adult Walleyes also potentially increases their susceptibility to angling (Palmer et al. 2005). The use of Cheat River for spawning and for summer habitat lends some evidence that a portion of the population may be protected from lake level fluctuations and angling pressure.

Residency indices of tagged Walleyes provided information on frequency of fish temporarily leaving the reservoir for the upstream Cheat River. Overall, over $50 \%$ of tagged Walleyes at some point temporarily exited the reservoir for the river upstream. When examining residency of tagged Walleyes monthly, clear patterns of temporal emigration from the reservoir dependent on time of year are evident. The heaviest use of the Cheat River occurred in April. This is likely due to Walleyes leaving the reservoir to spawn in the Cheat River upstream. Although female Walleyes typically returned to utilizing primarily main lake habitats in summer with occasional forays into upstream riverine habitats, a large proportion of males continued to utilize upstream riverine habitats throughout the summer until fall. Some Walleyes (primarily males) continued to periodically utilize the Cheat River upstream, while others continued to occupy the Cheat River until fall. It is unknown why some fish choose to remain in Cheat River or utilize it frequently compared to others. Walleyes remaining in the river may simply be choosing to limit post-spawn movement and instead focus on immediately foraging upon available prey in the river (DePhilip et al. 2005). 
The dichotomy in habitat use between males and females could affect management strategies and angling pressure (Palmer et al. 2005; Wang et al. 2007; Hayden et al. 2014). Fisheries managers should be aware that fishing pressure may not be equivalent between males and females. Specifically, female Walleyes in Cheat Lake may experience higher susceptibility to angling given their closer proximity to the angler access areas in the main lake. Anecdotal observations suggest that most angling occurs in Cheat Lake from May-October, when the reservoir fluctuations are restricted for recreational activity. This coincides with the time period that female Walleyes have largely returned to utilizing main lake habitats. An angler creel survey and research into the effort and harvest habits of Cheat Lake anglers would be beneficial for future management.

A substantial proportion of tagged Walleyes (19.2\%) passed over or through the dam during the study. Most Walleyes passed over the dam during high water events in November and December. However, two Walleyes likely passed through the turbines leading to mortality of at least one fish. Research is limited regarding dam passage of Walleyes in reservoir systems. Jernejcic (1986) found substantial movement of Walleyes through the dam on Tygart Lake, WV. Most of these fish were juveniles (age-0), indicating that younger fish were more inclined to bypass the dam than larger, older individuals (Jernejcic 1986). Additionally, Jernejcic (1986) found evidence of some mortality of Walleyes as a result of dam passage. Weber et al. (2013) found similar results with regards to dam passage. In their study, tagged Walleyes $>300 \mathrm{~mm}$ were released into Rathbun Lake, IA and the tailwaters were monitored for tagged fish (Weber et al. 2013). Fish passage through the dam increased with increasing discharged and decreasing fish length, indicating most fish passing through were small individuals doing so at high discharge events (Weber et al. 2013). In our study, Walleyes passing through the dam were all larger individuals due to the size restrictions associated with implanting acoustic transmitters. Walleyes also primarily passed the dam during high water events, but two 
individuals passed during drawdown events and likely perished as a result. It is unknown how common these passage events are for Walleyes in Cheat Lake. Weber et al. (2013) suggested that fisheries managers should stock Walleyes at the largest size possible and as far away from the dam as possible. Very small Walleyes (i.e., fry, small fingerlings) may have limited ability to avoid bypassing the dam given their limited swimming ability. Additionally, by stocking Walleyes close to the dam, individuals may be more likely to exit the reservoir (Weber et al. 2013). Walleyes have traditionally been stocked relatively close to the dam in Cheat Lake, so fisheries managers should consider releasing fish at locations further away from the dam.

\section{Management Implications}

Knowledge of the spatial ecology of sportfish, especially top predators such as Walleyes, can be important for effective management of fisheries. Walleyes are top predators that can structure ecosystems (Craig 2000; Quist et al. 2003; Bozek et al. 2011; Pothoven et al. 2016) and are also an economically important species (Craig 2000; Bozek et al. 2011; Hayden et al. 2014; Kirby et al. 2017). Therefore, effective management of this species can have wide ranging consequences. Space use patterns of Walleyes have implications for both fisheries management and angling exploitation. Results from this study provide valuable information on the temporal distribution, core and home range areas, and lake residency of Walleyes in Cheat Lake. Given Walleyes were once extirpated from Cheat Lake due to acid mine drainage but have since been reestablished, knowledge of the distribution and space use of this Walleye population is important for future management.

Understanding seasonal movements and distributions can improve the management of Walleye populations (Williams 2001; Rasmussen et al. 2002; Palmer et al. 2005; Hanson 2006). Specifically, this information would be useful from a management perspective as knowing when 
and where congregations of Walleyes will occur seasonally could help direct survey efforts and potentially improve angler success rates (Williams 2001; Palmer et al. 2005). This study demonstrated seasonal patterns and sex-based differences in Walleye distribution in Cheat Lake. Specifically, male Walleyes spent greater periods of time utilizing upstream riverine habitats and the Cheat River, while females spent more time utilizing main lake habitats downstream. In spring, most adult Walleyes congregated near the headwaters of Cheat Lake and some left the lake to spawn in Cheat River. These springtime congregations are important for fisheries managers, as they offer an opportunity to collect adult Walleyes for broodstock purposes, or conduct further monitoring and research on the spawning population. Additionally, these congregations could have significant implications should anglers begin to capitalize on this pattern. Other studies have shown that a substantial portion of harvest can occur on Walleyes congregating in small areas to spawn (Palmer et al. 2005). Fisheries managers should monitor the angling impact of these spawning congregations in Cheat Lake to ensure overharvest does not occur. Additionally, the tendency for female Walleyes to utilize downstream main lake habitats in the summer could also have important management implications. Stock assessment surveys should take into account the sex-based segregation of Walleyes within Cheat Lake during these time periods. Additionally, consideration should be given to the potential impact of angler harvest on female Walleyes during summer periods. It is possible, given proximity to access sites, that anglers primarily harvest female fish during summer in Cheat Lake. Creel survey and angler effort research should be conducted on Cheat Lake to determine the potential impacts of these seasonal, sex-based distributions. Overall, results from this study provide fisheries managers with valuable information that will be beneficial in the future management of this reestablished fishery. Information gained will help guide future monitoring and research, and aide in directing future management actions to maintain and potentially improve this fishery. 


\section{References}

Bates, D., M. Maechler, B. Bolker, and S. Walker. 2015. Fitting linear mixed-effects models using Ime4. Journal of Statistical Software 67: 1-48.

Bolker, B.M., M.E. Brooks, C.J. Clark, S.W. Geange, J.R. Poulsen, M. Henry, H. Stevens, and J.S.S. White. 2008. Generalized linear mixed models: a practical guide for ecology and evolution. Trends in Ecology and Evolution 24: 127-135.

Bowlby, J. N. and J. A. Hoyle. 2011. Distribution and movement of Bay of Quinte Walleye in relation to temperature, prey availability, and Dreissenid colonization. Aquatic Ecosystem Health and Management 14: 56-65.

Bozek, M. A., Haxton, T.J. and J.K. Raabe. 2011. Walleye and Sauger Habitat. Pages 133-197 in B.A. Barton, editor. Biology, Management and Culture of Walleye and Sauger. American Fisheries Society, Bethesda, Maryland.

Buckmeier, D. L., N. G. Smith, and D. J. Daugherty. 2013. Alligator gar movement and macrohabitat use in the lower Trinity River, Texas. Transactions of the American Fisheries Society 142: 1025-1035.

Chevalier, J. R. 1977. Changes in walleye (Stizostedion vitreum vitreum) population in Rainy Lake and factors in abundance. Journal of the Fisheries Research Board of Canada 34: $1696-1702$.

Clark-Kolaks, S. 2008. Distribution and movement of walleye (Sander vitreus) in Monroe Reservoir, Indiana 2008 and 2009. Fish Research Final Report, Indiana Fisheries section, Indiana Department of Natural Resources, Division of Fish and Wildlife.

Colby, P. J., R. E. McNicol, and R. A. Ryder. 1979. Synopsis of biological data on the walleye Stizostedion v. vitreum. FAO Fisheries Synopsis 119, Rome. 
Core, E. L. 1959. Biological investigations of Cheat Lake. West Virginia University, Morgantown, WV.

Coutant, C. C. 1985. Striped bass, temperature, and dissolved oxygen: a speculative hypothesis for environmental risk. Transactions of the American Fisheries Society 114: 31-61.

Cowley, P. D., S. E. Kerwath, A. R. Childs, E. B. Thorstad, F. Okland, and T. F. Naesje. 2008. Estuarine habitat use by juvenile dusky kob Argyrosomus japonicas (Sciaenidae), with implications for management. African Journal of Marine Science 30: 247-253.

Craig, J. F. 2000. Percid Fishes: Systematics, Ecology and Exploitation. Blackwell Science, Oxford, UK.

Crowe, W.R. 1962. Homing behavior in walleyes. Transactions of the American Fisheries Society $91:$ 350-354.

Daly, R., M. J. Smale, P. D. Cowley, and P. W. Froneman. 2014. Residency patterns and migration dynamics of adult bull sharks (Carcharhinus leucas) on the east coast of southern Africa. PLoS One 9(10): e109357.https://doi.org/10.1371/journal.pone.0109357

DePhilip, M.M., J.S. Diana, and Smith, D. 2005. Movement of walleye in an impounded reach of the Au Sable River, Michigan, USA. Environmental Biology of Fishes 72: 455-463.

Eschemeyer, P.H. and W.R. Crowe. 1955. The movement and recovery of tagged walleyes in Michigan, 1929-1953. Michigan Department of Natural Resources, Research Report 8.

Fitz, R. B. and J. A. Holbrook II. 1978. Sauger and Walleye in Norris Reservoir, Tennessee. Pages 82-88 in R. L. Kendall, editor. Selected Coolwater Fishes of North America. Bethesda, American Fisheries Society, Special Publication Number 11. 
Foust, J. C. and J. M. Haynes. 2007. Failure of walleye recruitment in a lake with little suitable spawning habitat is probably exacerbated by restricted home ranges. Journal of Freshwater Ecology 22: 297-309.

Freund, J.G. and J.T. Petty. 2007. Response of Fish and Macroinvertebrate Bioassessment Indices to Water Chemistry in a Mined Appalachian Watershed. Environmental Management 39: 707-720.

Gilroy, D. J., O. P. Jensen, B. C. Allen, S. Chandra, B. Ganzorig, Z. Hogan, J. T. Maxted, and M. J. Vander Zanden. 2010. Home range and seasonal movement of taimen, Hucho taimen, in Mongolia. Ecology of Freshwater Fish 19: 545-554.

Hanson, J. R. 2006. Seasonal Movement Patterns of Walleye (Sander vitreus) in Muskegon River and Muskegon Lake, Michigan. Master's thesis, University of Michigan, Ann Arbor.

Harasti, D., K. A. Lee, C. Gallen, J. M. Hughes, and J. Stewart. 2015. Movements, Home Range and Site Fidelity of Snapper (Chrysophrys auratus) within a Temperate Marine Protected Area. PLoS ONE 10(11): e0142454. https://doi.org/10.1371/journal.pone.0142454

Hart, L. G., and R. C. Summerfelt. 1975. Surgical procedures for implanting ultrasonic transmitters into flathead catfish (Pylodictis olivaris). Transactions of the American Fisheries Society 104: 56-59. 
Hayden, T.A., C.M. Holbrook, D.G. Fielder, C.S. Vandergoot, R.A. Bergstedt, J.M. Dettmers, C.C. Krueger, and S.J. Cooke. 2014 Acoustic telemetry reveals large-scale migration patterns of walleye in Lake Huron. Plos One. 9(12): e114833. doi:10.1371/journal.pone. 0114833

Haxton, T. 2015. Characteristics and spatial segregation of sympatric Saugers and Walleyes in the Ottawa River, Canada. North American Journal of Fisheries Management 35: 418430.

Holt, C. S., G.D. Grant, G.P. Oberstar, C.C. Oakes, and Bradt, D.W. 1977. Movement of walleye, Stizostedion vitreum, in Lake Bemidji, Minnesota as determined by radiobiotelemetry. Transactions of the American Fisheries Society 106: 163-169.

Hulsman, P. F., P. M. Powles, and J. M. Gunn. 1983. Mortality of walleye eggs and rainbow trout yolk sac larvae in low pH waters of the La Cloche Mountain area, Ontario. Transactions of the American Fisheries Society 112: 680-688.

Ickes, B. S., A. G. Stevens, and D. L. Pereira. 1999. Seasonal distribution, habitat use, and spawning locations of walleye (Stizostedion vitreum vitreum) and sauger, (S. canadense) in pool 4 of the upper Mississippi River, with special emphasis on winter distribution related to a thermally altered environment. Minnesota Department of Natural Resources, Investigational Report 482, St. Paul.

Jernejcic, F. 1986. Walleye migration through Tygart Dam and angler utilization of the resulting tailwater and lake fisheries. Pages 294-300 in G. E. Hall and M. J. Van Den Avyle, editors. Reservoir Fisheries Management: Strategies for the 80s. Reservoir Committee, Southern Division American Fisheries Society, Bethesda, Maryland, USA. 
Johnson, F. H. 1961. Walleye egg survival during incubation on several types of bottom in Lake Winibigoshish, Minnesota, and connecting waters. Transactions of the American Fisheries Society 90: 312-322.

Kirby, L. J., S. L. Johnson, and N. H. Ringler. 2017. Diel movement and home range estimation of Walleye (Sander vitreus) within a no-take urban fishery. Journal of Freshwater Ecology 32: 49-64.

Landsman, S.J., V.M. Nguyen, L.F.G. Gutowsky, J. Gobin, K.V. Cook, T.R. Binder, N. Lower, R.L. McLaughlin, and S.J. Cooke. 2014. Fish movement and migration studies in the Laurentian Great Lakes: Research trends and knowledge gaps. Journal of Great Lakes Research 37: 365-379.

Littell, R.C., G. Milliken, W.W. Stroup, R. Wolfinger, and Schabenberger, O., 2006. SAS for Mixed Models, 2nd ed. SAS Institute, Cary, NC.

Lucas, M. C. and C. Baras. 2000. Methods for studying spatial behaviour of freshwater fishes in the natural environment. Fish and Fisheries 1: 283-316.

Martin, D. R., L. A. Powell, and K. L. Pope. 2012. Habitat selection by adult walleye during spawning season in irrigation reservoirs: A patch occupancy modeling approach. Environmental Biology of Fishes 93: 589-98.

McClurg, S. E., J. T. Petty, P. M. Mazik, and J. L. Clayton. 2007. Stream ecosystem response to limestone treatment in acid impacted watersheds of the Allegheny Plateau. Ecological Applications 17: 1087-1104.

Merovich, G. T., J. M. Stiles, J. T. Petty, J. Fulton, and P. F. Ziemkiewicz. 2007. Water chemistry based classification of streams and implications for restoring mined Appalachian watersheds. Environmental Toxicology and Chemistry 26: 1361-1369. 
Palmer, G.C., B.R. Murphy, and Hallerman, E.M. 2005. Movements of walleyes in Claytor Lake and the upper New River, Virginia, indicate distinct lake and river populations. North American Journal of Fisheries Management 25: 1448-1455.

Paragamian, V. L. 1989. Seasonal habitat use by walleye in a warmwater river system, as determined by radiotelemetry. North American Journal of Fisheries Management 9: 392401.

Phillips, T. K. 2014. Seasonal movement of the Sandstone Falls population of walleye in the lower New River. Master's thesis. Ohio University, Athens.

Pincock, D. G. 2011. False detections: what are they and how to remove them from detection data. VEMCO Whitepaper document DOC -004691, v03. Amrix Systems, Inc. Halifax, NS, Canada.

Potter, J., J. M. Byrne, D. S. Stich, and J. R. Foster. 2009. Walleye (Sander vitreus) seasonal activity and habitat utilization in Otsego Lake, New York. In $43^{\text {rd }}$ Annual Report SUNY Oneonta Biological Field Station, SUNY Oneonta.

Pothoven, S. A., C. P. Madenjian, and T. O. Hook. 2016. Feeding ecology of the Walleye (Percidae, Sander vitreus), a resurgent piscivore in Lake Huron (Laurentian Great Lakes) after shifts in the prey community. Ecology of Freshwater Fish 26: 676-685.

Priegel, G. R. 1970. Reproduction and early life history of the walleye in the Lake Winnebago region. Wisconsin Department of Natural Resources Technical Bulletin 45, Madison.

Pritt, J.J., M.R. DuFour, C.M. Mayer, P.M. Kocovsky, J.T. Tyson, E.J. Weimer, and C. S. Vandergoot. 2013. Including independent estimates and uncertainty to quantify total abundance of fish migrating in a large river system: walleye (Sander vitreus) in the Maumee River, Ohio. Canadian Journal of Fisheries and Aquatic Sciences 70: 803-814. 
Quist, M. C., C. S. Guy, R. D. Schultz, and J. L. Stephen. 2003. Latitudinal comparisons of walleye growth in North America and factors influencing growth of walleyes in Kansas reservoirs. North American Journal of Fisheries Management 23: 677-692.

Raby, G. D., C. S. Vandergoot, T. A. Hayden, M. D. Faust, R. T. Kraus, J. M. Dettmers, S. J. Cooke, Y. Zhao, A. T. Fisk, and C. C. Krueger. 2018. Does behavioural thermoregulation underlie seasonal movements in Lake Erie walleye? Canadian Journal of Fisheries and Aquatic Sciences 75: 488-496.

Rahel, F. J. and J. J. Magnuson. 1983. Low pH and the absence of fish species in naturally acidic Wisconsin lakes: inferences for cultural acidification. Canadian Journal of Fisheries and Aquatic Sciences 40: 3-9.

Ramsden, S., C. C. Cotton, and M. C. Curran. 2017. Using acoustic telemetry to assess patterns in the seasonal residency of the Atlantic stingray Dasyatis sabina. Environmental Biology of Fishes 100: 89-98.

Rasmussen, P. W., D. M. Heisey, S. J. Gilbert, R. M. King, and S. W. Hewett. 2002. Estimating postspawn movements of walleyes among interconnected lakes of northern Wisconsin. Transactions of the American Fisheries Society 131: 1020-1032.

Rosenblatt, A. E. and M. R. Heithaus. 2011. Does variation in movement tactics and trophic interactions among American alligators create habitat linkage? Journal of Animal Ecology 80: 786-798.

Rutz, C. and G.C. Hays. 2009. New frontiers in biologging science. Biology Letters 5: 289-292.

Swenson, W. A. and L. L. Smith Jr. 1976. Influence of food competition, predation, and cannibalism, on Walleye (Stizostedion vitreum vitreum) and Sauger (S. canadense) 
populations in Lake of the Woods, Minnesota. Journal of the Fisheries Research Board of Canada 33: 1946-1954.

Topping, D. T., C. G. Lowe, and J. E. Caselle. 2006. Site fidelity and seasonal movement patterns of adult California sheephead Semicossyphus pulcher (Labridae): an acoustic monitoring study. Marine Ecology Press Series 326: 257-267.

Schmalz, P.J., A.H. Fayram, D.A. Isermann, S.P. Newman, and C. J. Edwards. 2011. Harvest and exploitation. Pages 375-402 in B.A. Barton, editor. Biology, Management, and Culture of Walleye and Sauger. American Fisheries Society, Bethesda, Maryland.

Shroyer, S. M. and D. E. Logsdon. 2009. Detection distances of selected radio and acoustic tags in Minnesota Lakes and Rivers. North American Journal of Fisheries Management 29: 876-884.

Vokoun, J. C. 2003. Kernel density estimates of linear home ranges for stream fishes: advantages and data requirements. North American Journal of Fisheries Management 23: $1020-1029$.

Walburg, C. H. 1971. Loss of young fish in reservoir discharge and year-class survival in Lewis and Clark Lake, Missouri River. Pages 441-448 in G. E. Hall, editor. Reservoir Fisheries and Limnology, American Fisheries Society, Special Publication 8, Bethesda, Maryland.

Walsh, C. T., I. V. Reinfelds, C. A. Gray, R. J. West, D. E. van der Muelen, and J. R. Craig. 2012. Seasonal residency and movement patterns of two co-occurring catadromous percichthyids within a south-eastern Australian river. Ecology of Freshwater Fish 21: 145-159.

Wang, H. Y., E. S. Rutherford, H. A. Cook, D. W. Einhouse, R. C. Haas, T.B. Johnson, R. Kenyon, B. Locke, and M. W. Turner. 2007. Movement of walleyes in Lakes Erie and St. 
Clair inferred from tag return and fisheries data. Transactions of the American Fisheries Society $136: 539-551$.

Weber, M. J., M. Flammang, and M. Schultz. 2013. Estimating and evaluating mechanisms related to Walleye escapement from Rathbun Lake, lowa. North American Journal of Fisheries Management 33: 642-651.

Welsh, S. A. and S.A. Perry. 1997. Acidification and fish occurrence in the upper Cheat River drainage, West Virginia. Journal of the American Water Resources Association 33: 423429.

Williams, J. D. 2001. Walleye movement, distribution, and habitat use in Laurel River Lake, Kentucky. Proceedings of the Annual Conference of Southeastern Association of Fish and Wildlife Agencies 55: 257-269.

Winter, J. 1996. Advances in underwater biotelemetry. Pages 555-585 in B. R. Murphy and D. W. Willis, editors. Fisheries Techniques, $2^{\text {nd }}$ edition. American Fisheries Society, Bethesda, Maryland. 
Table 4.1. Overall proportional use (\%) of lake zones by male and female Walleyes in Cheat Lake.

\begin{tabular}{lcccc}
\hline & \multicolumn{2}{c}{ Males } & \multicolumn{2}{c}{ Females } \\
Lake Zone & Mean \% & SE & Mean \% & SE \\
\hline Lower & 5.09 & 2.61 & 14.26 & 5.27 \\
Middle & 50.74 & 5.14 & 71.60 & 5.80 \\
Riverine & 30.73 & 4.58 & 9.18 & 1.90 \\
Cheat River & 13.44 & 3.65 & 4.96 & 2.44 \\
\hline
\end{tabular}

Table 4.2. Summary of individual Cheat Lake Walleye telemetry histories. RI = residency index. Zone abbreviations: $\mathrm{L}=$ lower main lake, $\mathrm{M}=$ middle main lake, $\mathrm{R}=$ riverine zone, $\mathrm{C}=\mathrm{Cheat}$ River

\begin{tabular}{ccccccccc}
\hline ID & Sex & $\begin{array}{c}\text { Total Length } \\
(\mathbf{m m})\end{array}$ & $\begin{array}{c}\text { Tag } \\
\text { detections }\end{array}$ & $\begin{array}{c}\text { Days } \\
\text { Monitored }\end{array}$ & RI & $\begin{array}{c}\text { No. Core } \\
\text { Areas }\end{array}$ & $\begin{array}{c}\text { Core } \\
\text { Zone }\end{array}$ & $\begin{array}{c}\text { Home } \\
\text { Range Zone }\end{array}$ \\
\hline 87 & $\mathrm{~F}$ & 449 & 65,013 & 504 & 1.00 & 1 & $\mathrm{M}$ & $\mathrm{L}-\mathrm{M}$ \\
57 & $\mathrm{~F}$ & 459 & 52,193 & 527 & 1.00 & 1 & $\mathrm{M}$ & $\mathrm{M}$ \\
88 & $\mathrm{~F}$ & 465 & 156,416 & 907 & 0.93 & 1 & $\mathrm{M}$ & L-M-R-C \\
33 & $\mathrm{~F}$ & 466 & 126,026 & 907 & 1.00 & 1 & $\mathrm{M}$ & $\mathrm{M}$ \\
60 & $\mathrm{~F}$ & 476 & 79,394 & 555 & 1.00 & 1 & $\mathrm{M}$ & L-M \\
84 & $\mathrm{~F}$ & 480 & 123,248 & 907 & 1.00 & 1 & $\mathrm{E}$ & L-M-R \\
55 & $\mathrm{~F}$ & 485 & 91,428 & 868 & 1.00 & 1 & $\mathrm{M}$ & L-M-R \\
83 & $\mathrm{~F}$ & 499 & 16,500 & 528 & 0.57 & 2 & $\mathrm{M}-\mathrm{C}$ & $\mathrm{M}-\mathrm{R}-\mathrm{C}$ \\
41 & $\mathrm{~F}$ & 516 & 181,523 & 874 & 0.99 & 1 & $\mathrm{M}$ & $\mathrm{M}$ \\
96 & $\mathrm{~F}$ & 518 & 38,921 & 907 & 0.81 & 2 & $\mathrm{~L}-\mathrm{M}$ & L-M-R-C \\
79 & $\mathrm{~F}$ & 542 & 59,752 & 662 & 1.00 & 1 & $\mathrm{M}$ & $\mathrm{L}-\mathrm{M}$ \\
59 & $\mathrm{~F}$ & 559 & 114,804 & 907 & 1.00 & 1 & $\mathrm{M}$ & $\mathrm{M}-\mathrm{R}$ \\
185 & $\mathrm{~F}$ & 568 & 98,932 & 542 & 1.00 & 1 & $\mathrm{M}$ & $\mathrm{M}$ \\
85 & $\mathrm{~F}$ & 570 & 40,697 & 358 & 1.00 & 1 & $\mathrm{M}$ & $\mathrm{M}$ \\
190 & $\mathrm{~F}$ & 580 & 67,026 & 493 & 1.00 & 2 & L-M & L-M-R \\
53 & $\mathrm{~F}$ & 600 & 109,467 & 403 & 1.00 & 1 & $\mathrm{M}$ & L-M-R \\
157 & $\mathrm{~F}$ & 617 & 4,168 & 131 & 0.86 & 1 & $\mathrm{M}$ & $\mathrm{M}-\mathrm{R}-\mathrm{C}$ \\
179 & $\mathrm{~F}$ & 652 & 24,320 & 196 & 0.91 & 1 & $\mathrm{M}$ & L-M-R-C \\
52 & $\mathrm{~F}$ & 708 & 113,147 & 883 & 0.98 & 1 & $\mathrm{M}$ & $\mathrm{M}-\mathrm{R}$ \\
58 & $\mathrm{M}$ & 430 & 71,744 & 428 & 0.63 & 2 & $\mathrm{M}-\mathrm{C}$ & $\mathrm{M}-\mathrm{R}-\mathrm{C}$ \\
89 & $\mathrm{M}$ & 430 & 35,368 & 697 & 0.79 & 2 & $\mathrm{M}-\mathrm{R}$ & $\mathrm{M}-\mathrm{R}-\mathrm{C}$ \\
38 & $\mathrm{M}$ & 432 & 15,713 & 51 & 1.00 & 1 & $\mathrm{M}$ & $\mathrm{M}-\mathrm{R}$ \\
51 & $\mathrm{M}$ & 435 & 28,906 & 258 & 1.00 & 1 & $\mathrm{M}$ & $\mathrm{M}-\mathrm{R}$ \\
39 & $\mathrm{M}$ & 437 & 62,214 & 777 & 0.80 & 2 & $\mathrm{M}-\mathrm{R}$ & $\mathrm{M}-\mathrm{R}-\mathrm{C}$ \\
& & & & & & &
\end{tabular}




\begin{tabular}{ccccccccc}
90 & $\mathrm{M}$ & 440 & 23,483 & 358 & 1.00 & 1 & $\mathrm{M}$ & L-M-R \\
42 & $\mathrm{M}$ & 443 & 52,491 & 69 & 1.00 & 2 & $\mathrm{M}-\mathrm{R}$ & $\mathrm{M}-\mathrm{R}$ \\
35 & $\mathrm{M}$ & 446 & 55,040 & 829 & 1.00 & 1 & $\mathrm{R}$ & $\mathrm{M}-\mathrm{R}$ \\
93 & $\mathrm{M}$ & 450 & 11,072 & 301 & 0.98 & 2 & $\mathrm{~L}-\mathrm{M}$ & $\mathrm{L}-\mathrm{M}-\mathrm{R}$ \\
86 & $\mathrm{M}$ & 452 & 132,350 & 907 & 0.92 & 1 & $\mathrm{M}$ & L-M-R-C \\
40 & $\mathrm{M}$ & 459 & 73,191 & 919 & 0.80 & 2 & $\mathrm{M}-\mathrm{R}$ & $\mathrm{M}-\mathrm{R}-\mathrm{C}$ \\
43 & $\mathrm{M}$ & 467 & 114,870 & 747 & 0.84 & 2 & $\mathrm{M}-\mathrm{R}$ & $\mathrm{M}-\mathrm{R}-\mathrm{C}$ \\
50 & $\mathrm{M}$ & 475 & 86,944 & 801 & 0.56 & 2 & $\mathrm{M}-\mathrm{C}$ & $\mathrm{M}-\mathrm{R}-\mathrm{C}$ \\
98 & $\mathrm{M}$ & 487 & 50,550 & 639 & 0.62 & 2 & $\mathrm{M}-\mathrm{C}$ & $\mathrm{M}-\mathrm{R}-\mathrm{C}$ \\
193 & $\mathrm{M}$ & 487 & 16,890 & 546 & 0.59 & 2 & $\mathrm{M}-\mathrm{C}$ & L-M-R-C \\
80 & $\mathrm{M}$ & 495 & 188,272 & 907 & 0.96 & 1 & $\mathrm{M}$ & $\mathrm{M}-\mathrm{R}-\mathrm{C}$ \\
94 & $\mathrm{M}$ & 500 & 39,589 & 651 & 0.96 & 2 & $\mathrm{M}-\mathrm{R}$ & $\mathrm{M}-\mathrm{R}-\mathrm{C}$ \\
82 & $\mathrm{M}$ & 505 & 70,594 & 651 & 0.99 & 1 & $\mathrm{M}$ & $\mathrm{M}-\mathrm{R}$ \\
189 & $\mathrm{M}$ & 556 & 41,557 & 71 & 1.00 & 1 & $\mathrm{M}$ & $\mathrm{M}-\mathrm{R}$ \\
44 & $\mathrm{U}$ & 476 & 21,991 & 854 & 0.73 & 2 & $\mathrm{R}-\mathrm{C}$ & $\mathrm{M}-\mathrm{R}-\mathrm{C}$ \\
151 & $\mathrm{U}$ & 490 & 14,132 & 46 & 1.00 & 2 & $\mathrm{~L}-\mathrm{L}$ & L-M \\
\hline
\end{tabular}

Table 4.3. Average overall proportional use (with standard errors in parentheses) of lake zones by tagged Walleyes from 2012-2015.

\begin{tabular}{ccccccc}
\hline ID & Sex & Monitoring Period & Lower & Middle & Riverine & Cheat River \\
\hline 33 & $\mathrm{~F}$ & $2013-2015$ & $0.00 \%(0)$ & $99.01 \%(9.81)$ & $0.99 \%(0.13)$ & $0.00 \%(0)$ \\
41 & $\mathrm{~F}$ & $2012-2014$ & $0.11 \%(0.07)$ & $95.42 \%(7.41)$ & $3.55 \%(0.45)$ & $0.92 \%(0.99)$ \\
52 & $\mathrm{~F}$ & $2012-2014$ & $0.57 \%(0.27)$ & $69.31 \%(7.12)$ & $28.20 \%(2.16)$ & $1.93 \%(1.41)$ \\
53 & $\mathrm{~F}$ & 2013 & $6.45 \%(1.18)$ & $76.18 \%(9.01)$ & $17.37 \%(2.83)$ & $0.00 \%(0)$ \\
55 & $\mathrm{~F}$ & $2013-2015$ & $4.38 \%(0.93)$ & $88.02 \%(7.09)$ & $7.26 \%(1.36)$ & $0.35 \%(0.21)$ \\
57 & $\mathrm{~F}$ & 2013 & $0.00 \%(0)$ & $100.00 \%(8.91)$ & $0.00 \%(0)$ & $0.00 \%(0)$ \\
59 & $\mathrm{~F}$ & $2013-2015$ & $0.44 \%(0.21)$ & $86.99 \%(9.42)$ & $12.13 \%(1.73)$ & $0.44 \%(0.29)$ \\
60 & $\mathrm{~F}$ & 2013 & $20.36 \%(2.26)$ & $79.64 \%(7.22)$ & $0.00 \%(0)$ & $0.00 \%(0)$ \\
79 & $\mathrm{~F}$ & $2013-2014$ & $16.01 \%(3.63)$ & $81.42 \%(8.29)$ & $2.57 \%(0.58)$ & $0.00 \%(0)$ \\
83 & $\mathrm{~F}$ & $2013-2014$ & $0.00 \%(0)$ & $40.72 \%(6.61)$ & $16.29 \%(2.14)$ & $42.99 \%(13.77)$ \\
84 & $\mathrm{~F}$ & $2013-2015$ & $90.41 \%(7.68)$ & $3.97 \%(0.89)$ & $5.62 \%(0.79)$ & $0.00 \%(0)$ \\
85 & $\mathrm{~F}$ & 2013 & $0.00 \%(0)$ & $94.97 \%(9.28)$ & $5.03 \%(0.69)$ & $0.00 \%(0)$ \\
87 & $\mathrm{~F}$ & 2013 & $49.60 \%(7.28)$ & $50.40 \%(6.77)$ & $0.00 \%(0)$ & $0.00 \%(0)$ \\
88 & $\mathrm{~F}$ & $2013-2015$ & $9.37 \%(2.43)$ & $65.60 \%(6.80)$ & $18.52 \%(2.22)$ & $6.50 \%(3.59)$ \\
96 & $\mathrm{~F}$ & $2013-2015$ & $28.45 \%(5.37)$ & $36.05 \%(5.97)$ & $16.76 \%(1.88)$ & $18.74 \%(9.36)$ \\
157 & $\mathrm{~F}$ & $2014-2015$ & $2.29 \%(1.07)$ & $65.65 \%(13.58)$ & $18.32 \%(3.51)$ & $13.74 \%(14.4)$
\end{tabular}




\begin{tabular}{ccccccc}
179 & $\mathrm{~F}$ & $2014-2015$ & $11.22 \%(2.44)$ & $65.82 \%(9.91)$ & $14.29 \%(2.27)$ & $8.67 \%(6.61)$ \\
185 & $\mathrm{~F}$ & $2014-2015$ & $0.00 \%(0)$ & $98.52 \%(8.75)$ & $1.48 \%(0.20)$ & $0.00 \%(0)$ \\
190 & $\mathrm{~F}$ & $2014-2015$ & $31.24 \%(4.54)$ & $62.68 \%(5.96)$ & $6.09 \%(0.98)$ & $0.00 \%(0)$ \\
35 & $\mathrm{M}$ & $2012-2014$ & $0.00 \%(0)$ & $41.74 \%(6.16)$ & $58.26 \%(5.70)$ & $0.00 \%(0)$ \\
38 & $\mathrm{M}$ & 2012 & $0.00 \%(0)$ & $92.16 \%(20.58)$ & $7.84 \%(2.26)$ & $0.00 \%(0)$ \\
39 & $\mathrm{M}$ & $2013-2014$ & $0.00 \%(0)$ & $33.98 \%(5.60)$ & $45.56 \%(3.77)$ & $20.46 \%(8.15)$ \\
40 & $\mathrm{M}$ & $2012-2014$ & $0.65 \%(0.28)$ & $27.09 \%(6.20)$ & $52.45 \%(3.72)$ & $19.80 \%(7.93)$ \\
42 & $\mathrm{M}$ & 2012 & $0.00 \%(0)$ & $46.38 \%(19.09)$ & $53.62 \%(10.20)$ & $0.00 \%(0)$ \\
43 & $\mathrm{M}$ & $2012-2013$ & $1.61 \%(0.52)$ & $25.70 \%(4.92)$ & $57.03 \%(3.64)$ & $15.66 \%(6.52)$ \\
50 & $\mathrm{M}$ & $2012-2014$ & $0.00 \%(0)$ & $38.95 \%(7.22)$ & $17.23 \%(2.30)$ & $43.82 \%(13.18)$ \\
51 & $\mathrm{M}$ & 2013 & $0.39 \%(0.19)$ & $81.78 \%(8.30)$ & $17.83 \%(3.71)$ & $0.00 \%(13.18)$ \\
58 & $\mathrm{M}$ & 2013 & $0.00 \%(0)$ & $46.73 \%(7.30)$ & $16.36 \%(3.41)$ & $36.92 \%(14.54)$ \\
80 & $\mathrm{M}$ & $2013-2015$ & $0.22 \%(0.10)$ & $82.03 \%(9.80)$ & $13.56 \%(2.07)$ & $4.19 \%(3.10)$ \\
82 & $\mathrm{M}$ & $2013-2014$ & $1.69 \%(0.45)$ & $54.38 \%(6.95)$ & $42.86 \%(3.27)$ & $1.08 \%(0.83)$ \\
86 & $\mathrm{M}$ & $2013-2015$ & $7.50 \%(1.00)$ & $77.18 \%(8.59)$ & $7.06 \%(1.23)$ & $8.27 \%(4.91)$ \\
89 & $\mathrm{M}$ & $2013-2014$ & $0.00 \%(0)$ & $26.69 \%(5.64)$ & $52.80 \%(2.97)$ & $20.52 \%(7.38)$ \\
90 & $\mathrm{M}$ & 2013 & $17.32 \%(4.02)$ & $72.63 \%(9.24)$ & $10.06 \%(2.16)$ & $0.00 \%(0)$ \\
93 & $\mathrm{M}$ & 2013 & $44.85 \%(9.19)$ & $34.88 \%(7.66)$ & $18.60 \%(3.50)$ & $1.66 \%(1.13)$ \\
94 & $\mathrm{M}$ & $2013-2014$ & $1.38 \%(0.35)$ & $37.94 \%(7.05)$ & $56.53 \%(4.04)$ & $4.15 \%(1.55)$ \\
98 & $\mathrm{M}$ & $2013-2014$ & $0.00 \%(0)$ & $33.49 \%(6.26)$ & $28.95 \%(3.49)$ & $37.56 \%(12.88)$ \\
189 & $\mathrm{M}$ & $2014-2015$ & $0.00 \%(0)$ & $78.87 \%(15.64)$ & $21.13 \%(5.06)$ & $0.00 \%(0)$ \\
193 & $\mathrm{M}$ & $2014-2015$ & $21.06 \%(3.41)$ & $31.50 \%(5.38)$ & $6.23 \%(0.97)$ & $41.21 \%(14.00)$ \\
44 & $\mathrm{U}$ & $2013-2015$ & $0.00 \%(0)$ & $21.31 \%(3.41)$ & $51.52 \%(3.49)$ & $27.17 \%(6.87)$ \\
151 & $\mathrm{U}$ & 2014 & $82.61 \%(8.99)$ & $17.39 \%(6.67)$ & $0.00 \%(0)$ & $0.00 \%(0)$ \\
\hline & & & & &
\end{tabular}

Table 4.4. Mean proportional occurrence of lake zones in monthly core use areas occupied by

Walleyes in Cheat Lake.

\begin{tabular}{lcccccccccccc}
\hline \multicolumn{1}{c}{ Zone } & Jan & Feb & Mar & Apr & May & Jun & Jul & Aug & Sep & Oct & Nov & Dec \\
\hline Lower & 4.88 & 2.22 & 2.27 & 6.98 & 17.95 & 13.16 & 11.90 & 11.11 & 8.11 & 15.00 & 12.50 & 9.76 \\
Middle & 92.68 & 80.00 & 29.55 & 30.23 & 43.59 & 44.74 & 40.48 & 47.22 & 48.65 & 60.00 & 85.00 & 87.80 \\
Riverine & 2.44 & 17.78 & 59.09 & 34.88 & 15.38 & 23.68 & 30.95 & 22.22 & 24.32 & 20.00 & 2.50 & 2.44 \\
Cheat River & 0.00 & 0.00 & 9.09 & 27.91 & 23.08 & 18.42 & 16.67 & 19.44 & 18.92 & 5.00 & 0.00 & 0.00 \\
\hline
\end{tabular}


Table 4.5. Monthly core use area lake zones occupied by Walleyes in Cheat Lake ( $\mathrm{L}=$ lower main lake zone, $\mathrm{M}=$ middle main lake zone, $\mathrm{R}=$ riverine zone, and $\mathrm{C}=$ Cheat River).

\begin{tabular}{|c|c|c|c|c|c|c|c|c|c|c|c|c|c|}
\hline ID & Sex & Jan. & Feb. & Mar. & Apr. & May & Jun. & Jul. & Aug. & Sep. & Oct. & Nov. & Dec. \\
\hline 33 & $\mathbf{F}$ & $M$ & $M$ & $M$ & $M$ & $M$ & $M$ & $M$ & $M$ & $M$ & $M$ & $M$ & $M$ \\
\hline 41 & $\mathbf{F}$ & $M$ & $M$ & $M$ & $M$ & $M$ & $M$ & $M$ & $M$ & $M$ & $M$ & $M$ & $M$ \\
\hline 52 & $\mathbf{F}$ & $M$ & $M$ & $\mathrm{R}$ & $M-R$ & $M$ & $M$ & $\mathrm{R}$ & $M$ & $M$ & $M$ & $M$ & $M$ \\
\hline 53 & $\mathbf{F}$ & $M$ & $M$ & $\mathrm{R}$ & $\mathrm{M}$ & $M$ & $M$ & $M-R$ & $\mathrm{R}$ & $M$ & $M$ & $M$ & $M$ \\
\hline 55 & $\mathbf{F}$ & $M$ & $M$ & $M$ & $M$ & $M-R$ & $M$ & $\mathrm{M}$ & $M$ & $M$ & $M$ & $M$ & $M$ \\
\hline 57 & $\mathbf{F}$ & $M$ & $M$ & $M$ & $M$ & $\mathrm{M}$ & $M$ & $M$ & $M$ & $M$ & $M$ & $M$ & $M$ \\
\hline 59 & $\mathbf{F}$ & $M$ & $M$ & $\mathrm{R}$ & $M$ & $\mathrm{M}$ & $M$ & $\mathrm{M}$ & $M$ & $M$ & $M$ & $M$ & $M$ \\
\hline 60 & $\mathbf{F}$ & $M$ & $M$ & $M$ & $M$ & L-M & $M$ & L-M & $M$ & $M$ & $M$ & $M$ & $M$ \\
\hline 79 & $\mathbf{F}$ & $M$ & $M$ & $M$ & $M$ & $M$ & $M$ & $M$ & $M$ & $M$ & $\mathrm{~L}$ & $M$ & $M$ \\
\hline 83 & $F$ & $M$ & $M$ & $\mathrm{R}$ & $C$ & $C$ & $C$ & $C$ & $C$ & $C$ & C & $M$ & $M$ \\
\hline 84 & $F$ & $\mathrm{~L}$ & $\mathrm{~L}$ & $\mathrm{~L}$ & L-R & L & L & $\mathrm{L}$ & L & $L$ & L & $\mathrm{L}$ & $\mathrm{L}$ \\
\hline 85 & $\mathbf{F}$ & $M$ & $M$ & $M$ & $\mathrm{M}$ & $M$ & $M$ & $M$ & $M$ & $M$ & $M$ & $M$ & $M$ \\
\hline 87 & $\mathbf{F}$ & $M$ & $M$ & $M$ & $\mathrm{M}$ & L-M & $\mathrm{L}$ & $\mathrm{L}$ & $\mathrm{L}$ & $\mathrm{L}$ & $\mathrm{L}$ & L-M & $M$ \\
\hline 88 & $\mathbf{F}$ & $M$ & $M$ & $\mathrm{R}$ & $\mathrm{R}-\mathrm{C}$ & $\mathrm{M}$ & $M$ & $M$ & $M$ & $M$ & L-M & $\mathrm{M}$ & $M$ \\
\hline 96 & $\mathbf{F}$ & $M$ & $M$ & $\mathrm{R}$ & $C$ & $C$ & $\mathrm{~L}$ & $\mathrm{~L}$ & $\mathrm{~L}$ & $\mathrm{~L}$ & $\mathrm{~L}$ & $M$ & $M$ \\
\hline 157 & $\mathbf{F}$ & $M$ & $M$ & $\mathrm{R}$ & $C$ & . & . & . & . & . & . & . & $M$ \\
\hline 179 & $F$ & $M$ & $M$ & $M-R$ & $\mathrm{R}-\mathrm{C}$ & . & . & . & . & . & $M$ & $M$ & $M$ \\
\hline 185 & $\mathbf{F}$ & $M$ & $M$ & $\mathrm{M}$ & $\mathrm{M}$ & $M$ & $M$ & $M$ & $M$ & $M$ & $M$ & $M$ & $M$ \\
\hline 190 & $\mathbf{F}$ & L-M & $M$ & $M$ & $\mathrm{~L}$ & $\mathrm{~L}$ & $M$ & $M$ & $M$ & $\mathrm{M}$ & $M$ & $M$ & L-M \\
\hline 35 & $\mathbf{M}$ & $\mathrm{M}$ & $M$ & $\mathrm{R}$ & $\mathrm{R}$ & $\mathrm{R}$ & $\mathrm{R}$ & $\mathrm{R}$ & $\mathrm{R}$ & $M-R$ & $M$ & $M$ & $\mathrm{M}$ \\
\hline 38 & $\mathbf{M}$ & $\mathrm{M}$ & $M$ & $M$ & . & . & . & . & . & . & . & . & . \\
\hline 39 & $\mathbf{M}$ & $M$ & $\mathrm{R}$ & $\mathrm{R}$ & $\mathrm{R}$ & $\mathrm{R}$ & $\mathrm{R}$ & $C$ & C & $C$ & $M-R$ & $M$ & $M$ \\
\hline 40 & $\mathbf{M}$ & $M$ & $M$ & $C$ & C & $\mathrm{R}$ & $R$ & $\mathrm{R}$ & $\mathrm{R}$ & $\mathrm{R}$ & $M-R$ & $M$ & $M$ \\
\hline 42 & $\mathbf{M}$ & $M$ & $\mathrm{M}$ & $\mathrm{R}$ & . & . & . & . & . & $\cdot$ & . & . & . \\
\hline 43 & $\mathbf{M}$ & $M$ & $M-R$ & $\mathrm{R}$ & $\mathrm{R}$ & C & $\mathrm{R}$ & $\mathrm{R}$ & $\mathrm{R}$ & $\mathrm{R}-\mathrm{C}$ & $M-R$ & $M$ & $M-R$ \\
\hline 50 & $\mathbf{M}$ & $M$ & $\mathrm{M}$ & $\mathrm{R}-\mathrm{C}$ & C & $C$ & $C$ & $C$ & C & $\mathrm{R}$ & $\mathrm{M}$ & $M$ & $\mathrm{M}$ \\
\hline 51 & $\mathbf{M}$ & $M$ & $M$ & $\mathrm{R}$ & $\mathrm{R}$ & $M$ & $M$ & $M$ & . & . & . & $M$ & $M$ \\
\hline 58 & $\mathbf{M}$ & $M$ & $M$ & $M-R$ & $\mathrm{R}$ & $C$ & $C$ & $C$ & $C$ & $C$ & $\mathrm{R}$ & $M$ & $M$ \\
\hline 80 & $\mathbf{M}$ & $M$ & $M$ & $\mathrm{R}$ & $\mathrm{M}-\mathrm{C}$ & $M$ & $M$ & $M$ & $\mathrm{M}$ & $M$ & $\mathrm{M}$ & $M$ & $M$ \\
\hline 82 & $\mathbf{M}$ & $M$ & $M$ & $\mathrm{R}$ & $\mathrm{R}$ & $M$ & $M$ & $\mathrm{R}$ & $M-R$ & $\mathrm{R}$ & $M-R$ & $M$ & $M$ \\
\hline 86 & $\mathbf{M}$ & $M$ & $\mathrm{M}$ & $\mathrm{R}-\mathrm{C}$ & C & $M$ & $M$ & $M$ & $\mathrm{M}$ & $M$ & $\mathrm{M}$ & $M$ & $M$ \\
\hline 89 & $\mathbf{M}$ & $M$ & $M-R$ & $\mathrm{R}$ & C & $C$ & $\mathrm{R}-\mathrm{C}$ & $\mathrm{R}$ & $\mathrm{R}$ & $\mathrm{R}$ & $\mathrm{R}$ & $M$ & $M$ \\
\hline 90 & $\mathbf{M}$ & $M$ & $\mathrm{M}$ & $\mathrm{R}$ & $\mathrm{R}$ & L & $\mathrm{L}$ & $M$ & $M$ & $M$ & $M$ & $M$ & $M$ \\
\hline 93 & $\mathbf{M}$ & $M$ & $M-R$ & $\mathrm{R}$ & L-R & L & $\mathrm{L}$ & $\mathrm{L}$ & $L$ & . & . & $M$ & $M$ \\
\hline 94 & $\mathbf{M}$ & $M$ & $\mathrm{M}$ & $\mathrm{R}$ & $\mathrm{R}$ & $\mathrm{R}$ & $\mathrm{R}$ & $\mathrm{R}$ & $\mathrm{R}$ & $M$ & $M$ & $M$ & $M$ \\
\hline 98 & $\mathbf{M}$ & $M$ & $\mathrm{M}$ & $\mathrm{R}$ & $\mathrm{R}$ & C & C & $C$ & $C$ & $C$ & $\mathrm{R}$ & $M$ & $M$ \\
\hline 189 & $M$ & $\mathrm{M}$ & $M-R$ & . & . & . & . & . & . & . & . & . & $M$ \\
\hline 44 & $U$ & $M-R$ & $\mathrm{R}$ & $\mathrm{R}$ & $\mathrm{R}-\mathrm{C}$ & $\mathrm{R}-\mathrm{C}$ & $\mathrm{R}-\mathrm{C}$ & $\mathrm{R}-\mathrm{C}$ & C & $\mathrm{R}-\mathrm{C}$ & $C$ & $M-R$ & $M$ \\
\hline
\end{tabular}




\begin{tabular}{llllllllllllll}
151 & $\mathrm{U}$ & $\cdot$ & $\cdot$ & $\cdot$ & $\cdot$ & $\cdot$ & $\cdot$ & $\cdot$ & $\cdot$ & $\cdot$ & $\cdot$ & $\mathrm{L}$ & $\mathrm{L}$ \\
193 & $\mathrm{M}$ & $\mathrm{M}$ & $\mathrm{M}$ & $\mathrm{R}-\mathrm{C}$ & $\mathrm{C}$ & $\mathrm{C}$ & $\mathrm{C}$ & $\mathrm{C}$ & $\mathrm{C}$ & $\mathrm{C}$ & $\mathrm{M}$ & $\mathrm{L}-\mathrm{M}$ & $\mathrm{L}-\mathrm{M}$ \\
\hline
\end{tabular}

Table 4.6. Results of generalized linear mixed model analysis of monthly core range shifts in Walleyes in Cheat Lake, WV. Sex (female) and Month (January) are used as the baseline for the estimation of the categorical variables sex and month, and therefore, do not appear in the model summary. Asterisk * indicates statistical significance $(\alpha<0.05)$.

\begin{tabular}{lcccccl}
\hline & Estimate & SE & z value & p value & \\
\hline Intercept & -3.462 & 0.7949 & -4.355 & $<0.001$ & $*$ & \\
Sex (male) & 1.0631 & 0.3756 & 2.831 & 0.00465 & $*$ & \\
Month (February) & 0.8095 & 0.9269 & 0.873 & 0.3825 & \\
Month (March) & 3.5147 & 0.8566 & 4.103 & $<0.001$ & $*$ & \\
Month (April) & 2.748 & 0.8456 & 3.25 & 0.00116 & $*$ & \\
Month (May) & 2.7486 & 0.8456 & 3.25 & 0.00115 & $*$ & \\
Month (June) & 1.5592 & 0.8711 & 1.79 & 0.07348 & \\
Month (July) & 1.5551 & 0.8713 & 1.785 & 0.0743 & \\
Month (August) & 0.8106 & 0.9268 & 0.875 & 0.38177 & \\
Month (September) & 1.3384 & 0.8834 & 1.515 & 0.12975 & \\
Month (October) & 2.2768 & 0.8488 & 2.682 & 0.00731 & $*$ \\
Month (November) & 2.5961 & 0.8458 & 3.069 & 0.00214 & $*$ \\
Month (December) & 0.4522 & 0.9711 & 0.466 & 0.64148 & \\
\hline
\end{tabular}


Figure 4.1. Acoustic telemetry receiver locations and associated lake zones in Cheat Lake, WV.

Figure 4.2. Typical core range for Walleyes occupying the middle main lake zone of Cheat Lake, WV.

Figure 4.3. Typical core range for Walleyes occupying the riverine zone of Cheat Lake, WV.

Figure 4.4. Typical core range for Walleyes occupying the Cheat River, upstream of Cheat Lake, WV.

Figure 4.5. Mean proportional monthly lake zone use by male Walleyes in Cheat Lake, WV. Error bars are \pm standard error.

Figure 4.6. Mean proportional monthly lake zone use by female Walleyes in Cheat Lake, WV. Error bars are \pm standard error.

Figure 4.7. Mean proportion of monthly core range shifts by male and female Walleyes in Cheat Lake, WV

Figure 4.8. Mean monthly deviation in receiver use (linear range) by Walleyes in Cheat Lake, WV. Error bars are \pm standard error.

Figure 4.9. Mean monthly deviation in residency index by male and female Walleyes in Cheat Lake, WV. Error bars are \pm standard error. 


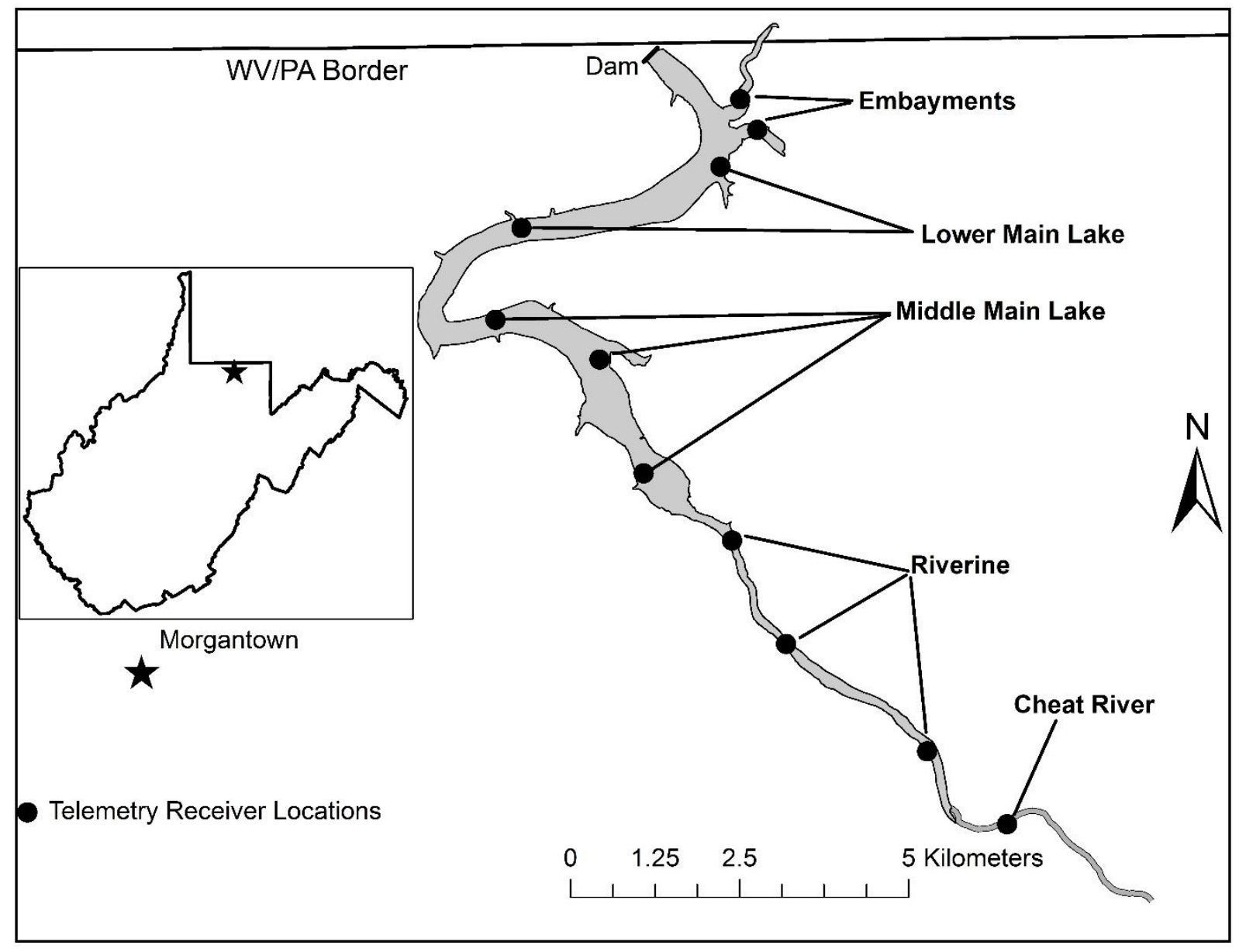




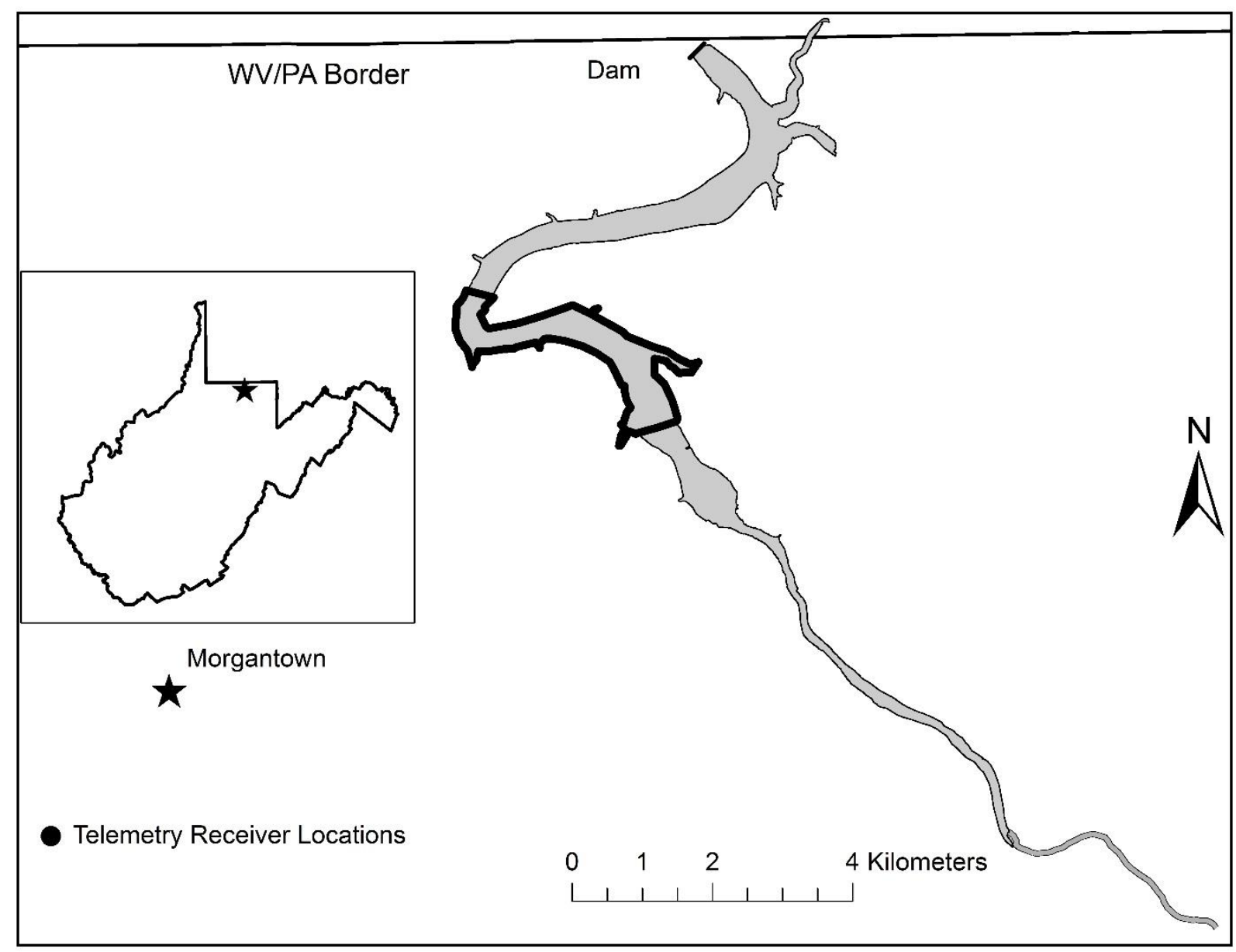




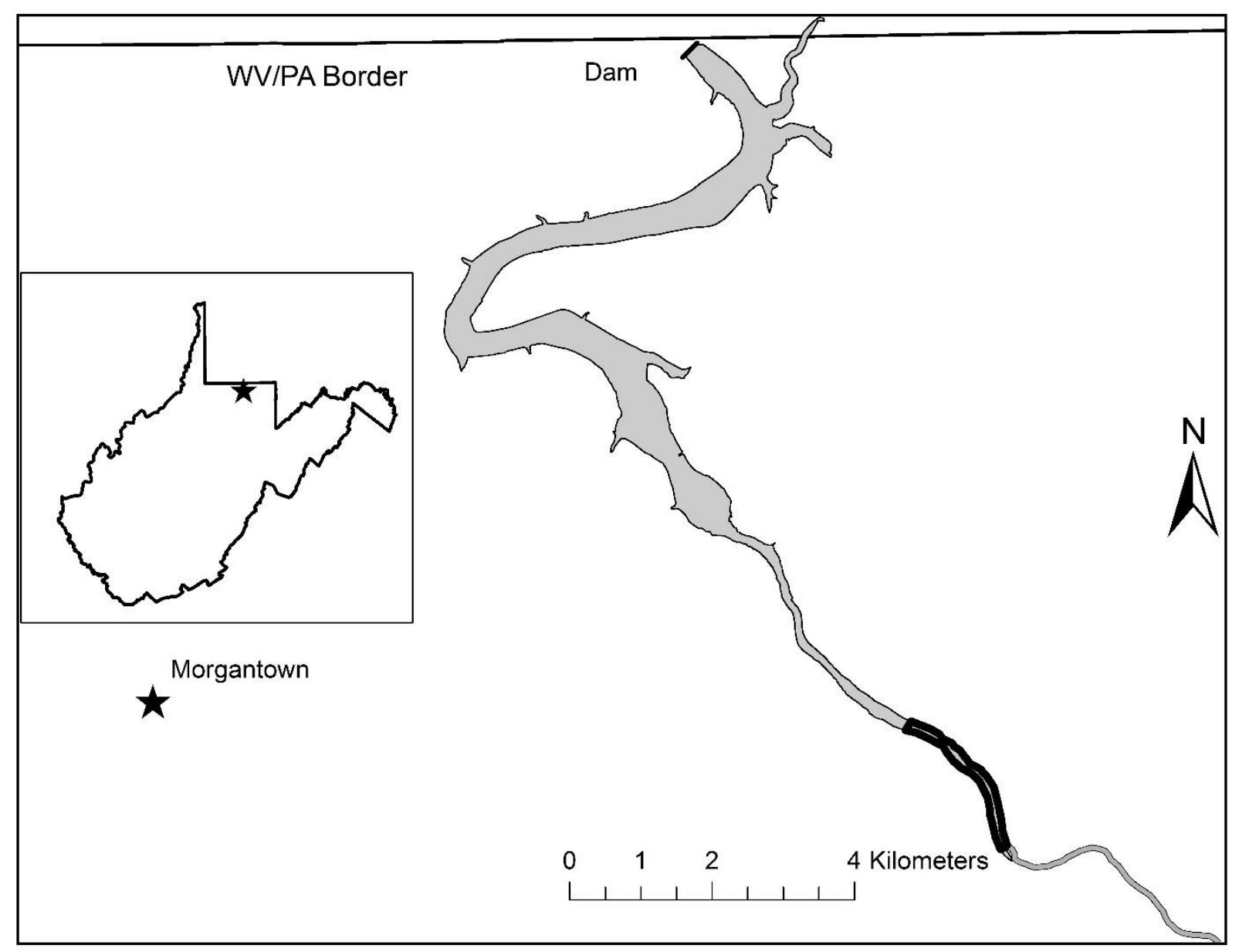




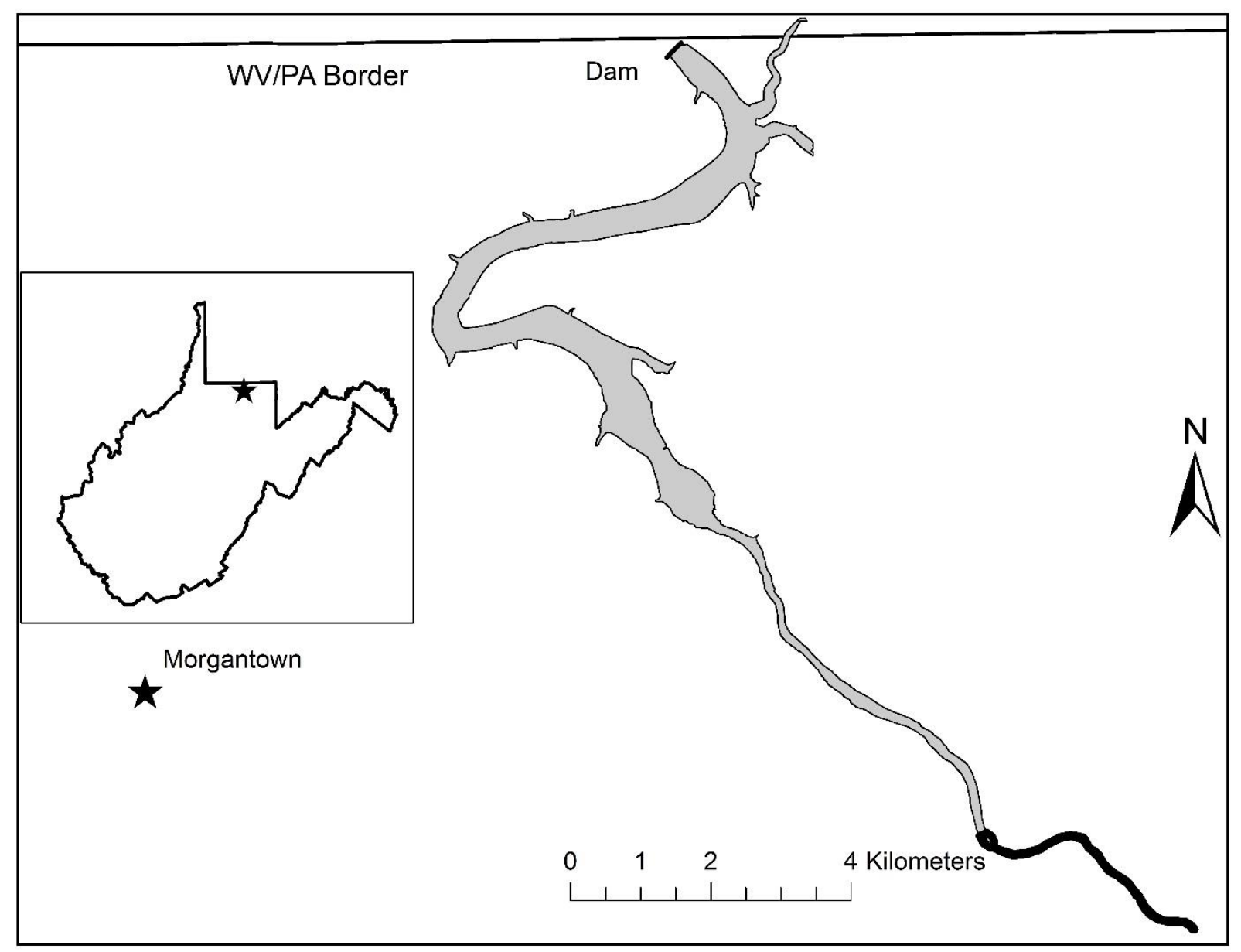




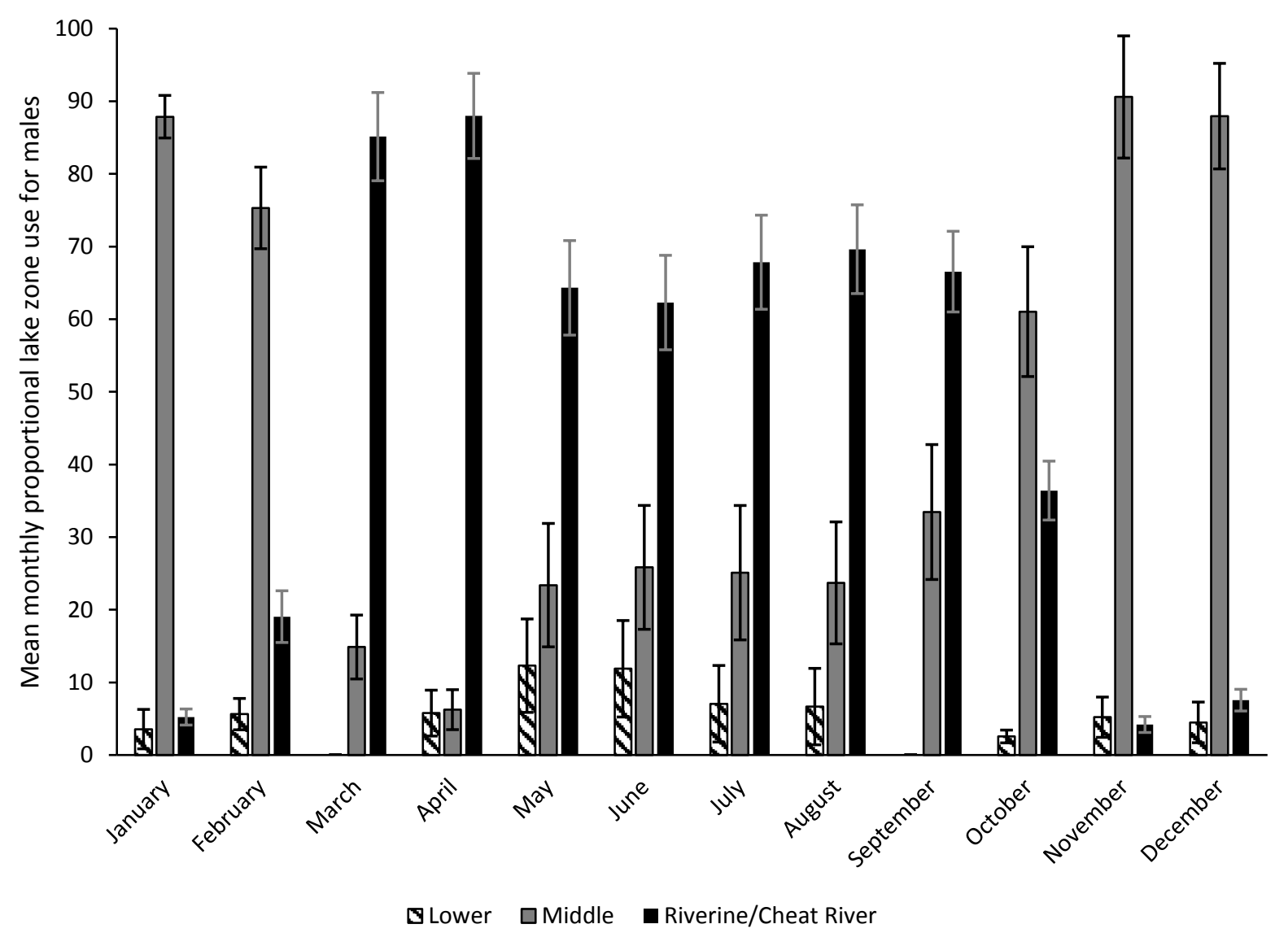




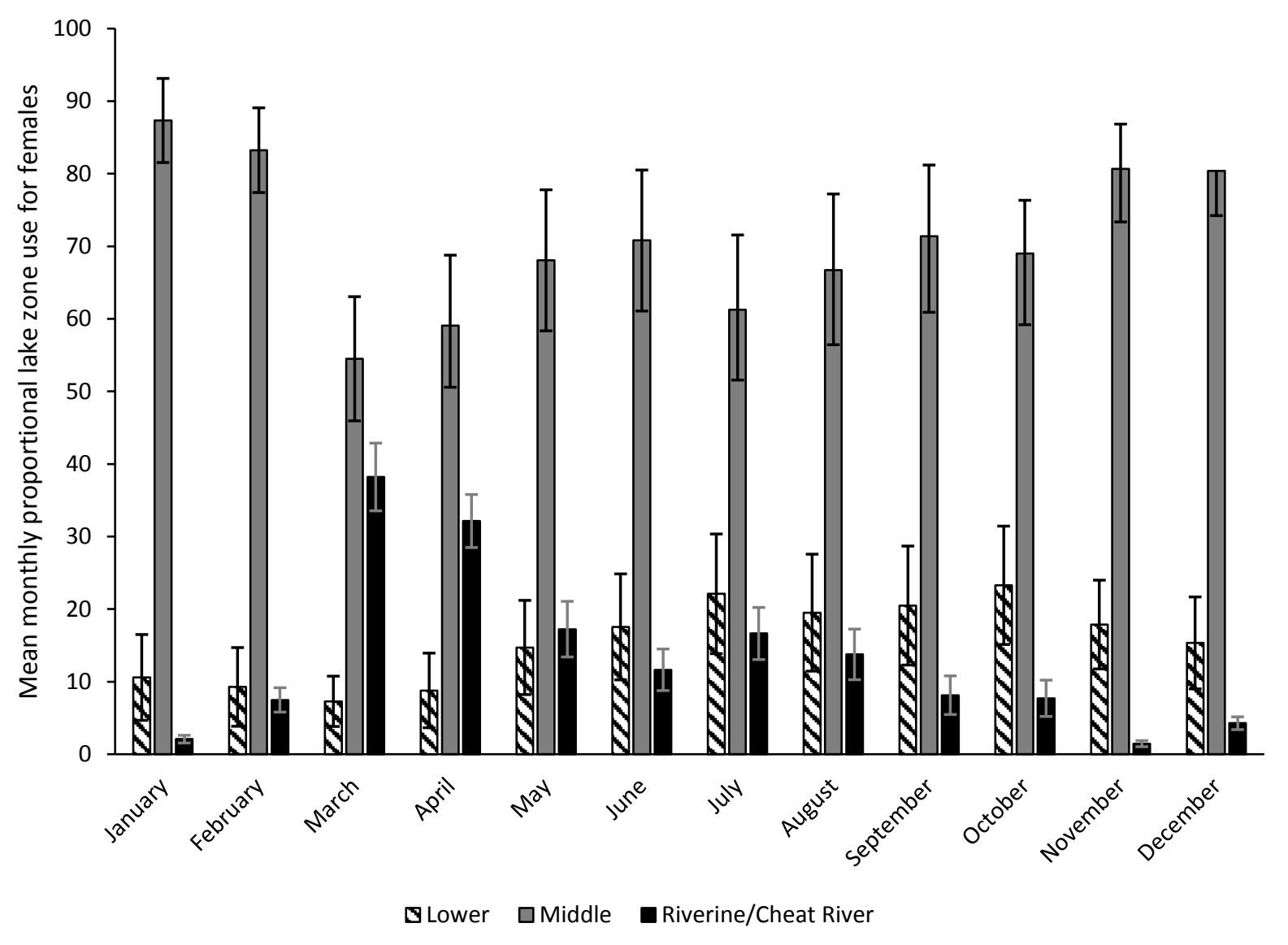




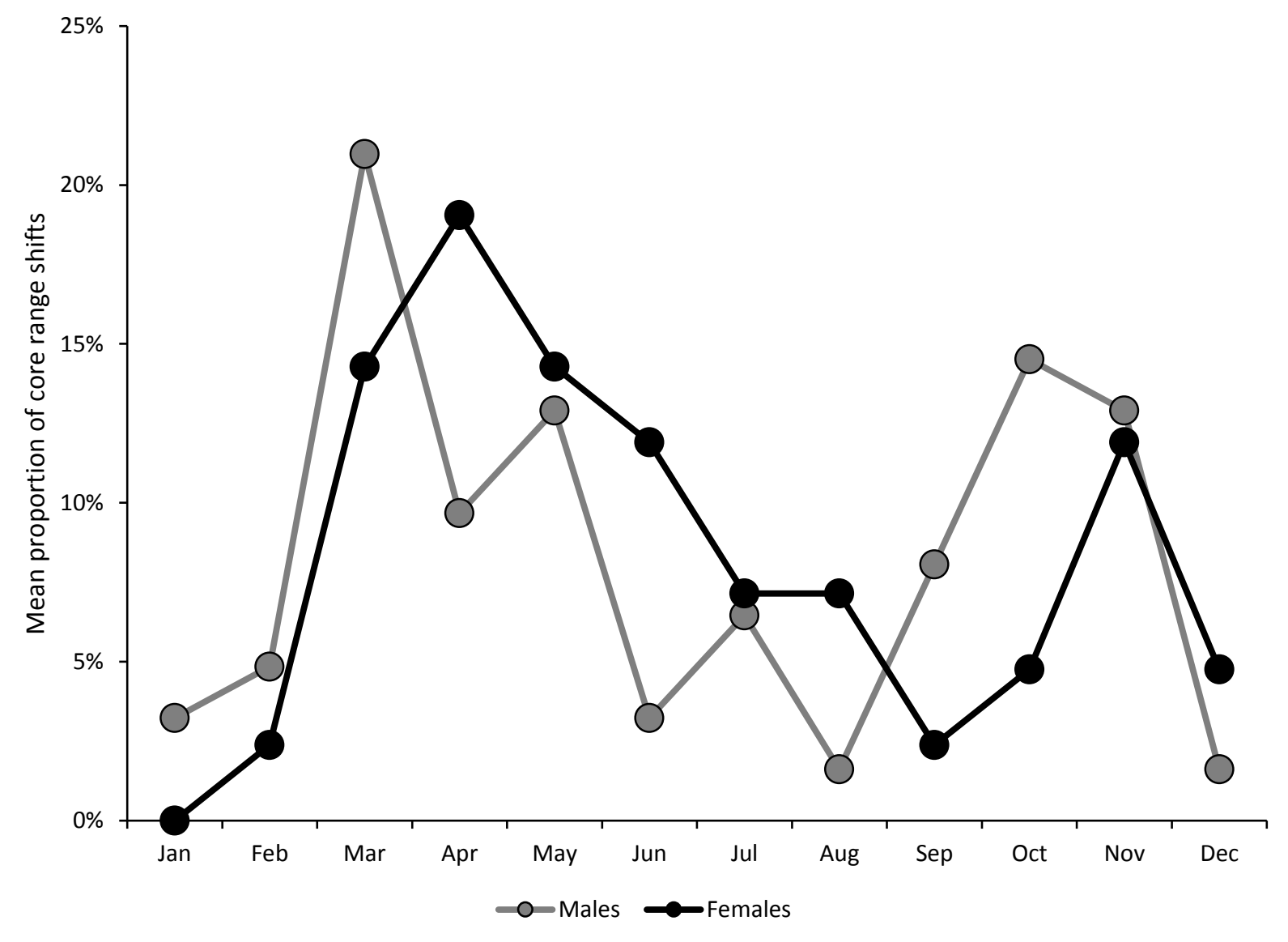




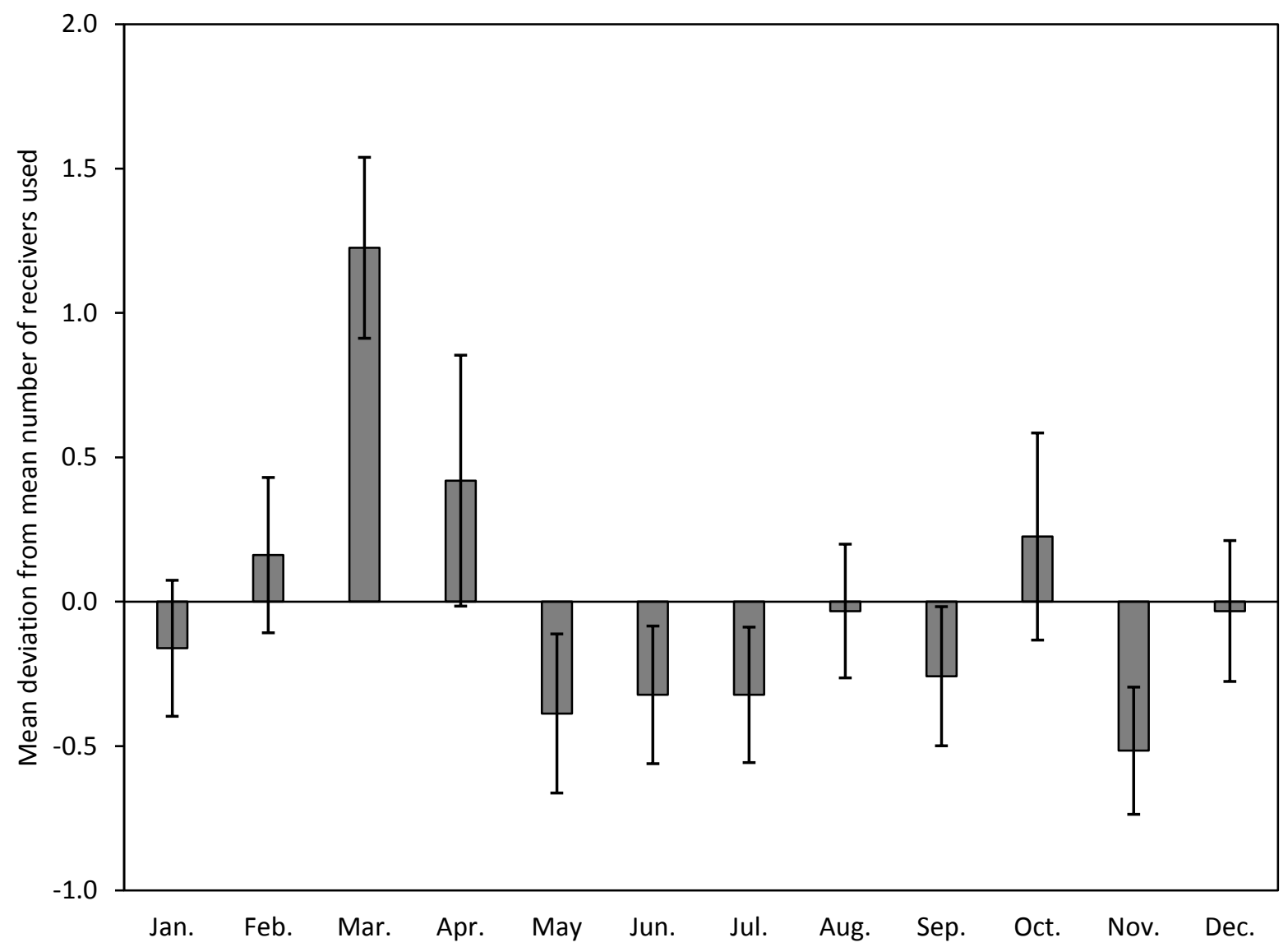




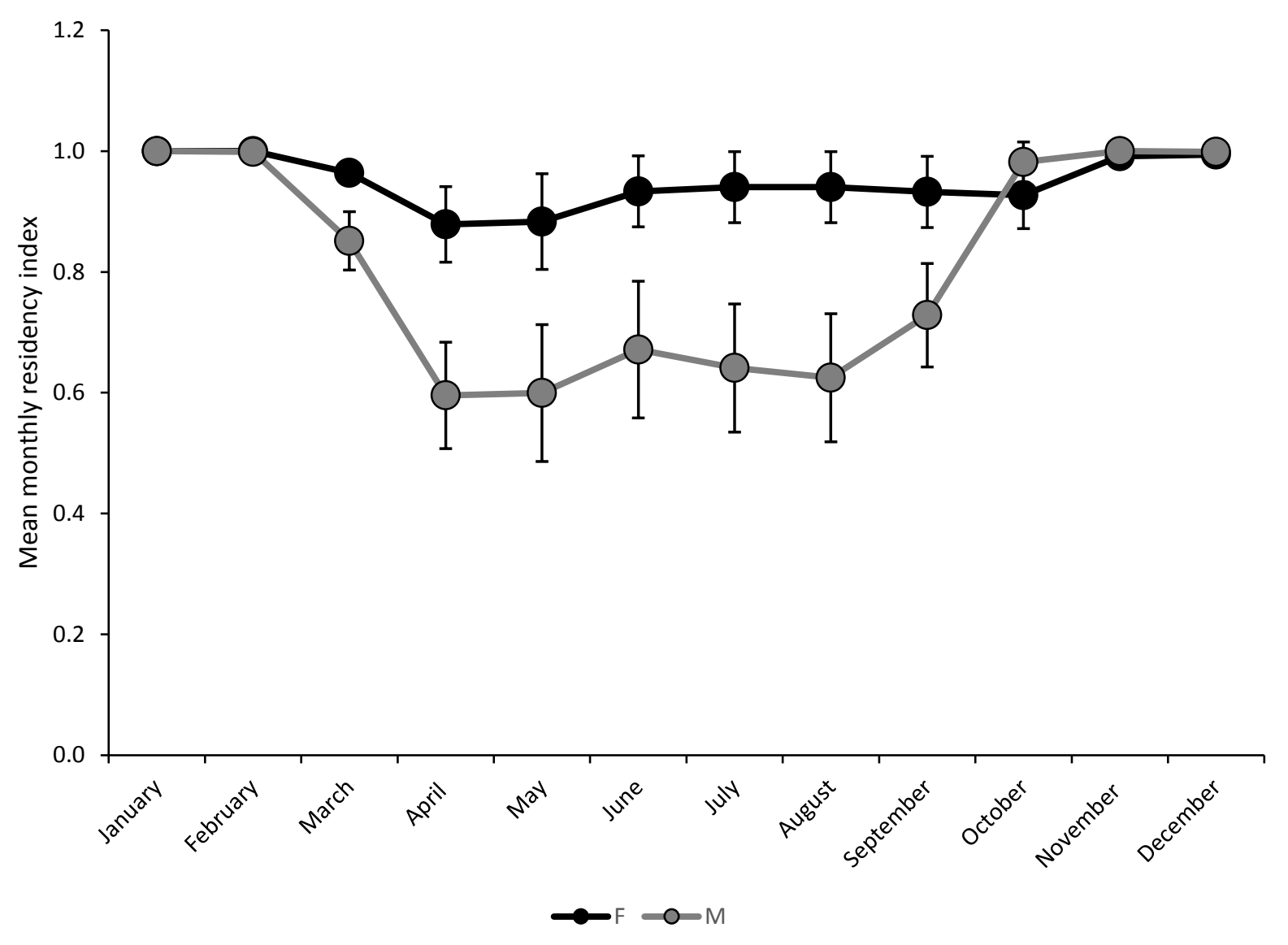




\section{Chapter 5 - Environmental correlates of large scale seasonal movements of Walleyes in a hydropower reservoir}

\section{Abstract}

Walleyes were recently reestablished in Cheat Lake, WV in response to water quality improvements after years of impairment from acid mine drainage. As part of the reintroduction effort, Walleye stockings have regularly occurred since 1999. Although stockings have been conducted, a naturally reproducing population is ultimately desired. To better understand the spawning habits and seasonal movement patterns within the lake, a telemetry study was initiated. From 2012-2015, 50 Walleyes were tagged with acoustic transmitters to determine seasonal movements and spawning locations. Binomial logistic regression was used to determine what environmental variables best predict large scale seasonal movements during pre-spawn, post-spawn and non-spawn time periods. Using an information theoretic approach, the best approximating models composed of environmental variables were identified for each time period of interest. Walleyes made pre-spawn upstream migrations in late winter/early spring to spawning areas during periods of elevated water temperatures $(75 \%$ of migrations occurred at water temperatures $>4.1^{\circ} \mathrm{C}$ ). Male Walleyes were more likely to make upstream pre-spawn migrations earlier than females. Walleyes spawned in shallow, riffle-run habitat in the headwaters of Cheat Lake. Post-spawning migrations were most influenced by season and fish sex. Most females (83\%) made post-spawn migrations to the main lake in spring, while most males (61\%) made post-spawn migrations in fall. During non-spawning periods (May December) large movements (> $4 \mathrm{~km}$ ) were primarily influenced by river discharge and to a lesser extent water temperature. Most Walleyes made large non-spawning movements from the main lake zone to the riverine zone. Results from the study suggest that water temperature and river flow are important environmental predictors of Cheat Lake Walleye movements. However, 
the importance of water temperature and river discharge in predicting large scale movements can vary seasonally and with fish sex. Knowledge of spawning locations and seasonal movement patterns could be beneficial for management of this recovering population.

\section{Introduction}

An understanding of seasonal movements and spawning locations is critical for the management and conservation of fishes (Landsman et al. 2011). Advances in fish tracking via telemetry give researchers the ability to better understand fish movements, habitat use, and behavior (Lucas and Baras 2000; Rutz and Hayes 2009; Landsman et al. 2011). The Walleye is considered a highly mobile species, where individuals make frequent and long range movements associated with spawning, foraging, and overwintering (Paragamian 1989; DePhillip et al. 2005; Hanson 2006; Bozek et al. 2011). Habitat usage by Walleyes is often complex involving daily and seasonal habitat shifts (Bozek et al. 2011). Several studies have examined Walleye movements and habitat use via mark-recapture methods and telemetry (Eschemeyer and Crowe 1955; Crowe 1962; Paramagian 1989; DePhillip et al. 2005; Palmer et al. 2005; Hanson 2006; Hayden et al. 2014). Past studies have focused mostly on Walleye movements in rivers, natural lakes, or flood control reservoirs within northern or midwestern states (Holt et al. 1977; Paramagian 1989; Williams 2001; DePhillip et al. 2005; Hanson 2006; Bozek et al. 2011).

Among water bodies, Walleyes can be highly variable in patterns of movement and habitat use (Bozek et al. 2011). Seasonal movements of Walleyes have been correlated with various environmental factors (Paragamian 1989; Williams 2001; DePhillip et al. 2005; Palmer et al. 2005; Hanson 2006; Bozek et al. 2011). Walleyes exhibit more frequent and larger seasonal movements during late winter and early spring in relation to spawning activity (Paragamian 1989; DePhillip et al. 2005; Palmer et al. 2005; Hanson 2006; Bozek et al. 2011). 
Frequent environmental variables associated with increased spawning movements include water temperature and river discharge (Paragamian 1989; Palmer et al. 2005; Bozek et al. 2011). Despite numerous studies investigating an array of possible environmental influences on Walleye movement, limited research has been done investigating Walleye movements in Appalachian reservoirs (Williams 2001; Palmer et al. 2005). Additionally, most studies on Walleye movements have employed manual tracking techniques, primarily with radio telemetry. Only recently have researchers began to utilize continuous acoustic monitoring of Walleye movements through use of stationary acoustic receivers (Hanson 2006; Phillips 2014; Pritt et al. 2013; Hayden et al. 2014). Use of continuous acoustic monitoring could provide improved accuracy of movement patterns and aid in making more effective management decisions.

Cheat Lake, WV is a hydropower reservoir in northern West Virginia that supports a rebounding Walleye fishery that was originally extirpated due to acid mine drainage within the watershed (Core 1959; WVDNR, unpublished data). Water quality remediation and stocking efforts have reestablished a Walleye fishery within the reservoir (see Chapter 3). Although Walleyes have been reestablished within the reservoir, natural reproduction has been limited and little is known about the movement patterns and spawning locations of Walleyes in Cheat Lake. Cheat Lake also experiences seasonally varying fluctuations in water levels as a result of hydropower operations and it is unknown how these fluctuations may impact Walleye spawning and other seasonal movements. Water level fluctuations influence movements and can limit reproductive success of some fish species (Rogers and Bergerson 1995; Jones and Rogers 1998; Paukert and Fisher 2000; Paukert and Fisher 2001), including Walleyes during spawning periods (Johnson 1961; Priegel 1970; Bozek et al. 2011; Martin et al. 2012). Information regarding spawning location of Walleyes, environmental cues for spawning migration, and timing of spawning in relation to water levels are important for the future management of the Cheat Lake Walleye fishery. In addition, information gained on other seasonal movements 
would further enhance management opportunities for the fishery. Consequently, there is a management driven need for research investigating seasonal movements of Walleyes within Cheat Lake, and the potential influence of environmental factors. With knowledge of migration cues and seasonal movements, managers can better predict potential impacts to the population by environmental conditions and fishing pressure.

The goal of this study was to evaluate seasonal movement patterns of Walleyes within Cheat Lake in relation to environmental covariates. During the pre-spawn period, our objective was to determine important environmental cues associated with initiation of upstream migration towards spawning grounds. We were also interested in determining spawning locations and how changing lake elevation may impact spawning at these locations. During the post-spawn period, our objective was to determine timing and environmental covariates associated with the migration of individuals to pre-spawn locations. During non-spawning periods (i.e., summer, fall and winter) our objective was to determine environmental covariates associated with large scale movements.

\section{Methods}

\section{Study Area}

Cheat Lake was created in 1926 by damming the Cheat River near the West VirginiaPennsylvania border to serve the needs of a hydroelectric generating facility. The reservoir is approximately 700 ha in size, extends $21 \mathrm{~km}$ from the dam to the first riffle, and has a maximum depth of $24 \mathrm{~m}$ near the dam. The Cheat River watershed has experienced depressed water quality for over a century as a result of acid precipitation and acid mine drainage from abandoned mine lands (Core 1959; Welsh and Perry 1997; Freund and Petty 2007; Merovich et al. 2007). Consequently, since its establishment Cheat Lake has been subjected to acidification 
from these sources (Core 1959; WVDNR unpublished data). In recent years, the Cheat River watershed and Cheat Lake have seen substantial water quality improvements likely owing to mitigation efforts throughout the watershed (McClurg et al. 2007; WVDNR unpublished data).

For this study, we separated Cheat Lake into different zones to determine when initiation of migrations occurred. We used methodology similar to that used for Chapters 2 and 4 to designate lake zones, and used results from the Walleye distribution study in Chapter 4 to inform designation of lake zones. For this large-scale movement study, the reservoir was separated into two zones: the main lake zone (including embayments) and the riverine zone (Figure 5.1). Additionally, we regarded the Cheat River upstream of the reservoir as an additional zone (Figure 5.1). Separation of these zones was based on various factors including reservoir morphology, bathymetry, water chemistry differences and overwintering distribution of Walleyes obtained in a separate study (see Chapter 4). Specifically, based on morphology, there is a distinct morphological difference between the riverine zone and main lake zone. The riverine zone is relatively narrow in cross section, whereas the main lake zone is typically $2.5-3$ times the width of the riverine zone (Figure 5.1). There is also a distinct difference in hydrological characteristics between the zones. The riverine zone is heavily influenced by the incoming Cheat River in terms of river current. In contrast, the main lake zone is much more lacustrine in character. This is apparent by the typical pattern of overwinter ice formation in the main lake zone but absence of ice in the riverine zone. Additionally, throughout most of the main lake zone, average depths are greater than that occurring within the riverine zone. Also, Walleye distribution data examined in a separate study suggest that during winter all but two of our tagged fish spent most their time downstream of the riverine zone (see Chapter 4). 


\section{Fish Collection and Tagging}

Fifty Walleyes (31 males, 17 females, 2 undetermined, 432-708 mm TL) were collected using boat electrofishing or gill nets in late October/early February 2011-2013. Fish were anesthetized using MS-222 (tricaine methanesulfonate; $100 \mathrm{mg} / \mathrm{L}$ ). An acoustic transmitter was surgically-implanted into the abdominal cavity of each Walleye (Hart and Summerfelt 1975). Sonotronics coded temperature transmitters (CTT-83-3-I, $62 \mathrm{~mm}$ length, $16 \mathrm{~mm}$ diameter, $10 \mathrm{~g}$ in water) with a battery life of 3 years were used in this study. Fish were placed ventral side up in a V-shaped trough and the gills were continuously irrigated with oxygenated water during surgery. Surgical instruments were sterilized and betadine was applied to the incision site as an antiseptic. An incision of approximately $30-40 \mathrm{~mm}$ was made and 3-4 sutures of nonabsorbable monofilament were used to close the incision. Surgical procedures lasted less than 7 minutes. Additionally, each fish was marked with a numerically coded external t-bar anchor tag. Each anchor tag displayed contact information in the case of angler caught fish with information recommending the release of the fish (due to the 21 day hold time for MS-222). After surgery and tag placement, fish were placed in a livewell and were monitored until swimming upright and behaving normally (usually a period of 5-10 minutes). To reduce taginduced behavior, we followed the general rule of transmitter weight $(<2 \%$ of the fish weight), and included a recovery period of 4 weeks prior to data collection to monitor for abnormal behavior associated with gear-induced and post-surgery stress or injury (Winter 1996). Other data collected on tagged fish were length, weight, and sex (if determinable). Walleyes were sexed when possible by examination of the gonads through the surgical incision or by expulsion of milt for males. Some Walleyes that were initially difficult to sex were later recaptured via fish surveys or anglers and sex was verified. 


\section{Telemetry}

Walleye locations and movements were monitored year-round, primarily with fixed location telemetry via stationary receivers. Sonotronics submersible underwater receivers (SUR) were deployed at fixed locations throughout Cheat Lake (Figure 5.1). We attempted to deploy receivers in relatively equidistant locations along the length of the reservoir to maximize coverage. As many as 10 receivers were placed throughout the reservoir with an additional receiver located approximately $1 \mathrm{~km}$ upstream of the reservoir (above first riffle/run complex and suspected spawning area) in Cheat River. The purpose of the upstream receiver was to determine if at any point tagged Walleyes left the reservoir. The two receivers placed in the primary large embayments at the northern end of the reservoir were lost at the end of 2013 , and the receiver located $12 \mathrm{~km}$ upstream of the dam was added at the end of 2012. Mean distance between receivers in the main reservoir (not including two embayment receivers) was $2.4 \mathrm{rkm}$.

Tag detection range of receivers was influenced by thermal stratification, background noise in certain areas (i.e., bridges), and sinuosity of the reservoir. Tag detection range of each receiver varied seasonally due to thermal stratification which reduces the effective range (Shroyer and Logsdon 2009). Range detection tests showed that average detection range during periods of thermal stratification (summer) was approximately 200-500 m, while average detection range during periods of water temperature uniformity was approximately 400-900m. The detection range of receivers was always at least the width of the reservoir at each receiver location. Some supplementary tracking was conducted manually using an acoustic hydrophone, primarily to determine specific location of fish at spawning areas. 


\section{Environmental Data}

We collected data for several environmental covariates including lake elevation, water temperature, lunar illumination, and river discharge. Mean daily river discharge $\left(\mathrm{m}^{3} \mathrm{~s}^{-1}\right)$, lake elevation (meters above sea level), and water temperature $\left({ }^{\circ} \mathrm{C}\right)$ were acquired from the U.S. Geological Survey Water Watch website (http://water.usgs.gov/waterwatch). River discharge and water temperature data from the Albright gauging station on the Cheat River were used for data analysis. The Albright gauging station is approximately $24 \mathrm{rkm}$ upstream from the head of Cheat Lake. Lake elevation data were from the Lake Lynn hydropower station on Cheat Lake. Lunar illumination data were acquired from the U.S. Naval Observatory (http://www.usno.navy.mil/USNO/astronomical-applications). Lunar illumination data consisted of a daily lunar index of the illuminated percentage of the moon face ranging from 0 (new moon) to 1 (full moon).

\section{Data Analysis}

Data collected from stationary receivers were processed using the Sonotronics software SURsoftDPC. All data were exported to Microsoft Excel. False detections are possible with acoustic telemetry as a result of background noise or in instances when multiple fish are close to the hydrophone (Clements et al. 2005). These erroneous data were eliminated from the dataset by omitting detections that occurred only once within a $24 \mathrm{hr}$ period or by eliminating records when fish were detected as being in separate locations simultaneously (Ramsden et al. 2017).

We used generalized linear mixed models (GLMM) using the PROC GLIMMIX procedure in SAS (SAS 1990) to model covariance associated with repeated measures on movements of individuals. Specifically, binomial logistic regression models with repeated 
measures and a logit link function were used to examine the relationship between Walleye migration events and environmental covariates, along with non-environmental variables. Models incorporating repeated measures use specialized variance-covariance structures to account for serial correlations present (Henderson et al. 2014; Littell et al. 2006; Rogers and White 2007). Use of a mixed model was necessary due to the combination of fixed (i.e., year, season, sex, lake elevation, water temperature, river discharge, and lunar illumination) and random effects (individual fish) present in the models (Henderson et al. 2014; Littell et al. 2006; Bolker et al. 2008). Due to the use of a linear passive acoustic monitoring array movements could only be defined coarsely on the scale of hundreds of meters (Henderson et al. 2014). For our analyses, we were simply concerned with a binary response of migratory movement during certain periods (i.e., migration vs no migration) in response to environmental covariates. Several recent studies have employed a similar technique of using GLMM's with a binary response variable to model probability of fish movement or migration (Eyler 2014; Henderson et al. 2014; Amtstaetter et al. 2015). Potential covariates for our models included year, season, sex, and several environmental variables (water temperature, river discharge, lake elevation, lunar illumination) as fixed effects. Year was defined as the calendar year from January $1^{\text {st }}$-December $31^{\text {st }}$. We defined seasons as the following: winter (December-February), spring (March-May), summer (June-August), and fall (September-November). Individual fish were included as random effects to account for repeated measures on each fish (Rogers and White 2007).

We were interested in modeling migratory movements of Walleyes as related to different stages of the spawning period, including the pre-spawn migration, spawning locations, and postspawn return migrations. We were also interested in modeling large non-spawning movements occurring in summer, fall, and winter. Covariates were included as daily mean values of incoming river discharge, lake elevation, and water temperature. Lunar illumination data 
consisted of a daily lunar index of the illuminated percentage of the moon face ranging from 0 (new moon) to 1 (full moon).

The set of candidate models selected for each analysis were ranked by Bayesian Information Criterion (BIC) which has been shown to be more appropriate for models with large sample sizes (Aho et al. 2014; Eyler 2014). We chose to use BIC rather than Akaike Information Criterion (AIC) as BIC has been shown to reduce the likelihood of model overfitting when using large datasets in contrast to AIC (Aho et al. 2014; Eyler 2014). Like AIC, the model with the lowest BIC score was selected as the best fitting model. Information-theoretic approaches select the best model (or suite of competing models) through a parsimonious trade-off among bias, variance, and the number of estimable model parameters (Burnham and Anderson 2002). Given all potential combinations and interactions among covariates, many models could be fit to the data and we selected models to be fit based on published literature of fish movement (Paragamian 1989; Williams 2001; DePhillip et al. 2005; Hanson 2006; Bozek et al. 2011; Phillips 2014). Prior to analysis we assessed multicollinearity using Pearson's Correlation Coefficient and variance inflation factor (VIF). The VIF was calculated for the full model in SAS, and significant collinearity would be suggested by a VIF factor larger than 10 (O'Brien 2007; Eyler 2014). We also computed Pearson's Correlation Coefficient for variables in the full model to further explore potential collinearity between variables.

\section{Pre-Spawn Migration Analyses}

For the first set of analyses we were interested in determining important environmental covariates associated with migration to spawning grounds. We had a prior assumption that most Cheat Lake Walleyes utilized the riverine zone for spawning based on spring fisheries surveys and angler reports. This was confirmed by yearly direct movements of our study fish from the 
main lake zone to the riverine zone in the weeks prior to suitable spawning conditions (see Chapter 4). Therefore, our pre-spawn migration analysis is based on modeling the direct movements of our study fish from the main lake zone into the riverine zone under the assumption that these movements are correlated with spawning behavior. For this analysis, we modeled Walleye migratory movements and associated environmental covariates during the period of January $1^{\text {st }}$ to the final upstream migratory movement for each individual prior to spawning. For instance, if an individual fish made its final upstream migratory movement to the spawning area on April $1^{\text {st }}$, then data for that individual included the period of January $1^{\text {st }}$ to April $1^{\text {st. }}$ For the pre-spawning migration analysis, we included year and sex as fixed effects and individual fish as random effects. Environmental covariates included daily means of water temperature, river discharge (log transformed), and lake elevation, and a lunar illumination index. A global model including year, sex, lake elevation, water temperature, river discharge, and lunar illumination was included for comparison to candidate models. Candidate models included single variable and two variable additive effects models of sex and/or environmental covariates both with and without a year effect. Our final model fitted an intercept to the timeseries data.

For analysis of upstream migration we assigned a binomial response (1=migration upstream, $0=$ no migration upstream) for each Walleye each day prior to final initiation of upstream migration. Initiation of upstream migration was considered when an individual fish first entered the riverine zone of Cheat Lake, signaling departure from their overwintering locations in the main lake zone (lower/middle zones). Therefore, when a fish initiated upstream migration, a "1" was assigned for the day it entered the riverine zone and continued upstream. A "0" was assigned for all other days. Although most individuals in the study occupied the main lake zone downstream of the riverine zone during winter, two individuals displayed a tendency to remain in the riverine zone near the spawning grounds year-round and were thus excluded from this 
analysis. Additionally, individuals that did not make a pre-spawn migration due to immaturity, emigration from the study area (dam passage), transmitter failure, or mortality were excluded from the analysis.

Additionally, on several occasions upstream migration of individual Walleyes was interrupted and fish made temporary downstream movements back to the main lake. In all instances, these Walleyes eventually made an additional upstream migration back to the spawning area. We assumed these fish reacted to environmental cues to make their initial migration upstream, but subsequent environmental conditions may have interrupted migration resulting in their temporary return to overwintering areas. Due to the relatively small number of fish that exhibited this behavior we did not perform formal statistical testing on these movements. However, to investigate trends in this behavior relative to environmental conditions we did examine descriptive statistics of environmental covariates during these movements compared to periods without temporary downstream movements.

\section{Spawning Period}

To estimate timing of spawning during each year we used a combination of methods. We examined the final passage of the uppermost acoustic receiver by specific fish, manually tracked locations of telemetered fish during the suspected spawning period, determined periods when water temperatures were suitable for spawning based on previous studies, and used data from biological surveys (gill netting and boat electrofishing) on fish location and spawning status (pre- or post-spawn condition determined by presence-absence of milt or eggs).

We were able to narrow the likely period of spawning by examining passage of the uppermost receiver (below the suspected spawning shoal) by specific telemetered fish. Many fish reached the uppermost receiver and began moving onto the spawning grounds early in the 
pre-spawn period. These fish subsequently spent many days in the vicinity of the spawning shoal. Consequently, these early arrivals were not as useful in estimating the potential spawning period. Those fish that appeared to move up to the spawning area later (primarily females) were those most useful in estimation of the spawning period. We also periodically located tagged fish close to the spawning period using a portable hydrophone. This allowed us to determine and confirm if fish had in fact moved onto the spawning grounds and pinpoint specific locations of tagged fish in these areas. We also examined water temperature data during periods when tagged fish were located near the spawning shoal. Using published literature on spawning temperature ranges for this region ( 7-10 ${ }^{\circ} \mathrm{C}$; Bozek et al. 2011) helped determine if spawning was possibly occurring during periods of fish presence at spawning areas. Finally, we also conducted gill net and night-boat electrofishing surveys periodically during the study. By examining the spawning condition (pre- or post-spawn) of captured fish we were able to estimate if spawning commenced. By utilizing all of these methods we were able to come to a general estimation for when spawning likely occurred each year.

\section{Post-Spawn Migration Analysis}

For the second set of analyses we were interested in determining timing of return migration of individuals from spawning areas to the main lake zone and associated environmental covariates. For this analysis, we modeled Walleye post-spawn downstream migration and associated environmental covariates from the spawning period to the first day an individual fish re-entered the main lake zone. The start date for this analysis was the day after the last pre-spawn upstream migration for each fish. As an example, if an individual fish made its final pre-spawn upstream migration on March $1^{\text {st }}$ and then returned to the main lake zone on May $1^{\text {st }}$, the period of March $1^{\text {st }}-$ May $1^{\text {st }}$ would be used for that fish. For the post-spawn 
migration analysis we included year, season, sex, and environmental covariates (water temperature, river discharge, lake elevation, lunar illumination) as fixed effects and individual fish as random effects. We included season as a fixed effect due to the period from spawning to post-spawn return migration encompassing long time periods (several months for some individuals) for some individuals and due to the seasonal differences in post-spawn movements reported in other studies (DePhillip et al. 2005; Palmer et al. 2005; Hanson 2006). A global model including year, season, sex, lake elevation, water temperature, river discharge, and lunar illumination was included for comparison to candidate models. Candidate models included single variable and two variable additive effects models of sex and/or environmental covariates both with and without a year and/or season effect. A final model fitted an intercept to the timeseries data.

For analysis of post-spawn migration we assigned a binomial response ( $1=$ migration downstream, $0=$ no migration downstream) for each Walleye each day prior to return to the main lake. Post-spawn return migration was considered when an individual fish first entered the main lake zone of Cheat Lake, signaling departure from the spawning grounds and riverine zone. Any individuals that did not return to the main lake post-spawn but instead remained in the riverine zone were excluded from this analysis.

\section{Non-Spawning Movement Analysis}

For the third set of analyses we were interested in determining environmental covariates associated with large non-spawning movements. For this analysis we modeled Walleye nonspawning movements and associated environmental covariates from May $1^{\text {st }}$ to December $31^{\text {st }}$. This time period was chosen as it generally reflected the period when movements were not associated with spawning events. For the non-spawning movements analysis we included year, 
season, sex, and environmental covariates (water temperature, river discharge, lake elevation, lunar illumination) as fixed effects and individual fish as random effects. We included season as a fixed effect due to the period from May $1^{\text {st }}$ to December $31^{\text {st }}$ encompassing all seasons of the year and due to the seasonal differences in non-spawning movements reported in other studies (DePhillip et al. 2005; Palmer et al. 2005; Hanson 2006). A global model including year, season, sex, lake elevation, water temperature, river discharge, and lunar illumination was included for comparison to candidate models. Candidate models included single variable and two variable additive effects models of sex and/or environmental covariates both with and without a year and/or season effect. A final model fitted an intercept to the time-series data.

For analysis of large non-spawning movements we assigned a binomial response $(1=$ “movement", 0 = "no movement") for each Walleye during the analysis period. Non-spawning movements were considered as events when individual fish moved past at least 2 receivers (mean of $4.8 \mathrm{rkm}$ ) in an upstream or downstream direction in a single day. Individual fish moved frequently between neighboring receivers, but movements past 2 receivers were less common and usually signaled departure from core use areas. For instance, if an individual Walleye moved from receiver number 1 to 2 in a single day that movement was not counted as large scale movement event. However, if a Walleye moved from receiver number 1 to 3 in a single day that movement was considered a large-scale movement event. Limiting movements included in analyses to those of at least 2 receivers or more helped ensure that movements tested were those in which fish were wandering outside of their local ranges. Although most individuals in the study occasionally made large movements during the non-spawning period, a few fish failed to make large movements and were thus excluded from this analysis. 


\section{Results}

\section{Pre-Spawn Migration}

A total of 31 Walleyes (18 males; 13 females) made upstream migrations during the prespawn periods of 2012-2015, with yearly numbers of migrating fish ranging from 9 to 22 (Table 5.1). The earliest upstream migrations occurred in February in all years except 2013, when the earliest migration event occurred on January $13^{\text {th }}$. The latest upstream migrations occurred in early April just before spawning commenced. Number of days with upstream migration events ranged from seven days in 2012 to seventeen days in 2013 (Table 5.1). Two Walleyes were excluded from analysis of upstream migration due to their tendency to remain near the spawning grounds throughout the pre-spawn period and thus not make a significant migration. An additional six Walleyes were excluded from analysis due to their lack of a migration (i.e., non-spawning immature females) from the main lake zone towards the riverine spawning grounds. During surgery, we assumed these fish were immature females due to their large size (>450 mm) yet no evidence of mature gonads. Sexual immaturity would explain the lack of a spawning migration. We confirmed the immaturity of two of these fish as they were captured in gill netting surveys resulting in mortality and their immaturity was confirmed through dissection. Fish labeled as immature females exhibited no spawning migration and instead remained relatively sedentary in their respective locations in the main lake zone.

Walleyes made upstream pre-spawn migrations during a wide range of environmental conditions, but results did suggest some environmental correlates are better predictors than others. Upstream migration often occurred at times of higher river discharge and/or lake elevation, but conversely migration also often occurred during low river discharge and lake elevation. Upstream migration events occurred during river discharge ranging from 47.85 to $577.66 \mathrm{~m}^{3} \cdot \mathrm{s}^{-1}$ (Table 5.2). Upstream migration occurred during lake elevations ranging from 
261.64 to 265.15 meters above sea level (Table 5.2). Upstream migration events were more likely to occur during periods when water temperatures were warmer than average (Table 5.2; Figure 5.2). Upstream migration occurred at a range of water temperatures from $2.2^{\circ} \mathrm{C}$ to $10.1^{\circ}$ C, but most upstream migration events (75\%) occurred at water temperatures greater than $4.1^{\circ}$ C.

The GLMM analysis supported two different additive-effects models including a model of "year + water temperature" $(\Delta \mathrm{BIC}=0)$ and a model of "year + sex + water temperature" $(\Delta$ $\mathrm{BIC}=0.53)$. The BIC selected models had positive coefficients for water temperature for both the "year + water temperature" model $(\beta=0.83$, s.e. $=0.08)$ and the "year + sex + water temperature" model $(\beta=0.85$, s.e. $=0.08)$. Therefore, pre-spawn upstream migration events were associated with elevated water temperatures. The BIC selected model that included the variables year and water temperature was also supported through graphical comparison of the yearly data and by descriptive statistics (Figure 5.2; Table 5.2). Graphs of yearly data illustrated that upstream migrations were almost always clumped around spikes in water temperature (Figure 5.2). Descriptive statistics demonstrated that mean water temperature during upstream migration events each year was always greater than mean water temperature during non-migration (Table 5.2). Additionally, model selection statistics (Table 5.6) demonstrate that the top 10 models all include the predictor variable water temperature. Regarding the potential effect of sex on upstream migration, female Walleyes did initiate migration later on average compared to male Walleyes. Male Walleyes typically migrated upstream prior to March (68.9\%), with fewer migrating in March (28.9\%) or April (2.2\%). In contrast, fewer females migrated upstream prior to March (39.5\%) as most migrated upstream in March or April (52.6 \% in March, $7.9 \%$ in April). Models that included lake elevation, river discharge, and lunar illumination were not supported by the data. 
Our evaluation of variable collinearity using VIF and Pearson's Correlation Coefficient indicated that multicollinearity did not significantly affect model performance. O’Brien (2007) suggests that a VIF greater than 10 would indicate an issue with multicollinearity, but VIF in our study was less than 2 . We did not have any variable correlations greater than 0.49 and standard errors for all parameter estimates were relatively small (less than 1)

In addition to upstream migrations prior to spawning, at times the migration of Walleyes was interrupted resulting in their temporary return to the main lake. In all cases, fish eventually made a return upstream migration and reached the spawning grounds prior to spawning. In total, 13 fish ( 7 males; 6 females) made temporary downstream migrations and subsequently returned to the main lake prior to spawning. Additionally, three of these fish ( 1 male; 2 females) had two instances each of moving back into the main lake prior to spawning. Number of fish with temporary downstream displacement included zero in 2012 , seven fish in 2013 , four fish in 2014, and one fish in 2015. Descriptive statistics revealed that temporary downstream movements usually occurred during periods of low water temperatures (Figure 5.3). Specifically, these temporary downstream movements usually occurred when water temperatures cooled substantially after a period of warm water temperatures. Descriptive statistics demonstrated that mean water temperatures were lower during downstream movements (mean $=1.8^{\circ} \mathrm{C}$ ) compared to the mean during no downstream migration $\left(3.6{ }^{\circ} \mathrm{C}\right)$. Most of these downstream movements occurred when water temperature was near freezing (i.e., $<1{ }^{\circ} \mathrm{C}$; Figure 5.3). Water temperature was the only environmental variable without overlapping $95 \%$ confidence intervals $(1.96$ * standard error) between downstream movement and no movement periods. 


\section{Spawning Period}

Spawning locations and the timing of spawning were determined each year using a combination of telemetry data from upstream receivers, manual tracking of telemetered fish, water temperature data, and fish surveys (gill netting and electrofishing). Telemetry data indicated that spawning occurred from late March to early April in all years except 2012, when spawning occurred in mid-March (Figure 5.5). Spawning appeared to primarily occur in shallow $(<2 \mathrm{~m})$ rocky shoals just downstream of the first riffle/run at the head of the lake (Figure 5.1). In examining fluctuations of lake levels during periods of estimated spawning activity, the maximum decrease in lake elevation occurred during 2014, when lake elevation decreased by 2 meters (Figure 5.5). In comparison, the maximum decreases in lake elevation during spawning periods in 2012, 2013, and 2015 were $0.6 \mathrm{~m}, 1.7 \mathrm{~m}$, and $1.7 \mathrm{~m}$ respectively (Figure 5.5). Additionally, detection of some individuals at our receiver upstream of the reservoir may suggest that some Walleyes migrate upstream of the reservoir to spawn in the river. However, given the lack of a receiver further upstream, we were unable to determine if these fish continued to move upstream and spawn. It is possible that these fish were simply utilizing the pool area where our receiver was located and moved downstream onto the spawning shoal to spawn.

\section{Post-Spawn Migration}

From 2012-2014 a total of 24 Walleyes (14 males; 10 females) eventually made postspawn return migrations from the riverine zone to the main lake zone of the reservoir. Number of return migrants included 5 individuals in 2012, 22 individuals in 2013, and 12 individuals in 2014. Some fish made upstream spawning migrations but did not provide data on a return migration due to either mortality or transmitter failure. Post-spawn data on fish that spawned in 
2015 were not used as acoustic receivers were removed from the reservoir immediately after spawning.

The GLMM analysis of post-spawning downstream migration supported a single additive-effects model of "season + sex" ( $\triangle \mathrm{BIC}=0$; Table 5.7). After graphically examining postspawning movements related to season and sex, it was apparent that females were more likely to return to the main lake during the spring season and males were more likely to return during autumn. Specifically, most female fish had returned to the main lake by the end of April and most males did not return until October (Figure 5.4). Most post-spawn return migrations for female fish (83\%) occurred within 1-2 weeks after the estimated spawning period (i.e., late March in 2012; mid- to late April in 2013-2015). Only $18 \%$ of post-spawn return migration events for female fish occurred after April, with one post-spawn return trip each in late May, early June, and late October, respectively. In contrast, post-spawn return of male fish to the main lake was more evenly divided between two seasonal periods. For male Walleyes, $39 \%$ made post-spawn return movements to the main lake during the spring (12 April-8 May), while $61 \%$ did not return to the main lake until late summer/autumn (28 Aug-26 Oct). Models that included lake elevation, water temperature, river discharge, and lunar illumination were not supported by the data (Table 5.7).

Our evaluation of variable collinearity using VIF and Pearson's Correlation Coefficient indicated that multicollinearity did not significantly affect model performance. VIF suggested that multicollinearity was not a problem as our highest value was only 2.43 . Water temperature and lake elevation did have a relatively strong correlation (0.62), but standard errors for all parameter estimates were relatively small (less than 1). 


\section{Non-Spawning Movements}

From 2012-2014 a total of 34 Walleyes (16 males; 17 females; 1 unknown) provided data on movement during non-spawning periods. Four of 17 females were immature during part of the study period and five of the 17 females were believed to be immature during the entire study period. The number of fish monitored per year included 6 individuals in 2012, 31 individuals in 2013, and 20 individuals in 2014. Some fish did not provide data on non-spawning movement due to either mortality or transmitter failure. Fish that were tagged in winter of 2014 did not provide non-spawning movement data as acoustic receivers were removed from the reservoir the following spring.

The GLMM analysis of large non-spawning movements supported a single additiveeffects model of "river discharge + water temperature" ( $\triangle \mathrm{BIC}=0$; Table 5.8). The BIC selected model had positive coefficients for river discharge $(\beta=0.45, \mathrm{SE}=0.06)$ and water temperature $(\beta=0.03, S E=0.008)$. Therefore, large non-spawning movements were associated with elevated river discharge and to a lesser extent elevated water temperatures. Descriptive statistics demonstrated that mean river discharge during movement events each year were higher on average $\left(81.7 \mathrm{~m}^{3} \mathrm{~s}^{-1}\right)$ than mean river discharge during non-movement $\left(51.6 \mathrm{~m}^{3} \mathrm{~s}^{-1}\right)$. Additionally, model selection statistics (Table 5.8) demonstrate that the top 10 models all include the predictor variable river discharge, further supporting the importance of river discharge in modelling large non-spawning movements. The results of the GLMM analysis suggests that Walleyes make large non-spawning movements at higher water temperatures on average compared to when movements did not occur. Walleyes made non-spawning movements at water temperatures averaging $17.5^{\circ} \mathrm{C}$, whereas water temperature averaged 17.2 ${ }^{\circ} \mathrm{C}$ during periods of no long-distance movement, which is a small difference. The effect size of water temperature was also moderately low $(\beta=0.03)$, so it is likely that water 
temperature is not as important a predictor as river discharge. Models that included season, sex, lake elevation, and lunar illumination were not supported by the data (Table 5.8).

Our evaluation of variable collinearity using VIF and Pearson's Correlation Coefficient indicated that multicollinearity did not significantly affect model performance. VIF suggested that multicollinearity was not a problem as our highest value was only 1.99 . Water temperature and lake elevation did have a relatively strong correlation (0.58), but standard errors for all parameter estimates were relatively small (less than 1).

\section{Discussion}

Results from this study provide valuable information on the influence of environmental conditions on the seasonal movement and spawning locations of Walleyes in Cheat Lake. Specifically, our results relate to how Walleyes respond to environmental conditions in the context of a hydropower reservoir with varying levels of water level fluctuations. Our results suggest that the best predictors of Walleye movements in Cheat Lake include season, sex, water temperature and river discharge dependent on time period of interest. Specifically, our results suggest that the primary driver of Walleye upstream migration in Cheat Lake during the pre-spawn period is water temperature. Other environmental factors including lake level, river discharge, and lunar illumination were not supported as being significant predictors of Walleye pre-spawn migration. However, given the results of fish movements and locations during the spawning period, lake level fluctuations could potentially impact success of Walleye spawning

through stranding of eggs and larvae. During the post-spawn period, results suggest that return migrations back to the main lake are primarily seasonally driven with importance of sex as well. Finally, large movements during non-spawning months are primarily influenced by river discharge and to a lesser extent water temperature. 
During the pre-spawn migration period, water temperature was the primary driver of migration both upstream into the riverine zone and for temporary downstream movements prior to spawning. The BIC-selected model and supporting descriptive statistics suggest a positive correlation of water temperature and upstream migration. Additionally, descriptive statistics suggest a negative correlation of water temperature and temporary downstream migrations prior to spawning. Specifically, Walleyes were more likely to begin upstream migration towards spawning areas during periods of higher water temperatures, while some Walleyes would temporarily move back downstream if water temperatures decreased sharply prior to spawning. There was some evidence for sex specific differences in upstream migration. On average, males moved upstream earlier than females, but there were also some female fish that consistently moved upstream as early as males. However, the difference in timing of upstream migration between sexes does suggest sex has some impact on when upstream migration occurs.

Studies on Walleye movements have suggested that pre-spawn migration is correlated with warming water temperatures (Eschmeyer 1950; Preigel 1970; Paragamian 1989; Pitlo 1989; Bellgraph et al. 2008; Bozek et al. 2011). However, there is a wide range of water temperatures for which initiation of migration occurs in other studies (Bozek et al. 2011). Our data suggest that Walleyes typically begin upstream migration when water temperatures are on average greater than 4 degrees Celsius. However, there does appear to be variation among individuals in terms of at what temperatures migration occurs. For instance, if water temperatures remained at or near freezing for long periods, a subtle increase in water temperature may be enough to trigger upstream migration for some individuals. The only upstream migrations to occur at water temperatures less than 3 degrees Celsius during our study occurred during 2015 when water temperatures remained near freezing for most of the pre-spawn period. These movements occurred during slight elevations in water temperature 
during February and at the start of increasing water temperatures in March. Although Walleyes at times moved during periods of higher river discharge or higher lake elevation, there was large variability of these conditions when migrations occurred. Upstream migration occurred during both low and high periods of river discharge and lake elevation, but almost always occurred during periods of warmer water temperatures. It is apparent from statistical analysis and from graphical representation, that water temperature is the key environmental cue to initiation of upstream migration events.

Regarding temporary downstream migration, Walleyes nearly always made temporary trips back to the main lake during periods of decreasing water temperatures that followed an increase in water temperatures. Presumably, some fish responded to cues related to warming water temperatures and made upstream movements towards spawning areas. However, if these periods of increased water temperatures were subsequently followed by a decrease in water temperature, some fish made movements back into the main lake prior to spawning. In all cases, these fish that made early downstream movements eventually responded again to warmer water temperatures and made a final migration to the spawning grounds. To our knowledge, this specific behavior has not been mentioned in the literature, although some studies have recorded a delay in spawning after arriving at spawning shoals if water temperatures are unsuitably low (Bozek et al. 2011). Additionally, many authors suggest that in general Walleyes will travel to deep water areas when water temperatures decrease (Paragamian 1989; DePhillip et al. 2005; Hanson 2006). However, this is generally referring to Walleyes moving to overwintering areas in late autumn. It is possible that given the relatively short distance from the spawning area to the main lake zone in Cheat Lake $(\sim 8 \mathrm{~km})$ that some fish simply prefer to move into the deeper waters downstream during cold periods as opposed to remaining in shallower pools offered near the spawning grounds. 
Although lake level was not supported as being good a predictor of upstream migration, it could nevertheless have important consequences during the spawning period. Telemetry results and fishery surveys suggest that Cheat Lake Walleyes likely spawn in shallow shoal areas downstream of the first riffle/run complex at the head of the reservoir. This area is impacted by lake level fluctuations and could lead to stranding of eggs and larvae if lake levels decreased after deposition of eggs. Several studies have suggested the potential for decreasing water levels to lead to egg and larval mortality (Johnson 1961; Priegel 1970; Chevalier 1977; Bozek et al. 2011). Additionally, spawning appears to occur as early as mid-March during warmer years and as late as early April in colder years. Currently a lake drawdown restriction of 2.1 meters exists in April in an attempt to enhance success of Walleye reproduction by minimizing stranding potential. Therefore, any Walleye spawning that occurs prior to this date could be impacted by maximum lake level fluctuations $(3.96 \mathrm{~m})$. Walleyes have been documented in other studies as relatively shallow water spawners (<2 m) (Bozek et al. 2011). Likewise, our manual tracking data and night-time boat electrofishing surveys typically found Walleyes near spawning shoals to be in water less than $2 \mathrm{~m}$ deep. Therefore, although the lake elevation restriction of 2.1 meters imposed in April provides less extreme fluctuations, dewatering could still occur if spawning occurred at or near full pool.

Regarding post-spawn movements of Walleyes, other studies suggest that females will typically make return migrations to pre-spawn areas shortly after spawning occurs, while males may spend several weeks in the vicinity of spawning grounds before returning (Rawson 1957; Colby et al. 1979; Paragamian 1989; DePhillip et al. 2005; Hanson 2006; Hayden et al. 2014). However, some studies have identified genetic specific tendencies for post-spawn movements (Palmer et al. 2005). Specifically, Palmer et al. (2005) found that during post-spawn, fish of the Eastern Highland genetic stock remained in riverine habitat near spawning areas, while fish of the Great Lakes stock would quickly return downstream to main lake areas. Results from our 
study demonstrate an interesting pattern in terms of return movements back into the main lake zone between males and females. Most post-spawn return migrations for female fish occurred within 1-2 weeks after the estimated spawning period (i.e., late March in 2012; mid- to late April in 2013-2015). Only a small proportion of post-spawn return migration events for female fish occurred after April, with one post-spawn return trip each in late May, early June, and late October, respectively. In contrast, post-spawn return of male fish to the main lake was more evenly divided between two seasonal periods. Although several male Walleyes did make return trips to the main lake shortly after spawning, most male fish stayed in the riverine zone near the spawning grounds until autumn. During autumn, male fish would typically leave the riverine zone and switch to primarily occupying the main lake zone. Reasons for this dichotomy in male and female post-spawn behavior are unknown, but other studies have suggested several possibilities. Some studies suggest that males linger near spawning areas in order to have the opportunity to reproduce with several females (Hayden et al. 2014; Phillips 2014). However, this behavior would not explain male Walleyes remaining in these areas for much longer than 1-2 weeks after peak spawning. Other studies suggest that some fish simply choose to remain in these areas to exploit seasonally abundant prey resources (DePhillip et al. 2005). It is possible that our study fish that exhibited post-spawn preference for riverine areas were utilizing abundant prey sources. Electrofishing surveys indicate an abundance of Mimic Shiner, juvenile Smallmouth Bass, Logperch, and Yellow Perch in the riverine zone during spring. Yet another possibility is that riverine post-spawn residents are choosing to remain in the riverine zone to avoid potential thermal-oxygen stress that can occur in the main lake (DePhillip et al. 2005). Cheat Lake thermally stratifies during summer months, creating epilimnetic water temperatures that can be much warmer than the preferred range for Walleyes (Hokansen 1977; Williams 2001; Bozek et al. 2011; Hayden et al. 2014). Additionally, cooler water temperatures in the hypolimnion may not be available due to low dissolved oxygen (<2 mg/L) (Williams 2001; Bozek et al. 2011). Finally, it is possible that this is simply a learned or heritable preference for some 
fish to utilize the riverine zone for an extended period post-spawn (Palmer et al. 2005; Hanson 2006).

Statistical analysis of large non-spawning movements suggest that Walleyes move out of local ranges in response to elevated river discharge and to a lesser extent elevated water temperatures during non-spawning periods. These movements may be associated with locating more suitable feeding conditions (cooler, more oxygenated water) or exploiting forage availability (i.e. turbid water, prey concentrations, etc.). Other studies suggest that Walleyes will make movements to locate forage or suitable foraging conditions (Peat et al. 2015).

Additionally, other studies have pointed out the potential influences of a temperature-oxygen squeeze in reservoirs with significant stratification (Ficke et al. 2007; Bozek et al. 2011). Cheat Lake stratifies from June-September and preferred water temperatures may be at a depth in which oxygen levels are insufficient. Movements to the riverine zone, especially during elevated discharge events, could provide cooler more oxygenated water. Large scale movements in response to elevated river discharge and water temperature during periods without stratification could still possibly be due to Walleyes taking advantages of changes in conditions to forage for prey.

\section{Management Implications}

Understanding of how environmental conditions influence movements of Walleyes can improve the management of Walleye populations (Williams 2001; Rasmussen et al. 2002; Palmer et al. 2005; Hanson 2006). Specifically, with the knowledge of timing and cues to prespawn migration, managers can better predict when upstream migration events are likely to occur. This information would be useful from a management perspective as knowing when and where congregations of Walleyes will occur could help direct spawning stock surveys and 
potentially improve angler success rates (Williams 2001; Palmer et al. 2005). Additionally, with knowledge of timing and location of Walleye spawning, managers can better predict potential impacts of fluctuating lake levels and angler efforts on the spawning population. In other studies, anglers have heavily exploited Walleyes congregated for spawning (Palmer et al. 2005). Therefore, with knowledge of these spawning congregations in Cheat Lake, managers should be cognizant of the potential for overexploitation of Walleyes by anglers.

Walleyes in Cheat Lake appear to respond to similar cues for upstream migration compared to Walleyes in other studies (Eschmeyer 1950; Preigel 1970; Paragamian 1989; Pitlo 1989; DePhillip et al. 2005; Hanson 2006; Bellgraph et al. 2008; Bozek et al. 2011; Hayden et al. 2014). Cheat Lake Walleyes normally initiated upstream migration prior to spawning during periods of elevated water temperatures. Specifically, most upstream migration events occurred when water temperatures were greater than 4 degrees Celsius. With knowledge of approximate timing of upstream migration of Walleyes during warmer water temperatures from January through April, managers will be able to more accurately determine when Walleyes first begin to congregate in the upper reaches of Cheat Lake. Given the still recovering status of the Walleye population, knowledge of timing of congregating fish and location could be beneficial in assessing the spawning population by targeting these areas during periods of suspected congregation. Additionally, angler success and interest in the fishery could be improved with knowledge of timing of Walleye movements to specific locations. Also, knowledge of timing of spawning and location may be critical for the success of the population given potential impacts from lake elevation changes. Currently, lake elevation restrictions change from maximum drawdown $(3.9 \mathrm{~m})$ to a restricted drawdown $(2.1 \mathrm{~m})$ on April $1^{\text {st }}$ of each year. This restriction is designed to facilitate successful spawning conditions for Walleyes within Cheat Lake. However, as was witnessed in our study, Walleye spawning likely occurs as early as mid-March, especially in years with warmer temperatures. Therefore, the fluctuation restriction on April $1^{\text {st }}$ 
would provide little benefit during these years. Not only do decreasing lake levels potentially lead to egg and larval mortality from stranding, but it also could reduce available suitable spawning habitat for Walleyes (Priegel 1970; Chevalier 1977; Ickes et al. 1999; Bozek et al. 2011; Martin et al. 2012). Also, given the likely spawning of individuals in water less than 2 meters deep, the 2.1 meter restriction may not provide complete protection from stranding should spawning occur at or near full pool. This information will be valuable for managers to consider as the recovery of the Cheat Lake Walleye population continues to be monitored.

Results showing stark contrasts in post-spawn movement activity of male and female Walleyes provides managers with valuable information on where and when to expect female and male Walleyes to occur post-spawn. There is an obvious dichotomy in where male and female Walleyes are located post-spawn, and when fish make return trips to pre-spawn locations. Based on our data, we can expect most female Walleyes to make a return migration to the main lake zone shortly (1-2 weeks) after spawning has occurred. In contrast, a significant proportion of male fish remained at or near the spawning area in the riverine zone for several months post-spawning. Thus, managers and anglers should expect most large females to quickly return to their main lake locations after spawning, while many smaller male fish may remain in the riverine zone for several months. Additionally, many of these fish that do not make return migrations until autumn spend weeks or months completely removed from the reservoir and are located in the river upstream.

During non-spawning periods, Walleyes displayed a tendency to make large movements in relation to some environmental covariates. Specifically, during summer, winter, and fall, Walleyes made large scale movements in response to elevated river discharge and to a lesser extent, water temperature. Walleyes may make large movements during periods of elevated river discharge to exploit prey or find areas of recently cooled and oxygenated water. Specifically, the riverine zone and Cheat River typically provide cooler, more oxygenated water 
during warmer months than the main lake area. Again, knowledge of seasonal distribution of Walleyes in Cheat Lake can provide managers and anglers with improved ability to target specific areas during surveys or fishing trips.

In conclusion, results from our study suggest that seasonal movements of Walleyes in Cheat Lake are similar compared to other systems. Water temperature is a commonly reported driver of pre-spawn migration, however, given the wide range in reported temperatures at which migration occurs, typical temperatures during migration for Cheat Lake Walleyes will provide site specific conditions for this system. Also, just as Walleyes of Cheat Lake appear to respond to elevated water temperatures via upstream migration, stability of these warm temperatures may be important in assuring continued presence of some individuals in the riverine zone. Cold water temperatures on several occasions led to fish temporarily making return trips to the main lake zone. Knowledge of how adult Walleyes respond to changing water temperatures during the pre-spawn period will be useful for both managers and anglers in locating Walleyes during these periods. Presently, the distance from the only boat access ramp to the spawning grounds prior to 1 May is nearly the length of the reservoir $(\sim 20 \mathrm{~km})$. This presents challenges for anglers with small boats and/or limited outboard horsepower in reaching this area to exploit congregating adult Walleyes. Although the ability of anglers to adequately reach this area would likely lead to increased angler satisfaction with the resource, managers should be cautious given the relatively small population gathering in such a small area. Angler exploitation could add to any existing environmental challenges for recruitment success. Additionally, managers should further consider the potential impacts of lake level fluctuations on the success of Walleye recruitment. Given the timing and location of Cheat Lake Walleyes and their susceptibility to decreasing lake elevation, it is possible that recruitment is impacted by egg/larval stranding and/or reduced spawning habitat during years of greater variability in lake elevation. Ideally, future studies will examine angler attitudes and exploitation of Walleyes in Cheat Lake to better 
assess this aspect of the fishery. Additionally, future studies should aim to specifically pinpoint exact egg depositional areas to better understand what impacts lake elevations may or may not be having. By considering the findings of this study and implementing further research mangers should be better able to manage this improving Walleye population. 


\section{References}

Aho, K., D. Derryberry, and T. Peterson. 2014. Model selection for ecologists: the worldviews of AIC and BIC. Ecology 95: 631-636.

Amtstaetter, F., J. O'Connor, and A. Pickworth. 2015. Environmental flow releases trigger spawning migrations by Australian grayling Prototroctes maraena, a threatened, diadromous fish. Aquatic Conservation: Marine and Freshwater Ecosystems 26: 35-43.

Bellgraph, B. J., C. S. Guy, W. M. Gardner, and S. A. Leathe. 2008. Competition potential between saugers and walleyes in nonnative sympatry. Transactions of the American Fisheries Society 137: 790-800.

Bolker, B.M., M.E. Brooks, C.J. Clark, S.W. Geange, J.R. Poulsen, M. Henry, H. Stevens, and J. S. S. White. 2008. Generalized linear mixed models: a practical guide for ecology and evolution. Trends in Ecology and Evolution 24: 127-135.

Bozek, M. A., D. A. Baccante, and N. P. Lester. 2011. Walleye and Sauger life history. Pages 233-301 in B. A. Barton, editor. Biology, Management, and Culture of Walleye and Sauger. American Fisheries Society, Bethesda, Maryland.

Bozek, M. A., T.J. Haxton, and J.K. Raabe. 2011. Walleye and Sauger habitat. Pages 133-197 in B.A. Barton, editor. Biology, Management and Culture of Walleye and Sauger. American Fisheries Society, Bethesda, Maryland.

Buckmeier, D. L., N. G. Smith, and D. J. Daugherty. 2013. Alligator gar movement and macrohabitat use in the lower Trinity River, Texas. Transactions of the American Fisheries Society 142: 1025-1035.

Burnham, K.P. and D.R. Anderson. 2002. Model Selection and Multimodel Inference: a Practical Information-theoretic Approach, Second Edition. Springer, New York, New York. 
Chevalier, J. R. 1977. Changes in walleye (Stizostedion vitreum vitreum) populations in Rainy Lake and factors in abundance. Journal of the Fisheries Research Board of Canada 34: 1696-1702.

Clements, S., D. Jepsen, M. Karnowski, and C. B. Schreck. 2005. Optimization of an acoustic telemetry array for detecting transmitter-implanted fish. North American Journal of Fisheries Management 25: 429-436.

Colby, P. J., R. E. McNicol, and R. A. Ryder. 1979. Synopsis of biological data on the walleye Stizostedion v. vitreum. FAO Fisheries Synopsis 119, Rome.

Core, E. L. 1959. Biological investigations of Cheat Lake. West Virginia University, Morgantown, WV.

Crowe, W.R. 1962. Homing behavior in walleyes. Transactions of the American Fisheries Society $91:$ 350-354.

DePhilip, M.M., J.S. Diana, and D. Smith. 2005. Movement of walleye in an impounded reach of the Au Sable River, Michigan, USA. Environmental Biology of Fishes 72: 455-463.

Eschemeyer, P.H. and W.R. Crowe. 1955. The movement and recovery of tagged walleyes in Michigan, 1929-1953. Michigan Department of Natural Resources, Research Report 8.

Eschmeyer, P. H. 1950. The life history of the walleye, Stizostedion vitreum, in Michigan. Michigan Department of Conservation, Bulletin of the Institute of Fisheries Research 3, Ann Arbor.

Eyler, S. M. 2014. Timing and Survival of American Eels Migrating Past Hydroelectric Dams on the Shenandoah River. Doctoral Dissertation. West Virginia University, Morgantown. 
Ficke, A. D., C. A. Myrick, and L. J. Hansen. 2007. Potential impacts of global climate change on freshwater fisheries. Reviews in Fish Biology and Fisheries 17: 581-613.

Freund, J.G. and J.T. Petty. 2007. Response of fish and macroinvertebrate bioassessment indices to water chemistry in a mined Appalachian watershed. Environmental Management. 39: 707-720.

Hanson, J. R. 2006. Seasonal movement patterns of walleye (Sander vitreus) in Muskegon River and Muskegon Lake, Michigan. Master's thesis, University of Michigan, Ann Arbor.

Hart, L. G. and R. C. Summerfelt. 1975. Surgical procedures for implanting ultrasonic transmitters into flathead catfish (Pylodictis olivaris). Transactions of the American Fisheries Society 104: $56-59$.

Hayden, T.A., C.M. Holbrook, Fielder, D.G., Vandergoot, C.S., Bergstedt, R.A., Dettmers, J.M., Krueger, C.C. and S.J. Cooke. 2014. Acoustic telemetry reveals large-scale migration patterns of walleye in Lake Huron. Plos One. 9(12): e114833. doi:10.1371/journal.pone. 0114833

Henderson, M. J., M. C. Fabrizio, and J. A. Lucy. 2014. Movement patterns of summer flounder near an artificial reef: effects of fish size and environmental cues. Fisheries Research 153: $1-8$.

Hokanson, K. E. F. 1977. Temperature requirements of some percid fishes and adaptations to the seasonal temperature cycle. Journal of the Fisheries Research Board of Canada 34: $1524-1550$.

Holt, C. S., G.D. Grant, G.P. Oberstar, C.C. Oakes, and D. W. Bradt 1977. Movement of walleye, Stizostedion vitreum, in Lake Bemidji, Minnesota as determined by radiobiotelemetry. Transactions of the American Fisheries Society 106: 163-169.

Ickes, B. S., A. G. Stevens, and D. L. Pereira. 1999. Seasonal distribution, habitat use, and spawning locations of walleye (Stizostedion vitreum vitreum) and sauger, (S. 
canadense) in pool 4 of the upper Mississippi River, with special emphasis on winter distribution related to a thermally altered environment. Minnesota Department of Natural Resources, Investigational Report 482, St. Paul.

Johnson, F. H. 1961. Walleye egg survival during incubation on several types of bottom in Lake Winnibigoshish, Minnesota, and connecting waters. Transactions of the American Fisheries Society 90: 312-322.

Jones, M. S. and K. B. Rogers. 1998. Palmetto bass movements and habitat use in a fluctuating Colorado irrigation reservoir. North American Journal of Fisheries Management 18: 640648.

Landsman, S.J., V.M. Nguyen, L.F.G. Gutowsky, J. Gobin, K.V. Cook, T.R. Binder, N. Lower, R.L. McLaughlin, and S.J. Cooke. 2014. Fish movement and migration studies in the Laurentian Great Lakes: Research trends and knowledge gaps. Journal of Great Lakes Research 37: 365-379.

Littell, R.C., G. Milliken, W.W. Stroup, R. Wolfinger, and O. Schabenberger. 2006. SAS for Mixed Models, 2nd ed. SAS Institute, Cary, NC.

Lucas, M. C. and C. Baras. 2000. Methods for studying spatial behaviour of freshwater fishes in the natural environment. Fish and Fisheries 1: 283-316.

Martin, D. R., L. A. Powell, and K. L. Pope. 2012. Habitat selection by adult walleye during spawning season in irrigation reservoirs: A patch occupancy modeling approach. Environmental Biology of Fishes 93: 589-98.

McClurg, S. E., J. T. Petty, P. M. Mazik, and J. L. Clayton. 2007. Stream ecosystem response to limestone treatment in acid impacted watersheds of the Allegheny Plateau. Ecological Applications 17: 1087-1104. 
Merovich, G. T., J. M. Stiles, J. T. Petty, J. Fulton, and P. F. Ziemkiewicz. 2007. Water chemistry based classification of streams and implications for restoring mined Appalachian watersheds. Environmental Toxicology and Chemistry 26: 1361-1369.

O'Brien, R. M. 2007. A caution regarding rules of thumb for variance inflation factors. Quality and Quantity 41: 673-690.

Palmer, G.C., B.R. Murphy, and E. M. Hallerman. 2005. Movements of walleyes in Claytor Lake and the upper New River, Virginia, indicate distinct lake and river populations. North American Journal of Fisheries Management 25: 1448-1455.

Paragamian, V. L. 1989. Seasonal habitat use by walleye in a warmwater river system, as determined by radiotelemetry. North American Journal of Fisheries Management 9: 392401.

Paukert, C. P. and W. L. Fisher. 2000. Abiotic factors affecting summer distribution and movement of male paddlefish, Polyodon spatula, in a prairie reservoir. The Southwestern Naturalist 45: 133-140.

Paukert, C.P. and W.L. Fisher. 2001. Spring movements of paddlefish in a prairie reservoir system. Journal of Freshwater Ecology. 16: 113-124.

Peat, T. B., T. A. Hayden, L. F. Gutowsky, C. S. Vandergoot, D. G. Fielder, C. P. Madenjian, K. J. Murchie, J. M. Dettmers, C. C. Krueger and S. J. Cooke. 2015. Seasonal thermal ecology of adult walleye (Sander vitreus) in Lake Huron and Lake Erie. Journal of Thermal Biology 53: 98-106.

Phillips, T. K. 2014. Seasonal movement of the Sandstone Falls population of walleye in the lower New River. Master's thesis. Ohio University, Athens.

Pitlo, J., Jr. 1989. Walleye spawning habitat in pool 13 of the Upper Mississippi River. North American Journal of Fisheries Management 9: 303-308.

Priegel, G. R. 1970. Reproduction and early life history of the walleye in the Lake Winnebago region. Wisconsin Department of Natural Resources Technical Bulletin 45, Madison. 
Pritt, J.J., M.R. DuFour, C.M. Mayer, P.M. Kocovsky, J.T. Tyson, E.J. Weimer, and C.S. Vandergoot. 2013. Including independent estimates and uncertainty to quantify total abundance of fish migrating in a large river system: walleye (Sander vitreus) in the Maumee River, Ohio. Canadian Journal of Fisheries and Aquatic Sciences 70: 803-814.

Ramsden, S., C. F. Cotton, and M. C. Curran. 2017. Using acoustic telemetry to assess patterns in the seasonal residency of the Atlantic stingray Dasyatis sabina. Environmental Biology of Fishes 100: 89-98.

Rasmussen, P. W., D. M. Heisey, S. J. Gilbert, R. M. King, and S. W. Hewett. 2002. Estimating postspawn movements of walleyes among interconnected lakes of northern Wisconsin. Transactions of the American Fisheries Society 131: 1020-1032.

Rawson, D. S. 1957. The life history of the yellow walleye (Stizostedion vitreum) in Lac La Ronge, Saskatchewan. Transactions of the American Fisheries Society 86:15-37.

Rogers, K. B. and E. P. Bergersen. 1995. Effects of a fall drawdown on movement of adult northern pike and largemouth bass. North American Journal of Fisheries Management 15: $596-600$.

Rogers, K.B. and G. C. White. 2007. Analysis of movement and habitat use from telemetry data. Pages 625-676 in C. S. Guy, M. L. Brown, editors. Analysis and Interpretation of Freshwater Fisheries Data. American Fisheries Society, Bethesda, MD

Rutz, C. and G.C. Hays. 2009. New frontiers in biologging science. Biology Letters 5: 289-292. Schmalz, P.J., A.H. Fayram, D.A. Isermann, S.P. Newman, and C. J. Edwards. 2011. Harvest and exploitation. Pages 375-402 in B.A. Barton, editor. Biology, Management, and Culture of Walleye and Sauger. American Fisheries Society, Bethesda, Maryland.

Shroyer, S. M. and D. E. Logsdon. 2009. Detection distances of selected radio and acoustic tags in Minnesota Lakes and Rivers. North American Journal of Fisheries Management 29: $876-884$. 
Welsh, S. A. and S.A. Perry. 1997. Acidification and fish occurrence in the upper Cheat River drainage, West Virginia. Journal of the American Water Resources Association 33: 423429.

Williams, J. D. 2001. Walleye movement, distribution, and habitat use in Laurel River Lake, Kentucky. Proceedings of the Annual Conference of Southeastern Association of Fish and Wildlife Agencies 55: 257-269.

Winter, J. 1996. Advances in underwater biotelemetry. Pages 555-585 in B. R. Murphy and D. W. Willis, editors. Fisheries Techniques, $2^{\text {nd }}$ edition. American Fisheries Society, Bethesda, Maryland. 
Table 5.1. Annual count of tagged Walleyes migrating to riverine zone of Cheat Lake prior to spawning, including pre-spawn period duration, earliest movement dates, and number of days with migration.

\begin{tabular}{cccccc}
\hline Year & Time period & Earliest movement & Days & Days with migration & No. migrating Walleyes \\
\hline 2012 & 23 January-10 March & 3 February & 48 & 7 & 9 \\
2013 & 1 January-4 April & 13 January & 94 & 17 & 22 \\
2014 & 1 January-4 April & 21 February & 94 & 13 & 19 \\
2015 & 1 January-20 March & 11 February & 79 & 7 & 10 \\
\hline
\end{tabular}


Table 5.2. Summary statistics of three environmental variables (mean daily lake elevation, mean daily river discharge, and mean daily water temperature) during days of upstream pre-spawn migration and days without upstream pre-spawn migration.

\begin{tabular}{ccccccc}
\hline \multirow{2}{*}{ Year } & \multicolumn{2}{c}{ Lake elevation (m above sea level) } & \multicolumn{2}{c}{ River discharge $(\mathrm{cms})$} & \multicolumn{2}{c}{ Water temperature $\left({ }^{\circ} \mathrm{C}\right)$} \\
& Mean $(95 \% \mathrm{Cl})$ & Range & Mean $(95 \% \mathrm{Cl})$ & Range & Mean $(95 \% \mathrm{Cl})$ & Range \\
\hline \multicolumn{7}{c}{ Days with upstream pre-spawn migration } \\
2012 & $263.2(262.3,264.2)$ & $261.6-264.8$ & $126.7(40.3,213.1)$ & $53.2-317.1$ & $6.3(5.7,6.9)$ & $5.5-7.2$ \\
2013 & $264.1(263.7,264.6)$ & $262.5-265.1$ & $132.9(93.5,172.2)$ & $47.9-302.9$ & $4.7(4.0,5.4)$ & $3.2-6.6$ \\
2014 & $263.9(263.3,264.5)$ & $262.3-265.2$ & $145.0(86.3,203.7)$ & $60.6-379.5$ & $5.9(4.7,7.2)$ & $3.6-10.1$ \\
2015 & $264.4(263.7,265.1)$ & $263.2-265.1$ & $232.3(66.0,398.5)$ & $107.0-577.7$ & $4.7(3.0,6.4)$ & $2.2-6.6$ \\
All & $263.9(263.7,264.3)$ & $261.6-265.2$ & $151.3(118.2,184.4)$ & $47.9-577.7$ & $5.3(4.8,5.9)$ & $2.2-10.1$ \\
& & \multicolumn{2}{c}{ Days without upstream pre-spawn migration } & & \\
2012 & $264.0(263.8,264.3)$ & $261.6-265.1$ & $113.7(80.1,147.2)$ & $30.6-656.9$ & $4.2(3.7,4.8)$ & $0.1-7.3$ \\
2013 & $263.9(263.7,264.0)$ & $262.5-265.1$ & $108.7(83.1,134.6)$ & $29.2-699.4$ & $2.6(2.2,3.0)$ & $0-7.1$ \\
2014 & $263.1(262.9,263.3)$ & $261.9-265.2$ & $86.7(71.3,102.0)$ & $18.8-413.4$ & $1.9(1.4,2.4)$ & $0.1-10.1$ \\
2015 & $263.8(263.5,263.9)$ & $262.0-265.1$ & $116.9(78.3,155.5)$ & $33.1-880.7$ & $1.5(1.1,1.9)$ & $0-7.7$ \\
All & $263.6(263.5,263.7)$ & $261.6-265.2$ & $105.1(90.9,119.2)$ & $18.8-880.7$ & $2.3(2.0,2.6)$ & $0-10.1$ \\
\hline \multicolumn{7}{c}{}
\end{tabular}

Table 5.3. Parameter estimates for best-fitting logistic regression model using environmental variables to describe upstream pre-spawn migration of Walleyes in Cheat Lake, WV from 20122015. The intercept includes Year 2015.

\begin{tabular}{lccccc}
\hline \multicolumn{1}{c}{ Parameter } & Estimate & SE & DF & t-Value & p-value \\
\hline Intercept & -5.8386 & 0.4375 & 30 & -13.34 & $<0.0001$ \\
Year 2012 & -2.339 & 0.6163 & 3546 & -3.8 & 0.0001 \\
Year 2013 & -1.1799 & 0.4423 & 3546 & -2.67 & 0.0077 \\
Year 2014 & -0.3609 & 0.4243 & 3546 & -0.85 & 0.3951 \\
Year 2015 & 0 &. &. &. &.
\end{tabular}




\begin{tabular}{llllll} 
Water temperature & 0.8339 & 0.0769 & 3546 & 10.84 & $<0.0001$ \\
\hline
\end{tabular}

Table 5.4. Parameter estimates for best-fitting logistic regression model using environmental variables to describe downstream post-spawn migration of Walleyes in Cheat Lake, WV from 2012-2014.

\begin{tabular}{lccccc}
\hline Parameter & Estimate & SE & DF & t-Value & $\mathrm{p}$-value \\
\hline Intercept & -3.0168 & 0.4991 & 24 & -6.04 & $<0.0001$ \\
Spring & -1.9592 & 0.6006 & 3616 & -3.26 & 0.0011 \\
Summer & -3.2676 & 0.7815 & 3616 & -4.18 & $<0.0001$ \\
Autumn & 0 &. &. &. &. \\
Female & 1.6466 & 0.5676 & 3616 & 3616 & 0.0037 \\
Male & 0 &. &. &. &. \\
\hline
\end{tabular}

Table 5.5. Parameter estimates for best-fitting logistic regression model using environmental variables to describe large non-spawning movements of Walleyes in Cheat Lake, WV from 2012-2014.

\begin{tabular}{lccccc}
\hline \multicolumn{1}{c}{ Parameter } & Estimate & $\mathrm{SE}$ & $\mathrm{DF}$ & $\mathrm{t}$-Value & $\mathrm{p}$-value \\
\hline Intercept & -6.3036 & 0.4024 & 31 & -15.67 & $<0.0001$ \\
River discharge & 0.4490 & 0.0586 & 11491 & 7.66 & $<0.0001$ \\
Water temperature & 0.0309 & 0.0086 & 11491 & 3.56 & 0.0004 \\
\hline
\end{tabular}


Table 5.6. BIC model selection statistics for 30 candidate models fit to a 2012-2015 time series of daily upstream pre-spawn migration of Walleyes in Cheat Lake, WV. Single variable and additive-effects models included year (YR), sex (SX), percent lunar illumination (LI), water temperature (WT), log transformed river discharge (RD), and lake elevation (LE). $\triangle \mathrm{BIC}$ is the difference between a model and a model with the lowest BIC value.

\begin{tabular}{|c|c|c|}
\hline Model & $\mathrm{BIC}$ & $\Delta \mathrm{BIC}$ \\
\hline YR + WT & 616.53 & 0 \\
\hline$Y R+W T+S X$ & 617.06 & 0.53 \\
\hline$Y R+W T+L E$ & 619.20 & 2.67 \\
\hline YR + WT + LI & 619.50 & 2.97 \\
\hline$Y R+W T+R D$ & 619.60 & 3.07 \\
\hline YR + WT + LE + RD + LI + SX (Full) & 624.70 & 8.17 \\
\hline WT & 626.83 & 10.30 \\
\hline$W T+L E$ & 628.11 & 11.58 \\
\hline$W T+R D$ & 629.97 & 13.44 \\
\hline$W T+S X$ & 630.27 & 13.74 \\
\hline RD & 734.21 & 117.68 \\
\hline$R D+L E$ & 735.49 & 118.96 \\
\hline$R D+S X$ & 737.52 & 120.99 \\
\hline$Y R+R D$ & 743.42 & 126.89 \\
\hline$Y R+R D+L I$ & 744.02 & 127.49 \\
\hline$Y R+R D+L E$ & 744.41 & 127.88 \\
\hline$Y R+R D+S X$ & 746.85 & 130.32 \\
\hline LE & 764.07 & 147.54 \\
\hline$L E+S X$ & 767.41 & 150.88 \\
\hline $\mathrm{YR}+\mathrm{LE}+\mathrm{LI}$ & 769.90 & 153.37 \\
\hline $\mathrm{YR}+\mathrm{LE}$ & 771.58 & 155.05 \\
\hline$Y R+L E+S X$ & 775.00 & 158.47 \\
\hline LI & 792.30 & 175.77 \\
\hline Intercept & 792.41 & 175.88 \\
\hline $\mathrm{LI}+\mathrm{SX}$ & 795.57 & 179.04 \\
\hline SX & 795.63 & 179.10 \\
\hline YR & 800.17 & 183.64 \\
\hline $\mathrm{YR}+\mathrm{LI}$ & 800.60 & 184.07 \\
\hline$Y R+S X$ & 803.61 & 187.08 \\
\hline $\mathrm{YR}+\mathrm{SX}+\mathrm{LI}$ & 804.03 & 187.50 \\
\hline
\end{tabular}


Table 5.7. BIC model selection statistics for 45 candidate models fit to a 2012-2014 time series of daily downstream post-spawn migration of Walleyes in Cheat Lake, WV. Single variable and additive-effects models included year (YR), season (SEAS), sex (SX), percent lunar illumination (LI), water temperature (WT), log transformed river discharge (RD), and lake elevation (LE). $\triangle \mathrm{BIC}$ is the difference between a model and a model with the lowest BIC value.

\begin{tabular}{lcc}
\hline \multicolumn{1}{c}{ Model } & BIC & $\Delta B I C$ \\
\hline SEAS + SX & 409.68 & 0 \\
SEAS + SX + WT & 411.92 & 2.24 \\
SEAS + SX + LE & 412.39 & 2.71 \\
SEAS + SX + RD & 412.45 & 2.77 \\
SEAS + SX + LI & 412.82 & 3.14 \\
YR + SEAS + WT & 413.11 & 3.43 \\
YR + SEAS + SX & 414.58 & 4.90 \\
SEAS & 414.59 & 4.91 \\
YR + SEAS + RD & 415.73 & 6.05 \\
SEAS + WT & 416.05 & 6.37 \\
SEAS + RD & 417.42 & 7.74 \\
SEAS + LE & 417.43 & 7.75 \\
SEAS + LI & 417.66 & 7.98 \\
YR + SEAS + SX + WT + RD + LE + LI & 420.60 & 10.92 \\
YR + SEAS + LE & 421.14 & 11.46 \\
YR + SEAS + LI & 421.26 & 11.58 \\
SX + WT & 425.70 & 16.02 \\
YR + WT + RD & 427.92 & 18.24 \\
YR + SX + WT & 429.72 & 20.04 \\
WT & 430.48 & 20.80 \\
YR + WT & 430.76 & 21.08 \\
WT + RD & 430.93 & 21.25 \\
YR + LE + WT & 431.55 & 21.87 \\
LE + WT & 432.18 & 22.50 \\
SX & 432.52 & 22.84 \\
SX + RD & 433.57 & 23.89 \\
YR + WT + LI & 433.89 & 24.21 \\
SX + LI & 435.44 & 25.76 \\
SX + LE & 435.72 & 26.04 \\
YR + SX + LE & 436.42 & 26.74 \\
YR + SX & 436.52 & 26.84 \\
& & \\
\hline
\end{tabular}




\begin{tabular}{lll} 
YR + SX + RD & 438.22 & 28.54 \\
Intercept & 438.90 & 29.22 \\
YR + SX + LI & 439.56 & 29.88 \\
RD & 439.66 & 29.98 \\
YR & 441.46 & 31.78 \\
LI & 441.69 & 32.01 \\
LE & 442.09 & 32.41 \\
LE + RD & 442.61 & 32.93 \\
YR + RD & 443.19 & 33.51 \\
YR + LI & 444.45 & 34.77 \\
YR + LE & 444.67 & 34.99 \\
YR + RD + LI & 446.27 & 36.59 \\
YR + LE + RD & 446.38 & 36.70 \\
YR + LE + LI & 447.63 & 37.95 \\
\hline
\end{tabular}

Table 5.8. BIC model selection statistics for 45 candidate models fit to a 2012-2014 time series of daily long distance non-spawning movements of Walleyes in Cheat Lake, WV. Single variable and additive-effects models included year (YR), season (SEAS), sex (SX), percent lunar illumination (LI), water temperature (WT), log transformed river discharge (RD), and lake elevation (LE). $\triangle \mathrm{BIC}$ is the difference between a model and a model with the lowest $\mathrm{BIC}$ value.

\begin{tabular}{|c|c|c|}
\hline Model & $\mathrm{BIC}$ & $\Delta \mathrm{BIC}$ \\
\hline $\mathrm{RD}+\mathrm{WT}$ & 2838.83 & 0 \\
\hline$R D+L E$ & 2841.08 & 2.25 \\
\hline$Y R+R D+W T$ & 2844.21 & 5.38 \\
\hline$Y R+R D+L E$ & 2845.55 & 6.72 \\
\hline $\mathrm{RD}$ & 2848.73 & 9.9 \\
\hline $\mathrm{SEAS}+\mathrm{RD}$ & 2851 & 12.17 \\
\hline $\mathrm{YR}+\mathrm{RD}$ & 2853.24 & 14.41 \\
\hline$S X+R D$ & 2854.28 & 15.45 \\
\hline $\mathrm{YR}+\mathrm{SEAS}+\mathrm{SX}+\mathrm{RD}+\mathrm{WT}+\mathrm{LE}+\mathrm{LI}$ (Full) & 2854.89 & 16.06 \\
\hline$Y R+S E A S+R D$ & 2855.05 & 16.22 \\
\hline $\mathrm{YR}+\mathrm{RD}+\mathrm{LI}$ & 2856.47 & 17.64 \\
\hline$S E A S+S X+R D$ & 2856.6 & 17.77 \\
\hline$Y R+S X+R D$ & 2859.77 & 20.94 \\
\hline SEAS + LE & 2873.06 & 34.23 \\
\hline
\end{tabular}




\begin{tabular}{lcc} 
SEAS + SX + LE & 2879.43 & 40.6 \\
YR + SEAS + LE & 2879.55 & 40.72 \\
LE + WT & 2881.84 & 43.01 \\
LE & 2881.88 & 43.05 \\
SX + LE & 2888.29 & 49.46 \\
YR + LE + WT & 2888.33 & 49.5 \\
YR + LE & 2888.53 & 49.7 \\
Intercept & 2890.64 & 51.81 \\
YR + LE + LI & 2891.44 & 52.61 \\
WT & 2893.92 & 55.09 \\
LI & 2894 & 55.17 \\
SEAS & 2894.24 & 55.41 \\
YR + SX + LE & 2895.08 & 56.25 \\
SX & 2896.86 & 58.03 \\
SEAS + LI & 2897.58 & 58.75 \\
SEAS + WT & 2897.7 & 58.87 \\
YR + WT & 2899.77 & 60.94 \\
YR + LI & 2899.78 & 60.95 \\
SX + WT & 2900.17 & 61.34 \\
SX + LI & 2900.22 & 61.39 \\
SEAS + SX & 2900.48 & 61.65 \\
YR + SX & 2903.05 & 64.22 \\
YR + WT + LI & 2903.11 & 64.28 \\
YR + SEAS + LI & 2903.54 & 64.71 \\
YR + SEAS + WT & 2903.67 & 64.84 \\
SEAS + SX + LI & 2903.82 & 64.99 \\
SEAS + SX + WT & 2903.94 & 65.11 \\
YR + SX + WT & 2906.38 & 67.55 \\
YR + SX + LI & 2906.4 & 67.57 \\
YR + SEAS + SX & 2906.77 & 67.94 \\
\hline & & \\
\hline
\end{tabular}


Figure 5.1. Study site location and map showing location of acoustic receivers, separation of main lake zone and riverine zone (represented by black bar in between two entry points), and location of spawning area in Cheat Lake, WV. Lower Main Lake is located from the dashed line to the dam

Figure 5.2. Daily proportion of tagged Walleyes migrating into the riverine zone (gray bars) and associated water temperature (black line) data for 2012-2015

Figure 5.3. Proportion of temporary downstream pre-spawn movement events from riverine zone into main lake zone.

Figure 5.4. Monthly post-spawn migration of tagged Walleyes into the main lake represented by proportion of tagged fish migrating per month and separated by sex

Figure 5.5. Lake elevation and water temperature during Walleye spawning 20122015. April $1^{\text {st }}$ lake level restriction designated by dashed black line. 


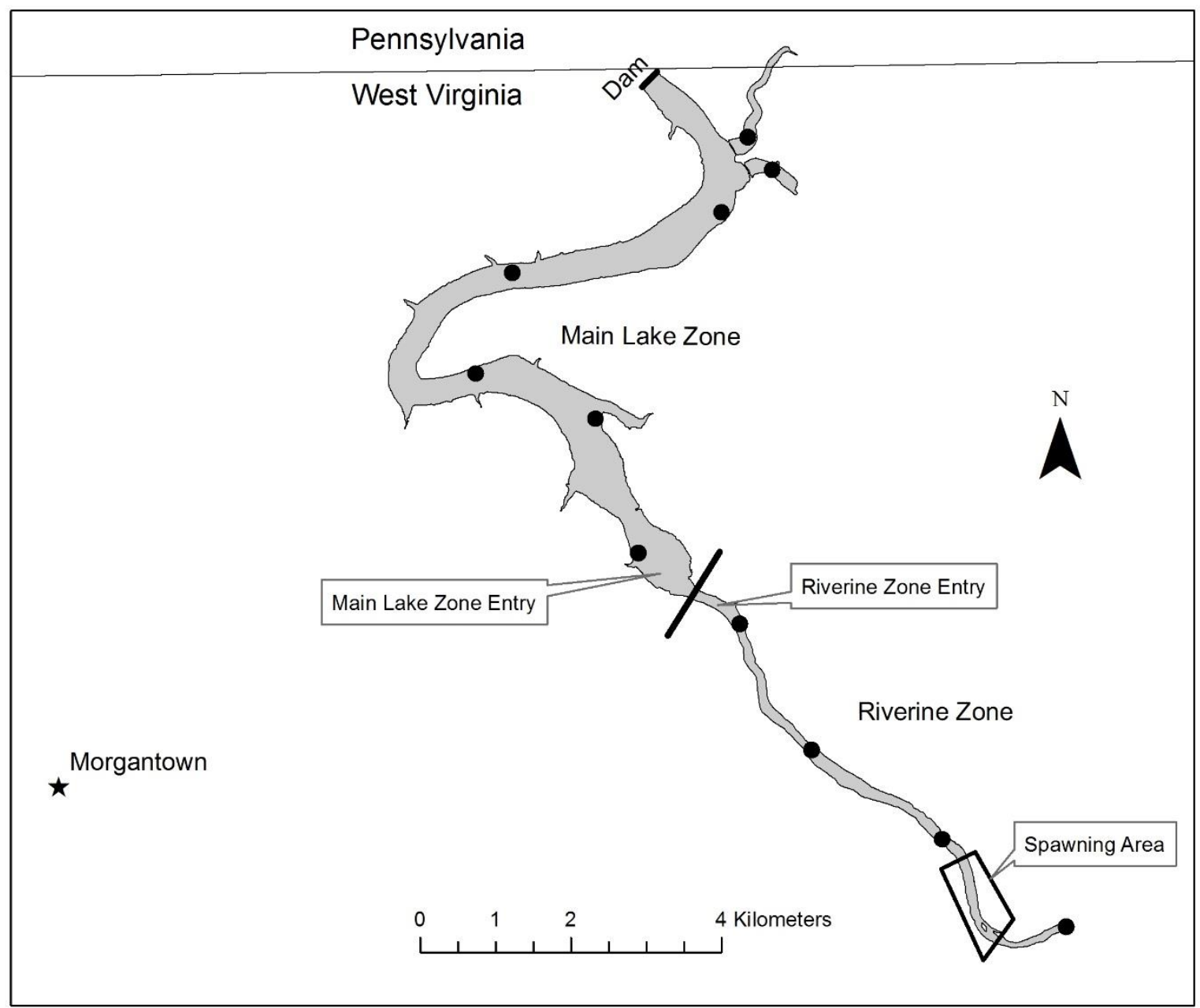

- Receiver Locations

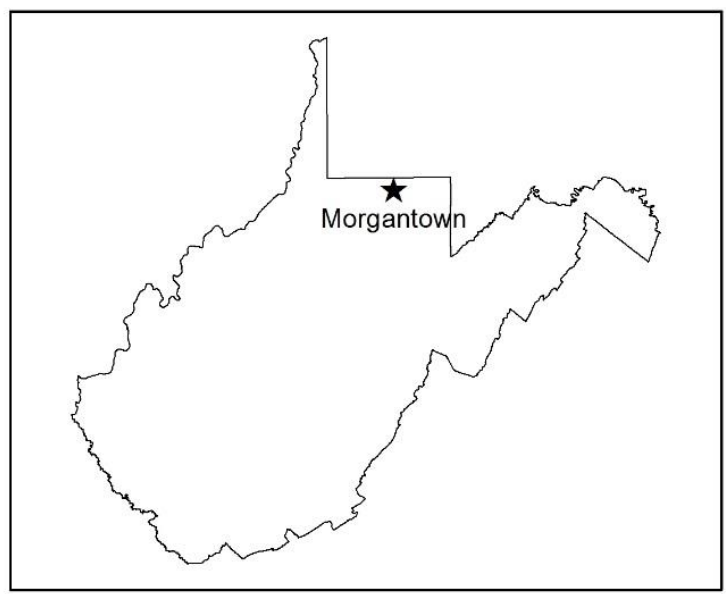




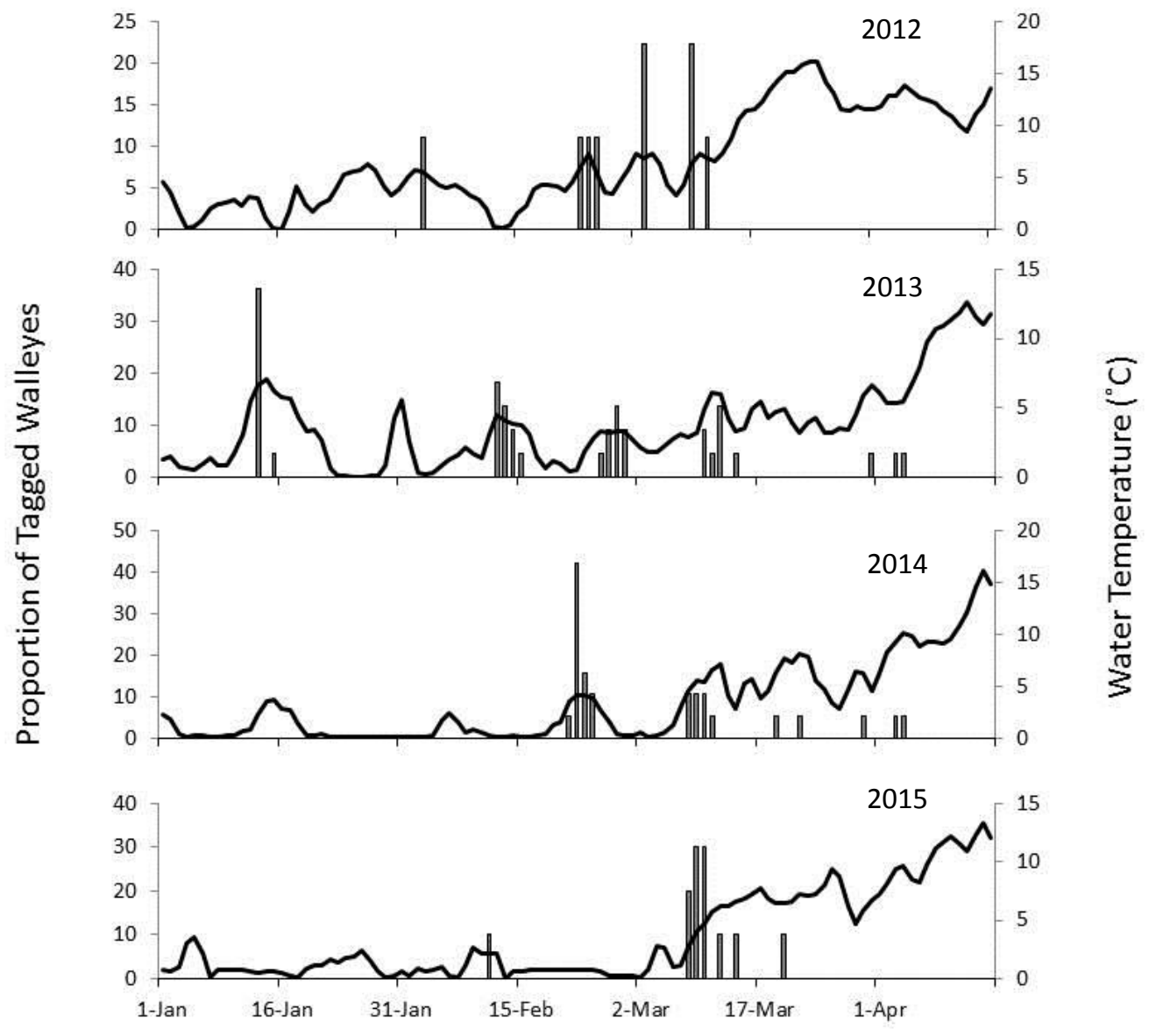




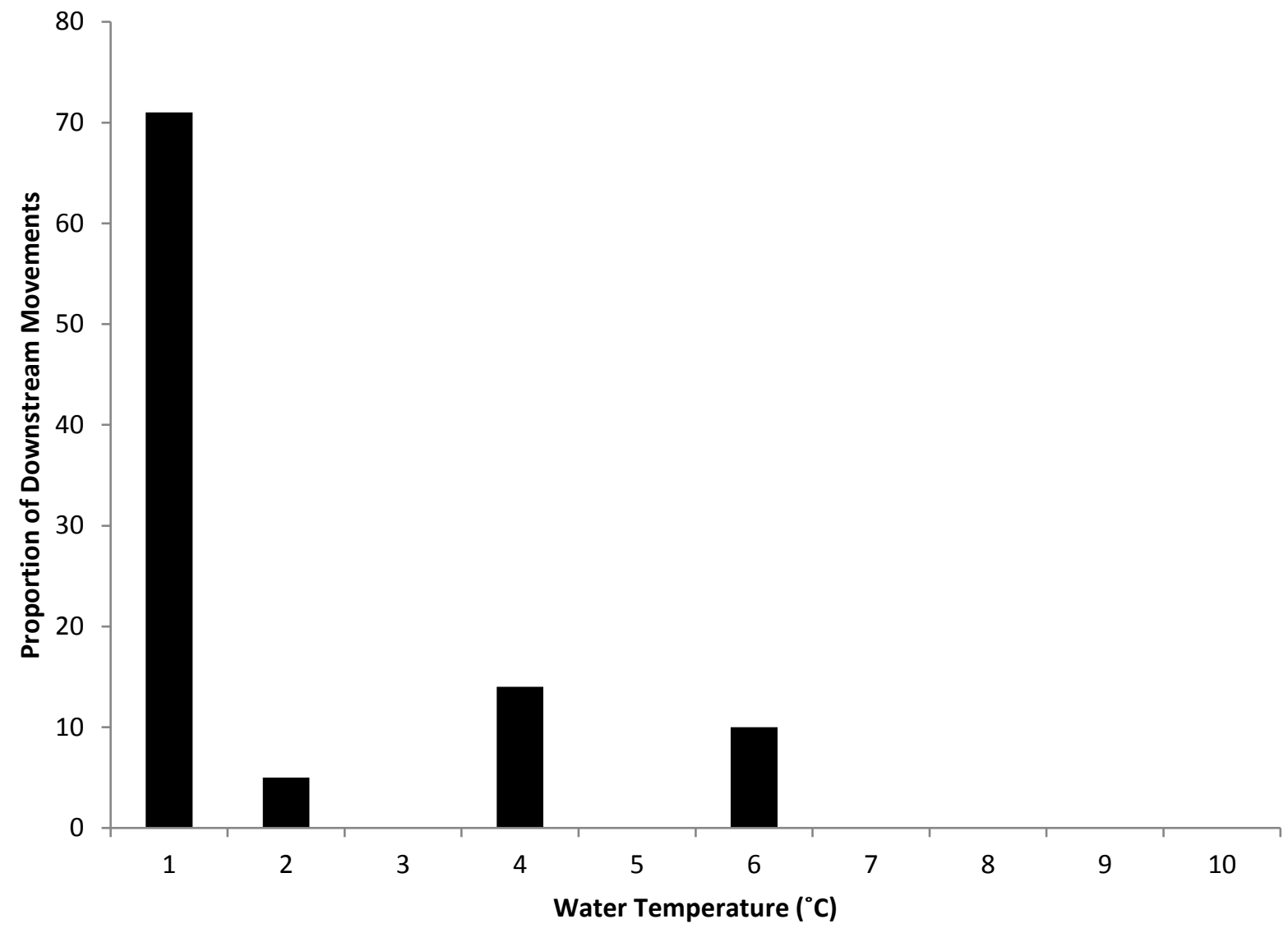




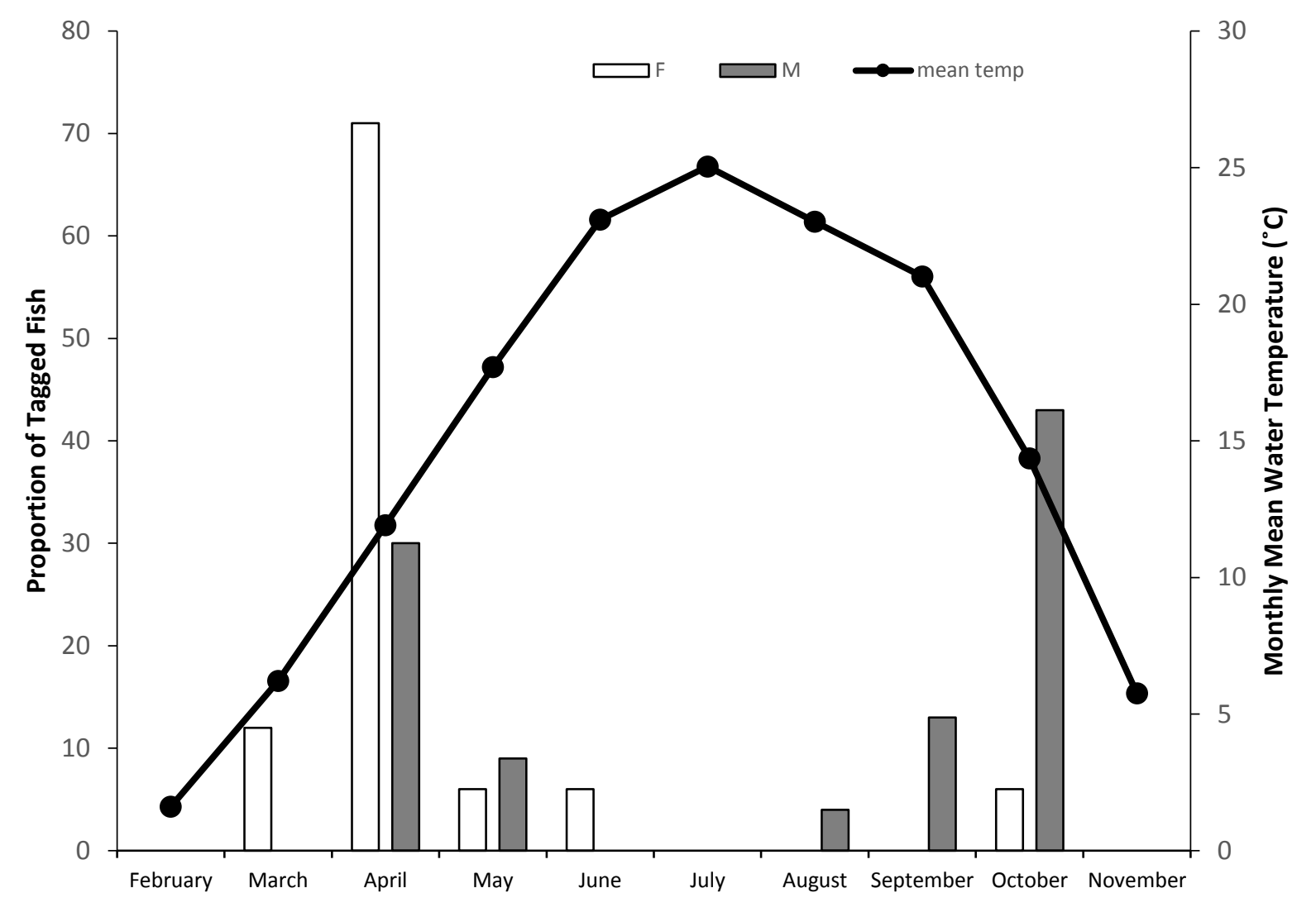




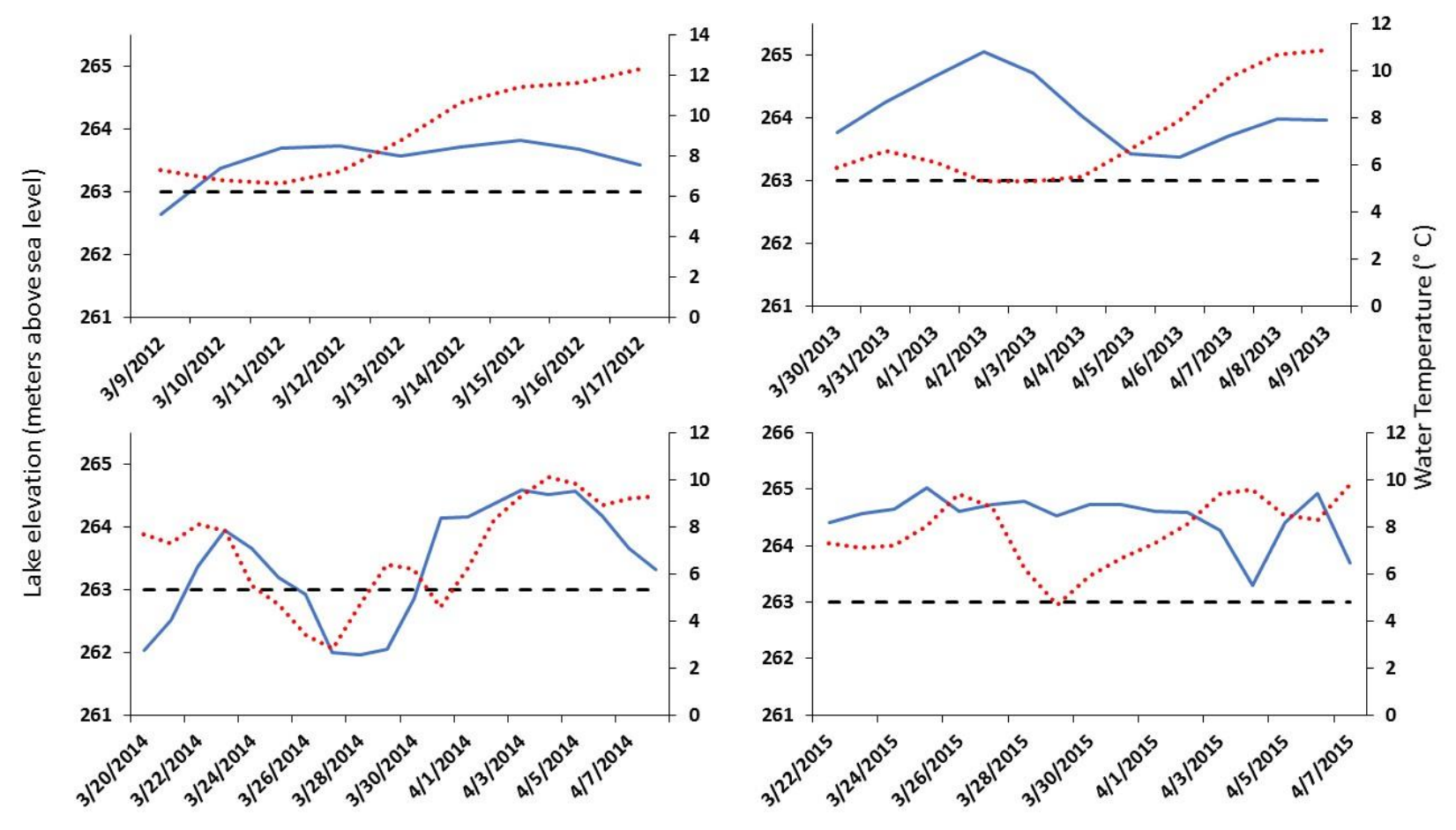

lake elevation

- - - 1 April restriction

water temperature 


\section{Chapter 6 - Future Management Strategies for the Fish Communities of Cheat Lake, WV}

The aquatic community of Cheat Lake was impacted for decades as a result of acidification, largely resulting from acid mine drainage (Core 1959). As a result of water quality impairment, species richness and fish abundance was limited (Core 1959; WVDNR unpublished data). Brown Bullhead and White Sucker (both acid tolerant species) were the dominant species (82\% of mean annual fish abundance) within the reservoir. Additionally, several species, including Walleye, were extirpated from Cheat Lake during this period (Core 1959). As a result of limited fishery resources available in Cheat Lake, angler opportunities were limited. After the passage of the Clean Water Act (1972), Surface Mining Control and Reclamation Act (1977), and the emergence of additional funding sources to treat acid mine drainage, water quality within the Cheat River watershed began to gradually improve, along with the fish community of Cheat Lake. Additionally, with improvements in water quality, a Walleye population was reestablished within Cheat Lake. Our study aimed to quantify temporal changes in the fish community of Cheat Lake, as they might be related to improvements in water quality. We also focused on evaluating the reestablished Walleye population to further understand population characteristics and spatial ecology within Cheat Lake. We found that the fish community of Cheat Lake has significantly changed over time, likely owing to improvements in water quality. We also found that the Walleye population within Cheat Lake is characterized by fast growing individuals, that reach large maximum sizes. Additionally, Cheat Lake Walleyes exhibit seasonal and sex-based differences in distribution and movement, that could have implications for management of this new fishery.

Given the extensive treatment of acid mine drainage and acid precipitation within the Cheat River watershed over the last few decades, we summarized changes in the $\mathrm{pH}$ of Cheat Lake since 1952. We found mean annual $\mathrm{pH}$ within the reservoir to remain above 6.0 since 
1997, a vast improvement to the pre-1990 era when mean annual $\mathrm{pH}$ was regularly less than 5.0. Current acid mine drainage and precipitation treatment within the watershed appears to have improved water quality to suitable levels for most aquatic life. Gradual improvements to water quality within the watershed have led to improvements to the reservoir fish community. Specifically, we found fish species richness and overall fish abundance has significantly increased over time since water quality treatment began. A total of 44 species were collected cumulatively since 1990, compared to the 15 species captured from 1952-1977. Additionally, fish community composition has significantly changed over time due in part to the increases in several acid intolerant species (e.g., Smallmouth Bass, Walleye, Emerald Shiner, Silver Shiner, etc.). Smallmouth Bass, one of the first species to disappear when acidification occurs (Beamish 1976), was nearly absent from the reservoir in 1990, but now represents one of the most abundant sportfish in Cheat Lake. Additionally, while Brown Bullheads and White Suckers used to dominate the reservoir, these tolerant species have decreased in abundance. Instead, Channel Catfish and Golden Redhorse, comparatively intolerant species, have replaced Brown Bullhead and White Sucker as the dominant catfish and sucker species within the lake, respectively. Finally, forage species such as Emerald Shiner, Silver Shiner, Mimic Shiner, Gizzard Shad, Logperch, and Brook Silverside, once essentially extirpated from the lake, have seen substantial increases in abundance.

Another result of improved water quality has been the reestablishment of a Walleye population within Cheat Lake. Reestablishment of a Walleye population was spearheaded by stocking efforts that were deemed feasible due to improved water quality. The reestablished Walleye population exhibits particularly fast growth, with the potential for trophy sizes, especially in female fish. Data also suggest that natural reproduction/recruitment has increased in recent years, likely owing to water quality improvements. The increases in natural reproduction, along 
with the fast growth and large sizes attained by Cheat Lake Walleyes, creates a potentially valuable fishery for anglers of Cheat Lake.

We used telemetry to assess distribution and movements of Walleyes in Cheat Lake. Walleyes displayed significant seasonal and sex-based differences in habitat use and movement patterns. Additionally, certain environmental factors were important predictors of large scale Walleye movements. Specifically, Walleyes made upstream migrations in the late winter/early spring in preparation for spawning. Models that best predicted occurrence of spawning migrations included variables of sex and water temperature. Specifically, male Walleyes migrated to spawning grounds earlier than female Walleyes and remained there until spawning commenced. Most male Walleyes migrated to spawning grounds prior to March (68.9\%) while most females migrated during March (52.6\%). An increase in water temperature was a significant predictor of upstream migration as most Walleyes (75\%) made upstream migrations at water temperatures $>4.1^{\circ} \mathrm{C}$. Spawning occurred in the upper $1 \mathrm{~km}$ of Cheat Lake on rocky shoreline areas in water less than 2 meters deep. Spawning also potentially occurred in the Cheat River upstream of the lake as some tagged fish used this area during the spawning period. Female Walleyes returned quickly to the main lake area, while a substantial proportion of male Walleyes remained near the spawning area or in the upstream Cheat River until fall. During non-spawning periods, elevated river discharge and water temperature were associated with large scale movements of Walleyes. Male Walleyes were more likely to use riverine habitats compared to female Walleyes, except during fall and winter when nearly all Walleyes congregated in main lake habitats.

My research has shown that water quality improvements throughout the Cheat River watershed have also led to improved water quality within Cheat Lake. In conjunction with these water quality improvements, there have been significant changes to the fish community of Cheat Lake, with increased species richness, total fish abundance, and increases in pollution intolerant 
species. However, acid mine drainage issues are persistent through time and effectively require permanent treatment (Skousen et al. 1998). Treatment of mine drainage within the watershed is made possible by regulatory mandates such as SMCRA and CWA, in addition to other state and federal funding sources. Lapses or reductions in funding of water quality treatment would likely result in the worsening of acidification within Cheat Lake and the return of pre-1990 conditions. Likewise, the fish community of Cheat Lake would be negatively impacted by the return of acidic conditions. Certainly, species such as Walleye and Smallmouth Bass, along with many acid intolerant forage species would eventually face extirpation.

In addition to treatment of mine drainage, the current water regime of Cheat Lake provides for relatively stable water levels from May-October. These stable water levels likely facilitate successful reproduction by late spring/early summer spawners such as Centarchids and Ictalurids. These stable water levels also guarantee inundation of important littoral habitat such as aquatic vegetation and coarse woody debris, providing refuge and nursery areas for age-0 fishes such as Yellow Perch. However, despite relatively stable water levels during late spring/early summer, some Cheat Lake fishes are still vulnerable to potential effects from hydropower operations during periods of larger water level fluctuations (November-April). Specifically, water level fluctuations during March and April could significantly impact early spawning fishes such as Walleye and Yellow Perch. These species spawn in shallow water and water level fluctuations can limit available habitat or cause stranding of already deposited eggs (Priegel 1970; Krieger et al. 1983). In our study, we witnessed dewatered Yellow Perch eggs and determined that Walleye spawning occurred in relatively shallow water $(<2 \mathrm{~m})$ susceptible to water level decreases. Currently, water level fluctuations are limited in April to help reduce impacts to spawning Walleye and Yellow Perch. These reductions in water level fluctuations may benefit these species, although at current levels littoral spawning areas are still impacted. Additionally, telemetered Walleyes were found to spawn as early as mid-March during some 
years. Specifically, in some years, water temperatures reached $5^{\circ} \mathrm{C}$ or greater by mid-March and maintained this temperature resulting in spawning activity. In this scenario, spawning Walleyes would not benefit from the April reductions in water level fluctuations. Additionally, spent Yellow Perch were captured in surveys in the month of March, likewise indicating that in years when water temperatures suitable for spawning are reached prior to April, spawning may occur.

My research indicates that a Walleye population has been successfully reestablished within Cheat Lake, and population characteristics create both a unique and potentially vulnerable fishery. Cheat Lake Walleyes show faster growth and larger maximum sizes than in many other West Virginia reservoirs, and provide anglers a unique opportunity. Additionally, there is evidence of increasing natural reproduction. However, resource managers should be aware of the potential for impacts to the population via exploitation. Given the improvements to the fish community and the inevitable increase in angler use with better fishing opportunities, managers should be wary of the impacts to the fisheries. Given uncertainties with hatchery production of Walleyes in WV, natural reproduction may be important for sustaining the Cheat Lake population. However, large congregations of Walleyes near the lake headwaters during spawning and concentration of females during non-spawning periods in main lake areas closer to public access points, potentially create vulnerability of this population to overexploitation. Currently, there is an 8 fish per day, $381 \mathrm{~mm}$ minimum length limit on Walleyes in Cheat Lake. This current regulation allows for liberal harvest of Walleyes, at a minimum length that does little to protect mature females. If harvest were to increase or female fish show increased vulnerability, managers may need to consider altering regulations.

Given the findings of this study and to ensure the future persistence of the fish community of Cheat Lake, it would be beneficial for resource managers to incorporate these results and management implications into future monitoring and management plans. Future 
plans could identify management goals for the fish community, along with monitoring plans and management actions that could be implemented in response to future findings. Given the research findings presented within this dissertation, the following are some potential management goals for the Cheat Lake fish community: 1). Maintain the fish community of Cheat Lake (considering current fish community composition, species richness, relative abundance, etc.). 2). Improve natural reproduction/recruitment success of Walleyes in Cheat Lake, and 3). Improve recreational fishing opportunities for trophy Walleye and other sportfish in Cheat Lake. Resource managers should develop future monitoring and management plans while considering these management goals. Resource managers should continue monitoring of water quality (i.e., $\mathrm{pH}$ ) of Cheat Lake. Continued water quality monitoring will detect any unexpected decreases in $\mathrm{pH}$ which could impact the fish community. Unexpected decreases in $\mathrm{pH}$ could indicate issues with water quality treatment within the watershed which could be investigated further with pertinent agencies. Additionally, there should be continued periodic monitoring of the fish community of Cheat Lake to monitor for changes to the fish community structure. Changes to the fish community of Cheat Lake could indicate stressors from water quality or water level fluctuations. Additionally, further research should be conducted on the impacts of angler harvest on the sportfish of Cheat Lake. To accomplish this, a creel survey should be implemented. Without harvest information that could be quantified from a creel survey, it will be difficult to model the impact of future regulations. Likewise, further age and growth studies of additional sportfish in Cheat Lake would provide baseline data for future comparisons and to aid in management regulations. Also, given the potential impacts of spring water level fluctuations to Yellow Perch and Walleye, consideration should be given to altering the current water regime. Ideally water level restrictions would be extended to approximately mid-March, however, economic considerations for the hydropower company will be important in future actions. Should changes to the water level regime not be feasible, then enhancements to deep-water spawning habitat should be considered to facilitate reproduction of Walleye and Yellow Perch during 
periods of low water levels. Additional, monitoring steps and adaptive management actions could be outlined to most effectively manage the Cheat Lake fish community.

\section{References}

Beamish, R. J. 1976. Acidification of lakes in Canada by acid precipitation and the resulting effects on fishes. Water, Air, and Soil Pollution 6: 501-514.

Core, E. L. 1959. Biological investigations of Cheat Lake. West Virginia University, Morgantown, WV.

Krieger, D. A., Terrell, J. W., and Nelson, P. C. 1983. Habitat suitability information: Yellow Perch. US Fish and Wildlife Service, Washington, D. C.

Priegel, G. R. 1970. Reproduction and early life history of the walleye in the Lake Winnebago region. Wisconsin Department of Natural Resources Technical Bulletin 45, Madison.

Skousen, J., Rose, A., Geidel, G., Foreman, J., Evans, R. and W. Hellier. 1998. A handbook of technologies for avoidance and remediation of acid mine drainage. Acid Drainage Technology Initiative, National Mine Land Reclamation Center, WVU, Morgantown, WV. 